Portland State University

PDXScholar

Winter 3-19-2013

\title{
A 30-Year Record of the Isotopic Composition of Atmospheric Methane
}

Doaa Galal Mohammed Teama

Portland State University

Follow this and additional works at: https://pdxscholar.library.pdx.edu/open_access_etds

Part of the Environmental Sciences Commons, and the Other Physics Commons Let us know how access to this document benefits you.

\section{Recommended Citation}

Teama, Doaa Galal Mohammed, "A 30-Year Record of the Isotopic Composition of Atmospheric Methane" (2013). Dissertations and Theses. Paper 642.

https://doi.org/10.15760/etd.642

This Thesis is brought to you for free and open access. It has been accepted for inclusion in Dissertations and Theses by an authorized administrator of PDXScholar. Please contact us if we can make this document more accessible: pdxscholar@pdx.edu. 
A 30-Year Record of the Isotopic Composition of Atmospheric Methane

by

Doaa Galal Teama

A dissertation submitted in partial fulfillment of the requirements for the degree of

Doctor of Philosophy

in

Applied Physics

Dissertation Committee:

Andrew L. Rice, Chair

Linda George

Christina Hulbe

M. Aslam K. Khalil

Drake Mitchell

Portland State University

2013 
(C)2013 Doaa Galal Teama 


\begin{abstract}
Methane $\left(\mathrm{CH}_{4}\right)$ is one of the most important greenhouse gases after water vapor and carbon dioxide due to its high concentration and global warming potential 25 times than that of $\mathrm{CO}_{2}$ (based on a 100 year time horizon). Its atmospheric concentration has more than doubled from the preindustrial era due to anthropogenic activities such as rice cultivation, biomass burning, and fossil fuel production. However, the rate of increase of atmospheric $\mathrm{CH}_{4}$ (or the growth rate) slowed from 1980 until present. The main reason for this trend is a slowdown in the trend of $\mathrm{CH}_{4}$ sources. Measuring stable isotopes of atmospheric $\mathrm{CH}_{4}$ can constrain changes of $\mathrm{CH}_{4}$ sources. The main goal of this work is to interpret the $\mathrm{CH}_{4}$ trend from 1978-2010 in terms of its sources using measurements of $\mathrm{CH}_{4}$ mixing ratio and its isotopes.
\end{abstract}

The current work presents the measurements and analysis of $\mathrm{CH}_{4}$ and its isotopes $\left(\delta^{13} \mathrm{C}\right.$ and $\left.\delta \mathrm{D}\right)$ of four air archive sample sets collected by the Oregon Graduate Institute (OGI). $\mathrm{CH}_{4}$ isotope ratios $\left(\delta^{13} \mathrm{C}\right.$ and $\left.\delta \mathrm{D}\right)$ were measured by a continuous flow isotope ratio mass spectrometer technique developed at PSU. The first set is for Cape Meares, Oregon which is the oldest and longest set and spans 1977-1999. The integrity of this sample set was evaluated by comparing between our measured $\mathrm{CH}_{4}$ mixing ratio values with those measured values by OGI and was found to be stable. Resulting $\mathrm{CH}_{4}$ seasonal cycle was evaluated from the Cape Meares data. The $\mathrm{CH}_{4}$ seasonal cycle shows a broad maximum during October-April and a minimum between July and August. The seasonal cycles of $\delta^{13} \mathrm{C}$ and $\delta \mathrm{D}$ have maximum values in May for $\delta^{13} \mathrm{C}$ and in July for $\delta \mathrm{D}$ and 
minimum values between September-October for $\delta^{13} \mathrm{C}$ and in October for $\delta \mathrm{D}$. These results indicate a $\mathrm{CH}_{4}$ source that is more enriched January-May (e.g. biomass burning) and a source that is more depleted August-October (e.g. microbial). In addition to Cape Meares, air archive sets were analyzed from: South Pole (SPO), Samoa (SMO), Mauna Loa (MLO) 1992-1996. The presented $\delta \mathrm{D}$ measurements are unique measured values during these time periods at these stations.

To obtain the long-term in isotopic $\mathrm{CH}_{4}$ from 1978-2010, other datasets of Northern Hemisphere mid-latitude sites are included with Cape Meares. These sites are Olympic Peninsula, Washington; Montaña de Oro, California; and Niwot Ridge, Colorado. The seasonal cycles of $\mathrm{CH}_{4}$ and its isotopes from the composite dataset have the same phase and amplitudes as the Cape Meares site. $\mathrm{CH}_{4}$ growth rate shows a decrease over time 1978-2010 with three main spikes in 1992, 1998, and 2003 consistent with the literature from the global trend. $\mathrm{CH}_{4}$ lifetime is estimated to $9.7 \mathrm{yrs}$. The $\delta^{13} \mathrm{C}$ trend in the composite data shows a slow increase from 1978-1987, a more rapid rate of change 1987-2005, and a gradual depletion during 2005-2010. The $\delta \mathrm{D}$ trend in the composite data shows a gradual increase during 1978-2001 and decrease from 20012005. From these results, the global $\mathrm{CH}_{4}$ emissions are estimated and show a leveling off sources 1982-2010 with two large peak anomalies in 1998 and 2003. The global average $\delta^{13} \mathrm{C}$ and $\delta \mathrm{D}$ of $\mathrm{CH}_{4}$ sources are estimated from measured values. The results of these calculations indicate that there is more than one source which controls the decrease in the global $\mathrm{CH}_{4}$ trend. From $1982-2001, \delta^{13} \mathrm{C}$ and $\delta \mathrm{D}$ of $\mathrm{CH}_{4}$ sources becomes more depleted due to a decrease in fossil and/or biomass burning sources relative to microbial sources. 
From 2005-2010, $\delta^{13} \mathrm{C}_{\text {of }} \mathrm{CH}_{4}$ sources returns to its 1981 value. There are two significant peaks in $\delta^{13} \mathrm{C}$ and $\delta \mathrm{D}$ of $\mathrm{CH}_{4}$ sources in 1998 and 2003 due to the wildfire emissions in boreal areas and in Europe. 


\section{Dedication}

To my loving husband Dr. Mohammed Hegazy and my sweethearts Rawdah Hegazy, Ahmed Hegazy, and Tarek Hegazy for their support and love. 


\section{Acknowledgements}

I would like to thank all those people who made this thesis possible and an unforgettable experience for me.

First of all, I would like to express my deepest gratitude to my supervisor Dr Andrew Rice, who offered his continuous advice and encouragement throughout the course of this thesis. I thank him for the systematic guidance and great effort he put into training me in the scientific field.

I would like to thank the members of my Dissertation Committee; Dr. Linda George, Dr. Christina Hulbe, Dr. M. Aslam K. Khalil and Dr. Drake Mitchell for their full support, fruitful discussions and suggestions.

Gratitude also goes to all my dear friends and colleagues Ashgan Mohammed, Salma Abed AlRahman, Nermin Khalil, Doaa Hussien, Rehab Soliman, Hanan El Kady, Fatma Mohammed, Dr. Rania Huessin, Noha El Foaty and Nabwia Shaban, Erica Hanson, Gregory Bostrom, Mariela Brooks, Ellynne Kutschera, and special thanks to Lucas Hill for their continual support and encouragement.

Finally, deepest thanks and gratitude go to my father Mr. Galal Teama, my mother Mrs. Asrar Mustafa, my uncle Dr. Rizk Teama, my brother Mr. Mohamed Teama and his wife Mrs Wafaa El kholy and my niece Nadeen Teama and my nephew Galal Teama for their prayers and encouragement. 
Abstract

Dedication $\quad$ iv

Acknowledgements $\quad$ V

List of Tables $\quad$ viii

List of Figures $\quad$ ix

Chapter 1. Introduction 1

1.1. Atmospheric $\mathrm{CH}_{4}$

1.2. Measurement of atmospheric $\mathrm{CH}_{4}$

1.3. $\mathrm{CH}_{4}$ sources and sinks 3

1.3.1. $\mathrm{CH}_{4}$ Sources $\quad 3$

1.3.2. $\mathrm{CH}_{4}$ Sinks 6

1.4. Isotopic composition of $\mathrm{CH}_{4}$

1.4.1. The use of isotopes to study atmospheric $\mathrm{CH}_{4}$

1.4.2. Seasonal cycle of $\delta^{13} \mathrm{C}$ and $\delta \mathrm{D}$ of atmospheric $\mathrm{CH}_{4} \quad 19$

1.4.3. Ice core measurements of $\delta^{13} \mathrm{C}$ and $\delta \mathrm{D}$ of atmospheric $\mathrm{CH}_{4} \quad 20$

Chapter 2. Experiment and Methodology 23

2.1. Air archived samples $\quad 24$

2.2. Methane isotopic analytical method 25

$\begin{array}{ll}2.2 .1 \text {. Isotope calibration } & 33\end{array}$

2.3. Methane concentration analytical method 34

2.4. Recent Air sampling from Cape Meares (March, 2012-Septemeber, 37 2012)

Chapter 3. Results of Analyses at PSU $\quad 41$

3.1 Cape Meares $\mathrm{CH}_{4}$ mixing ratio Results $\quad 42$

3.1.1. $\mathrm{CH}_{4}$ mixing ratio results measured at PSU 42

3.1.2. A comparison of $\mathrm{CH}_{4}$ mixing ratios at Cape Meares air $\quad 50$

3.2. Atmospheric $\delta^{13} \mathrm{C}-\mathrm{CH}_{4}$ and its seasonal trend 52

3.3. Atmospheric $\delta \mathrm{D}-\mathrm{CH}_{4}$ and its seasonal trend 56

3.4. Discussion of seasonal cycles of $\mathrm{CH}_{4}, \delta^{13} \mathrm{C}$, and $\delta \mathrm{D}$ at Cape Meares $\quad 58$

3.5. Recent measurements at Cape Meares, Oregon (March 2012- 64

Septemeber 2012)

3.5.1. Atmospheric $\mathrm{CH}_{4}$ mixing ratios (2012) 65

3.5.2. Isotope Ratios 66 
3.6. Archived samples from South Pole, Mauna Loa, and Samoa 67

3.6.1. South Pole $\left(90^{\circ} \mathrm{S}\right) \quad 68$

3.6.2. Samoa $\left(14.1^{\circ} \mathrm{S}, 170.6^{\circ} \mathrm{W}\right)$

3.6.3. Mauna Loa $\left(21.08^{\circ} \mathrm{N}, 157.2^{\circ} \mathrm{W}\right)$

Chapter 4. Analysis and Discussions $\quad 80$

4.1. Composite data from Cape Meares and other locations 81

4.1.1. Atmospheric $\mathrm{CH}_{4}$ mixing ratio $\quad 82$

4.1.2. Atmospheric $\delta^{13} \mathrm{C}_{-}-\mathrm{CH}_{4} \quad 85$

4.1.3. Atmospheric $\delta \mathrm{D}-\mathrm{CH}_{4} \quad 88$

4.2. Statistical Methods $\quad 90$

4.2.1. LOWESS 90

4.2.2. Bootstrap $\quad 92$

4.3. $\mathrm{CH} 4, \delta^{13} \mathrm{C}$, and $\delta \mathrm{D}$ Seasonal Cycles of $\mathrm{CH}_{4}$ of the composite 93 datasets

4.3.1. Atmospheric $\mathrm{CH}_{4}$ seasonal cycle for the composite 94

Northern hemisphere dataset

4.3.2. Atmospheric $\delta^{13} \mathrm{C}-\mathrm{CH}_{4}$ seasonal cycle for the composite $\quad 96$

Northern hemisphere dataset

4.3.3. Atmospheric $\delta \mathrm{D}^{-} \mathrm{CH}_{4}$ seasonal cycle for the composite 97

Northern hemisphere dataset

4.3.4. Discussion of seasonal cycles of $\mathrm{CH}_{4}$ mixing ratio, $\delta^{13} \mathrm{C} \quad 98$

and $\delta \mathrm{D}$ for the composite mid-latitude datasets

4.4. The secular and interannual variability in the composite dataset for 104

$\mathrm{CH} 4, \quad \delta^{13} \mathrm{C}$ and $\delta \mathrm{D}$

4.4.1. Atmospheric $\mathrm{CH}_{4}$ and its growth rate 107

4.4.2. Atmospheric $\delta^{13} \mathrm{C}-\mathrm{CH}_{4}$ and its time rate of change 111

4.4.3. Atmospheric $\delta \mathrm{D}-\mathrm{CH}_{4}$ and its time rate of change 114

4.4.4. Discussion about the time rates of change of $\mathrm{CH}_{4}, \delta^{13} \mathrm{C}$ and 116

$\delta \mathrm{D}$ of the composite data

4.5. The $\mathrm{CH}_{4}$ sources 1978-2010 119

4.5.1 Total $\mathrm{CH}_{4}$ emissions 1978-2010 120

4.5.2. The $\delta^{13} \mathrm{C}$ of the $\mathrm{CH}_{4}$ sources 1978-2010 123

4.5.3. The $\delta \mathrm{D}$ of $\mathrm{CH}_{4}$ sources 1978-2005 128

Chapter 5. Summary and Conclusion 134

$\begin{array}{ll}\text { References } & 140\end{array}$

Appendices

$\begin{array}{ll}\text { A. Tables } & 157\end{array}$ 
$\begin{array}{lr}\text { B. Figures } & 169\end{array}$

C. Recent Air Sampling at Cape Meares (March 2012- October 2012) 


\section{List of Tables}

\begin{tabular}{|c|c|c|}
\hline \# & Caption & Page \\
\hline 1.1 & $\mathrm{CH}_{4}$ budget from different sources with their $\delta^{13} \mathrm{C}$ and $\delta \mathrm{D}$ signatures. & 11 \\
\hline 1.2 & Summary of ${ }^{13 C} \alpha_{j}$ and ${ }^{D} \alpha_{j}$. & 12 \\
\hline 1.3 & $\begin{array}{l}\text { Summary of } \delta^{13} \mathrm{C} \text { and } \delta \mathrm{D} \text { of atmospheric } \mathrm{CH}_{4} \text { measurements at fixed } \\
\text { sites by location }\end{array}$ & 18 \\
\hline & $\begin{array}{l}\text { Samples with } 10 \mathrm{ppb} \text { or more difference between measured values of } \\
\mathrm{CH}_{4} \text { mixing ratios at OGI and PSU and their measured } \delta^{13} \mathrm{C} \text { values }\end{array}$ & \\
\hline & Summary of the annual $\mathrm{CH}_{4}, \delta^{13} \mathrm{C}, \delta \mathrm{D}$ and their growth & 11 \\
\hline & The annual total $\mathrm{CH}_{4}$ total emissions, $\delta^{13} \mathrm{C}$ and $\delta \mathrm{D}$ of $\mathrm{CH}_{4}$ sources & \\
\hline
\end{tabular}




\section{List of Figures}

1.1 Contribution of individual sources to the total anthropogenic $\mathrm{CH}_{4}$ emissions (Figure is generated using data from Khalil, [2000]).

1.2 Contribution of individual natural sources to the total natural $\mathrm{CH}_{4} 5$ emissions (Figure is generated using data from Khalil, [2000]).

1.3 Contribution of individual sinks to the total $\mathrm{CH}_{4}$ sink (Figure is 7 generated using data from [IPCC, 2007]).

2.1 Schematic view of continuous-flow gas chromatography isototopic ratio mass spectrometer system for measurements of $\delta^{13} \mathrm{C}$ and $\delta \mathrm{D}$ of atmospheric $\mathrm{CH}_{4}$

2.2 Light and heavy ions are moved under the magnetic field and their deflection

2.3 The different isotopic ions of hydrogen and carbon dioxide are focused in the collectors (Faraday cups).

2.4 The output of $\delta^{13} \mathrm{C}$ running air sample. Ion trace shows $\mathrm{m} / \mathrm{z}=44,45$, 46.

2.5 Schematic view of the analytical system of gas chromatography to measure the concentration of atmospheric $\mathrm{CH}_{4}$ in air samples

2.6 The display of $\mathrm{CH}_{4}$ peaks in the same acquisition. The third peak of each set is $\mathrm{CH}_{4}$.

2.7 Field sampling system configuration

2.8 The location at Cape Meares where air is collected.

38

3.1 The atmospheric $\mathrm{CH}_{4}$ mixing ratio measurements from air archive samples at Cape Meares, Oregon collected 1 October 1977 to 24 August 1999. The $\mathrm{CH}_{4}$ mixing ratio is expressed on the National Institute for Standards and Technology (NIST) scale. Error bars represent $\pm 1 \sigma$ (standard deviation) from six determinations for each sample. The peak height method (as explained in Chapter 2) is used to determine the $\mathrm{CH}_{4}$ mixing ratio

3.2 Seasonal trend of atmospheric $\mathrm{CH}_{4}$ mixing ratio from air archive samples. The residual $\mathrm{CH}_{4}$ mixing ratio is expressed on NIST scale. Error bars represent \pm 1 standard error.

3.3 $\mathrm{CH}_{4}$ mixing ratio measurements of Cape Meares air archive samples at OGI (green star) and at PSU (red circle). Both measurements are on the NIST scale.

3.4 Comparison between $\mathrm{CH}_{4}$ concentrations measured at OGI and at PSU using (GC-FID).

3.5 The difference in $\mathrm{CH}_{4}$ mixing ratio between OGI and PSU in [ppb] with the collected date after removing the outlier value.

3.6 (a). Gaussian distribution of the differences of Cape Meares samples between OGI and PSU. (b). Gaussian distribution of a simulated dataset generated by a random sampling. (c). The difference between 
Gaussian distributions in Q-Q Plot.

3.7 Atmospheric $\mathrm{CH}_{4}$ mixing ratio measurements at Cape Meares from different datasets. The average monthly mixing ratios of Cape Meares measured by OGI (green star) [Khalil et al.1993] between 1979 and 1992 and by NOAA (blue cross) [Dlugokencky et al. 2012], which spans (1983-1998), and at PSU (red circle) during 1977-1999. The first and third datasets have been adjusted to be on NOAA04 scale.

3.8 Seasonal trend of atmospheric $\mathrm{CH}_{4}$ mixing ratio at Cape Meares from three different datasets.

3.9 The $\delta^{13} \mathrm{C}$ of atmospheric $\mathrm{CH}_{4}$ observed at Cape Meares, Oregon from 1 October 1977 to 24 August 1999. Error bars are $\pm 1 \sigma$ from the average of multiple runs of each sample.

3.10 Seasonal trend of $\delta^{13} \mathrm{C}$ of atmospheric $\mathrm{CH}_{4}$ at Cape Meares from 1 October 1977 to 24 August 1999. The error bars represent \pm 1 standard error.

3.11 The $\delta \mathrm{D}$ of atmospheric $\mathrm{CH}_{4}$ observed at Cape Meares, Oregon from 1 October 1977 to 24 August 1999. Error bars are $\pm 1 \sigma$ from the average of multiple measurements of each sample.

3.12 Seasonal trend of $\delta \mathrm{D}$ of atmospheric $\mathrm{CH}_{4}$ at Cape Meares 1 October 1977 to 24 August 1999. The error bars represent \pm 1 standard error.

3.13 Seasonal cycles of (a) atmospheric $\mathrm{CH}_{4}$ mixing ratio, (b) $\delta^{13} \mathrm{C}$, and (c) $\delta \mathrm{D}$ at Cape Meares based on the measurements from air archive samples collected from 1 October 1977 to 24 Aug 1999. Error bars represent \pm 1 standard error.

3.14 Phase ellipse for $\mathrm{CH}_{4}$ at Cape Meares, Oregon, made by plotting (a) residual of $\delta^{13} \mathrm{C}-\mathrm{CH}_{4}$ versus residual of $\mathrm{CH}_{4}$ mixing ratio and (b) residual of $\delta \mathrm{D}-\mathrm{CH}_{4}$ versus residual of $\mathrm{CH}_{4}$ mixing ratio. The black stars are mean monthly residual values of $\mathrm{CH}_{4}, \delta{ }^{13} \mathrm{C}$, and $\delta \mathrm{D}$. The results of KIE of both ${ }^{13 C} \alpha$ and ${ }^{D} \alpha$ are $1.006 \pm 0.004$ and $1.19 \pm 0.09$, respectively

3.15 The seasonal trend of $\mathrm{CH}_{4}$ mixing ratio starting from 28 March 2012 to October 2012. The measured $\mathrm{CH}_{4}$ mixing ratio is on the NOAA04 scale. Error bars represent $\pm 1 \sigma$.

The seasonal trend of $\delta^{13} \mathrm{C}$ of atmospheric $\mathrm{CH}_{4}$ starting from $28 \mathrm{March}$

3.162012 to October 2012. Error bars represent \pm 1 standard error.

(a) $\mathrm{CH}_{4}$ mixing ratio (b) $\delta^{13} \mathrm{C}-\mathrm{CH}_{4}$, and (c) $\delta \mathrm{D}-\mathrm{CH}_{4}$ measurements for South Pole from January 1992 to February 1995. Error bars represent $\pm 1 \sigma$. $\mathrm{CH}_{4}$ mixing ratio measurements at PSU were adjusted to be in NOAA scale.

3.18 (a) $\mathrm{CH}_{4}$ mixing ratio (b) $\delta^{13} \mathrm{C}-\mathrm{CH}_{4}$, and (c) $\delta \mathrm{D}-\mathrm{CH}_{4}$ measurements at Samoa from February 1995 to April 1996. Error bars in represent $\pm 1 \sigma$. $\mathrm{CH}_{4}$ mixing ratio (a) measurements at PSU were adjusted to be in NOAA scale. 
3.19 (a) $\mathrm{CH}_{4}$ mixing ratio (b) $\delta{ }^{13} \mathrm{C}-\mathrm{CH}_{4}$, and (c) $\delta \mathrm{D}-\mathrm{CH}_{4}$ measurements at Mauna Loa from February 1995 to December 1995. Error bars in represent $\pm 1 \sigma . \mathrm{CH}_{4}$ mixing ratio measurements at PSU were adjusted to be on the NOAA04 scale.

4.1 (a) atmospheric $\mathrm{CH}_{4}$ mixing ratios for mid-latitude Northern hemisphere sites (1977-2010) after adjusting them to NOAA04 scale. Error bars represent $\pm 1 \sigma$. (b) Atmospheric $\mathrm{CH}_{4}$ mixing ratios for midlatitude Northern hemisphere sites (1977-2010) after adjusting for the latitude of each dataset based on $\mathrm{CM}$ site. Error bars represent $\pm 1 \sigma$.

4.2 (a) $\delta^{13} \mathrm{C}$ record of atmospheric $\mathrm{CH}_{4}$ from datasets in the Northern hemisphere mid-latitudes (1977-2010). All of the results are reported relative to VPDB. Errors bars represent $\pm 1 \sigma$. (b) $\delta^{13} \mathrm{C}$ record of atmospheric $\mathrm{CH}_{4}$ from datasets in the Northern hemisphere midlatitudes (1977-2010) after adjusting the latitude of each dataset based on the CM site.

4.3 (a) $\delta \mathrm{D}$ record of atmospheric $\mathrm{CH}_{4}$ from datasets in the Northern hemisphere mid-latitudes (1977-2005). All of the results are reported relative to VSMOW. Errors bars represent $\pm 1 \sigma$. (b) $\delta \mathrm{D}$ record of atmospheric $\mathrm{CH}_{4}$ from datasets in the Northern hemisphere midlatitudes (1977-2005) after adjusting both datasets based on CM site.

4.4 Seasonal trend of $\mathrm{CH}_{4}$ mixing ratio from datasets in the Northern hemisphere mid-latitudes (1977-2010) from data in figure 4.1(b). Error bars represent \pm one standard error

4.5 $\quad \delta^{13} \mathrm{C}$ seasonal trend from datasets in the Northern hemisphere midlatitudes (1977-2010) from data in figure 4.2(b). Error bars represent \pm one standard error

4.6 $\delta \mathrm{D}$ seasonal trend from datasets in the Northern hemisphere midlatitudes (1977-2005) from data in figure 4.3(b). Error bars represent \pm one standard error

4.7 Seasonal cycles of (a) atmospheric $\mathrm{CH}_{4}$ mixing ratio,(b) $\delta^{13} \mathrm{C}$, and (c) $\delta \mathrm{D}$ from mid-latitude sites in the Northern hemisphere. Error bars represent \pm 1 standard error

4.8 Phase ellipse for the composite datasets, made by plotting (a) residual of $\delta^{13} \mathrm{C}-\mathrm{CH}_{4}$ versus residual of $\mathrm{CH}_{4}$ mixing ratio and (b) residual $\delta \mathrm{D}$ $\mathrm{CH}_{4}$ versus residual $\mathrm{CH}_{4}$ mixing ratio. The black stars are mean monthly residual values of $\mathrm{CH}_{4}, \delta^{13} \mathrm{C}$, and $\delta \mathrm{D}$. The results of $\mathrm{KIE}$ of both ${ }^{13 C} \alpha$ and ${ }^{D} \alpha_{j}$ are $1.004 \pm 0.002$ and $1.21 \pm 0.06$, respectively

4.9 (a) Residual of $\delta^{13} \mathrm{C}-\mathrm{CH}_{4}$ versus residual of $\mathrm{CH}_{4}$ mixing ratio as in figure 4.8(a) but with datasets individually and aggregated.(b) Residual of $\delta \mathrm{D}-\mathrm{CH}_{4}$ versus residual of $\mathrm{CH}_{4}$ mixing ratio as in figure 4.8(b) with datasets individually and aggregated.

4.10 The composite data before and after removing the seasonal trend for (a) 106 $\mathrm{CH}_{4}$ mixing ratio (b) $\delta^{13} \mathrm{C}-\mathrm{CH}^{4}$ and (C) $\delta \mathrm{D}-\mathrm{CH}_{4}$ 
4.11 The instantaneous atmospheric $\mathrm{CH}_{4}$ mixing ratio (1978-2010) with mean values (black line), $\pm 1 \sigma$ (red dots), and average yearly values (black circles) with $\pm 1 \sigma$ by smoothing the deseasonalize data in figure 4.10(a).

4.12 The instantaneous $\mathrm{CH}_{4}$ growth rate (1978-2010) calculated from the derivative of the black line in figure 4.11 with respect to time $\pm 1 \sigma$ (red dots), and average yearly values ( black circles) with $\pm 1 \sigma$.

4.13 The annual increases $\mathrm{CH}_{4}$ growth rate for the composite data with black circles during 1978-2010 measured in ppb/yr. Green stars are the annual $\mathrm{CH}_{4}$ growth rate calculated from NOAA Global Cooperative Air Sampling Network measurements (values are taken from figure 1.(b) [Dlugokencky et al. 2011])

4.14 The instantaneous $\delta^{13} \mathrm{C}$ trend during 1978-2010 with mean values (black line), $\pm 1 \sigma$ (red dots), and average yearly values (black circles) with $\pm 1 \sigma$ calculate from 1 January in one year to 1 January in the next year by smoothing the deseasonalize data in figure 4.10(b).

4.15 The instantaneous $\delta^{13} \mathrm{C}$ growth rate of composite data during 19782010. Red dots are \pm standard deviation and black circles are the average yearly value calculated from 1 January in one year to 1 January in the next year.

4.16 The instantaneous $\delta \mathrm{D}$ trend (1978-2005) with mean values (black line), $\pm 1 \sigma$ (red dots), and average yearly values (black circles) with $\pm 1 \sigma$ calculate from 1 January in one year to 1 January in the next year by smoothing the deseasonalized data in figure 4.10(c)

4.17 The instantaneous $\delta \mathrm{D}$ time rate of change of composite data during 1978-2005. Red dots are \pm standard deviation and black circles are the average yearly values calculated from 1 January in one year to 1 January in the next year.

4.18 The annual time rate of change of (a) $\mathrm{CH}_{4}(\mathrm{~b}) \delta^{13} \mathrm{C}(\mathrm{c}) \delta \mathrm{D}$ of composite 118 data

4.19 Annual $\mathrm{CH}_{4}$ emission during 1978-2010 using the mass balance equation (4.10) and based on $\mathrm{CH}_{4}$ lifetime of $9.7 \mathrm{yrs}$.

4.20 The annual $\delta^{13} \mathrm{C}$ of the $\mathrm{CH}_{4}$ sources during 1978-2010. 126

4.21 The annual $\delta \mathrm{D}$ of the $\mathrm{CH}_{4}$ source during 1978-2005 131

$4.22 \delta{ }^{13} \mathrm{C}-\mathrm{CH}_{4}$ source vs. $\delta \mathrm{D}-\mathrm{CH}_{4}$ source for Microbial, Fossil Fuel, and Biomass Burning with the results obtained from figure 4.20 and figure 4.21 during 1978-2005.

4.23 The annual values of $\delta^{13} \mathrm{C}-\mathrm{CH}_{4}$ sources vs. the annual values $\delta \mathrm{D}-\mathrm{CH}_{4}$ sources from figure 4.20 and figure 4.21 during 1978-2005. 


\section{Chapter 1}

\section{Introduction}

\subsection{Atmospheric $\mathrm{CH}_{4}$}

Methane $\left(\mathrm{CH}_{4}\right)$ is the most abundant hydrocarbon in the atmosphere [Wubbles and Hayhoe, 2002; Tyler et al, 2007]. It is also one of the most abundant greenhouse gases in the Earth's atmosphere after water vapor $\left(\mathrm{H}_{2} \mathrm{O}\right)$ and carbon dioxide $\left(\mathrm{CO}_{2}\right)$. It absorbs infrared radiation strongly at $7.66 \mu \mathrm{m}$, a spectral region where $\mathrm{CO}_{2}$ and $\mathrm{H}_{2} \mathrm{O}$ absorb weakly [Nelson et al., 1948; Goody and Robinson, 1951]. Therefore, $\mathrm{CH}_{4}$ has a direct effect on the earth's radiation budget; not only in the troposphere but also in the stratosphere [Donner and Ramanathan, 1980; Ramanathan et al., 1985]. The contribution of $\mathrm{CH}_{4}$ emissions to radiative forcing is 25 times that of $\mathrm{CO}_{2}$ on a per molecule basis, based on a 100 year time scale [IPCC, 2007]. It is understood that increasing the atmospheric $\mathrm{CH}_{4}$ concentrations will cause global temperature to increase [Lashof and Ahuja, 1990].

$\mathrm{CH}_{4}$ plays an important role in tropospheric and stratospheric chemistry [Tyler, 1986; Dlugokencky et al., 1994]. In the troposphere, $\mathrm{CH}_{4}$ is oxidized primarily by hydroxyl radicals $(\mathrm{OH})$, which is the major atmospheric oxidant [Cicerone et al., 1988]. $\mathrm{CH}_{4}$ consumes about $25 \%$ of $\mathrm{OH}$ and therefore $\mathrm{CH}_{4}$ strongly controls the concentration of $\mathrm{OH}$ in the troposphere. It is also a source of tropospheric ozone $\left(\mathrm{O}_{3}\right)$, carbon monoxide (CO) and hydrogen $\left(\mathrm{H}_{2}\right)$ [Thompson, 1992]. In the stratosphere, $\mathrm{CH}_{4}$ oxidation is a major source of the upper stratospheric $\mathrm{H}_{2} \mathrm{O}$ vapor. $\mathrm{CH}_{4}$ is also a primary sink for $\mathrm{Cl}$ radical, 
which terminates the $\mathrm{O}_{3}$-destroying catalytic chain mechanism in the stratosphere [Ehhalt, 1974; Stolarski and Cicerone, 1974; Tyler, 1986; Cicerone and Oremland, 1988].

\subsection{Measurement of atmospheric $\mathrm{CH}_{4}$}

The direct systematic measurements of atmospheric $\mathrm{CH}_{4}$ using gas chromatography (GC) did not begin until 1978 [Rasmussen and Khalil, 1981; Craig and Chou, 1982; Steel et al., 1987; 1992]. The trend of atmospheric $\mathrm{CH}_{4}$ from these direct time series measurements has been observed to increase with different rates over different time periods (e.g. 2\%/yr [Rasmussen and Khalil, 1981], 1.3\%/yr [Khalil and Rasmussen, 1983], 0.8\%/yr [Steele et al., 1987], and 1\%/yr [Blake and Rowland, 1988]). Information about the mixing ratio of atmospheric $\mathrm{CH}_{4}$ for older atmospheres was obtained by measuring methane concentration in air bubbles trapped in polar ice [Legrand et al, 1988]. Measurements of $\mathrm{CH}_{4}$ in air samples extracted from Antarctic and Greenland ice cores showed that the atmospheric $\mathrm{CH}_{4}$ during the last ice age $(\sim 30,000$ years ago) was 300-400 ppb [Stauffer et al., 1988; Brook et al.,1996] and the preindustrial era (around 1750) was $\sim 700 \mathrm{ppb}$ [Craig and Chou, 1982; IPCC, 2007]. It then increased dramatically (more than doubling) in the industrial era. The global average methane concentration from a network of surface air sampling sites was $1774 \pm 1.8 \mathrm{ppb}$ in 2005 [IPCC, 2007] and 1794 ppb in 2009 [Dlugokencky et al.2011].

The increase of atmospheric $\mathrm{CH}_{4}$ since the preindustrial era has been attributed to the increase in world population [Blunier et al., 1993] and intensified human activities such as fossil fuel extraction/consumption [Khalil et al., 1993(a)], biomass burning [Seiler and Crutzen, 1980], and agriculture activities [Khalil and Rasmussen, 1987]. 
The growth rate of $\mathrm{CH}_{4}$ in the atmosphere averaged 1\%/year between 1960 and 1981 [Etheridge et al., 1998]. In fact, the rate of increase of atmospheric $\mathrm{CH}_{4}$ has been steadily slowing down since the beginning of NOAA's global record in 1983. It dramatically dropped to zero in 1992 [Francey et al., 1999] and reached its first negative value in 2000 [Dlugokencky et al., 2003 and 2009; Khalil et al., 2007]. More recently, the growth rate has been increasing again (up to $10 \mathrm{ppb} / \mathrm{yr}$ ) since the beginning of 2007 [Rigby et al., 2008]. The reasons of the interannual variability in the growth rate were explained due to the changes in emissions from biomass burning and wetlands [Dlugokencky et al., 2001] and changes in the concentration of $\mathrm{OH}$ [Dlugokencky et al., 1996].

Neither the rapid increase nor the slowdown of the growth rate of atmospheric $\mathrm{CH}_{4}$ is fully understood but they are related to the imbalance between $\mathrm{CH}_{4}$ sources and sinks [IPCC, 2007]. Despite considerable research conducted on this topic, there are large uncertainties in the magnitude and spatial distribution of identified $\mathrm{CH}_{4}$ sources and sinks [Miller et al., 2002; Dlugokencky et al., 2003; Bousquet et al., 2006].

\section{3. $\mathrm{CH}_{4}$ sources and sinks}

\subsection{1. $\mathrm{CH}_{4}$ Sources}

$\mathrm{CH}_{4}$ is not only emitted from natural sources such as wetlands, lakes, and oceans but is also emitted from anthropogenic sources, which act together to influence the global burden of atmospheric $\mathrm{CH}_{4}$ [Rasmussen and Khalil, 1981]. Anthropogenic emissions come from biogenic sources due to anaerobic decomposition and reduction of organic material by bacteria in rice paddies [Cao et al., 1966], in animal ruminants [Johnson et 
al., 2000], in waste disposal systems [Thorneloe et al., 2000]. Non-anaerobic sources are also important such as $\mathrm{CH}_{4}$ emitted in biomass burning and from the extraction, transportation, and use of fossil fuels such as natural gas, coal and petroleum [Crutzen and Andreae, 1990]. The contribution of annual anthropogenic $\mathrm{CH}_{4}$ emissions is shown in figure 1.1 [Khalil, 2000].

\section{Anthropogenic Methane Emission( $358 \mathrm{Tg} / \mathrm{yr}$ )}

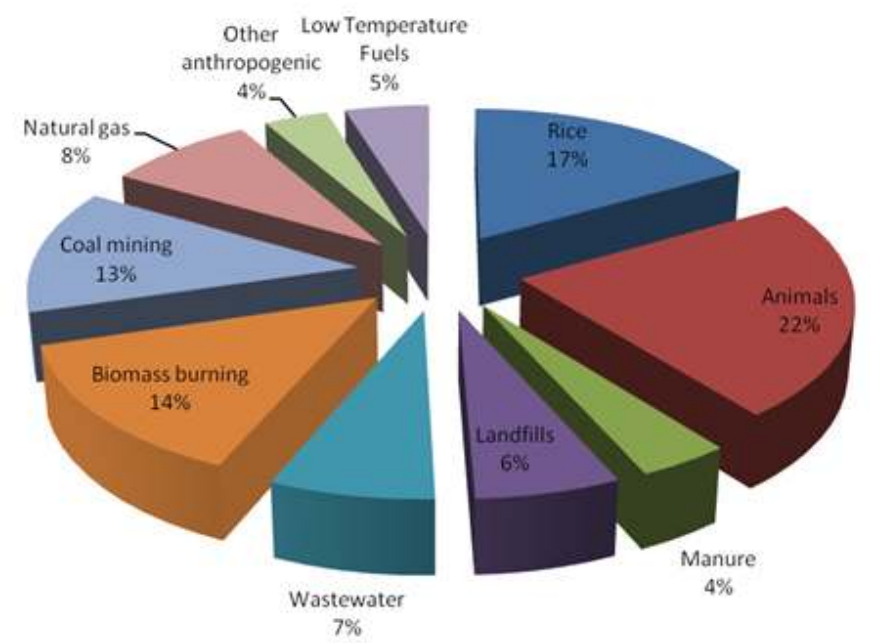

Figure 1.1. Contribution of individual sources to the total anthropogenic $\mathrm{CH}_{4}$ emissions (Figure is generated using data from Khalil, [2000]).

Natural sources of $\mathrm{CH}_{4}$ arise from wetlands [Bartlett and Harris, 1993], termites [Sanderson, 1996], wild ruminant animals [Crutzen et al., 1986], oceans [Bates et al., 1996], geological sources and marine sediments [Judd, 2000], and wild fires [Kasischke and Bruhwiler, 2003]. The contribution of each natural source to the total annual natural $\mathrm{CH}_{4}$ source is shown in figure 1.2 [Khalil, 2000]. 


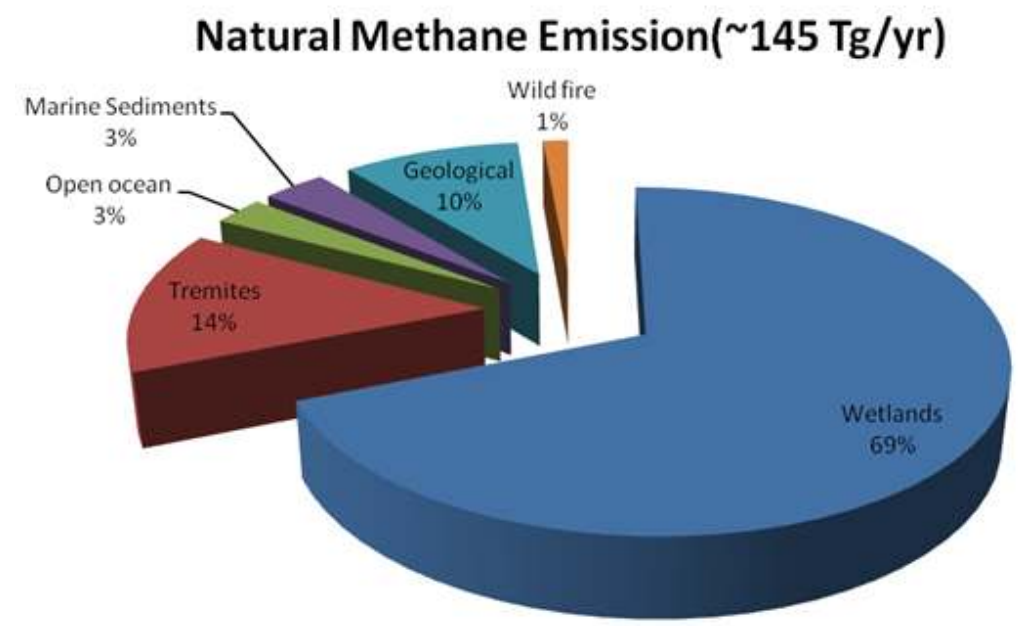

Figure 1.2. Contribution of individual natural sources to the total natural $\mathrm{CH}_{4}$ emissions (Figure is generated using data from Khalil, [2000]).

Estimates of the global magnitudes of emission (flux) from each $\mathrm{CH}_{4}$ source (either anthropogenic or natural) have been made by measuring the emission rates from unit source elements and multiplied by the global distribution of sources. This method was used to estimate the $\mathrm{CH}_{4}$ emission from termites, wetlands, oceans, biomass burning, landfills, and rice agriculture. Although this method is direct, it has many uncertainties due to spatial and temporal dependences of emission sources as well as source-specific parameters. For example, $\mathrm{CH}_{4}$ emission from the widely distributed wetlands depends on their soil type, vegetation type and cover, water depth, and soil temperature [Dlugokencky et al., 1994; Tyler et al., 1994]. For the case of rice paddies, $\mathrm{CH}_{4}$ emission depends on water management, fertilizer, type of rice plants and additives [Tyler et al., 1994; Khalil et al., 1998]. 


\subsection{2. $\mathrm{CH}_{4}$ Sinks}

The number of known $\mathrm{CH}_{4}$ sinks is fewer than the number of its known sources. The main known three sinks of atmospheric $\mathrm{CH}_{4}$ are tropospheric $\mathrm{OH}$, soil uptake, and transport to the stratosphere as shown in figure 1.3 [IPCC, 2007]. Tropospheric OH sink of $\mathrm{CH}_{4}$ constitutes about $88 \%$ of the total $\mathrm{CH}_{4}$ sink [IPCC, 2007], which makes $\mathrm{OH}$ concentration the most important factor of $\mathrm{CH}_{4}$ removal from the atmosphere. A smaller contribution to atmospheric $\mathrm{CH}_{4}$ removal is through dry soil-oxidation in "aerobic soils" $(\sim 5 \%)$ while the rest of $\mathrm{CH}_{4}$ removal is due to transport to the stratosphere [IPCC, 2007]. Finally, marine boundary layer oxidation by $\mathrm{Cl}$ radicals is a potential sink of $\mathrm{CH}_{4}$ [Allan et al., 2007].

$\mathrm{OH}$ can be formed through different mechanisms; the primary of which is the photodissociation of tropospheric $\mathrm{O}_{3}$ in the presence of sunlight and $\mathrm{H}_{2} \mathrm{O}$, as shown in the following reactions

$$
\begin{aligned}
& \mathrm{O}_{3}+\mathrm{h} v \stackrel{\text { Sunlight }}{\longrightarrow} \mathrm{O}\left({ }^{1} \mathrm{D}\right)+\mathrm{O}_{2} \\
& \left(\mathrm{O}^{1} \mathrm{D}\right)+\mathrm{H}_{2} \mathrm{O} \stackrel{\text { yields }}{\longrightarrow} 2 \mathrm{OH}
\end{aligned}
$$

In addition to $\mathrm{CH}_{4}$ oxidation, $\mathrm{OH}$ is also the primary oxidant for some tropospheric pollutants such as $\mathrm{NO}_{\mathrm{x}}, \mathrm{SO}_{2}$, and $\mathrm{CO}$ [Zellner and Ehhalt, 1999]. The rate of $\mathrm{CH}_{4}$ destruction depends on temperature [Vaghijani and Ravishankara, 1991] as well as $\mathrm{OH}$ levels and $\mathrm{CH}_{4}$ burden. The rate of $\mathrm{CH}_{4}$ destruction can be written as

$$
\frac{\mathrm{d}\left[\mathrm{CH}_{4}\right]}{\mathrm{dt}}=-\mathrm{k}_{1}[\mathrm{OH}]\left[\mathrm{CH}_{4}\right]
$$


where $\mathrm{k}_{1}$ is the rate coefficient for the reaction is given as a function of $\mathrm{T}\left({ }^{\mathrm{o}} \mathrm{K}\right)$ as

$\mathrm{k}_{1}(\mathrm{~T})=\left(2.45 * 10^{-12}\right) \mathrm{e}^{\frac{-1775}{\mathrm{~T}}} \mathrm{~cm}^{3}$ molecule $\mathrm{s}^{-1}$

and $[\mathrm{OH}]$ and $\left[\mathrm{CH}_{4}\right]$ are the concentrations of $\mathrm{OH}$ and $\mathrm{CH}_{4}$ respectively.

\section{Methane Sinks}

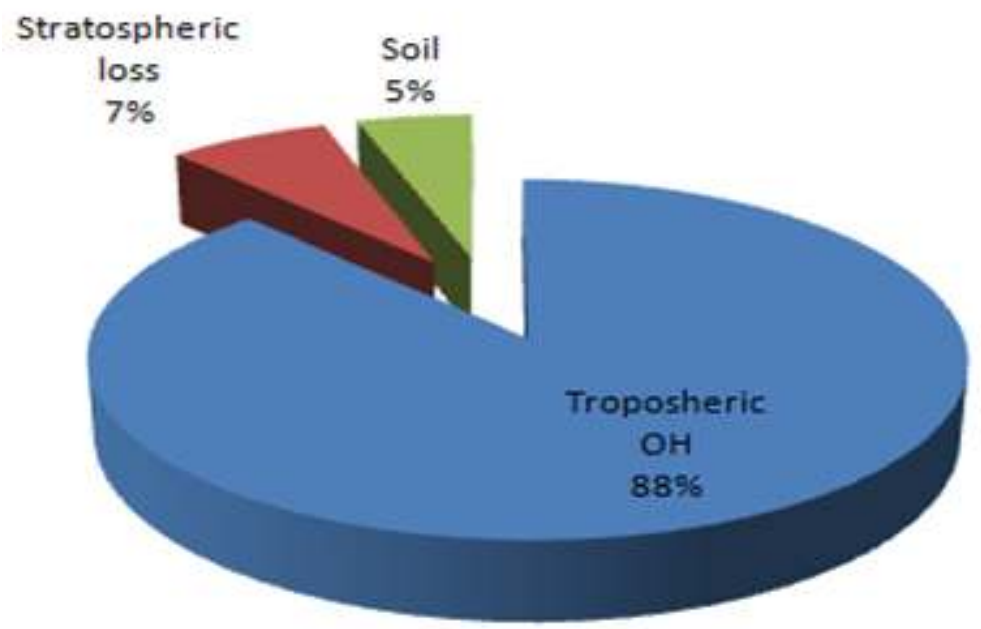

Figure 1.3. Contribution of individual sinks to the total $\mathrm{CH}_{4}$ sink (Figure is generated using data from [IPCC, 2007]).

A few measurements for $\mathrm{OH}$ concentration have been made at certain locations using long path absorption spectroscopy. The measured $\mathrm{OH}$ concentrations in a moderately polluted location has a range $(2.5$ to 8$) \times 10^{6}$ molecules $/ \mathrm{cm}^{3}$ [ Hard et al.1992; Poppe et al.1995]. However, the actual global concentration of $\mathrm{OH}$ is not known yet due to the short lifetime of $\mathrm{OH}$ in the atmosphere [George et al.1999]. Most estimates of global $\mathrm{OH}$ concentration have been obtained through measuring the concentration of a tracer molecule such as methylcholoform $\left(\mathrm{CH}_{3} \mathrm{CCl}_{3}\right)$ since $\mathrm{OH}$ is the only sink of this compound while its known sources are only anthropogenic [Prinn et al.,1992]. By 
measuring the $\mathrm{CH}_{3} \mathrm{CCl}_{3}$ emissions at different locations over certain time intervals, information about the destruction rate (due to $\mathrm{OH}$ ) can be deduced and therefore the concentration of $\mathrm{OH}$ can be calculated. According to Prinn et al., (1992), the average OH concentration from $1978-1990$ was $8.1( \pm 0.9) \times 10^{5} / \mathrm{cm}^{3}$. They also noticed the lower tropical troposphere showed positive $\mathrm{OH}$ trend because of the changes in $\mathrm{OH}$ and $\mathrm{O}_{3}$ concentrations driven by tropical urbanization, biomass burning, land use changes, and long-term warming. In 2001, Prinn et al. calculated the global OH levels between 1978 and 2000. Their analysis showed global OH levels increase from 1978 to 1988 and then began to decline after 1988. The global average $\mathrm{OH}$ between 1978 and 2000 was 9.4( \pm 1.3$) \times 10^{5} / \mathrm{cm}^{3}$ [Prinn et al., 2001].

The lifetime of $\mathrm{CH}_{4}$ can be calculated from the knowledge of the average hydroxyl radical concentrations (from $\mathrm{CH}_{3} \mathrm{CCl}_{3}$ concentrations), the $\mathrm{OH}$ rate constant, the observed temperatures, and the global concentration of $\mathrm{CH}_{4} \cdot \mathrm{CH}_{4}$ lifetime was calculated to be $9.6(+2.2,-1.5)$ yrs [Prinn et al., 1987], 11.3 yrs [Fung et al., 1991], 8.9 yrs [Prinn et al., 1995], 10 yrs [Dlugokencky et al., 1998], 7.9 yrs [Lelieveld et al., 1998], and 12 yrs [IPCC, 2007]. Changes in the abundance of $\mathrm{OH}$ in the atmosphere will result in changes in the $\mathrm{CH}_{4}$ lifetime and its global concentrations [Prather, 1996]. Consequently, long-term changes in $\mathrm{OH}$ will have a feedback on climate.

\subsection{Isotopic composition of $\mathrm{CH}_{4}$}

\subsubsection{The use of isotopes to study atmospheric $\mathrm{CH}_{4}$}

The isotopic species of both carbon and hydrogen in $\mathrm{CH}_{4}$, i.e. ${ }^{12} \mathrm{CH}_{4},{ }^{13} \mathrm{CH}_{4}$,

${ }^{14} \mathrm{CH}_{4}$ and $\mathrm{CH}_{3} \mathrm{D}$ can be used to study the different $\mathrm{CH}_{4}$ sources. Each $\mathrm{CH}_{4}$ source has its 
own characteristic ${ }^{13} \mathrm{C} /{ }^{12} \mathrm{C}$ and $\mathrm{D} / \mathrm{H}$, which will depend on the mechanisms of $\mathrm{CH}_{4}$ formation and consumption before its release to the atmosphere. Some sources are relatively enriched with respect to the atmospheric value while others are relatively depleted [Tyler, 1986].

Small variations in the ratios of ${ }^{13} \mathrm{C} /{ }^{12} \mathrm{C}$ and $\mathrm{D} / \mathrm{H}$ in $\mathrm{CH}_{4}$ sources are due to changes in the vibrational energy states of the isotopic species. The vibrational zero point energy $E_{0}(v)$ is proportional to the frequency of that vibration. Wolfsberg (1972) defined vibrational frequency, $v$, as

$v_{\mathrm{i}}=\frac{1}{2 \pi} \sqrt{\frac{\mathrm{k}}{\mu_{\mathrm{i}}}}$

where $\mu_{i}$ is the reduced mass of the molecular bond and $k$ is the force constant. Increasing the mass of the isotopologue (for example, by changing carbon from ${ }^{12} \mathrm{CH}_{4}$ to ${ }^{13} \mathrm{CH}_{4}$ ), will act to decrease the zero point energy and to increase the strength of chemical bonds. Therefore, molecules containing heavy isotope ${ }^{13} \mathrm{CH}_{4}$ are more stable, and consequently have higher dissociation energy than lighter molecules with the lighter isotope ${ }^{12} \mathrm{CH}_{4}$. Hence, the reaction rate of ${ }^{13} \mathrm{CH}_{4}\left(\mathrm{k}_{13}\right)$ is slower than that of ${ }^{12} \mathrm{CH}_{4}\left(\mathrm{k}_{12}\right)$.

The most commonly measured isotopes (or isotopologues) of atmospheric $\mathrm{CH}_{4}$ are ${ }^{13} \mathrm{CH}_{4}$ and $\mathrm{CH}_{3} \mathrm{D}$. Because the variations that occur are on the order of one part in a thousand and smaller, they are denoted using the delta notation by $\delta^{13} \mathrm{C}$ and $\delta \mathrm{D}$ where

$\delta(\%))=\left[\frac{\mathrm{R}_{\text {sample }}}{\mathrm{R}_{\text {standard }}}-1\right] 1000$

and

$$
\mathrm{R}=\frac{{ }^{13} \mathrm{C}}{{ }^{12} \mathrm{C}} \text { or } \frac{\mathrm{D}}{\mathrm{H}}
$$


Isotopic ratios are reported relative to Vienna Peedee Belemnite (VPDB) for ${ }^{13} \mathrm{C} /{ }^{12} \mathrm{C}$ and Vienna Standard Mean Ocean Water (VSMOW) for D/H as established by the International Atomic Energy Agency (IAEA) in Vienna, Austria [IAEA Tec Doc 825, 1995].

Different $\mathrm{CH}_{4}$ sources have different levels of ${ }^{13} \mathrm{C}$ and D depletion. For example, sources of biogenic origin have $\delta^{13} \mathrm{C} \sim-60 \%$ and $\delta \mathrm{D} \sim-300 \%$, whereas for nonbiogenic sources $\mathrm{CH}_{4}$ is less depleted with $\delta^{13} \mathrm{C} \sim-40 \%$ and $\delta \mathrm{D} \sim-200 \%$ [Bräunlich et al., 2001]. The values of $\delta^{13} \mathrm{C}$ and $\delta \mathrm{D}$ from different sources such as wetlands, biomass burning, rice paddies, and marshes have been measured [Stevens and Rust, 1982; Tyler, 1986; Quay et al., 1991]. The global budget of $\mathrm{CH}_{4}$ known sources and their isotopic signatures are shown in table 1.1 [Tyler et al., 2007].

Table $1.1 \mathrm{CH}_{4}$ budget from different sources with their $\delta^{13} \mathrm{C}$ and $\delta \mathrm{D}$ signatures

\begin{tabular}{|c|c|c|c|}
\hline Source & $\begin{array}{c}\text { Emission Strength } \\
\left(\mathbf{T g} \mathbf{C H}_{\mathbf{4}} / \mathbf{y r}\right)\end{array}$ & $\begin{array}{c}\boldsymbol{\delta}^{\mathbf{1 3}} \mathbf{C} \\
(\mathbf{\% o}, \mathbf{P D B})\end{array}$ & $\begin{array}{c}\boldsymbol{\delta} \mathbf{D} \\
(\mathbf{\% o}, \mathbf{S M O W})\end{array}$ \\
\hline Tundra & 10 & -65 & $-317^{\mathrm{a}}$ \\
\hline Lakes(bogs, fens, and lakes) & 75 & -59 & -322 \\
\hline Swamps and marshes & 106 & -56 & -322 \\
\hline Rice paddies & 80 & -59 & -323 \\
\hline Animals & 95 & -62 & -305 \\
\hline Landfills & 42 & -50 & -293 \\
\hline Gas venting and leakage & 54 & -38 & -175 \\
\hline Oceans(costal margins) & 10 & -40 & $-220^{\mathrm{b}}$ \\
\hline Coal mining & 27 & -37 & -175 \\
\hline Biomass burning & 45 & -26 & -210 \\
\hline Termites & 20 & -57 & $-390^{\mathrm{b}}$ \\
\hline Gas hydrates & 10 & -52 & $-240^{\mathrm{b}}$ \\
\hline Atmospheric Background(NH) & & $-47.4^{\mathrm{a}}$ & $-96^{\mathrm{a}}$ \\
\hline Atmospheric Background(SH) & & $-47.2^{\mathrm{a}}$ & $-86^{\mathrm{a}}$ \\
\hline Mean Source & & -52 & -287 \\
\hline
\end{tabular}

${ }^{\mathrm{a}}$ see [Stevens and Whalen, 2000]

${ }^{\mathrm{b}}$ see [Whiticar, 2000] 
The $\delta^{13} \mathrm{C}$ and $\delta \mathrm{D}$ of the mean $\mathrm{CH}_{4}$ sources (in table 1.1) are calculated according to the following equation

$\bar{\delta}=\frac{\sum_{\mathrm{i}=1}^{\mathrm{M}} \mathrm{E}_{\mathrm{i}} * \delta_{\mathrm{i}}}{\sum_{\mathrm{i}=1}^{\mathrm{n}} \mathrm{E}_{\mathrm{i}}}$

where $\delta_{\mathrm{i}}$ is either $\delta^{13} \mathrm{C}$ or $\delta \mathrm{D}$ for source $\mathrm{i}(\%)$ and $\mathrm{E}_{\mathrm{i}}$ is the emission of the source $\mathrm{i}$ $(\mathrm{Tg} / \mathrm{yr})$

Sink processes also affect the isotopic composition of $\mathrm{CH}_{4}$ through differences in the rate constants between isotopic species, i.e., kinetic isotopic effects. Kinetic isotope effects (KIE or $\alpha$ ) of $\mathrm{CH}_{4}$ oxidation are measured in controlled laboratory experiments [e.g., Cantrell et al., 1990; Tyler et al., 2000]. KIE is defined as the ratio of the reaction rate constant of the abundant isotope to the rate of reaction of the rare isotope. In the case of $\mathrm{CH}_{4}$, the carbon $\mathrm{KIE}$ is defined as

$$
\alpha_{j}=\frac{\mathrm{k}_{\mathrm{j}}\left({ }^{12} \mathrm{CH}_{4}\right)}{\mathrm{k}_{\mathrm{j}}\left({ }^{13} \mathrm{CH}_{4}\right)}
$$

and the hydrogen KIE is defined as

$$
\alpha_{j}=\frac{k_{j}\left(\mathrm{CH}_{4}\right)}{\mathrm{k}_{\mathrm{j}}\left(\mathrm{CH}_{3} \mathrm{D}\right)}
$$

where $j$ is an arbitrary sink reaction, i.e. $\mathrm{OH}, \mathrm{Cl}$, or $\mathrm{O}\left({ }^{1} \mathrm{D}\right)$ and $k_{j}$ is the rate coefficient for the reaction of ${ }^{12} \mathrm{CH}_{4},{ }^{13} \mathrm{CH}_{4},{ }^{12} \mathrm{CH}_{3} \mathrm{D}$ with $\mathrm{OH}, \mathrm{Cl}$, or $\mathrm{O}\left({ }^{1} \mathrm{D}\right)$. Because of a lower zero point energy from the larger molecular mass of ${ }^{13} \mathrm{CH}_{4} \cdot \mathrm{k}_{\mathrm{j}}\left({ }^{13} \mathrm{CH}_{4}\right)$ is smaller than $\mathrm{k}_{\mathrm{j}}\left({ }^{12} \mathrm{CH}_{4}\right)$. Consequently, ${ }^{13 \mathrm{C}} \alpha_{\mathrm{j}} \geq 1$ and therefore $\mathrm{CH}_{4}$ will become enriched in ${ }^{13} \mathrm{CH}_{4}$ as a reaction proceeds. Similarly, because $\mathrm{k}_{\mathrm{j}}\left(\mathrm{CH}_{3} \mathrm{D}\right)$ is typically smaller than $\mathrm{k}_{\mathrm{j}}\left(\mathrm{CH}_{4}\right)$, then ${ }^{\mathrm{D}} \alpha_{\mathrm{j}}$ 
$\geq 1$ and $\mathrm{CH}_{4}$ will become enriched in $\mathrm{CH}_{3} \mathrm{D}$ as a reaction proceeds . Table 1.2 summarizes the values of ${ }^{13 \mathrm{C}} \alpha_{\mathrm{j}}$ and ${ }^{\mathrm{D}} \alpha_{\mathrm{j}}$ of $\mathrm{CH}_{4}$ reactions with $\mathrm{OH}, \mathrm{Cl}$, and $\mathrm{O}\left({ }^{1} \mathrm{D}\right)$.

Table 1.2. Summary of ${ }^{13 \mathrm{C}} \alpha_{\mathrm{j}}$ and ${ }^{\mathrm{D}} \alpha_{\mathrm{j}}$

\begin{tabular}{|l|l|l|l|}
\hline Reaction & ${ }^{\mathbf{1 3}} \boldsymbol{\alpha}_{\mathbf{j}}$ & ${ }^{\mathbf{D}} \boldsymbol{\alpha}_{\mathbf{j}}$ & Ref. \\
\hline $\mathrm{CH}_{4}+\mathrm{OH}$ & $1.0054 \pm 0.0009$ & ---- & Cantrell et al.,1990 \\
& $1.0039 \pm 0.0004$ & $1.294 \pm 0.018$ & Saueressig et al.,2001 \\
\hline $\mathrm{CH}_{4}+\mathrm{Cl}$ & $1.0621 \pm 0.0001$ & $1.474 \pm 0.02$ & Tyler et al.,2000 \\
\hline $\mathrm{CH}_{4}+\mathrm{O}\left({ }^{1} \mathrm{D}\right)$ & $1.013 \pm 0.0006$ & $1.06 \pm 0.011$ & Saueressig et al.,2001 \\
\hline $\begin{array}{l}\mathrm{CH}_{4}+\text { soils } \\
\text { (grassland) } \\
\text { (forest) }\end{array}$ & $1.022 \pm 0.004$ & & Tyler et al., 1994 \\
& $1.0173 \pm 0.001$ & $1.099 \pm 0.030$ & Snover and Quay,2000 \\
\hline
\end{tabular}

Typically, the fractionation factor is defined as (Miller et al., 2002) $\varepsilon_{\mathrm{j}}(\% 0)=\left(\frac{1}{\alpha_{\mathrm{j}}}-1\right) * 1000$

The knowledge of $\varepsilon_{\mathrm{j}}\left(\right.$ or $\alpha_{\mathrm{j}}$ ) is important since the characterization of the $\mathrm{CH}_{4}$ isotopic fractionation by different sinks (such as $\mathrm{OH}, \mathrm{Cl}$, and $\mathrm{O}\left({ }^{1} \mathrm{D}\right)$ ) is needed to constrain the estimation of the global $\mathrm{CH}_{4}$ budget [Quay et al., 1991]. The fraction factor $\left(\varepsilon_{\mathrm{j}}\right)$ is convenient because at steady state the source $\delta$ value is depleted by $\sim \varepsilon$ of the sinks.

Cantrell et al. [1990] used a simple equation to connect between $\delta_{\text {source }}$ and $\alpha_{j}$ (in two-sink processes: tropospheric $\mathrm{OH}$ and soil) by the steady state formula

$$
\delta_{\text {source }}=\delta_{\text {atm }}+\left(\mathrm{F}_{\mathrm{atm}} \frac{\left(1-\alpha_{\mathrm{atm}}\right)}{\alpha_{\mathrm{atm}}}+\mathrm{F}_{\text {soil }} \frac{\left(1-\alpha_{\text {soil }}\right)}{\alpha_{\text {soil }}}\right) *\left(1+\frac{\delta_{\mathrm{atm}}}{1000}\right) * 1000
$$


where $\mathrm{F}_{\mathrm{atm}}$ is the fraction of $\mathrm{CH}_{4}$ that is removed chemically by tropospheric $\mathrm{OH}$ $\left(\mathrm{F}_{\mathrm{atm}}=0.88\right.$ from figure 1.3$), \mathrm{F}_{\text {soil }}$ is the fraction removed by soils $\left(\mathrm{F}_{\text {soil }} \approx 0.05\right)$. If $F_{\text {soil }}$ is negligible, $\alpha_{a t m}$ is 1.0054 (for tropospheric $\mathrm{OH}$ ), and $\delta_{a t m}$ is $-47.7 \%$, hence $\delta_{\text {source }} \approx$ $-52.2 \%$.

The measurements of the isotopic composition of atmospheric $\mathrm{CH}_{4}$ with $\mathrm{CH}_{4}$ sources provide a major constraint on $\mathrm{CH}_{4}$ sources and sink processes [Steven and Rust, 1982; Tyler et al.,1994; Francey et al., 1999; Tyler et al., 2007] and consequently can be used to reduce uncertainties in the $\mathrm{CH}_{4}$ budget (e.g. Table 1.1). The $\delta^{13} \mathrm{C}$ and $\delta \mathrm{D}$ of atmospheric $\mathrm{CH}_{4}$ depend on the flux weighted average source strength.

Using the approach of Quay et al. (1999), the sources and sinks of methane are related through the mass balance equation

$\frac{\mathrm{dC}}{\mathrm{dt}}=\mathrm{S}-\left[\frac{\mathrm{C}}{\tau}\right]$

where $\mathrm{C}$ is the global burden of $\mathrm{CH}_{4}(\mathrm{Tg}), \mathrm{S}$ is the total $\mathrm{CH}_{4}$ emission in $(\mathrm{Tg} / \mathrm{yr})$, and $\tau$ is the methane life time (yr), which could be calculated from

$\frac{1}{\tau}=\frac{1}{\tau_{\mathrm{OH}}}+\frac{1}{\tau_{\text {soil }}}+\frac{1}{\tau_{\text {strato }}}$

$\tau_{\mathrm{OH}}, \tau_{\text {soil }}$, and $\tau_{\text {strato }}$ are the lifetimes of $\mathrm{CH}_{4}$ due to $\mathrm{OH}$, soils uptake, and stratosphere.

At steady state $\left(\frac{\mathrm{dC}}{\mathrm{dt}}=0\right)$, equation (1.11) will be reduced to

$\mathrm{S}=\left[\frac{\mathrm{C}}{\tau}\right]$

More generally, equations (1.11) and (1.13) could be written in the following forms

$\frac{\mathrm{dC}_{\mathrm{i}}}{\mathrm{dt}}=\mathrm{S}_{\mathrm{i}}-\left[\frac{\mathrm{C}_{\mathrm{i}}}{\tau_{\mathrm{i}}}\right]$

and 
$\mathrm{S}_{\mathrm{i}}=\frac{\mathrm{C}_{\mathrm{i}}}{\tau_{\mathrm{i}}}$

where the subscript $\mathrm{i}$ refers to one the $\mathrm{CH}_{4}$ isotopes such as ${ }^{12} \mathrm{CH}_{4},{ }^{13} \mathrm{CH}_{4}$, or $\mathrm{CH}_{3} \mathrm{D}$. In that equation $\mathrm{S}_{\mathrm{i}}, \mathrm{C}_{\mathrm{i}}$, and $\tau_{\mathrm{i}}$ are the global source, burden, and the lifetime of that isotopic species.

The global atmospheric value for $\delta^{13} \mathrm{C}$ of atmospheric methane (in case of ${ }^{13} \mathrm{CH}_{4}$ ) will depend on the $\delta^{13} \mathrm{C}$ of $\mathrm{CH}_{4}$ sources and the fractionation effect during $\mathrm{CH}_{4}$ loss [Quay et al., 1999]

$\frac{\mathrm{d}}{\mathrm{dt}}\left[{ }^{13} \mathrm{CH}_{4}\right]=\mathrm{S} *\left(\frac{{ }^{13} \mathrm{C}}{{ }^{12} \mathrm{C}}\right)_{\mathrm{S}}-\frac{\left[\mathrm{CH}_{4}\right]}{\tau *{ }^{13 \mathrm{C}} \alpha} *\left(\frac{{ }^{13} \mathrm{C}}{{ }^{12} \mathrm{C}}\right)$

At steady state, equation (1.16) will be

$\mathrm{S} *\left(\frac{{ }^{13} \mathrm{C}}{{ }^{12} \mathrm{C}}\right)_{\mathrm{S}}=\frac{\left[\mathrm{CH}_{4}\right]}{\tau^{13 \mathrm{C}} \alpha} *\left(\frac{{ }^{13} \mathrm{C}}{{ }^{12} \mathrm{C}}\right)$

where $\left({ }^{13} \mathrm{C} /{ }^{12} \mathrm{C}\right)_{\mathrm{s}}$ is the average ${ }^{13} \mathrm{C} /{ }^{12} \mathrm{C}$ of the $\mathrm{CH}_{4}$ sources, $\left({ }^{13} \mathrm{C} /{ }^{12} \mathrm{C}\right)$ is ${ }^{13} \mathrm{C} /{ }^{12} \mathrm{C}$ of the atmospheric $\mathrm{CH}_{4},{ }^{13 \mathrm{C}} \alpha$ was defined by equation (1.7). From equation (1.16), the $\delta^{13} \mathrm{C}$ of atmospheric $\mathrm{CH}_{4}$ depends on the total source strength (S), the average ${ }^{13} \mathrm{C} /{ }^{12} \mathrm{C}$ of the $\mathrm{CH}_{4}$ sources, $\mathrm{CH}_{4}$ concentration $\left[\mathrm{CH}_{4}\right]$, lifetime of $\mathrm{CH}_{4}(\tau)$, and the fractionation effect during $\mathrm{CH}_{4} \operatorname{loss}\left({ }^{13 \mathrm{C}} \alpha\right)$. Similarly for $\delta \mathrm{D}$ in case of ${ }^{12} \mathrm{CH}_{3} \mathrm{D}$

$\mathrm{S} *\left(\frac{\mathrm{D}}{\mathrm{H}}\right)_{\mathrm{S}}=\frac{\left[\mathrm{CH}_{4}\right]}{\tau * \mathrm{D}_{\alpha}} *\left(\frac{\mathrm{D}}{\mathrm{H}}\right)$

where $(\mathrm{D} / \mathrm{H})_{\mathrm{s}}$ is the average $\mathrm{D} / \mathrm{H}$ of the $\mathrm{CH}_{4}$ sources, $(\mathrm{D} / \mathrm{H})$ is $\mathrm{D} / \mathrm{H}$ of the atmospheric $\mathrm{CH}_{4},{ }^{\mathrm{D}} \alpha$ was defined by equation (1.8). 
The $\delta^{13} \mathrm{C}$ of atmospheric $\mathrm{CH}_{4}$ has been measured by some groups around the world. In the beginning of 1988 , Stevens reported the first measurements of $\delta^{13} \mathrm{C}$ of atmospheric $\mathrm{CH}_{4}$ in some locations of Northern and Southern hemispheres in the period from 1978 to 1987 (see table 1.3). He deduced that $\delta^{13} \mathrm{C}$ of atmospheric $\mathrm{CH}_{4}$ is more enriched in the Southern hemisphere due to the increased $\mathrm{CH}_{4}$ flux from biomass burning associated with the rapid deforestation in that hemisphere [Stevens, 1988]. More recent work has shown that the average interhemispheric gradient in $\delta^{13} \mathrm{C}$ of $\mathrm{CH}_{4}$ is $\sim 0.2 \%$ [Quay et al., 1999] or 0.3\%o [Miller et al., 2002] and 10\%o for $\delta \mathrm{D}$. Additionally, these studies determined that it is, in fact, the sink effects that are responsible for the enrichment in the Southern hemisphere. Since the majority of $\mathrm{CH}_{4}$ sources are located in the Northern Hemisphere $\left(75 \%\right.$ of $\mathrm{CH}_{4}$ emissions are from Northern Hemisphere [Fung et al, 1991]), $\mathrm{CH}_{4}$ in the Southern hemisphere has had more time to react with $\mathrm{OH}$, providing for the enriched values of $\delta^{13} \mathrm{C}$ and $\delta \mathrm{D}$ of $\mathrm{CH}_{4}$ in the Southern hemisphere. Typical values for $\delta^{13} \mathrm{C}$ and $\delta \mathrm{D}$ of atmospheric $\mathrm{CH}_{4}$ are $-47.4 \%$ and $-91 \%$ in the Northern Hemisphere and $-47.2 \%$ and $-81 \%$ in the Southern hemisphere [Quay et al., 1999].

Different global averages of $\delta^{13} \mathrm{C}$ have been reported by several groups. Table 1.3 summarizes some of these measurements. The global $\delta^{13} \mathrm{C}$ of atmospheric $\mathrm{CH}_{4}$ has changed from $-47.6 \%$ in 1978 to $-47.1 \%$ in 1987 according to samples collected from Cape Meares, North Illinois, North Minnesota, Key largo, Mendocino, Potage, Greenland, Pacific, South Pole, Samao, Tasmonia, and Canberra [Stevens, 1988]. Later, Quay et al. reported the global $\delta^{13} \mathrm{C}$ of atmospheric $\mathrm{CH}_{4}-47.2 \%$ from 1987 to 1989 
according to air samples collected from Point Barrow, Olympic Peninsula, Mauna Loa and Cape Grim [Quay et al., 1991], and $-47.3 \%$ from 1990 to 1995 according to samples collected from Point Barrow, Olympic Pennsuila, Mauna Loa, American Samoa, Cape Grim, and Baring Head [Quay et al., 1999]. In 2002, Miller et al. reported the global $\delta^{13} \mathrm{C}$ of atmospheric $\mathrm{CH}_{4}$ was $-47.1 \%$ from 1998 to 1999 according to air samples collected from Point Barrow, Niwot Ridge, Mauna Loa, American Samoa, Cape Grim, and South Pole [Miller et al., 2002].

Table 1.3 also shows that $\delta^{13} \mathrm{C}$ of atmospheric $\mathrm{CH}_{4}$ has been considerably studied in different locations while this is not the case for $\delta \mathrm{D}$ of atmospheric $\mathrm{CH}_{4}$. This is primarily due to the complexity of $\delta \mathrm{D}$ measurements. Quay et al. (1999) was the first group to measure $\delta \mathrm{D}$ of atmospheric $\mathrm{CH}_{4}$ and reported $\delta \mathrm{D}$ of atmospheric $\mathrm{CH}_{4}$ is $-96 \%$ in the Northern Hemisphere and $-86 \%$ in the Southern hemisphere during the time period between 1989 and 1995 [Quay et al.1999]. Bergmaschi et al. (2000) measured the isotopic composition of $\mathrm{CH}_{4}$ and found significant seasonal cycle for $\delta \mathrm{D}$ (as will be discussed in section 1.4.2) and also investigated the significant influence of bogs and rice paddies on $\delta \mathrm{D}$ at Izaña, Tenerife $\left(28^{\circ} \mathrm{N}, 16^{\circ} \mathrm{W}, 2370 \mathrm{~m}\right.$ above sea level). Yamada et al. (2003) measured $\delta \mathrm{D}$ at Yokohama, Japan $\left(35.5^{\circ} \mathrm{N}, 139^{\circ} \mathrm{W}\right)$ during November 2001 and reported that $\delta \mathrm{D}$ fluctuated throughout the day from $-96 \%$ to $-118 \%$ and this was correlated to $\mathrm{CH}_{4}$ concentration. Tyler et al. (2007) compared $\delta \mathrm{D}$ for two locations; one mid continental: Niwot Ridge, Colorado $\left(40^{\circ} \mathrm{N}, 105^{\circ} \mathrm{W}\right)$ and the other on the Pacific coast: Montaña de Oro, California $\left(35^{\circ} \mathrm{N}, 121^{\circ} \mathrm{W}\right)$. They found that $\delta \mathrm{D}$ is more depleted 
for the coastal site than for the mid continental site during the same time. They also noted a strong anticorrelation between $\delta \mathrm{D}$ and atmospheric $\mathrm{CH}_{4}$ concentration.

The first global value of $\delta \mathrm{D}$ of atmospheric $\mathrm{CH}_{4}$ was reported by Quay et al. (1999) as $-86 \%$ based on air samples collected on board ocean going vessels in Northern and Southern hemisphere between 1989 and 1995 (table 1.3). 
Table 1.3. Summary of $\delta^{13} \mathrm{C}$ and $\delta \mathrm{D}$ of atmospheric $\mathrm{CH}_{4}$ measurements at fixed sites by location.

\begin{tabular}{|c|c|c|c|c|}
\hline Locations & Period & $\delta^{13} \mathrm{C}(\%)$ & $\delta D(\%)$ & Ref. \\
\hline Rural, IL & $\begin{array}{l}\text { 1980(May- } \\
\text { July) }\end{array}$ & $-47.0 \pm 0.3$ & ----- & $\begin{array}{l}\text { Stevens and } \\
\text { Rust, } 1982\end{array}$ \\
\hline $\begin{array}{c}\text { *N.H \{Cape Meares,OR; } \\
\text { North llinoia,;North } \\
\text { Minnesota; Key largo, FL; } \\
\text { Mendocino,CA; } \\
\text { Potage,AK;Greenland; and } \\
\text { Pacific\} } \\
\text { *S.H.\{Pacific; South Pole; } \\
\text { Samao; Tasmonia; and } \\
\text { Canberra\} }\end{array}$ & $\begin{array}{l}1978-1983 \\
1983-1987 \\
1978-1982 \\
1982-1987\end{array}$ & $\begin{array}{c}-47.7 \pm 0 \\
-47.6 \pm 0.38 \\
-47.6 \pm 0.35 \\
-47.6 \pm 0.55\end{array}$ & ------- & Stevens, 1988 \\
\hline $\begin{array}{l}\text { Baring Head, New } \\
\text { Zealand(S.H.) }\end{array}$ & $\begin{array}{l}\text { 1989(July)- } \\
1992 \text { (june) }\end{array}$ & $-47.14 \pm 0.03$ & ------ & Lassey et al.,1993 \\
\hline $\begin{array}{c}\text { * N.H. }\{\text { Point Barrow,AK; } \\
\text { Olympic Pennsuila,WA; and } \\
\text { Mauna Loa,HI\} } \\
\text { *S.H. }\{\text { American Samoa; Cape } \\
\text { Grim, Australia; and Baring } \\
\text { Head ,New Zealand }\end{array}$ & $1990-1995$ & -47.2 & -96 & Quay et al.,1999 \\
\hline Izana,Tenerife (N.H.) & 1996-1998 & $-47.3 \pm 0.1$ & $-81 \pm 2$ & $\begin{array}{l}\text { Bergmaschi et } \\
\text { al.,2000 }\end{array}$ \\
\hline $\begin{array}{c}\text { *N.H }\{\text { Point } \\
\text { Barrow,AK;Niwot Ridge,CO; } \\
\text { and Mauna Loa,HI\} } \\
\text { *S.H. }\{\text { American Samoa; Cape } \\
\text { Grim, Australia; and South } \\
\text { Pole\} } \\
\end{array}$ & 1998-1999 & $\begin{array}{l}-47.28 \\
-46.93\end{array}$ & ---- & Miller et al.2002 \\
\hline $\begin{array}{l}\text { Baring Head, New } \\
\text { Zealand(S.H.) }\end{array}$ & 1989 & $-47.13 \pm 0.2$ & ------ & Lowe et al.,1991 \\
\hline Suva, Fiji(S.H.) & 1994-2002 & -47.2 & ----- & Lowe et al.,2004 \\
\hline Ny Ålesund,Svalbard(N.H.) & 1996-2004 & $-47.2 \pm 0.21$ & ------ & Morimoto rt al.,2006 \\
\hline $\begin{array}{c}\text { Independence Pass and } \\
\text { Wolcott, } \mathrm{CO} \text { and Denver, } \mathrm{CO}\end{array}$ & 1984,1985 & $-46.5 \pm 0.4$ & ------ & Tyler,1986 \\
\hline $\begin{array}{l}\text { N.H.(Niwot Ridge,CO; } \\
\text { Montaña de Oro,CA) }\end{array}$ & $1995-2001$ & $\begin{array}{l}-47.22 \pm 0.13 \\
-47.26 \pm 0.17\end{array}$ & $\begin{array}{l}(-93.1 \pm 3)^{*} \\
(-97.3 \pm 3.7)^{* *}\end{array}$ & Tyler et al.,2007 \\
\hline
\end{tabular}

$\mathrm{N} . \mathrm{H} . \equiv$ Northern hemisphere location, $\mathrm{S} . \mathrm{H} . \equiv$ Southern hemisphere location

${ }^{*}$ measured in the period (1999-2001)

${ }^{* *}$ measured in the period $(2000-2001)$ 


\subsubsection{Seasonal cycle of $\delta^{13} \mathrm{C}$ and $\delta \mathrm{D}$ of atmospheric $\mathrm{CH}_{4}$}

The seasonal cycle of $\delta^{13} \mathrm{C}$ and $\delta \mathrm{D}$ has been characterized in several studies. Quay et al. (1991 and 1999) reported the amplitude of the seasonal cycle of $\delta^{13} \mathrm{C}$ to be $\sim 0.4 \%$ in the Northern hemisphere located at Point Barrow, Alaska $\left(71^{\circ} \mathrm{N}, 156^{\circ} \mathrm{W}\right)$. This is higher than $\sim 0.1 \%$ measured in the Southern hemisphere at American Samoa $\left(14^{\circ} \mathrm{S}\right.$, $\left.170^{\circ} \mathrm{W}\right)$. The highest Northern latitudes had the strongest seasonal cycle of $\delta^{13} \mathrm{C}$. The seasonal cycle of $\delta^{13} \mathrm{C}$ was determined to be $\approx 180^{\circ}$ "out of phase" with the seasonal cycle in the $\mathrm{CH}_{4}$ concentrations, where the minimum $\delta^{13} \mathrm{C}$ values are in the fall and maximum values are in the summer.

Lassey et al. (1993) reported $\delta^{13} \mathrm{C}$ data from Baring Head, New Zealand $\left(41^{\circ} 25^{\prime}\right.$ S, $174^{\circ} 52^{\prime}$ E) from 1989 to 1992 . Their data showed a large seasonal cycle (0.3\% peak to peak). Their model explained the seasonality in the observed $\delta^{13} \mathrm{C}$ as due to seasonal burning of biomass during the Southern hemisphere spring.

Later in 2000, Bergmaschi et al. studied $\delta^{13} \mathrm{C}$ and $\delta \mathrm{D}$ of atmospheric $\mathrm{CH}_{4}$ at Izaña, Tenerife $\left(28^{\circ} \mathrm{N}, 16^{\circ} \mathrm{W}, 2370 \mathrm{~m}\right)$ from $1996-1998$ and found the seasonal cycle of $\delta^{13} \mathrm{C}$ and $\delta \mathrm{D}$ to be $0.2 \%$ and $3.5 \%$, respectively. The seasonal cycle of $\delta \mathrm{D}$ was found to be out of phase with the mixing ratio $\mathrm{CH}_{4}$. They also found $\delta^{13} \mathrm{C}$ wasn't perfectly shifted by 6 months with $\mathrm{CH}_{4}$ mixing ratios. This indicates that $\delta^{13} \mathrm{C}$ is good indicator of sources while $\delta \mathrm{D}$ is more sensitive to sinks due to their large KIE.

Lowe et al. (1991) reported the $\delta^{13} \mathrm{C}$ seasonality for Baring Head, New Zealand $\left(41^{\circ} 25^{\prime} \mathrm{S}, 174^{\circ} 52^{\prime} \mathrm{E}\right)$ during 1989 . They explained that seasonality due to $\mathrm{OH}$ variations 
and local meteorology. Later in 1997, Lowe et al. (1997) investigated the $\delta^{13} \mathrm{C}$ seasonality at New Zealand $\left(41^{\circ} 25^{\prime} \mathrm{S}, 174^{\circ} 52^{\prime} \mathrm{E}\right)$ and Scott Base, Antarctica $\left(77^{\circ} 51^{\prime} \mathrm{S}\right.$, $166^{\circ} 45^{\prime}$ E) from 1989-1996. Their amplitudes were between 0.1 and $0.3 \%$, and there were no difference in the phase of the seasonal cycle for the two sites. Moreover in 2004, Lowe et al. found the seasonal cycles at Suva, Fiji $\left(18^{\circ} \mathrm{S}, 178^{\circ} \mathrm{W}\right)$ were smaller and more

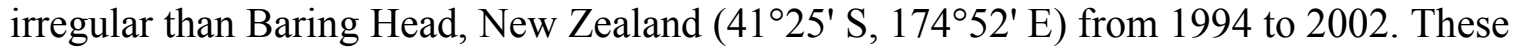
cycles were driven by $\mathrm{OH}$ and $\mathrm{Cl}$ in tropical regions. They also noticed that the summer (1999) variability of $\delta^{13} \mathrm{C}$ at Suva, Fiji $\left(18^{\circ} \mathrm{S}, 178^{\circ} \mathrm{W}\right)$ is larger than further southern locations during the same time period. Such variability was correlated to the La Niña conditions (1998-2000).

In 2007, Tyler et al. reported that the seasonal cycles in $\delta^{13} \mathrm{C}$ and $\delta \mathrm{D}$ of atmospheric $\mathrm{CH}_{4}$ at Montaña de Oro, California $\left(35^{\circ} \mathrm{N}, 121^{\circ} \mathrm{W}\right)$ were larger than those observed at Niwot Ridge, Colorado $\left(40^{\circ} \mathrm{N}, 105^{\circ} \mathrm{W}\right)$. They also found a poor correlation between $\mathrm{CH}_{4}$ mixing ratios and $\delta^{13} \mathrm{C}$, and a strong anticorrelation between $\mathrm{CH}_{4}$ mixing ratios and $\delta \mathrm{D}$ with the maxima and the minima approximately 6 month out of phase.

\subsubsection{Ice core measurements of $\delta^{13} \mathrm{C}$, and $\delta \mathrm{D}$ of atmospheric $\mathrm{CH}_{4}$}

Studying old records of atmospheric $\mathrm{CH}_{4}, \delta^{13} \mathrm{C}$, and $\delta \mathrm{D}$ can give a better understanding of the changes in $\mathrm{CH}_{4}$ sources and sinks in the past. Such understanding will allow for better predictions of the current and future trends of the $\mathrm{CH}_{4}$ sources and sinks. Using the air trapped in the polar ice and firn air provides us an analysis of the long -term behavior of $\mathrm{CH}_{4}, \delta^{13} \mathrm{C}$, and $\delta \mathrm{D}$ over the past 2000 years. 
Bräunlich et al. (2001) measured $\delta^{13} \mathrm{C}$ and $\delta \mathrm{D}$ in firn air for two Antarctica sites; Dronning Maud Land $\left(77^{\circ} \mathrm{S}, 10^{\circ} \mathrm{W} ; 2300 \mathrm{~m}\right.$ above sea level) and Dome Concordia $\left(75^{\circ}\right.$ $\mathrm{S}, 123^{\circ} \mathrm{E} ; 3233 \mathrm{~m}$ above sea level) then reconstructed the trends of $\delta^{13} \mathrm{C}$ and $\delta \mathrm{D}$ via Monte Carlo approach using a firn air model. They found a positive trend in $\delta^{13} \mathrm{C}$ over 50 years (1950-2000). $\delta$ D had a declining trend from 1950 and reached a minimum value in 1975 before staring a gradual increase (1975-2000). The minimum value of $\delta \mathrm{D}$ reflects the non-equilibrium state between atmospheric $\mathrm{CH}_{4}$ and its sources and sinks during changes in the budget of $\mathrm{CH}_{4}$.

In 2005, Ferretti et al. (2005) generated the first high resolution record $\delta^{13} \mathrm{C}$ of atmospheric $\mathrm{CH}_{4}$ over the last 2000 years. The record showed that $\delta^{13} \mathrm{C}$ between 0 and 1500 A.D. had similar value to the present. After 1500 A.D., $\delta^{13} \mathrm{C}$ was depleted by about $2 \%$ and reached to a minimum value $\sim-49 \%$. This steady state value lasted for about 2 centuries then it became enriched until the present value of $\sim-47 \%$.

The reason for such enrichment of atmospheric $\delta^{13} \mathrm{C}$ (between 0 and 1500 A.D.) was thought to be due to biomass burning while its depletion (between 1500 and 1700 A.D.) was due to the decrease of biomass burning associated with the decrease in the population in central and South America [Ferretti et al., 2005]. Another explanation for the trend of the $\delta^{13} \mathrm{C}$ over the past two millennia was proposed by Houwelling et al. (2008). They assumed that the enriched value of $\delta^{13} \mathrm{C}$ was due to the elevated emissions of aerobic methane from plants. The depletion of $\delta^{13} \mathrm{C}(1500-1700$ A.D) was due to the higher emissions from some depleted sources of $\delta^{13} \mathrm{C}$ of $\mathrm{CH}_{4}$ such as rice cultivation, domestic ruminants, and waste treatment compared to the emissions from enriched 
sources of $\delta^{13} \mathrm{C}$ of $\mathrm{CH}_{4}$ such as fossil fuel and biomass burning. After 1700 A.D., the rapid enrichment of $\delta^{13} \mathrm{C}$ of $\mathrm{CH}_{4}$ was due to increasing emissions from fossil fuel since the start of industrialization.

Mischler et al. (2009) published the measurements of $\delta^{13} \mathrm{C}_{\text {of }} \mathrm{CH}_{4}$ and $\delta \mathrm{D}$ of $\mathrm{CH}_{4}$ (900-1730 A.D.) from Antarctica, ice core (WDC05A). Their measurements showed that the trend of $\delta^{13} \mathrm{C}$ was consistent with $\delta \mathrm{D}$. Both $\delta^{13} \mathrm{C}$ and $\delta \mathrm{D}$ were relatively stable and close to the present-day values from $\sim 1000$ to $\sim 1500$ A.D. They started to decrease at 1460 A.D while $\mathrm{CH}_{4}$ began to rise. They continued to decrease as $\mathrm{CH}_{4}$ reversed its trend and suddenly decreased starting in the 1580 A.D. $\mathrm{CH}_{4}$ remained low while $\delta^{13} \mathrm{C}$ and $\delta \mathrm{D}$ reached their lowest values. From the late of the $18^{\text {th }}$ century, $\mathrm{CH}_{4}, \delta^{13} \mathrm{C}$, and $\delta \mathrm{D}$ increased exponentially to the present-day values. Mischler et al. (2009) were first group to show the measurements of $\delta \mathrm{D}$ during this time period. To confirm the fidelity of their results, they compared between $\delta^{13} \mathrm{C}$ of their results and of Ferretti et al. (2005). There is a good agreement between the two $\delta^{13} \mathrm{C}$ data sets. 


\section{Chapter 2}

\section{Experiment and Methodology}

The first section in this chapter introduces information about the air archive samples acquired from OGI and measured at PSU. The main archive from Cape Meares includes 211 samples. The other air archives were collected from South Pole, Samoa, and

Mauna Loa. The analytical method used to measure the isotopes of $\mathrm{CH}_{4}\left(\delta^{13} \mathrm{C}\right.$ and $\left.\delta \mathrm{D}\right)$ of the above samples is described in section 2.2. A detailed description of the analytical system used to measure the $\mathrm{CH}_{4}$ mixing ratio is found in section 2.3. Finally, the system configuration and procedure of field sampling air from Cape Meares is presented in section 2.4. 


\subsection{Air archived samples}

A full set of 211 archived samples were collected at Cape Meares, Oregon (45.5 N, $124^{\circ}$ W, $30 \mathrm{~m}$ ) from 1977 till 1998 by Prof. R. A. Rasmussen (Department of Environmental and Bimolecular Systems, Oregon Graduate Institute of Science and Engineering) and Prof. M. A. Khalil (Physics Department, Portland State University). The samples were collected using air liquefaction to compress $1000 \mathrm{~L}$ of air (STP) to 450 psi into 33L electropolished stainless steel canisters. Those samples represent one of the most complete and longest record of historical archived air samples from anywhere in the world. Cape Meares station also represents one of six locations (three in each hemisphere in polar, middle and tropical latitudes) that were monitored for the trends of some gases (e.g., $\mathrm{CO}_{2}, \mathrm{CH}_{4}, \mathrm{CO}, \mathrm{N}_{2} \mathrm{O}$ ) in the atmosphere over a 20 year period by OGI. Sample collection date and canister number are Tabulated in Table A.1. in Appendix A.

Three other locations South Pole, Samoa, and Mauna Loa also have modest sized archives. The air archive samples from these sites are not as long and continuous as Cape Meares. There are some uncertainties associated with these samples; for example most of the samples are from different samples collected over the same month of collection that were mixed into one canister. Additionally, the fractional weighting for each individual date is unknown. The second challenge is a few of these samples had unknown collection dates due to lost tags on theses samples. NOAA reported the $\mathrm{CH}_{4}$ mixing ratios at these locations from 1983, but the measurements of $\delta^{13} \mathrm{C}$ did not begin until 1998. Our measurements of $\delta^{13} \mathrm{C}$ and $\delta \mathrm{D}$ add unique data during these times periods at these stations. 
The first location at the South Pole $\left(90^{\circ} \mathrm{S}\right)$ consists of 15 archived samples collected from January 1992 to February 1995 . Three samples in the archive have unknown collection dates and two here from a single date of collection. The second location of Samoa $\left(14.1^{\circ} \mathrm{S}, 170.6^{\circ} \mathrm{W}\right)$ has 14 samples collected from March 1995 to April 1996, with a few missing months during this time interval. The third location at Mauna Loa $\left(21.08^{\circ} \mathrm{N}, 157.2^{\circ} \mathrm{W}\right)$ has 11 samples collected from February 1995 to December 1995.

\subsection{Methane isotopic analytical method}

Because the isotopic composition of atmospheric $\mathrm{CH}_{4}\left(\delta^{13} \mathrm{C}, \delta \mathrm{D}\right)$ provides us with important information about the sources and sinks of atmospheric $\mathrm{CH}_{4}$, it is very important to measure them with high accuracy and precision. One of the primary techniques used today is gas chromatography isotope ratio mass spectrometry or (GCIRMS), which has been developed since 1978 [Matthews and Hayes, 1978]. The GC separates the individual compounds in the air sample $\left(\mathrm{N}_{2}, \mathrm{O}_{2}, \mathrm{CH}_{4}\right.$, and other hydrocarbons), then $\mathrm{CH}_{4}$ is either oxidized to $\mathrm{CO}_{2}$ or pyrolyzed to $\mathrm{H}_{2}$ at high temperature and the IRMS will determine the relative abundance ratio of ${ }^{13} \mathrm{C} /{ }^{12} \mathrm{C}$ as $\mathrm{CO}_{2}$ or $\mathrm{D} / \mathrm{H}$ as $\mathrm{H}_{2}$. Continuous flow GC-IRMS to measure $\delta^{13} \mathrm{C}$ of atmospheric $\mathrm{CH}_{4}$ was performed by Merritt et al. [1995] and then modified by Rice et al. [2001].

The advantages of the modifications done by Rice et al. [2001]:

(1) allowed the measurement of not only $\delta^{13} \mathrm{C}$ but also of $\delta \mathrm{D}$ of atmospheric $\mathrm{CH}_{4}$, 
(2) improved the precision of $\delta^{13}{\mathrm{C}-\mathrm{CH}_{4}}_{4}$ and provided good accuracy and precision for $\delta \mathrm{D}-\mathrm{CH}_{4}$,

(3) enhanced simplicity and speed to run a large number of samples within a shorter time while small amounts $\left(0.1 \mathrm{~cm}^{3}<\right.$ sample size $\left.<125 \mathrm{~cm}^{3}\right)$ of samples are consumed. The time for each run at PSU is about 15 minutes.

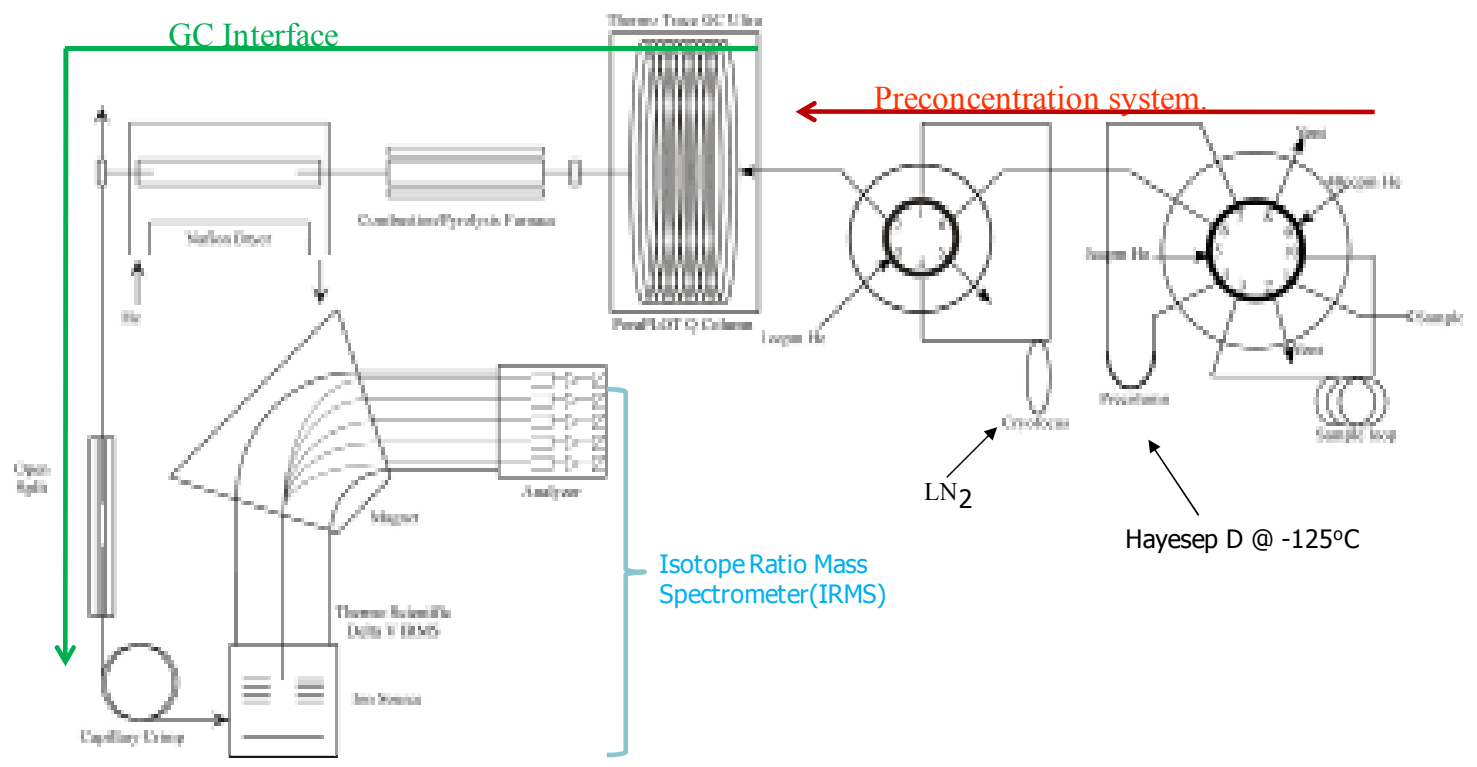

Figure 2.1. Schematic view of continuous-flow gas chromatography isototopic ratio mass spectrometer system for measurements of $\delta^{13} \mathrm{C}$ and $\delta \mathrm{D}$ of atmospheric $\mathrm{CH}_{4}$.

The analytical system used to measure $\delta^{13} \mathrm{C}$ and $\delta \mathrm{D}$ of atmospheric $\mathrm{CH}_{4}$ in our lab has been modified from Rice et al. [2001] as shown in figure 2.1. The analytical system is composed of three parts: preconcentration system, GC and interface, and IRMS.

(i) The preconcentration system: Initially $125 \mathrm{~cm}^{3}$ of air sample is purged through a $25 \mathrm{~cm}^{3}$ sample loop through connection 1 in the normal position of valve $\left(\mathrm{V}_{1}\right) . \mathrm{V}_{1}$ is then turned so that the air sample is swept up from the 
sample loop by a $\mathrm{He}$ carrier at $50 \mathrm{cc} / \mathrm{min}$ to pass through stainless steel precolumn packed with Hayesep D $(0.3 \mathrm{~m}, 3.17 \mathrm{~mm}$ o. d. $)$ cooled at $-125^{\circ} \mathrm{C}$ in a bath of ethanol chilled using liquid nitrogen $\left(\mathrm{LN}_{2}\right)$ for 9 minutes. At this temperature, the majority of molecules in the air sample (such as $\mathrm{N}_{2}, \mathrm{O}_{2}$ ) will pass through, however $\mathrm{CH}_{4}$ is retained in the precoulmn. After 9 minutes, the sample is then cryofocused by warming the precloumn from $-125^{\circ} \mathrm{C}$ to room temperature and transferring $\mathrm{CH}_{4}$ in the air sample to the PoraPLOT Q cryofocus loop $\left(0.6 \mathrm{~m}, 0.32 \mathrm{~mm}\right.$ i.d.) immersed in $\mathrm{LN}_{2}$ by a $\mathrm{He}$ carrier at 5 $\mathrm{cm}^{3} / \mathrm{min}$. This step furthers the removal of $\mathrm{N}_{2}$ and $\mathrm{O}_{2}$ and other molecules and retains $\mathrm{CH}_{4}$ and focuses the $\mathrm{CH}_{4}$ on a small section of tubing. After 3 minutes, valve $\left(\mathrm{V}_{2}\right)$ is switched to inject $\mathrm{CH}_{4}$ in the sample to $\mathrm{GC}$ separation column.

(ii) The $\mathrm{GC}$ and interface: $\mathrm{CH}_{4}$ in the air sample is released to the separation column from $\mathrm{V}_{2}$. The separation column is a (30m, $0.32 \mathrm{~mm}$ i.d.) PoraPLOT Q column. The temperature of $\mathrm{GC}$ column $\left(30^{\circ} \mathrm{C}\right)$, pressure $(17 \mathrm{psi})$, and flow rate $\left(1 \mathrm{~cm}^{3} / \mathrm{min}\right)$ are regulated by a Thermo Scientific Trace Ultra GC. The GC allows further separation of air molecules such as $\mathrm{O}_{2}, \mathrm{~N}_{2}, \mathrm{Ar}, \mathrm{CO}$ and hydrocarbons that aren't removed during preconcentration or cryofocus and that may otherwise interfere with isotopic measurements. $\mathrm{As}^{\mathrm{CH}_{4}}$ elutes from the separation column, it is either: (1) quantitatively oxidized to $\mathrm{CO}_{2}$ and $\mathrm{H}_{2} \mathrm{O}$ for $\delta^{13} \mathrm{C}$ analysis in a combustion alumina tube $(0.3 \mathrm{~m}, 1.59 \mathrm{~mm}$ o.d.) packed with $\mathrm{CuO}, \mathrm{NiO}$, and $\mathrm{Pt}$ wires at $960^{\circ} \mathrm{C}$, or (2) quantitatively pyrolyzed to $\mathrm{H}_{2}$ and $\mathrm{C}$ for $\delta \mathrm{D}$ analysis in open alumina tube at $1400^{\circ} \mathrm{C}$. The $\mathrm{CO}_{2}$ or $\mathrm{H}_{2}$ sample 
is swept through a Nafion dryer to remove $\mathrm{H}_{2} \mathrm{O}$ entrained in the carrier flow and introduced into the IRMS via a Thermo Scientific Combustion III open split interface through a capillary leak at a rate of $0.4 \mathrm{ml} / \mathrm{min}$. The viscousflow in the capillary- crimp prevents isotopic fractionation of the gas as it enters the high vacuum $\left(\sim 10^{-6} \mathrm{mbar}\right)$ mass spectrometer.

(iii) Isotope ratio mass spectrometer (IRMS): The basic components of IRMS are an inlet system, ion source, a flight tube, an ion collector, and recording system. Both open split (in continuous flow) and capillary- crimp (in dual inlet mode) work as the inlet system which introduce the $\mathrm{CO}_{2}$ gas or $\mathrm{H}_{2}$ gas of air sample to the ion source. When the sample gas is introduced to the ion source, molecules $(\mathrm{M})$ are ionized molecules $\left(\mathrm{M}^{+}\right)$by bombarding them with electrons which come from a heated filament creates a positively ionized molecule:

$$
\mathrm{M}+\mathrm{e}^{-} \stackrel{\text { yields }}{\longrightarrow} 2 \mathrm{e}^{-}+\mathrm{M}^{+}
$$

In the case of $\mathrm{CO}_{2}$ gas, the three resulting ions are primarily ${ }^{12} \mathrm{C}^{16} \mathrm{O}_{2}{ }^{+},{ }^{13} \mathrm{C}^{16} \mathrm{O}_{2}{ }^{+}$, ${ }^{12} \mathrm{C}^{17} \mathrm{O}^{16} \mathrm{O}^{+}$, and ${ }^{12} \mathrm{C}^{18} \mathrm{O}^{16} \mathrm{O}^{+}$which correspond to a mass to charge ratio $(\mathrm{m} / \mathrm{z}) 44,45$, and 46. In case of $\mathrm{H}_{2}$ gas, the two resulting ions are ${ }^{1} \mathrm{H}_{2}{ }^{+}$and ${ }^{2} \mathrm{H}^{1} \mathrm{H}^{+}$which correspond to $(\mathrm{m} / \mathrm{z}) 2$ and $3\left({ }^{2} \mathrm{H}\right.$ is called deuterium D). These molecules are then accelerated to the mass analyzer by high voltage potential $(3 \mathrm{kV})$ and collimated into a coherent beam. The beam passes through a strong magnetic field that deflects the ions in a circular trajectory according to their $\mathrm{m} / \mathrm{z}$. From Lorentz force, when a particle moves into a magnetic field it 
will follow a circular path where the magnetic force provides the centripetal force of that particle in this circle with radius $r$ so that

$\mathrm{F}_{\mathrm{B}}=\mathrm{zvB}=\frac{\mathrm{mv}^{2}}{\mathrm{r}}$

So that the radius of particle will be given as

$\mathrm{r}=\frac{\mathrm{mv}}{\mathrm{zB}}$

where $\mathrm{m}$ is the mass of the particle $(\mathrm{kg})$, and $\mathrm{v}$ is the velocity of that charge $(\mathrm{m} / \mathrm{s}), \mathrm{z}$ is the electric charge of the particle (in Coulomb), and B is the magnetic field (in Tesla). Heavy ions (larger $\mathrm{m}$ ) are deflected to a lesser degree than lighter ions (smaller $\mathrm{m}$ ) of the same charge as shown in figure 2.2.

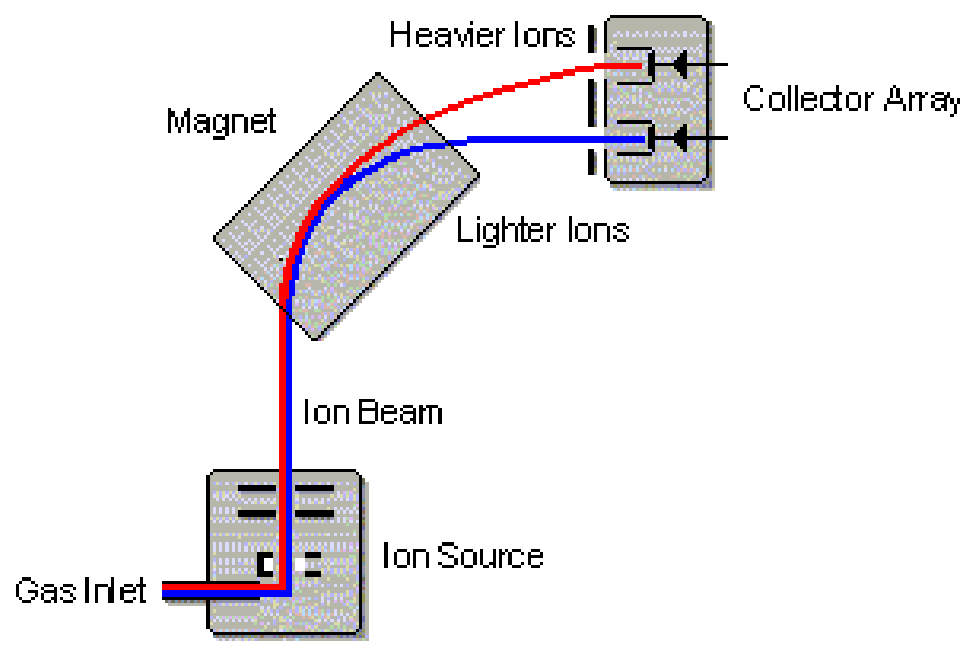

Figure 2.2. Light and heavy ions are moved under the magnetic field and their deflection.

The beam of ions is then converted into an electrical signal by the Faraday cups. From the ratios of these, the isotopic ratios of $\mathrm{H}_{2}$ and $\mathrm{CO}_{2}$ can be deduced as shown in figure 2.3. 


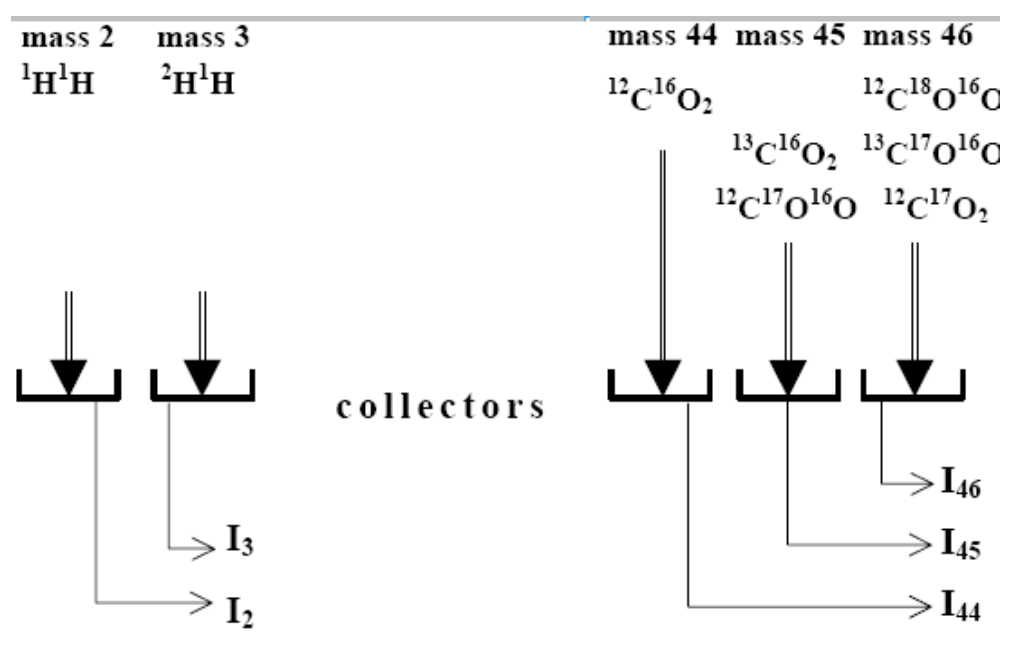

Figure 2.3. The different isotopic ions of hydrogen and carbon dioxide are focused in the collectors (Faraday cups).

The electric current from the isotope is proportional to the partial pressure of the respective component in the gas. These electrical signals are then stored in the computer, and displayed as shown in figure 2.4. Measurements of peak area are interpreted and connected to 8 values by comparison to reference peaks run at close intervals.

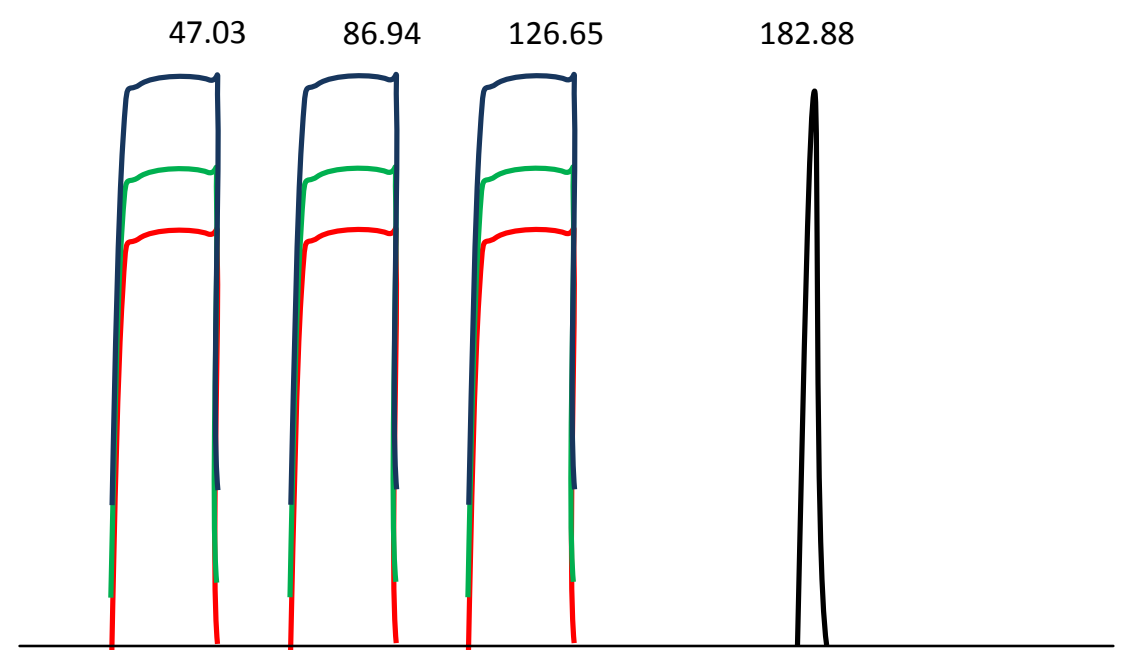

Figure 2.4. The output of $\delta^{13} \mathrm{C}$ running air sample. Ion trace shows $\mathrm{m} / \mathrm{z}=44,45,46$. 
In case of $\mathrm{CO}_{2}$, we have

$$
\begin{aligned}
& \mathrm{I}_{44}=\left[{ }^{12} \mathrm{C}^{16} \mathrm{O}^{16} \mathrm{O}\right] \\
& \mathrm{I}_{45}=2 *\left[{ }^{12} \mathrm{C}^{16} \mathrm{O}^{17} \mathrm{O}\right]+\left[{ }^{13} \mathrm{C}^{16} \mathrm{O}^{16} \mathrm{O}\right] \\
& \mathrm{I}_{46}=2 *\left[{ }^{12} \mathrm{C}^{18} \mathrm{O}^{16} \mathrm{O}\right]+2 *\left[{ }^{13} \mathrm{C}^{16} \mathrm{O}^{17} \mathrm{O}\right]+\left[{ }^{12} \mathrm{C}^{17} \mathrm{O}^{17} \mathrm{O}\right]
\end{aligned}
$$

Now

$$
\begin{aligned}
& { }^{45} \mathrm{R}=\frac{\mathrm{I}_{45}}{\mathrm{I}_{44}}=\frac{2 *\left[{ }^{12} \mathrm{C}^{16} \mathrm{O}^{17} \mathrm{O}\right]+\left[{ }^{13} \mathrm{C}^{16} \mathrm{O}^{16} \mathrm{O}\right]}{\left[{ }^{12} \mathrm{C}^{16} \mathrm{O}^{16} \mathrm{O}\right]}=2 *{ }^{17} \mathrm{R}+{ }^{13} \mathrm{R} \\
& { }^{46} \mathrm{R}=\frac{\mathrm{I}_{46}}{\mathrm{I}_{44}}=\frac{2 *\left[{ }^{12} \mathrm{C}^{18} \mathrm{O}^{16} \mathrm{O}\right]+2 *\left[{ }^{13} \mathrm{C}^{16} \mathrm{O}^{17} \mathrm{O}\right]+\left[{ }^{12} \mathrm{C}^{17} \mathrm{O}^{17} \mathrm{O}\right]}{\left[{ }^{12} \mathrm{C}^{16} \mathrm{O}^{16} \mathrm{O}\right]}=2^{18} \mathrm{R}+2{ }^{13} \mathrm{R}^{17} \mathrm{R}+{ }^{17} \mathrm{R}^{2}
\end{aligned}
$$

where ${ }^{13} \mathrm{R},{ }^{17} \mathrm{R}$, and ${ }^{18} \mathrm{R}$ are corresponding to the ratios ${ }^{13} \mathrm{C} /{ }^{12} \mathrm{C},{ }^{17} \mathrm{O} /{ }^{16} \mathrm{O}$, and ${ }^{18} \mathrm{O} /{ }^{16} \mathrm{O}$ respectively. From Equation (2.7) and (2.8), ${ }^{45} \mathrm{R}$ and ${ }^{46} \mathrm{R}$ are known however ${ }^{13} \mathrm{R},{ }^{17} \mathrm{R}$, and ${ }^{18} \mathrm{R}$ are unknown. Santrock et al. [1985] developed a technique to find ${ }^{13} \mathrm{R},{ }^{17} \mathrm{R}$, and ${ }^{18} \mathrm{R}$ with high accuracy. They used the following procedures

(1) ${ }^{17} \mathrm{R}=0 \rightarrow$ (from equation $\left.(2.7)\right){ }^{45} \mathrm{R}={ }^{13} \mathrm{R}$.

(2) from equation (2.8), calculate ${ }^{18} \mathrm{R}$ from ${ }^{46} \mathrm{R}$.

(3) calculate ${ }^{17} R$,using

$\frac{{ }^{17} \mathrm{R}_{\text {unkown }}}{{ }^{17} \mathrm{R}_{\text {standard }}}=\sqrt{\frac{{ }^{18} \mathrm{R}_{\text {unkown }}}{{ }^{18} \mathrm{R}_{\text {standard }}}}$

(4) insert ${ }^{17} \mathrm{R}$ into equation (2.7) to and recalculate ${ }^{13} \mathrm{R}$

(5) repeat steps (2) and (3) and (1) until ${ }^{13} \mathrm{R},{ }^{17} \mathrm{R}$, and ${ }^{18} \mathrm{R}$ converge

The values obtained for the isotopic composition of the sample are automatically corrected on the VPDB scale for ${ }^{13} \mathrm{C}$ and ${ }^{18} \mathrm{O}$. Measurements of isotopic $\mathrm{CH}_{4}\left(\delta^{13} \mathrm{C}\right.$ and $\delta$ D) are made relative to reference peaks of $\mathrm{CO}_{2}$ and $\mathrm{H}_{2}$. The first three peaks in figure 
2.4 are for the reference cylinder of ultra high purity (UHP) $\mathrm{CO}_{2}$ at PSU $\left(\delta^{13} \mathrm{C}=-40.76\right.$ $\pm 0.01 \%$ and $\delta^{18} \mathrm{O}=-40.05 \pm 0.01 \%$ versus $\left.\mathrm{VPDB}\right)$.

In the case of $\delta^{13} \mathrm{C}$ measurement, the fourth peak (chromatograph peak) is the $\mathrm{CO}_{2}$ that came from $\mathrm{CH}_{4}$ in the sample. A similar display (as in figure 2.4) will appear in case of $\delta \mathrm{D}$ where the reference gas cylinder is UHP of $\mathrm{H}_{2}(\delta \mathrm{D}=-185 \pm 1 \%$ versus VSMOW). In this case, the first three peaks are for the reference gas and the fourth peak (chromatograph peak) is $\mathrm{H}_{2}$ that came from $\mathrm{CH}_{4}$ in the sample.

\subsubsection{Isotope calibration}

Continuous-flow isotope reference gases were calibrated against our dual inlet reference gases which are a suite of three gas phase $\mathrm{CO}_{2}$ and three $\mathrm{H}_{2}$ aliquots stored in 1-L cylinders prepared and certified by Oztech Gas Company. These were calibrated to the VPDB $\left(\delta^{13} \mathrm{C}\right.$ and $\left.\delta^{18} \mathrm{O}\right)$ and VSMOW $(\delta \mathrm{D})$ scales using NBS 19 (RM 8544, $\delta^{13} \mathrm{C}=$ $+1.95 \%$ and $\delta^{18} \mathrm{O}=-2.2 \%$ oversus VPDB) and VSMOW $(\mathrm{RM} 8535, \delta \mathrm{D}=0 \%$ ).

The main calibration gas of $\delta^{13} \mathrm{C}$ and $\delta \mathrm{D}$ of $\mathrm{CH}_{4}$ is based on a $12 \mathrm{~L}$ (STP) aliquot of air collected at $\left(12^{\circ} 51^{\prime} \mathrm{S}, 159^{\circ} 8^{\prime} \mathrm{W}\right)$ and analyzed by the Stable Isotope Laboratory supervised by Professor Stanley Tyler at the University of California, Irvine $\left(\delta^{13} \mathrm{C}=-\right.$ $46.90 \pm 0.04-\%$ and $\delta \mathrm{D}=-84 \pm 1.93 \%$ o referred to as $\mathrm{ST}-438)$. The other calibrated gas that we use daily is a high pressure ( 800 PSI ) $30 \mathrm{~L}$ aluminum cylinder contains a whole air

sample collected at Cheeka Peak, Washington $\left(48^{0} \mathrm{~N}, 124^{\circ} \mathrm{W}, \delta^{13} \mathrm{C}=-47.24 \pm 0.07 \%\right.$ and $\delta \mathrm{D}=-94.8 \pm 1.9 \%$ referred to as ALM-032668). This latter gas was calibrated via ST-438. 
Since there is a drift in the GC-IRMS analytical system from day to day, we measure ALM-032668 gas at the beginning of each day 3 to 5 times, at the middle of the day 2 to 3 times, and at the end of the day 2-3 times. To know the deviation of IRMS from actual values, we first calculate the average value of measured $\delta^{13} \mathrm{C}$ denoted by $\left(\delta^{13} C\right)_{\text {standard }}^{\mathrm{ALM}}$. The deviation in $\left(\delta^{13} \mathrm{C}\right)_{\text {measured }}^{\mathrm{ALM}}$ will be

$\Delta\left(\delta^{13} \mathrm{C}\right)^{\mathrm{ALM}}=\left(\delta^{13} \mathrm{C}\right)_{\mathrm{actual}}^{\mathrm{ALM}}-\left(\delta^{13} \mathrm{C}\right)_{\mathrm{measured}}^{\mathrm{ALM}}$

where $\left(\delta^{13} \mathrm{C}\right)^{\mathrm{ALM}}$ actual is calculated by comparing values of ALM-032668 to ST-438. For example, we measure the ST-438 (4 times), then ALM-032668 (4 times), repeating the process several times. We calculate the deviation of GC-IRMS as, e.g.,

$$
\Delta\left(\delta^{13} \mathrm{C}\right)_{\text {Standard }}^{\mathrm{ST}}=\left(\delta^{13} \mathrm{C}\right)_{\mathrm{actual}}^{\mathrm{ST}}-\left(\delta^{13} \mathrm{C}\right)_{\text {measured }}^{\mathrm{ST}}=-46.90+45.276=-1.62 \% 0
$$

Therefore

$$
\left(\delta^{13} \mathrm{C}\right)_{\mathrm{Actual}}^{\mathrm{ALM}}=\Delta\left(\delta^{13} \mathrm{C}\right)_{\mathrm{Standard}}^{\mathrm{ST}}+\left(\delta^{13} \mathrm{C}\right)_{\text {measured }}^{\mathrm{ALM}}=-1.62-45.62=-47.24 \% 0
$$

For the sample, we calculate the average value of $\left(\delta^{13} \mathrm{C}\right)_{\text {measured }}^{\mathrm{Sa}}$ and the actual value of the sample will be

$$
\left(\delta^{13} \mathrm{C}\right)_{\mathrm{actual}}^{\mathrm{Sa}}=\overline{\left(\delta^{13} \mathrm{C}\right)_{\text {measured }}^{\mathrm{Sa}}}+\Delta\left(\delta^{13} \mathrm{C}\right)^{\mathrm{ALM}}
$$

And standard deviation of the sample (actual value) will be given as

$$
\sigma\left(\delta^{13} C_{\text {actual }}^{\text {Sa }}\right)=\sqrt{\left[\sigma\left(\delta^{13} C_{\text {measured }}^{\text {ALM }}\right)\right]^{2}+\left[\sigma\left(\delta^{13} C_{\text {measured }}^{\text {Sa }}\right)\right]^{2}}
$$




\subsection{Methane concentration analytical method}

The stability of the air samples stored in canisters from the time collected until now is a primary concern. Measuring the concentration of air samples allows us to verify that there has been no drift in $\mathrm{CH}_{4}$ over the storage period and can be done in either one of two ways:

(1) From the GC-IRMS measurement, we obtain the $\delta^{13} \mathrm{C}$ and peak area of $(\mathrm{m} / \mathrm{z}=44)$ for ${ }^{12} \mathrm{CH}_{4}$. Since the concentration of ALM-032668 is known well (1830 ppb) and the peak area is calculated based on ion current (from GC-IRMS) the concentration for each sample can be calculated using

$$
\mathrm{C}_{\text {Actual }}^{\text {Sa }}=\frac{\overline{(\text { Peak Area })_{\text {measured }}^{\text {Sa }}}}{\overline{\overline{\text { (Peak Area })}} \text { Stand }} * C_{\text {Actual }}^{\text {Stand }}
$$

where $\mathrm{C}_{\mathrm{Actual}}^{\mathrm{Sa}}$ and $\mathrm{C}_{\mathrm{Actual}}^{\mathrm{Stand}}$ are the actual value concentrations of the sample and standard, $\overline{(\text { Peak Area })}$ measured and $\overline{\overline{(\text { Peak Area })_{\text {measured }}^{\text {Stand }}}}$ are the average peak areas measured for the sample and standard. Precision using this method is $\sim 1 \%$ (20ppb if $\mathrm{C}=2011 \mathrm{ppb})$

(2) Using gas chromatography- flame ionization detector( GC-FID)

Our gas chromatography system is based on the analytical methodology of Dlugokencky et al. [2005)]. A schematic of the analytical system is shown in figure 2.5. This system is composed of: a mutiposition stream selection valve for sample selection (16 ports); a two position valve (four-port stream selection valve which two ports are 
plugged and used as off positions); a six-port valve for injection of gas to the GC column; a Hewlett-Packard 5890 gas chromatography with flame ionization detector (FID); Peak Simple software (SRI) and A/D board hardware for valve control and chromatogram data acquisition and peak integration.

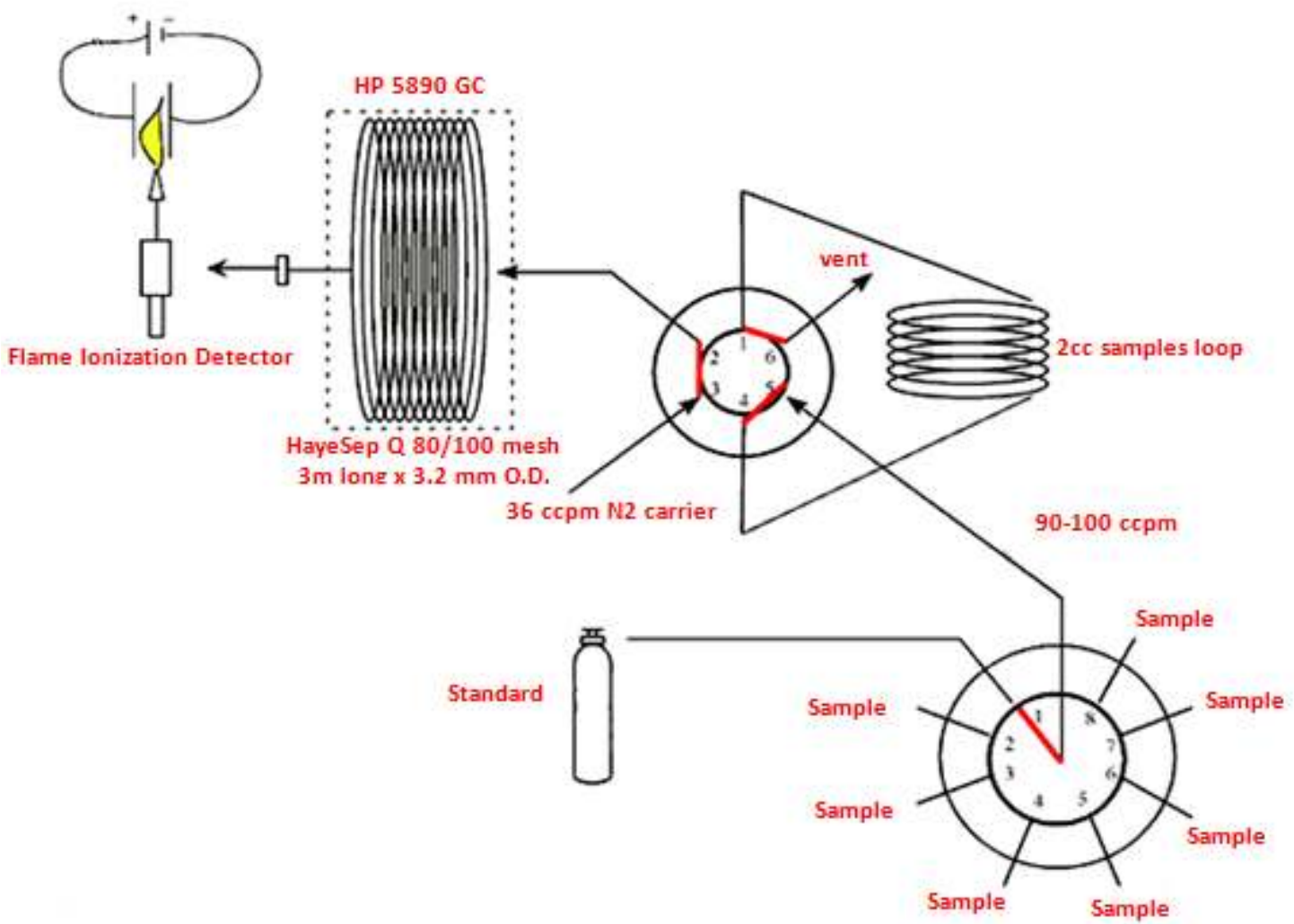

Figure 2.5. Schematic view of the gas chromatography analytical system to measure the concentration of atmospheric $\mathrm{CH}_{4}$ in air samples.

Initially, $50 \mathrm{~cm}^{3}$ of air sample or standard is flushed through the multiposition valve $\left(\mathrm{V}_{\mathrm{M}}\right)$ to the $2 \mathrm{~cm}^{3}$ sample loop for $30 \mathrm{~s}$. The flow is stopped by switching $\mathrm{V}_{\mathrm{M}}$ to off position. $15 \mathrm{~s}$ is allowed for sample loop contents to relax to atmospheric pressure before the air in the sample loop is injected through the six-port valve. A $\mathrm{N}_{2}$ carrier gas 
(99.9995\%) transfers the air sample from six-port valve to the GC column. GC column (3.2mm O.D. x $3 \mathrm{~m}$ long $80 / 100$ mesh HaySep Q) is held at $40^{\circ} \mathrm{C}$. This column is used to separate $\mathrm{CH}_{4}$ from the air. The FID flame is fueled by $\mathrm{H}_{2}$ (99.999\%) and ZeroAir. At the end of the run, the six-port valve is switched to the load position to prepare for the next injection. The total time for one run is $\sim 3$ minutes. In the same acquisition, we have six runs. Therefore, the total time to measure the concentration of a sample (or standard) is $18 \mathrm{~min}$. The output of an acquisition is shown in figure 2.6.

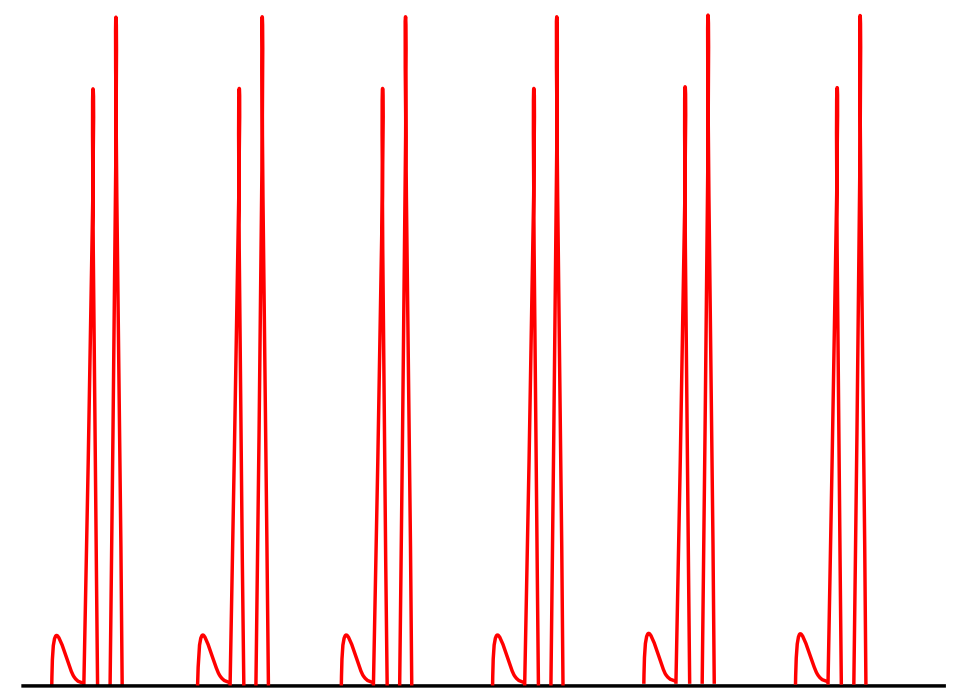

Figure 2.6. The display of $\mathrm{CH}_{4}$ peaks in the same acquisition. The third peak of each set is $\mathrm{CH}_{4}$.

Each three peaks represent one run where the first peak is due to the switch of the 6-port injection valve, the second and third peaks represent $\mathrm{O}_{2}$ and $\mathrm{CH}_{4}$ peaks in the air sample. The output from these peaks is retention time (the time at which the peak appears), peak area, and peak height. To calculate the concentration of the sample, we use $\mathrm{CH}_{4}$ in ultrapure air from Scott Marrin Inc. It has a pressure 2000 PSI and its concentration is $2011 \pm 20 \mathrm{ppb}$, traceable to NIST SRM 1659a. The standard gas is always 
measured before and after each sample from which average peak area and average peak height of the standard is calculated. We use equation (2.12) (either for peak area or for peak height), average peak height of the standard, and $C_{\text {Actual }}^{\text {Stand }}$ to calculate $C_{A c t u a l}^{\text {Sa }}$.

To calculate the actual concentration of any sample, we first calculated the

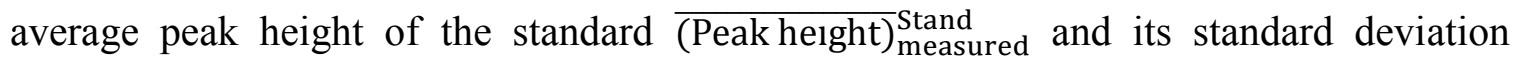
$\sigma(($ Peak height $)$ measured standard before and after the sample. We then calculate the average peak height of the sample $\overline{(\text { Peak height }})_{\text {measured }}^{\text {Sa }}$ and its standard deviation $\sigma\left((\text { Peak height })_{\text {measured }}^{\mathrm{Sa}}\right)$. Using equation (2.12), we calculate the concentration of the sample (where $C_{\text {Actual }}^{\text {Stand }}=2011 \mathrm{ppb}$ ) and calculate its standard deviation using

$$
\sigma\left(\mathrm{C}_{\mathrm{actual}}^{\mathrm{Sa}}\right)=\frac{\mathrm{C}_{\text {actual }}^{\mathrm{Sa}}}{(\text { Peak herght })_{\text {measured }}^{\mathrm{Sa}}} * \sigma\left((\text { Peak height })_{\text {measured }}^{\mathrm{Sa}}\right)
$$

Precision is $0.3 \%$ ( $1 \sigma \sim 6 \mathrm{ppb}$ if $\mathrm{C}=2011 \mathrm{ppb}$ ) on average using this method including uncertainties in standard and sample added in quadrate.

\subsection{Recent Air sampling from Cape Meares (March, 2012 - September, 2012)}

We have been collecting air samples from Cape Meares between March 2012 and September 2012. Two air samples are collected each time. Before sampling, the wind trajectory at Cape Meares is checked as will be described in section 3.5 and the maps of these trajectories are recorded in Appendix C. The canisters are evacuated before sampling and leak checked for their ability to preserve their vacuum pressures. 


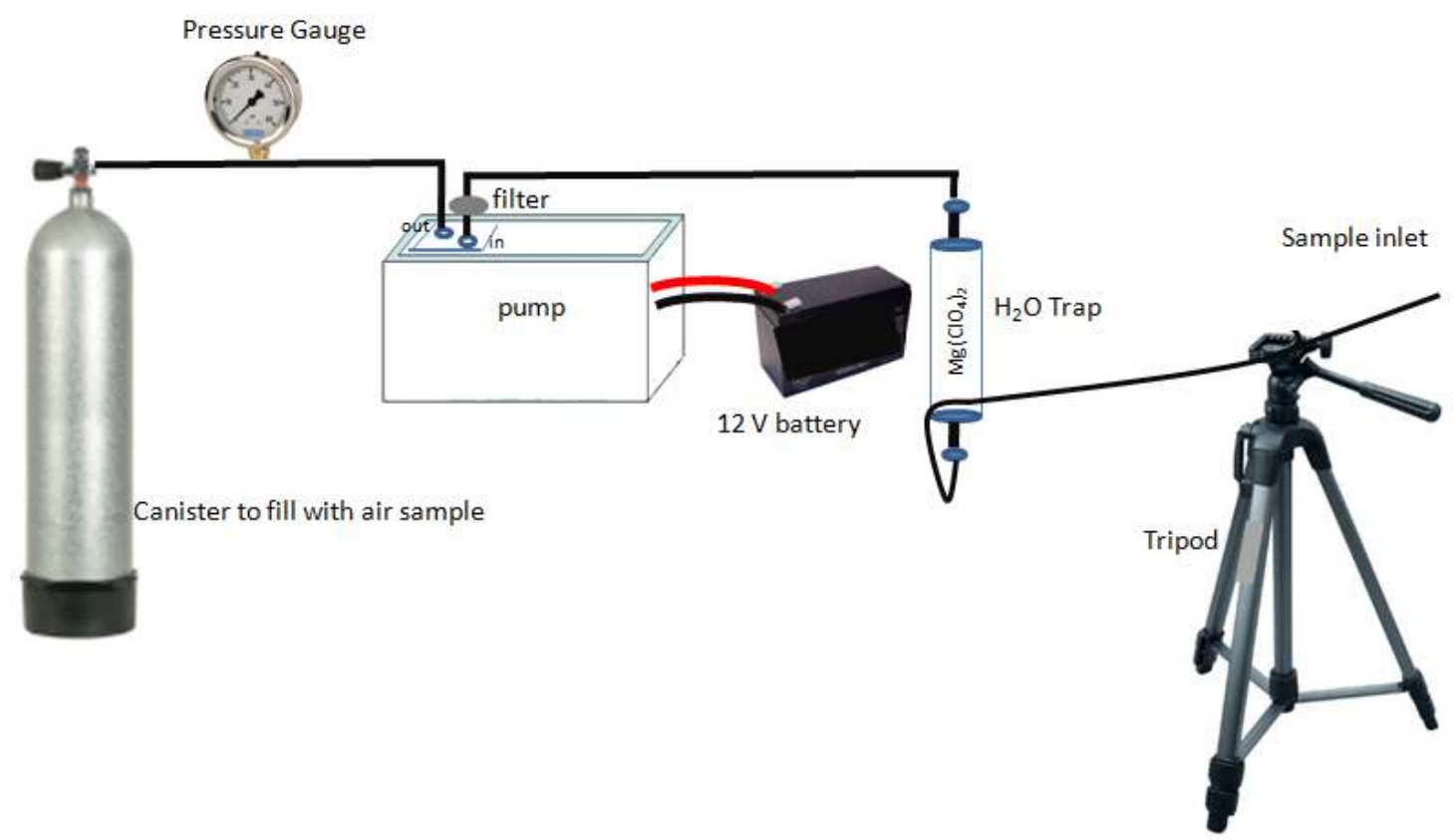

Figure 2.7. Field sampling system configuration

Air samples are collected using the field sampling system shown in figure 2.7. This system consists of a tripod, a sample inlet, a water trap, a $12 \mathrm{~V}$ battery, a pump with a particle filter, a pressure gauge, and two canisters. The sample inlet consists of synflex tubing (type 1300, $6.35 \mathrm{~mm}$ O.D.), which is supported on a tripod and directed into the prevailing wind. The other end is connected to a water trap, which is stainless steel tubing (length=254 mm, $6.35 \mathrm{~mm}$ O.D.) filled with magnesium perchlorate, $\mathrm{Mg}\left(\mathrm{ClO}_{4}\right)_{2}$, and held in place on both sides with glass wool. The purpose of $\mathrm{Mg}\left(\mathrm{ClO}_{4}\right)_{2}$ in the tube is to absorb water vapor during sampling. The other side of the $\mathrm{H}_{2} \mathrm{O}$ trap is connected to a stainless steel (all-welded in line 0.5 micron pore size) filter through synflex. The purpose of this filter is to remove large aerosols that are present in air and prevent their collection in the canister. The synflex and filter are then connected to the pump inlet. The pump is a $12 \mathrm{~V}$ teflon diaphragm pump (KNF Neuberger, mode; N05STI). The outlet of 
the pump is connected to a canister through a pressure gauge to measure the canister pressure.

The following procedures are followed each time we collect air:

1) Connect the system as shown in figure 2.7; finger tight first then using wrenches

2) Connect one side of the pressure gauge to the canister

3) Verify that the pump is providing air flow through the connection line between the pressure gauge and the canister

4) Purge the system for 3 minutes

5) Tighten connections using wrench and open the main valve of the canister. The pressure should drop very quickly since the canisters are evacuated. It takes several minutes to increase the pressure until it is on-scale

6) Fill the canister with air until 25 psig has been reached and purge the canister by slightly loosing the fitting to the canister.

7) Repeat steps 5 and 6 two times

8) Collect the air into the canister during the final and third time and fill it to $34 \mathrm{psig}$

9) Close the main valve of the canister and disconnect the battery from the pump.

10) Breakdown the sampling system by disconnecting sections. 


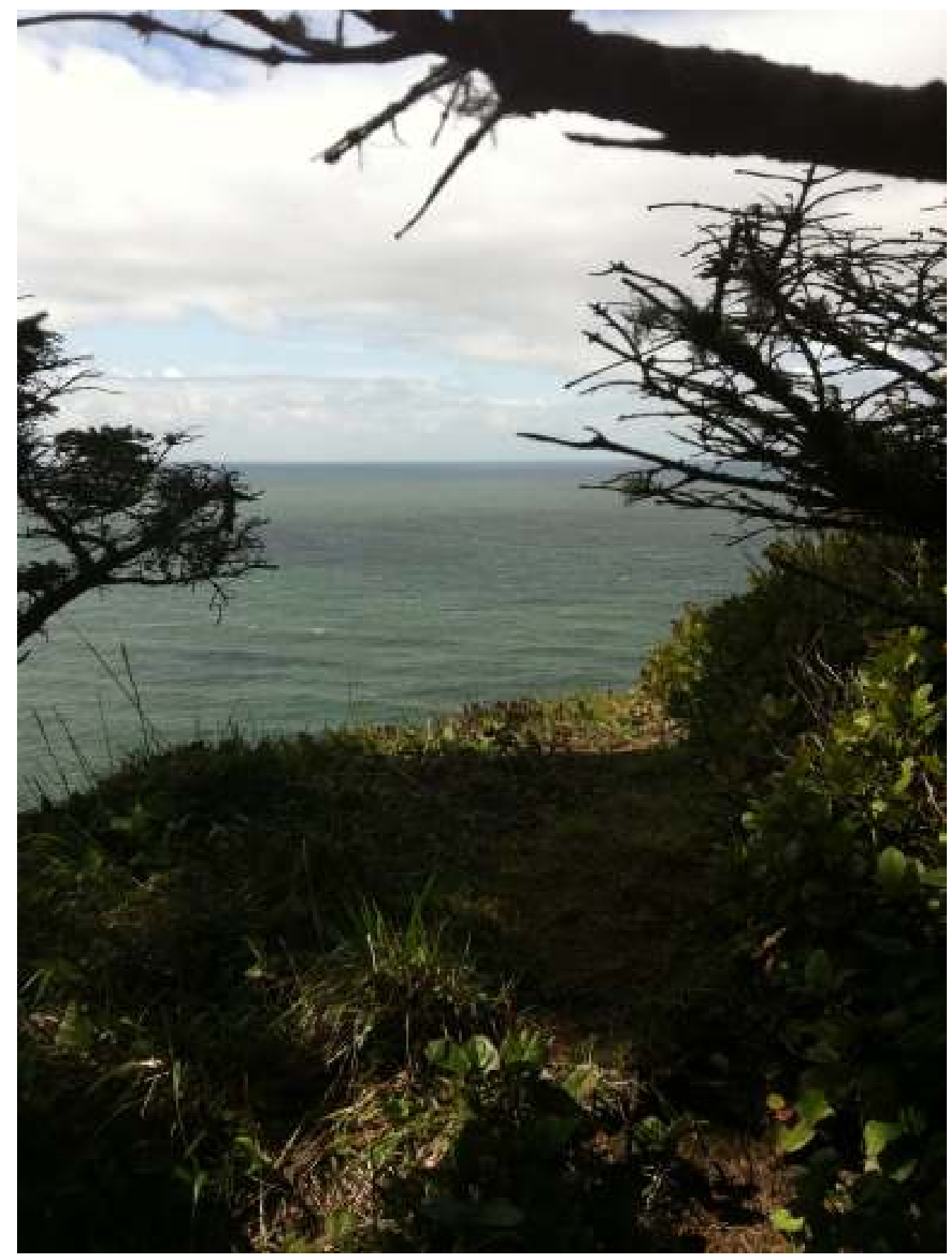

Figure 2.8. The location at Cape Meares where air is collected. 


\section{Chapter 3}

\section{Results of Analyses at PSU}

This Chapter will include results from measurements made at PSU and their analysis. The first section in this chapter (3.1) will show the results obtained from measuring the $\mathrm{CH}_{4}$ mixing ratio from Cape Meares $\left(45.5^{\circ} \mathrm{N}, 124^{\circ} \mathrm{W}\right)$ air archive samples collected from 1977 to 1999 . These measurements will also show the stability of air samples over the time and the seasonal cycle in mixing ratio at this site. This section will also present a comparison of $\mathrm{CH}_{4}$ mixing ratios from Cape Meares archive samples with those of a continuous measurement by gas chromatography measured by Oregon Graduate Institute and flask samples measured by NOAA. The results of measurements of the $\delta^{13} \mathrm{C}$ and $\delta \mathrm{D}$ of atmospheric $\mathrm{CH}_{4}$ in Cape Meares air archive samples will be presented in section (3.2) and section (3.3), respectively. Their seasonal cycles will be

discussed. The correlation between these seasonal cycles in $\mathrm{CH}_{4}, \delta^{13} \mathrm{C}$, and $\delta \mathrm{D}$ will be discussed in section (3.4). The results of recent measurements of Cape Meares air collected from March 2012 until October 2012 will be shown in section (3.5). Section (3.6) will present other measurement made at Portland State University from the OGI archive for three locations: South Pole $\left(90^{\circ} \mathrm{S}\right)$, Samoa $\left(14.1^{\circ} \mathrm{S}, 170.6^{\circ} \mathrm{W}\right)$, and Mauna Loa $\left(21.08^{\circ} \mathrm{N}, 157.2^{\circ} \mathrm{W}\right)$ 


\subsection{Cape Meares $\mathrm{CH}_{4}$ mixing ratio Results}

\subsection{1. $\mathrm{CH}_{4}$ mixing ratio results measured at $\mathrm{PSU}$}

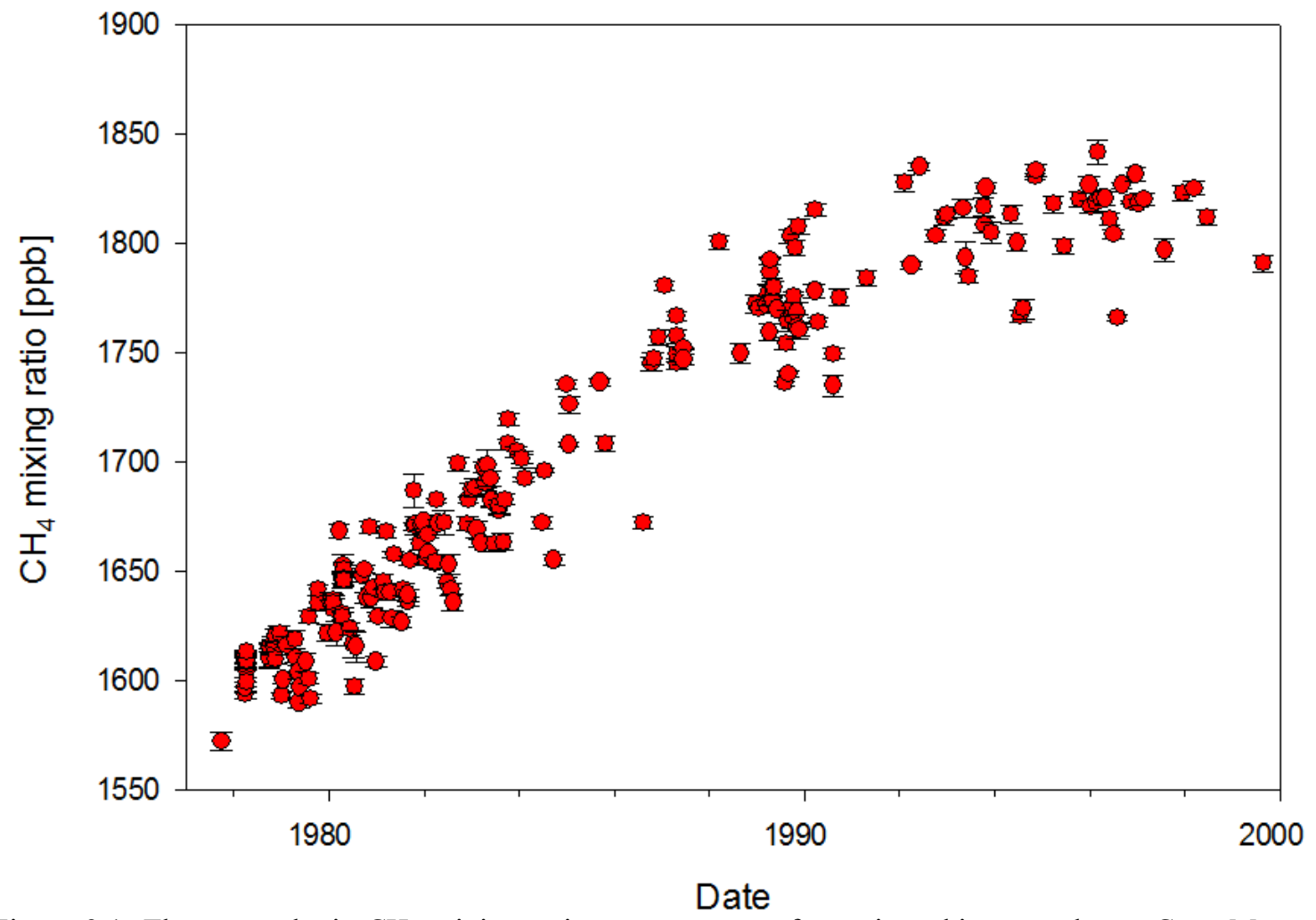

Figure 3.1. The atmospheric $\mathrm{CH}_{4}$ mixing ratio measurements from air archive samples at Cape Meares, Oregon collected 1 October 1977 to 24 August 1999. The $\mathrm{CH}_{4}$ mixing ratio is expressed on the National Institute for Standards and Technology (NIST) scale. Error bars represent $\pm 1 \sigma$ (standard deviation) from six determinations for each sample. The peak height method (as explained in Chapter 2) is used to determine the $\mathrm{CH}_{4}$ mixing ratio.

The trend of atmospheric $\mathrm{CH}_{4}$ for Cape Meares, Oregon from 1977 to 1999 is shown in figure 3.1. Tabulated values appear in table A.1 in Appendix A. It shows an average increase of $\mathrm{CH}_{4}$ mixing ratio in the atmosphere by $12.89 \pm 0.65 \mathrm{ppb} / \mathrm{yr}$ (growth rate \pm 1 standard error) during 1977 to 1999 . The rate of increase during 1977-1988 $(16.38 \pm 1.32 \mathrm{ppb} / \mathrm{yr})$ is faster than during $1988-1999(5.57 \pm 1.84 \mathrm{ppb} / \mathrm{y})$, in general agreement with the slowdown discussed in section 1.2. 
To calculate the seasonal trend, the $\mathrm{CH}_{4}$ data in figure 3.1 was smoothed using the localized linear regression technique LOWESS with a wide span in (0.3) (more details about LOWESS will be discussed in section 4.2.1) to get the long term trend without seasonality and neglecting the inter-annual variability. The smoothed data produced by LOWESS was then subtracted from the observed value of $\mathrm{CH}_{4}$ mixing ratio to get the residual for each data point. Resulting residuals were then graphed by month of collection and the average of residual, its standard deviation, and its standard error was calculated, whatever the year of collection. These values appear in a table A.2 in Appendix A.

The seasonal trend of atmospheric $\mathrm{CH}_{4}$ based on monthly observations at Cape Meares, Oregon from air archive samples collected from 1 October 1977 to 24 August 1999 is shown in figure 3.2. This figure shows that atmospheric $\mathrm{CH}_{4}$ mixing ratio has a broad maximum from October until April. It reaches to the lowest level between July and August. After August, it increases again. Maximum residual values of $\mathrm{CH}_{4}$ mixing ratio occur in March at $8 \mathrm{ppb}$ and minimum values of $-25 \mathrm{ppb}$ occur in late of August. The peak to peak amplitude is $33 \mathrm{ppb}$. This seasonal trend is very close to the one obtained from continuous measurements of $\mathrm{CH}_{4}$ mixing ratios at Cape Meares from 1979 to 1992 (see section 3.1.2) [Khalil et al., 1993]. The phase and amplitude of the seasonal cycle may change from year to year [Khalil et al., 1993; Dlugokencky et al., 1995]. 


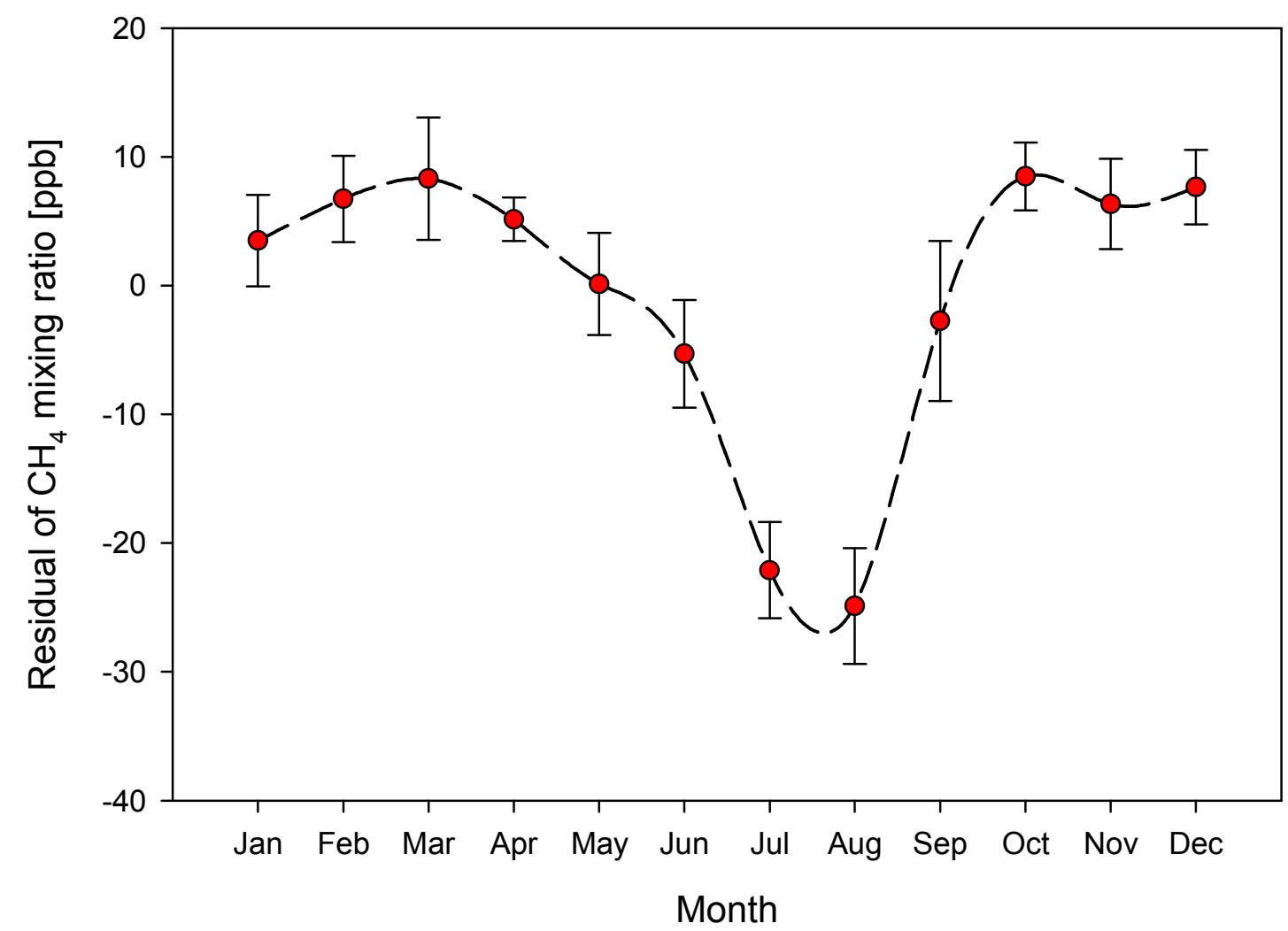

Figure 3.2. Seasonal trend of atmospheric $\mathrm{CH}_{4}$ mixing ratio from air archive samples. The residual $\mathrm{CH}_{4}$ mixing ratio is expressed on NIST scale. Error bars represent \pm 1 standard error.

The seasonal trend in atmospheric $\mathrm{CH}_{4}$ for any location gives us some indications about $\mathrm{CH}_{4}$ sources and sinks [Khalil et al., 1983; 1993]. When the $\mathrm{CH}_{4}$ mixing ratio is high, it means the effect of sink is low and/or emissions from sources are high. Based on the $\mathrm{CH}_{4}$ mixing ratio measurements and its seasonal trend, Khalil et al. [1993] found using different $\mathrm{CH}_{4}$ lifetimes 8,10 , and 12 years the highest $\mathrm{CH}_{4}$ emissions occur during the late summer and early fall. In terms of sinks, they deduced that the observed $\mathrm{CH}_{4}$ mixing ratio seasonal cycle was not driven by reaction of $\mathrm{CH}_{4}$ with $\mathrm{OH}$ or transport. Therefore, a significant seasonal cycle of emissions is required to explain the $\mathrm{CH}_{4}$ seasonal cycle from some sources such as wetlands, cattle and rice agriculture. The measurements of the stable isotopes $\delta^{13} \mathrm{C}$ and $\delta \mathrm{D}$, their seasonal trend, and the correlation 
with the seasonal trend of $\mathrm{CH}_{4}$ mixing ratio put more constraints to determine which source and/or sink causes this behavior [Tyler et al., 2007].

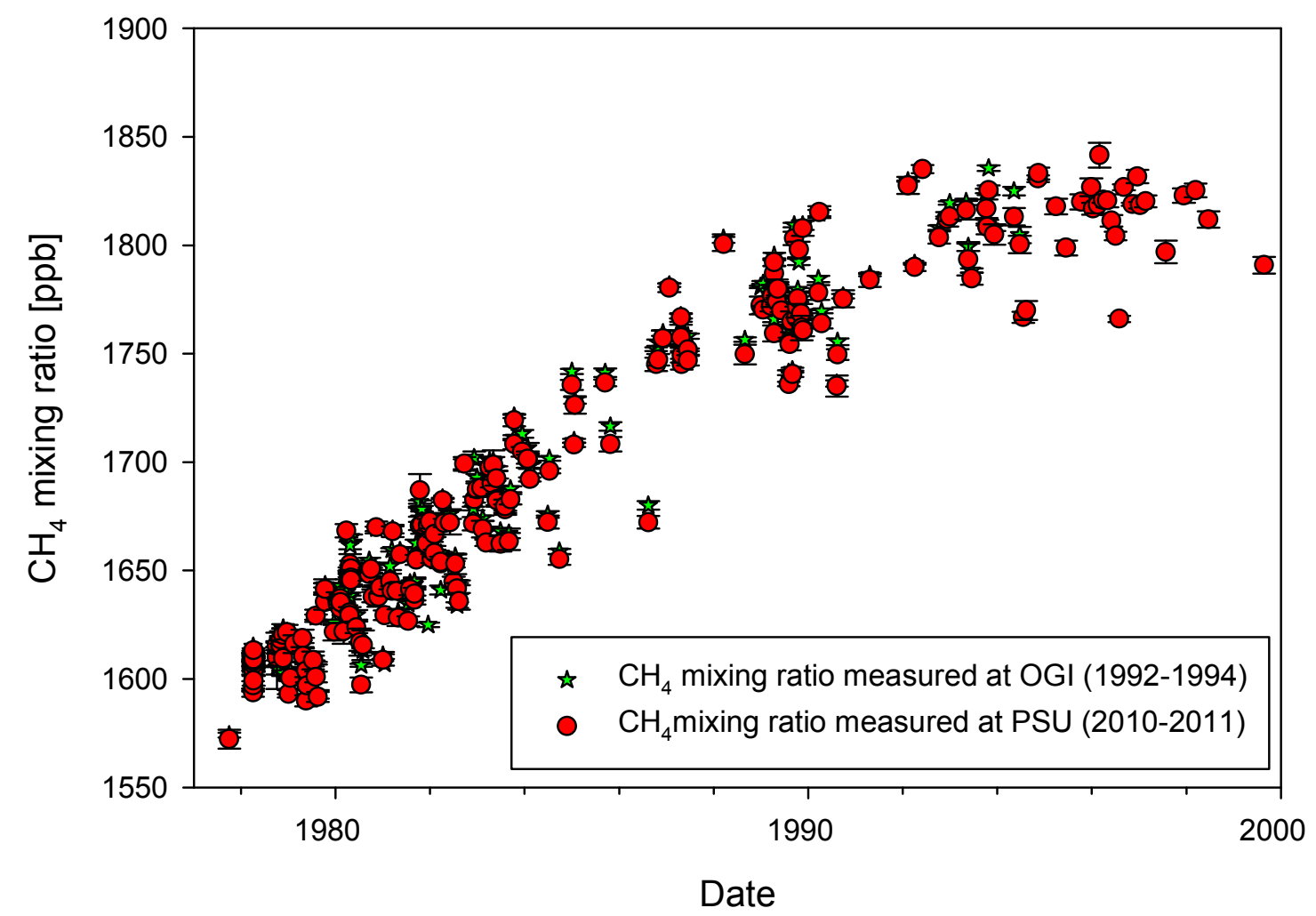

Figure 3.3. $\mathrm{CH}_{4}$ mixing ratio measurements of Cape Meares air archive samples at OGI (green star) and at PSU (red circle). Both measurements are on the NIST scale.

The stability of the air samples was checked by GC-FID (as mentioned in Chapter 2) by comparing the records of OGI (from measurements in 1992, 1993, and 1994) with the results measured by GC-FID at PSU (in 2010 and 2011). Both records are on the NIST calibration scale and so may be directly compared. Figure 3.3 shows the stability of air samples by comparing between measurements done at OGI (green star) and measurements done at PSU (red circle) of 211 samples. 


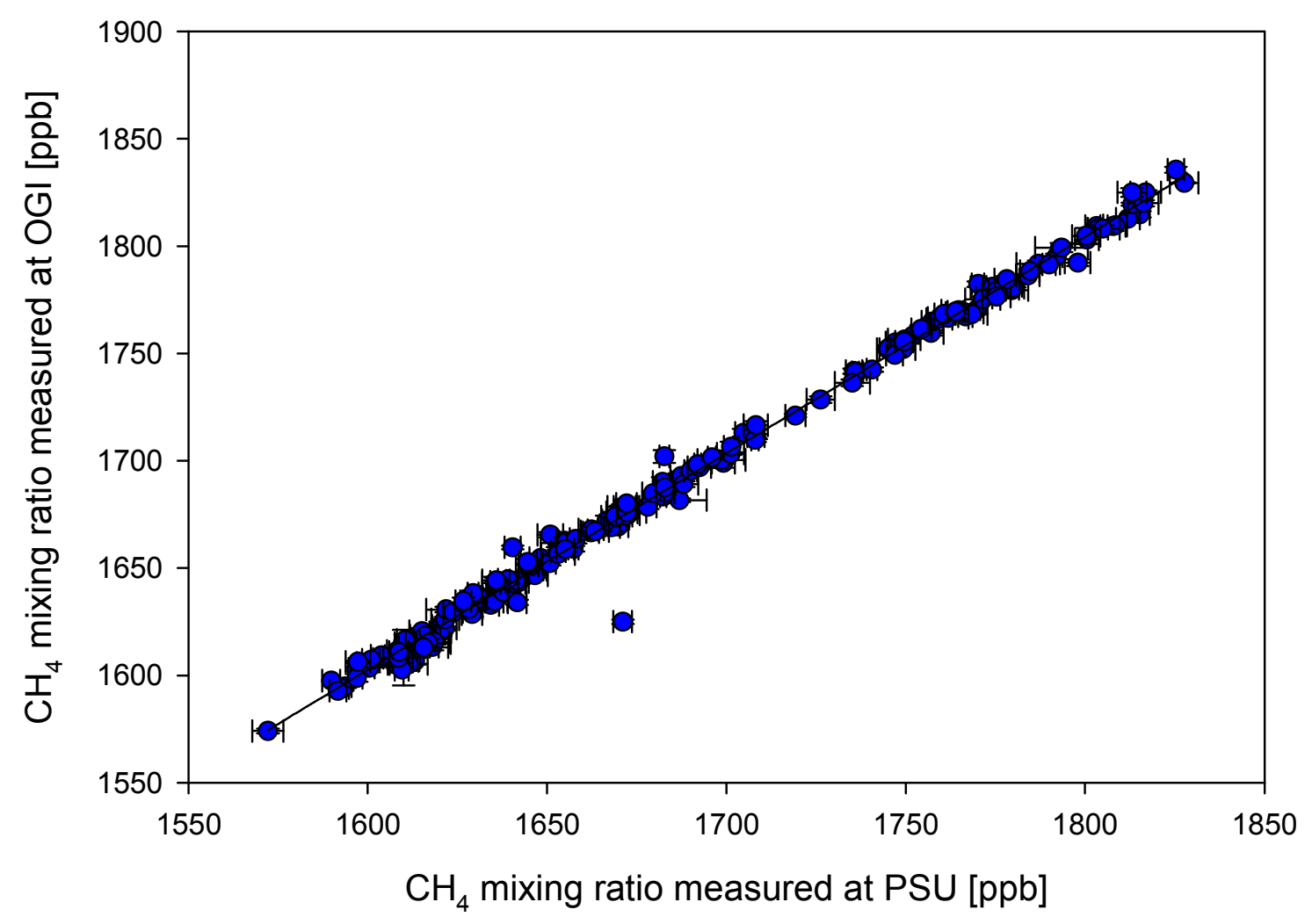

Figure 3.4. Comparison between $\mathrm{CH}_{4}$ concentrations measured at OGI and at PSU using GC-FID.

The OGI did not measure the $\mathrm{CH}_{4}$ mixing ratio of air samples collected after July 20th 1994, so that there is no comparison after this date (27 samples). In addition, there are 3 samples measured at OGI against standards of unknown calibration scales.

The high degree of correlation $\left(r^{2}=0.994\right)$ between PSU and OGI measurements is shown in figure 3.4. and indicates an agreement between PSU measurements and OGI measurements and that sample integrity is good in storage. There are only 6 samples that differ by more than $10 \mathrm{ppb}$ and 1 sample that differs by $>20 \mathrm{ppb}$. This sample was collected 16 December 1981 (Tank\# 192) has a PSU mixing ratio 46 ppb higher than expected from the OGI record. The reason for the discrepancy is unknown. Figure 3.5 shows the difference in $\mathrm{CH}_{4}$ mixing ratio measurements between OGI and PSU with the 
collected date. The best fit line has a slope $0.0004 \pm 0.0002$ from 1977 to 1994 showing that $\mathrm{CH}_{4}$ stability is not linked to storage time. However, there is a small difference between OGI and PSU dataset of an average of $3.5 \mathrm{ppb}$. The lack of trend in figure 3.5 suggests that the $3.5 \mathrm{ppb}$ average difference between PSU and OGI measurements is due to small calibration offset between the laboratories rather than stabilizing issue.

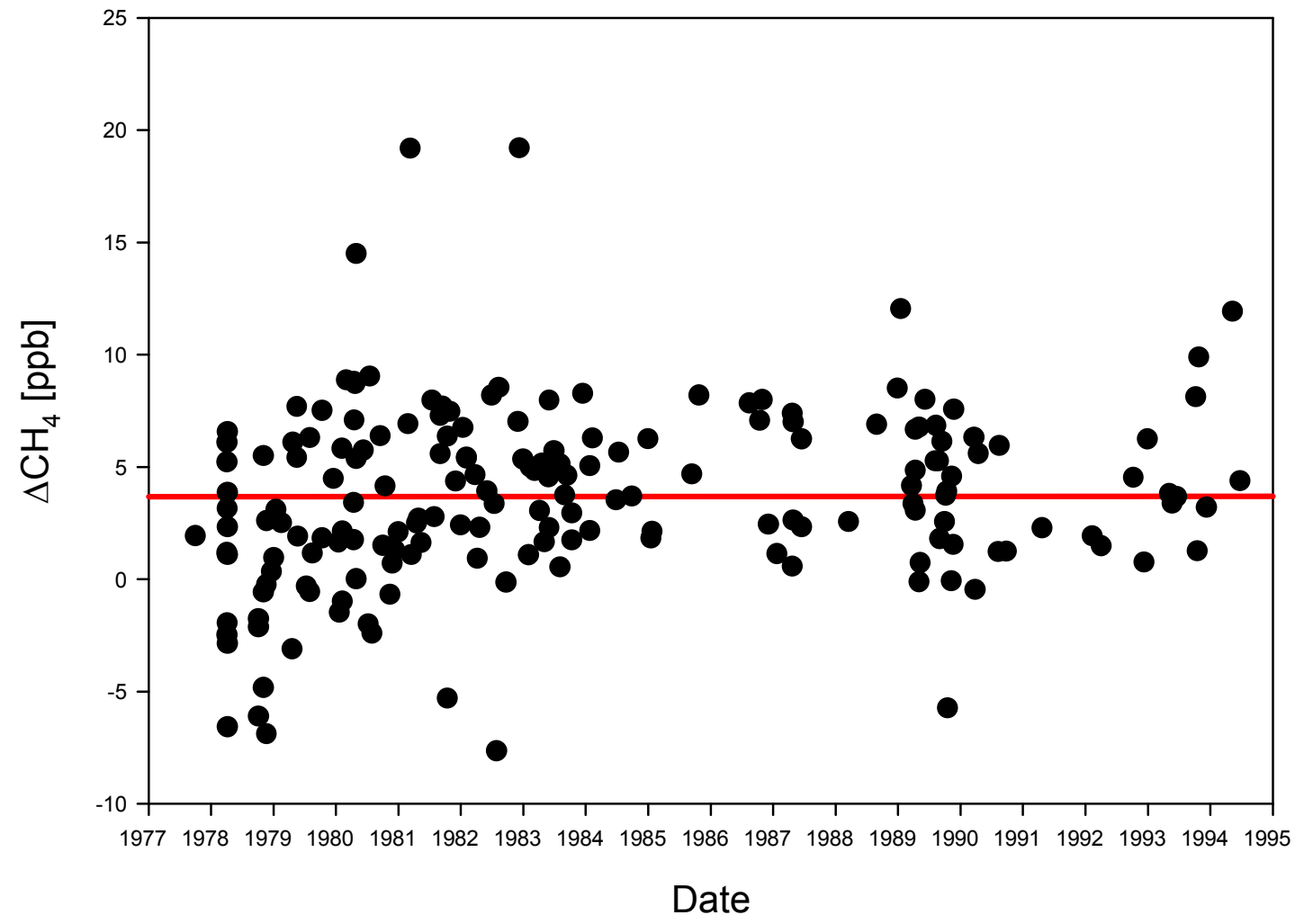

Figure 3.5. The difference in $\mathrm{CH}_{4}$ mixing ratio between OGI and PSU in [ppb] with the collected date after removing the outlier value.

Finally, differences between PSU and OGI determined concentrations are expected due to measurement uncertainty. Therefore, we generated a random dataset 
based on the average standard deviations of OGI and PSU measurements where this random dataset has a mean value of 0 and standard deviation defined by

$\sigma=\sqrt{\left(\sigma_{\mathrm{PSU}}\right)^{2}+\left(\sigma_{\mathrm{OGI}}\right)^{2}}$

Sampling from a Gaussian distribution 181 times generates the random distribution shown in figure 3.6(b). This can be compared with the observed distribution shown in figure 3.6(a).

The distribution in figure 3.6(b) is normalized about the mean value zero rather than in figure 3.6(a) which was about $3.5 \mathrm{ppb}$. We used a T-test to measure the difference between OGI and PSU dataset (before random sampling) and the average value 0 (used for random sampling) and the p-value was much less than 0.01, showing a high level of confidence. Additionally, there were 3 data points that have a difference in $\mathrm{CH}_{4}$ between PSU and OGI greater than $12.5 \mathrm{ppb}$ (as shown in figure 3.6(c)) that didn't exist in the random distribution. However, aside from these 3 points and the $3.5 \mathrm{ppb}$ offset between datasets the distributions show remarkable similarity (figure 3.6(a) and figure 3.6(b)) For this reason, and the lack of trend in the $3.5 \mathrm{ppb}$ offset (figure 3.5), we attribute this difference to calibration differences between the two laboratories. 

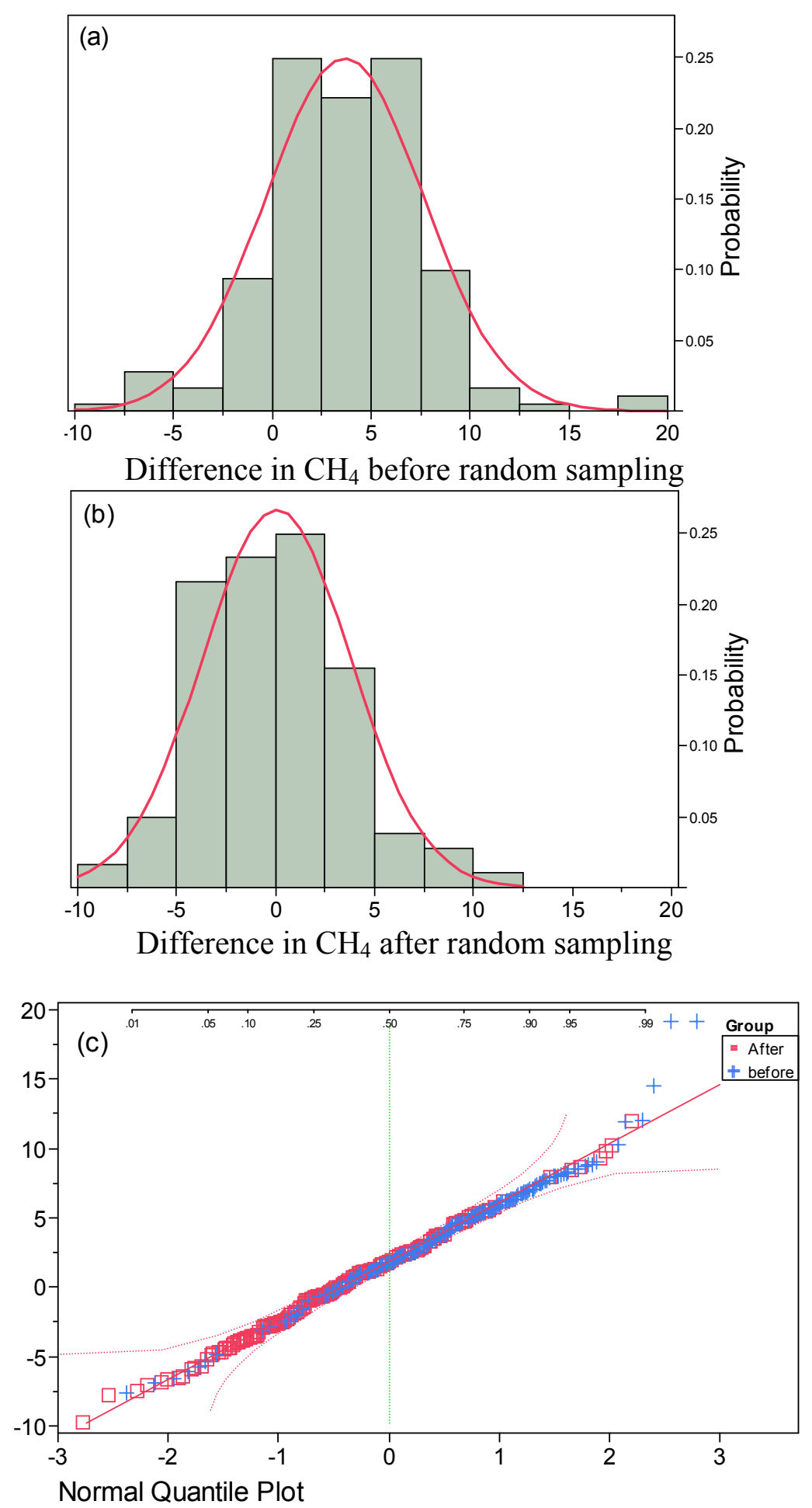

Figure 3.6 (a). Gaussian distribution of the differences of Cape Meares samples between OGI and PSU. (b). Gaussian distribution of a simulated dataset generated by a random sampling. (c). The difference between Gaussian distributions before in Q-Q Plot. 


\subsubsection{A comparison of $\mathrm{CH}_{4}$ mixing ratios at Cape Meares air}

In this section, a comparison is made between the mixing ratio results from the archived samples measured at PSU with two data sets. The first is a continuous measurement dataset by Professors Khalil and Rasmusssen of OGI (available at http://cdiac.ornl.gov/ndps/db1007.html), which covers 1979 to 1992 and is reported on the Climate Monitoring and Diagnostics Laboratory (cmdl83) scale [Khalil et al., 1993]. The other dataset is from the NOAA ESRL laboratory composed of flask samples (available at ftp://ftp.cmdl.noaa.gov/ccg), covers 1983 to 1998 and is reported in the (NOAA04) scale [Dlugokencky et al., 2012]. 1.0124 and 0.998 are conversion factors used to transfer from "cmd183" and "NIST" scales, respectively to (NOAA04) scale [Dlugokencky et al., 2005]. The measurements of atmospheric $\mathrm{CH}_{4}$ for each dataset are shown in figure 3.7 . 


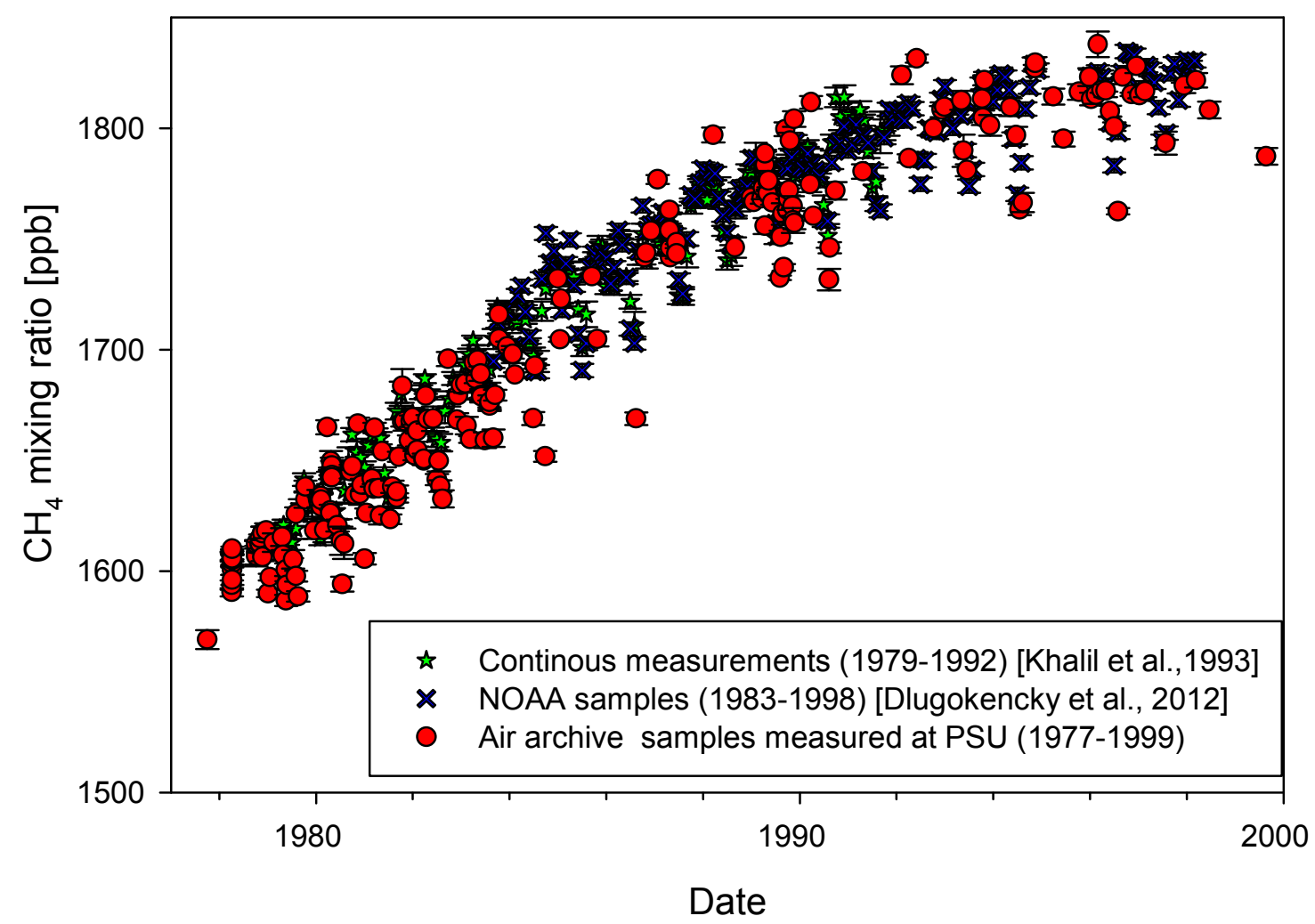

Figure 3.7 Atmospheric $\mathrm{CH}_{4}$ mixing ratio measurements at Cape Meares from different datasets. The average monthly mixing ratios of Cape Meares measured by OGI (green star) [Khalil et al.1993] between 1979 and 1992 and by NOAA (blue cross) [Dlugokencky et al. 2012], which spans (1983-1998), and at PSU (red circle) during 1977-1999. The first and third datasets have been adjusted to be on NOAA04 scale.

The same procedures were followed to calculate the seasonal trend of these datasets as in section 3.1.1. Figure 3.8 represents the seasonal trend in $\mathrm{CH}_{4}$ mixing ratio observed at Cape Meares based on these different sets. This figure shows a good agreement between the three datasets in all but one month (April). In this figure, monthly means overlap with one standard error of the PSU dataset with the lowest level between July and August and a broad maximum from October through April. The peak to peak amplitude for the continuous measurements, flask samples, and air archive samples are 31,37 , and $33 \mathrm{ppb}$, respectively. The values of the average residual per month are tabulated in table A.3 in Appendix A. 


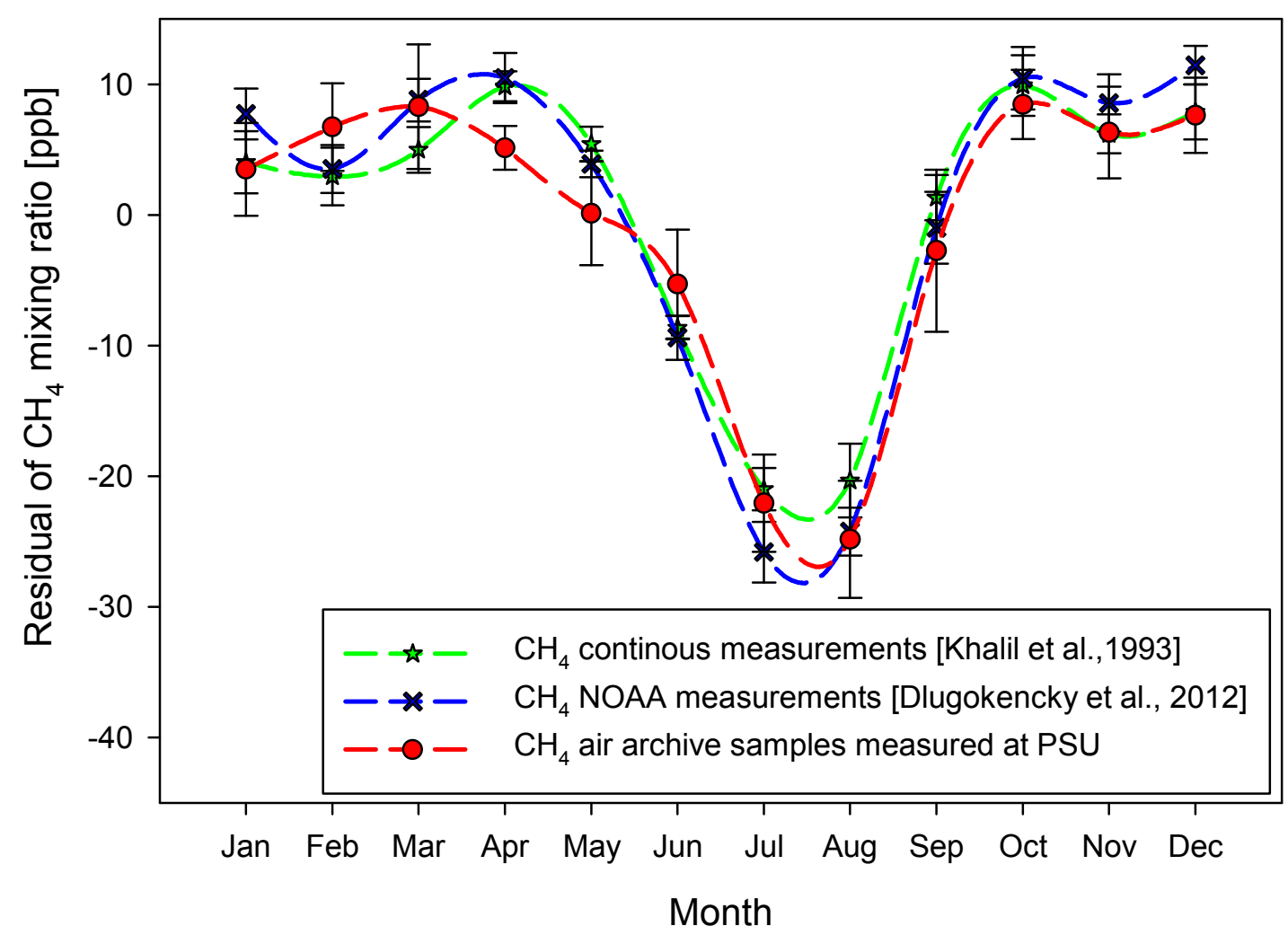

Figure 3.8 Seasonal trend of atmospheric $\mathrm{CH}_{4}$ mixing ratio at Cape Meares from three different datasets.

\subsection{Atmospheric $\delta^{13} \mathrm{C}-\mathrm{CH}_{4}$ and its seasonal trend}

The results for $\delta^{13} \mathrm{C}$ of atmospheric $\mathrm{CH}_{4}$ in all air samples from Cape Meares (1977-1999) are shown in figure 3.9. Additionally, measured values are listed in table A.1 in Appendix A. Average precision obtained is $0.08 \%$ from all the measured samples and each sample measured three times. The average value of measured $\delta^{13} \mathrm{C}$ is $-47.6 \pm 0.2$ $( \pm \sigma) \%$ with a minimum value $-48.0 \%$ which occurred on 22 November 1978 and a maximum value $-47.1 \%$ which occurred on 10 May 1995. The average rate of increase was $0.018 \pm 0.001 \% / \mathrm{yr}$ for $1977-1999 . \delta^{13} \mathrm{C}$ increased by $0.014 \pm 0.004 \% / \mathrm{yr}$ and 
$0.021 \pm 0.005 \% / y r$ for $1977-1988$ and $1988-1999$, respectively, showing a distinct trend from $\mathrm{CH}_{4}$ mixing ratio. The secular trend in $\delta^{13} \mathrm{C}$ will be discussed in section 4.4 .2

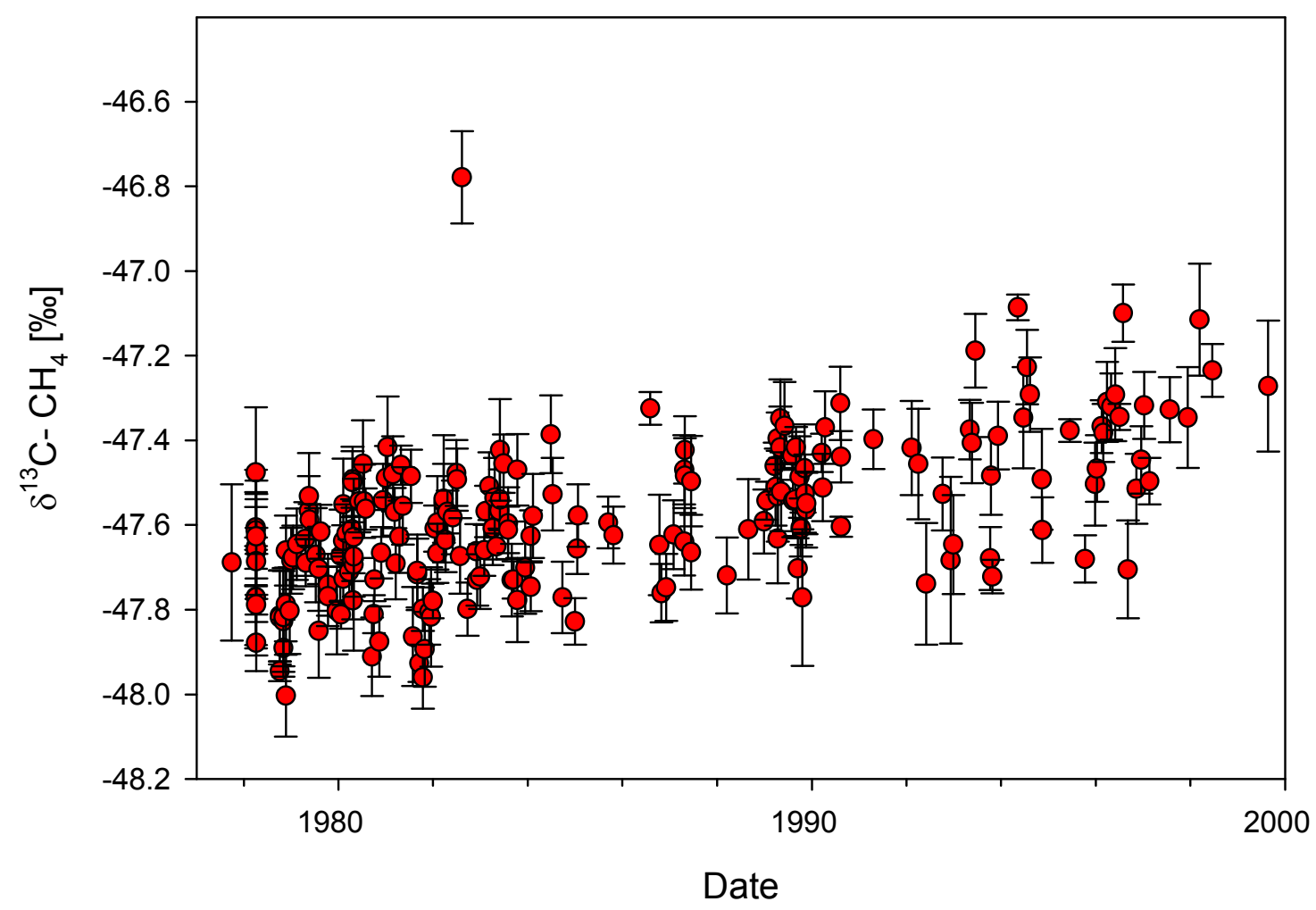

Figure.3.9 The $\delta^{13} \mathrm{C}$ of atmospheric $\mathrm{CH}_{4}$ observed at Cape Meares, Oregon from 1 October 1977 to 24 August 1999. Error bars are $\pm 1 \sigma$ from the average of multiple runs of each sample.

There is one sample outlier in this dataset which is shown in figure 3.9. This outlier measurement belongs to a tank number O-223 which was collected on 11 August 1982. Its measured $\delta^{13} \mathrm{C}$ value is $-46.8 \pm 0.1 \%$. Based on its $\delta^{13} \mathrm{C}$ value, it is expected that this sample would show unstable mixing ratio in storage, but the measurement of $\mathrm{CH}_{4}$ mixing ratio showed a reasonable stability, with the OGI value higher by $8.5 \mathrm{ppb}$. Comparing between the measured $\delta^{13} \mathrm{C}$ of this sample with the average $\delta^{13} \mathrm{C}$ of other 
samples collected in the same month (August, $-47.5 \pm 0.1 \%$ ), the sample O-223 is $>+3 \sigma$ from average. Therefore, this value is rejected as an outlier for further analysis.

The outlier samples from measured $\mathrm{CH}_{4}$ mixing ratios, which have more than 10 ppb difference between OGI and PSU (see section 3.1.1), show no discernible difference with other samples collected over the same month or the same year as shown in table 3.1.

Table 3.1 Samples with $10 \mathrm{ppb}$ or more difference between measured values of $\mathrm{CH}_{4}$ mixing ratios at OGI and PSU and their measured $\delta^{13} \mathrm{C}$ values

\begin{tabular}{|c|c|c|c|c|c|c|c|c|}
\hline $\begin{array}{c}\text { Collected } \\
\text { date }\end{array}$ & Tank No. & \multicolumn{2}{|c|}{$\begin{array}{c}\text { PSU mixing ratio } \\
\text { [ppb] }\end{array}$} & \multicolumn{2}{c|}{$\begin{array}{c}\text { OGI mixing } \\
\text { ratio[ppb] }\end{array}$} & \multicolumn{2}{|c|}{ Diff [ppb] } & \multicolumn{2}{|c|}{$\boldsymbol{\delta}^{\mathbf{1 3} \text { C [\%o] }}$} \\
\hline & & Ave. & Std. Dev & Ave. & $\begin{array}{c}\text { Std. } \\
\text { dev }\end{array}$ & OGI-PSU & Ave. & Std. Dev \\
\hline $4 / 29 / 1980$ & O-087 & 1650.9 & 3.51 & 1665.4 & 1.2 & 14.5 & 47.7 & 0.20 \\
\hline $3 / 11 / 1981$ & O-138 & 1640.4 & 2.23 & 1659.6 & 0.8 & 19.2 & 47.6 & 0.06 \\
\hline $12 / 16 / 1981$ & O-192 & 1671.1 & 2.60 & 1625.0 & 1 & -46.1 & -47.8 & 0.12 \\
\hline $12 / 8 / 1982$ & O-238 & 1682.7 & 1.40 & 1701.9 & 2.9 & 19.2 & 47.7 & 0.06 \\
\hline $1 / 17 / 1989$ & R 346B & 1770.2 & 1.70 & 1782.2 & 1.2 & 12.0 & 47.5 & 0.05 \\
\hline $10 / 25 / 1993$ & CO 435 & 1825.3 & 2.28 & 1835.6 & 1.3 & 10.3 & 47.7 & 0.04 \\
\hline $5 / 10 / 1994$ & CO 442 & 1813.1 & 4.02 & 1825.0 & 2 & 11.9 & 47.1 & 0.03 \\
\hline
\end{tabular}

The seasonal trend of $\delta^{13} \mathrm{C}$ of atmospheric $\mathrm{CH}_{4}$ was obtained by following the same procedures used to obtain the seasonal trend of $\mathrm{CH}_{4}$ mixing ratio: using a localized linear regression (LOWESS) with wide span $\sim(0.3)$ to get the long term trend; Calculating the residual which results from the subtraction of the predicted value of $\delta^{13} \mathrm{C}$ from the measured value; Aggregating the residuals by month; Calculating the average, standard deviation and standard error of the residual by month of collection. The result of these procedures is shown in figure 3.10. Their values are tabulated in table A.4 in Appendix A. 


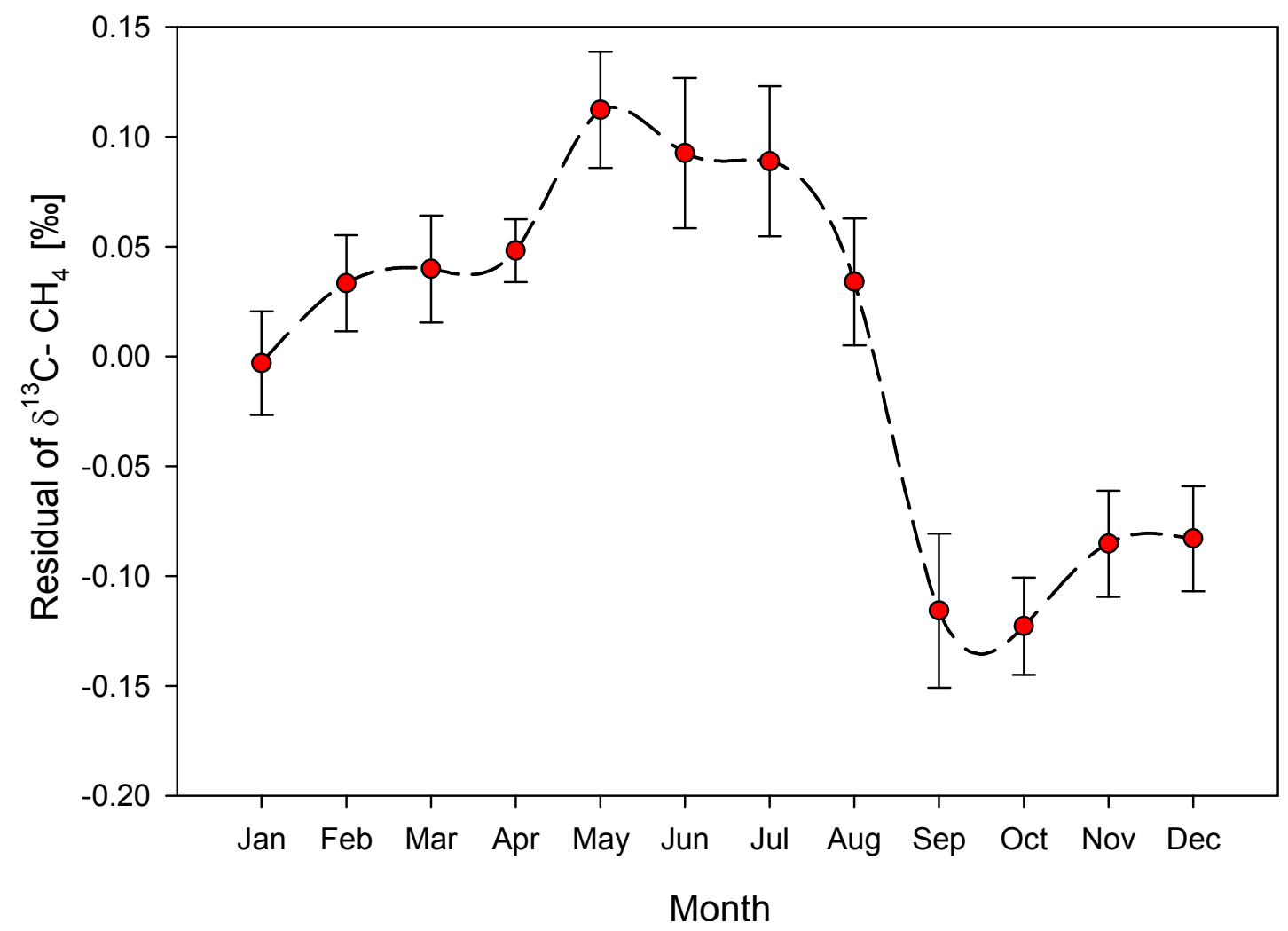

Figure 3.10. Seasonal trend of $\delta^{13} \mathrm{C}$ of atmospheric $\mathrm{CH}_{4}$ at Cape Meares from 1 October 1977 to 24 August 1999. The error bars represent \pm 1 standard error.

The seasonal trend of $\delta^{13} \mathrm{C}$ in figure 3.10 shows that it becomes increasingly enriched in the atmosphere from January and reaches its highest value of $(0.1 \%)$ in May. Subsequently, values become gradually depleted during June-August then rapidly falling to minimum $\left(-0.12 \%\right.$ ) between September and October. $\delta^{13} \mathrm{C}$ then gradually becomes enriched through the end of the year. Peak-to-peak seasonal amplitude for $\delta^{13} \mathrm{C}$ at Cape Meares is $0.22 \%$. A comparison between the seasonal cycles of $\mathrm{CH}_{4}$ in figure 3.2 and $\delta^{13} \mathrm{C}$ in figure 3.10 at Cape Meares will show a poor correlation between of $\delta^{13} \mathrm{C}$ with $\mathrm{CH}_{4}$ seasonal cycle (see section 3.4). 


\subsection{Atmospheric $\delta \mathrm{D}-\mathrm{CH}_{4}$ and its seasonal trend}

The results for $\delta \mathrm{D}$ of atmospheric $\mathrm{CH}_{4}$ in all air samples from Cape Meares (1977-1999) are shown in figure 3.10. Tabulated values are found in table A.1 in Appendix A. The average $\delta \mathrm{D}$ of $\mathrm{CH}_{4}$ from these results is $-107.07 \pm 5.06 \%$ with a minimum value (-117.17\%) on 21 July 1981 and a maximum value (-91.16\%o) on 31 July 1996. The $\delta \mathrm{D}$ of atmospheric $\mathrm{CH}_{4}$ increased at average rate of $0.68 \pm 0.03 \%$ \% $/ \mathrm{yr}$ for 1977 1999. The rates of change were $0.44 \pm 0.08 \% / \mathrm{yr}$ and $1.07 \pm 0.1 \%$ /yr during $1977-1988$ and 1988-1999, respectively, similar in behavior to that observed in $\delta^{13} \mathrm{C}$. The secular rate of change in $\delta \mathrm{D}$ will be discussed in more details in section 4.4.3.

The seasonal trend of $\delta \mathrm{D}$ is shown in figure 3.12. The values in this figure are tabulated in table A.5 in Appendix A. Average precision obtained is $2.3 \%$ and each sample measured three times. Beginning in January, the $\delta \mathrm{D}$ of atmospheric $\mathrm{CH}_{4}$ gradually increases in the atmosphere and reaches to the highest level $(2.4 \%)$ between July and August. During August, it drops rapidly reaching its lowest level (-1.7\%o) by October through December. Peak-to-peak seasonal amplitude for $\delta \mathrm{D}$ is $(4.1 \%$ ). From the seasonal cycles of $\mathrm{CH}_{4}$ in figure 3.2 and $\delta \mathrm{D}$ in figure 3.12 , it is noticed that $\mathrm{CH}_{4}$ seasonal cycle shows an anti-correlation with the $\delta \mathrm{D}$ seasonal cycle. More details about the relation between the seasonal cycles of $\mathrm{CH}_{4}, \delta^{13} \mathrm{C}$, and $\delta \mathrm{D}$ and how their behaviors give information about $\mathrm{CH}_{4}$ sources and sinks will be discussed in the next section 3.4. 


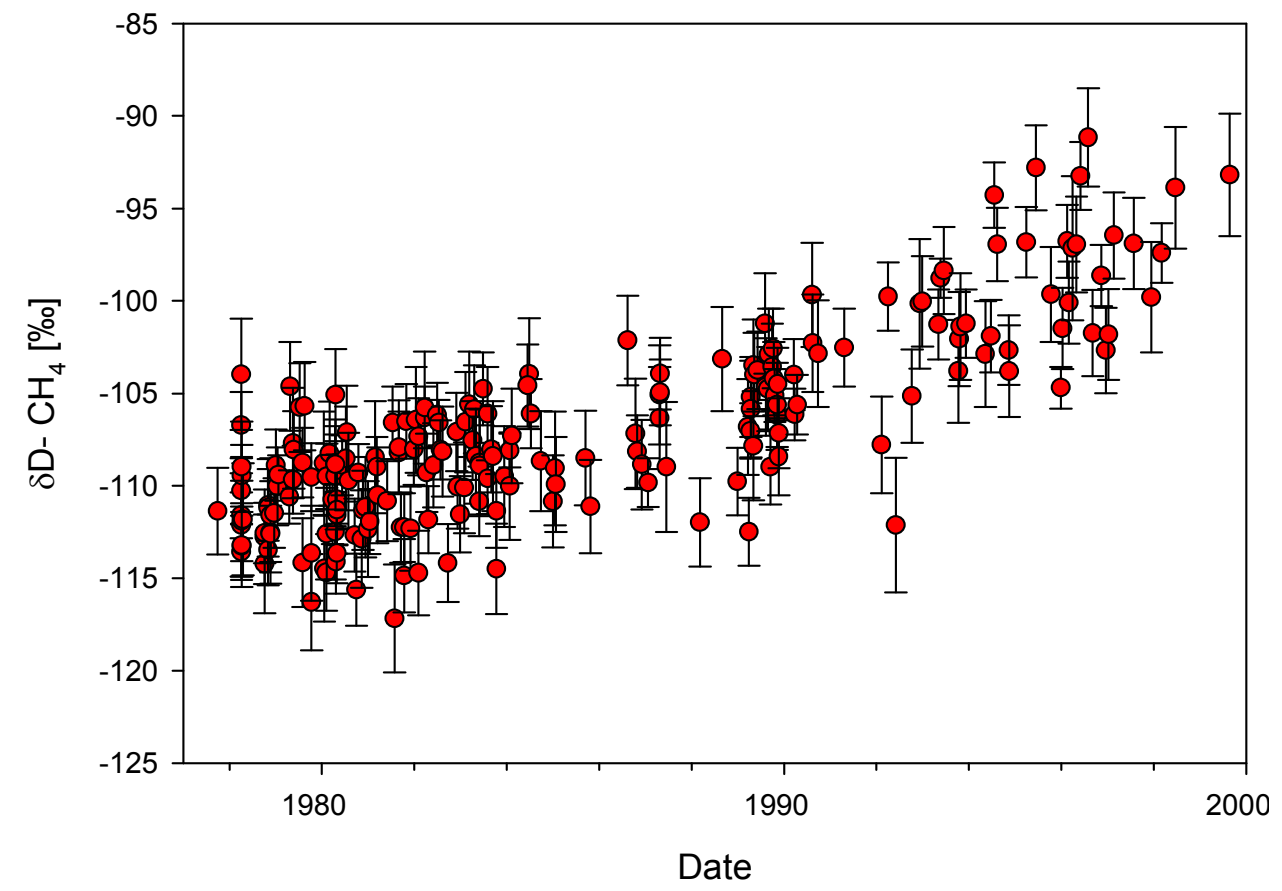

Figure 3.11. The $\delta \mathrm{D}$ of atmospheric $\mathrm{CH}_{4}$ observed at Cape Meares, Oregon from 1 October 1977 to 24 August 1999. Error bars are $\pm 1 \sigma$ from the average of multiple measurements of each sample.

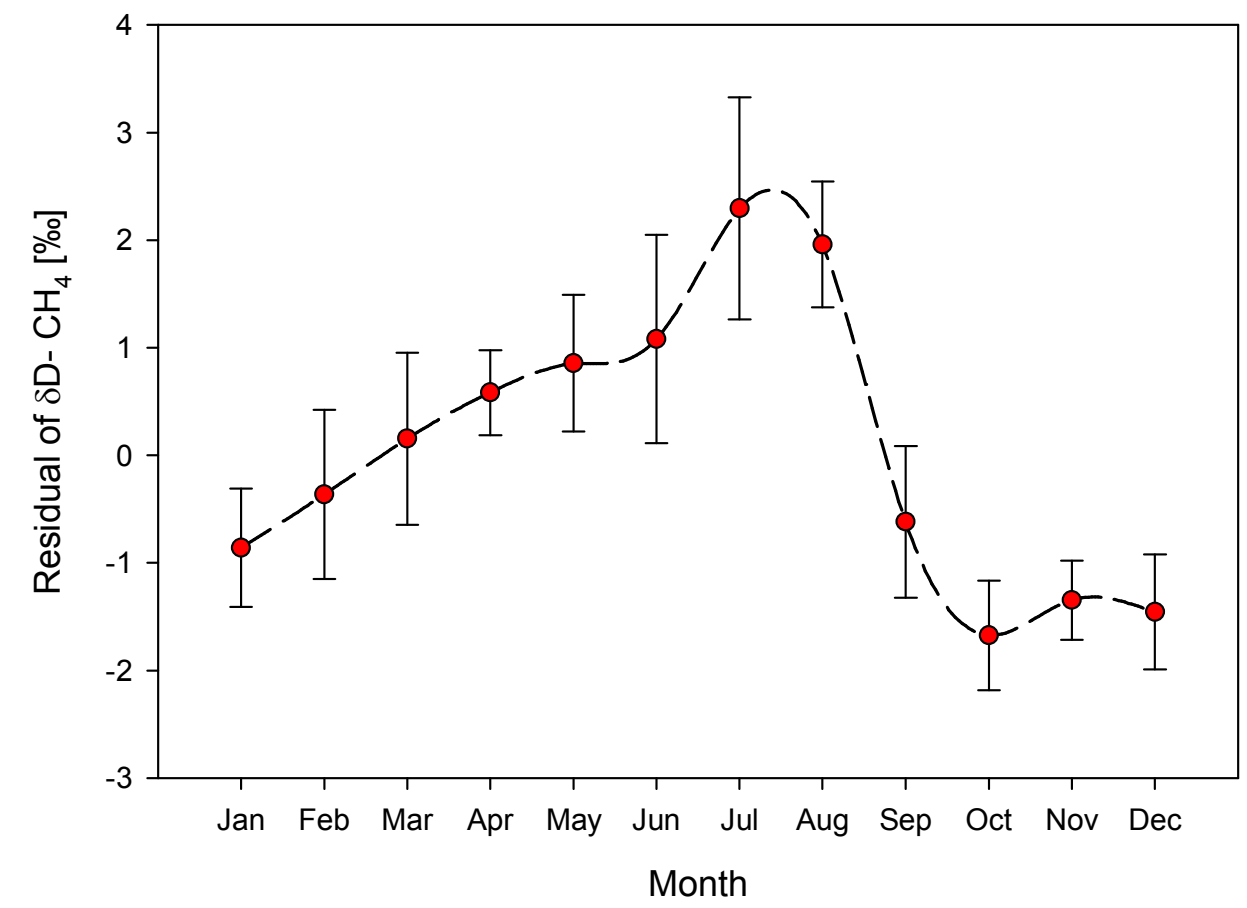

Figure 3.12 .Seasonal trend of $\delta \mathrm{D}$ of atmospheric $\mathrm{CH}_{4}$ at Cape Meares 1 October 1977 to 24 August 1999. The error bars represent \pm 1 standard error. 


\subsection{Discussion of seasonal cycles of $\mathrm{CH}_{4}, \delta^{13} \mathrm{C}$, and $\delta \mathrm{D}$ at Cape Meares}

This discussion examines two main effects. First, we explain the behaviors of $\mathrm{CH}_{4}, \delta^{13} \mathrm{C}$, and $\delta \mathrm{D}$ in terms of sources and sinks. Second, we use the correlation between isotopic compositions and mixing ratio to determine the kinetic isotopic effects for the atmospheric loss process, ${ }^{13 \mathrm{C}} \alpha$ and ${ }^{\mathrm{D}} \alpha$.

Bergamaschi et al. [2000] and Allan et al. [2001] describe a method to extract information about the isotopic signatures of the sources or the kinetic isotopic effects (KIE) of the sinks. They construct a phase ellipse to relate the seasonal change in the isotopic ratio either $\delta^{13} \mathrm{C}$ or $\delta \mathrm{D}$ to $\mathrm{CH}_{4}$ mixing ratio. They derive the following equation

$\frac{\Delta \delta}{\Delta \mathrm{C}} \sim \frac{\varepsilon\left(1+\delta_{0}\right)}{\mathrm{C}_{0}}$

where $\varepsilon$ is the kinetic isotopic effect (KIE) defined in section 1.4 and related to $\alpha$ from equation (1.9) for $\delta^{13} \mathrm{C}$ and for $\delta \mathrm{D} . \delta_{0}$ and $\mathrm{C}_{\mathrm{o}}$ are the mean values of $\delta$ and mixing ratio over a short time interval $\Delta \mathrm{t}$ ( here taken to be one year). The left hand side of equation (3.2) can be obtained by plotting a correlation between the changes in the isotopic signatures of the atmosphere with the change in the mixing ratio of the atmosphere. The slope of the line is called "KIE line". According to equation (3.2), the slope of this line is determined by the magnitude of $\mathrm{KIEs}$ in $\mathrm{CH}_{4}$ sink reactions. This line should be exactly a straight line with negative slope if only the sinks control the relation between the isotope and mixing ratio. When the sources are important to seasonal changes of mixing ratio and isotope ratio, the points will fall off this line and will be distributed around that line in an ellipse. Therefore, plotting the observed mean residual monthly value of the isotopic 
composition of the atmosphere with the mean residual value of mixing ratio will give an ellipse shape. In a modeling study, Allan et al. [2001a] found that increasing source dominance of the seasonality will increase the eccentricity of the ellipse.

Figures 3.14 (a) and (b) show the residual of $\delta^{13} \mathrm{C}$ and $\delta \mathrm{D}$ plotted versus the residual of $\mathrm{CH}_{4}$ mixing ratio at Cape Meares. For figure 3.14 (a), the slope is ($0.0036 \pm 0.0004) \% / \mathrm{ppb}$ and has $\mathrm{r}^{2}=0.2(\mathrm{n}=211)$. The slope in figure $3.14(\mathrm{~b})$ is ($0.0905 \pm 0.0092) \% / \mathrm{ppb}$ and has $\mathrm{r}^{2}=0.4(\mathrm{n}=209)$. The uncertainty of the slopes represents the standard errors with $95 \%$ confidence interval. From these results, we note that $\delta \mathrm{D}$ has a stronger antiorrelation with $\mathrm{CH}_{4}$ mixing ratio than $\delta^{13} \mathrm{C}$. This is thought to result from a considerably larger kinetic isotopic effect in $\mathrm{CH}_{3} \mathrm{D}$ reactions in sink processes (i.e. ${ }^{\mathrm{D}} \alpha>>$ ${ }^{13 C} \alpha$ ). From these figures we deduce from the following calculations of ${ }^{13 C} \alpha$ and ${ }^{D} \alpha$.

We choose 1980 to calculate $C_{o}$ (the mean mixing ratio), since this year has almost one sample for each month except for June, $\left(\delta^{13} \mathrm{C}\right)_{0}$, and $(\delta \mathrm{D})_{0}$ which are 1637 ppb, $-47.65 \%$, and $-110.8 \%$, respectively. The results of ${ }^{13 C} \alpha$ and ${ }^{\mathbf{D}} \alpha$ from regression lines in figure 3.14(a) and 3.14(b) are $1.006 \pm 0.0007$ and $1.19 \pm 0.02$, respectively. Again, the confidence interval for these results is $95 \%$.

To check if this value agrees with theory, the expected value for the carbon atmosphere KIE can be calculated from

${ }^{13 \mathrm{C}} \alpha_{\text {ave }}=\mathrm{f}_{\mathrm{OH}}{ }^{13 \mathrm{C}} \alpha_{\mathrm{OH}}+\mathrm{f}_{\text {soil }}{ }^{13 \mathrm{C}} \alpha_{\text {soil }}+\mathrm{f}_{\text {strato }}{ }^{13 \mathrm{C}} \alpha_{\text {strato }}$

where $\mathrm{f}_{\mathrm{OH}}, \mathrm{f}_{\text {soil }}$, and $\mathrm{f}_{\text {strato }}$ are the fractional contribution of $\mathrm{OH}$ sink, soil sink and stratospheric sink, respectively. Their values are $\mathrm{f}_{\mathrm{OH}}=0.88, \mathrm{f}_{\text {soil }}=0.05$ and $\mathrm{f}_{\text {strato }}=0.07$ [IPCC, 2007]. Inserting ${ }^{13 \mathrm{C}} \alpha_{\mathrm{OH}}=1.0039 \pm 0.0004 \quad$ [Saueressig et al., 2001], 
${ }^{13 \mathrm{C}} \alpha_{\text {soil }}=1.0181 \pm 0.0004$ [Snover and Quay, 2000], ${ }^{13 \mathrm{C}} \alpha_{\text {strato }}=1.0156 \pm 0.0004$ [Rice et al., 2003], the weighted value of carbon KIE is ${ }^{13 \mathrm{C}} \alpha_{\text {ave }}=1.0054 \pm 0.0007$.

The calculated value of KIE for carbon (1.0054) is lower than the value obtained from figure 3.14(a) (1.006). This discrepancy may be due to the effect of marine boundary layer $\mathrm{Cl}$ as one of the sinks for atmospheric $\mathrm{CH}_{4}$ which is not taken into account in the calculations in equation (3.3). The $\mathrm{Cl}$ sink has ${ }^{13 \mathrm{C}} \alpha_{\mathrm{Cl}}=1.0621$ [Tyler et al., 2000]. This effect will cause to increase atmospheric carbon KIE [Gupta et al., 1996; Allan et al., 2001(a)]. However, the differences between expected and observed ${ }^{13 C} \alpha$ agree within the error of measurement and may not be real.

An equation similar to equation (3.3) is used to calculate the expected hydrogen atmospheric KIE. It has the following form

${ }^{\mathrm{D}} \alpha_{\text {ave }}=\mathrm{f}_{\mathrm{OH}}{ }^{\mathrm{D}} \alpha_{\mathrm{OH}}+\mathrm{f}_{\text {soil }}{ }^{\mathrm{D}} \alpha_{\text {soil }}+\mathrm{f}_{\text {strato }}{ }^{\mathrm{D}} \alpha_{\text {strato }}$

$f_{\mathrm{OH}}, \mathrm{f}_{\text {soil }}$, and $\mathrm{f}_{\text {strato }}$ are defined as for the carbon KIE and have the same values. Inserting ${ }^{\mathbf{D}} \alpha_{\mathrm{OH}}=1.294 \pm 0.018$ [Saueressig et al., 2001], ${ }^{\mathbf{D}} \alpha_{\text {soil }}=1.066 \pm 0.007$ [Snover and Quay, 2000], ${ }^{\mathbf{D}} \alpha_{\text {strato }}=1.157 \pm 0.008$ [Rice et al., 2003], the average value of hydrogen KIE is ${ }^{\mathbf{D}} \alpha_{\text {ave }}=1.27 \pm 0.02$. The hydrogen KIE value obtained from figure 3.14(b) is less than the KIE value obtained from equation (3.4).

Tyler et al. [2007] calculated the KIEs for both isotopes for Niwot Ridge, Colorado (40 $\left.\mathrm{N}, 105^{\circ} \mathrm{W}\right)(\mathrm{NWR})$ and Montaña de Oro, $\left(35^{\circ} \mathrm{N}, 12^{\circ} \mathrm{W}\right)$ California (MDO) which both are northern hemisphere mid-latitude locations. For the carbon KIE, they obtained 1.009 \pm 0.003 and $1.010 \pm 0.003$ for NWR and MDO, respectively. Their values for the hydrogen 
KIE for NWR and MDO are $1.30 \pm 0.03$ and $1.29 \pm 0.07$, respectively. Their carbon and hydrogen KIE for both locations are higher than the obtained values for Cape Meares. Bergamashi et al. [2000] calculated the KIE of carbon and hydrogen for Izaña, Tenerife $\left(28^{\circ} \mathrm{N}, 16^{\circ} \mathrm{W}\right)$. They obtained $1.009 \pm 0.003$ and $1.23 \pm 0.04$ for KIE of carbon and hydrogen, respectively, again higher but within uncertainty of Cape Meares values.

The elliptical behavior of figure 3.14 reflects seasonal changes in $\mathrm{CH}_{4}$ sources. Early season (February-May) off-axis distortion show a significant enriched source of $\mathrm{CH}_{4}$, likely the result of biomass burning $\left(\delta^{13} \mathrm{C}=-26 \%\right.$ and $\delta \mathrm{D}=-210 \%$ ). In contrast, late season (August-October) sources are depleted and are likely microbial in nature $\left(\delta^{13} \mathrm{C}=\right.$ $60 \%$ and $\delta \mathrm{D}=-330 \%$ ). The seasonal cycle of $\delta \mathrm{D}-\mathrm{CH}_{4}$ is more sensitive to the sinks, due to the large KIE. However, the changes of $\delta \mathrm{D}$ with $\mathrm{CH}_{4}$ coincide with the changes of $\delta^{13} \mathrm{C}$ with $\mathrm{CH}_{4}$ mixing ratio and reflect an enriched source during Feburary-May and a depleted source during August-October. 

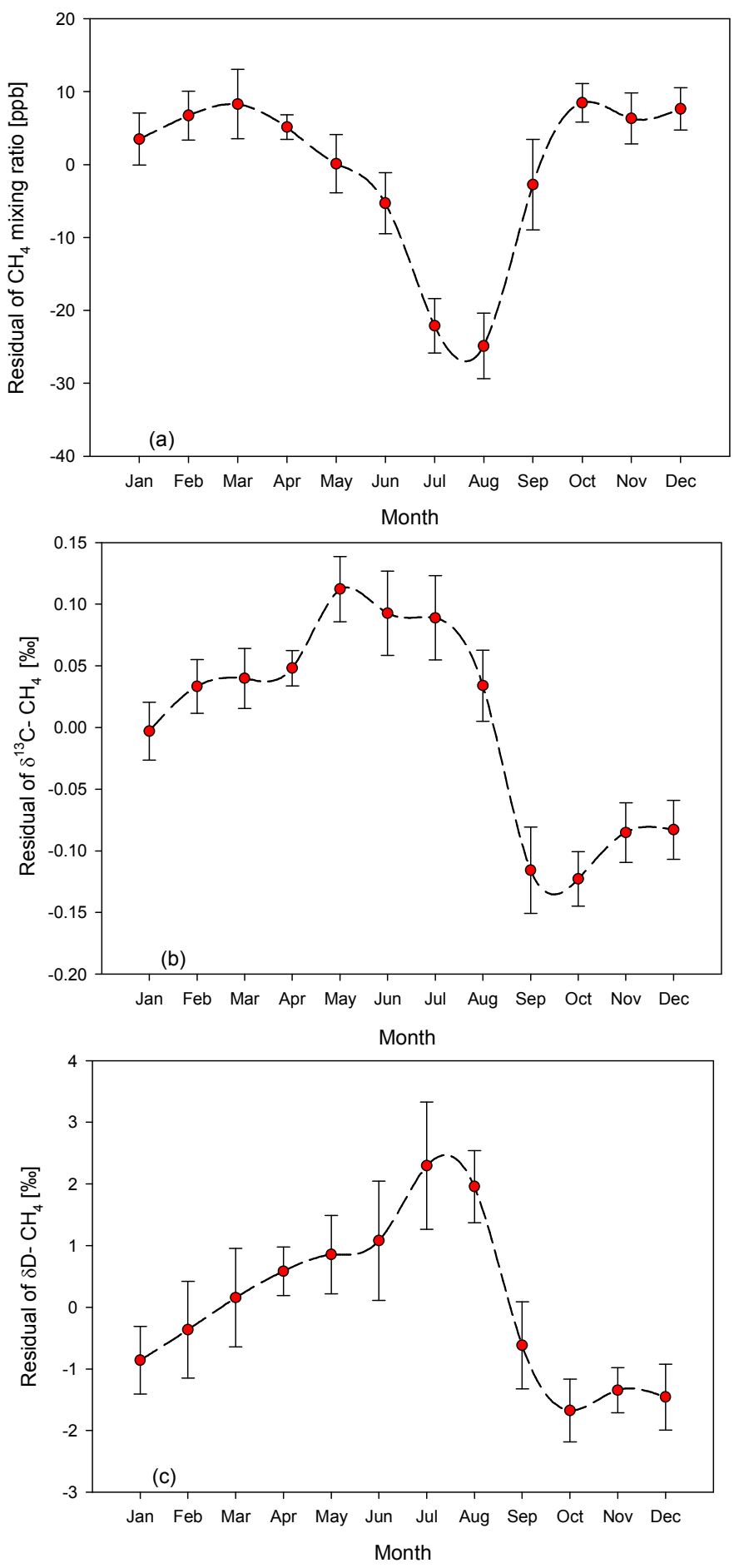

Figure 3.13. Seasonal cycles of (a) atmospheric $\mathrm{CH}_{4}$ mixing ratio, (b) $\delta^{13} \mathrm{C}$, and (c) $\delta \mathrm{D}$ at Cape Meares based on the measurements from air archive samples collected from 1 October 1977 to 24 Aug 1999. Error bars represent \pm 1 standard error. 

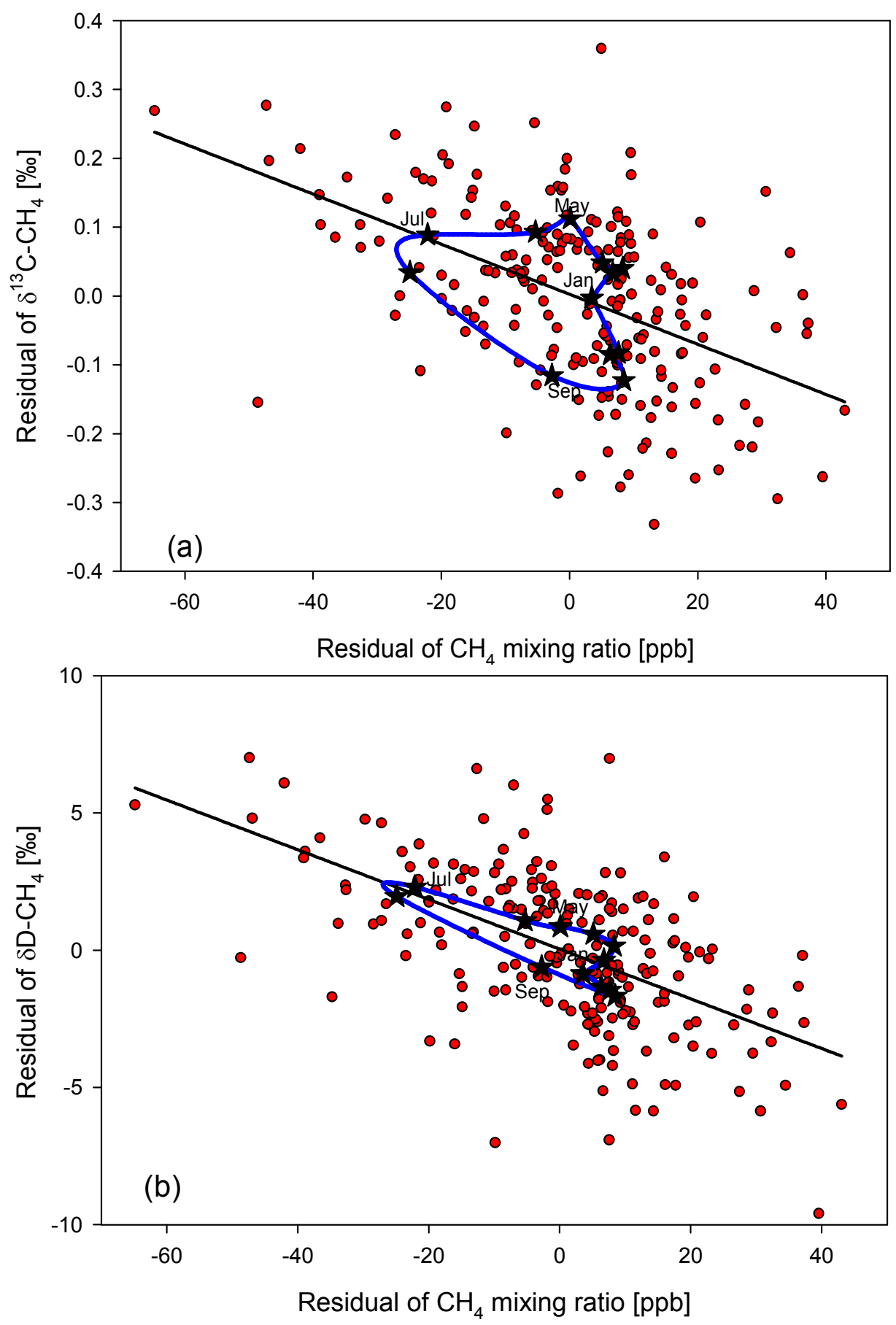

Figure 3.14. Phase ellipse for $\mathrm{CH}_{4}$ at Cape Meares, Oregon, made by plotting (a) residual of $\delta^{13} \mathrm{C}_{-} \mathrm{CH}_{4}$ versus residual of $\mathrm{CH}_{4}$ mixing ratio and (b) residual of $\delta \mathrm{D}-\mathrm{CH}_{4}$ versus residual of $\mathrm{CH}_{4}$ mixing ratio. The black stars are mean monthly residual values of $\mathrm{CH}_{4}, \delta^{13} \mathrm{C}$, and $\delta \mathrm{D}$. The results of KIE of both ${ }^{13 \mathrm{C}} \alpha$ and ${ }^{\mathbf{D}} \alpha$ are $1.006 \pm 0.004$ and $1.19 \pm 0.09$, respectively. 


\subsection{Recent measurements at Cape Meares, Oregon (March 2012-October 2012)}

Starting March 28th, 2012 monthly field work was initiated to collect air samples at the Cape Meares site. The main reason for these trips is to check the current values of atmospheric $\mathrm{CH}_{4}$ and its isotopes and to confirm the seasonal variability of the three measured parameters. Checking the forecast and more critically the wind trajectory is one of the important factors to collect air on the selected sampling days. The HYSPLIT forecast back trajectory NOAA ARL (http://www.ready.noaa.gov/HYSPLIT_traj.php [Draxler and Rolph, 2012]) is used to evaluate days of sample collection at Cape Meares $\left(45.5^{\circ} \mathrm{N}, 124^{\circ} \mathrm{W}\right)$. A backward trajectory is run to predict the zonal wind direction that will hit Cape Meares on the day of collection for 72 hours prior to collection. From model run, we choose a day with wind prevailing from westerly directions to avoid sampling effects from regional continental sources. For measured meteorology information on the day of collection such as wind direction (WDIR), wind speed (WSPD), wind gust (GST) atmospheric pressure (PRES), and air temperature (ATMP), a NOAA National weather service Northwest station is used in Tillamook bay $\left(45^{\circ} 33^{\prime} \mathrm{N}, 123^{\circ} 55^{\prime}\right.$ W) (http://www.ndbc.noaa.gov/station_page.php?station=TLBO3) is used which measures all the parameters mentioned. This station is the closest Northwest station to Cape Meares. Detailed information about the wind trajectory and all the measured parameters at Tillamook Bay for each sample collected is included in Appendix C. 


\subsubsection{Atmospheric $\mathrm{CH}_{4}$ mixing ratios (2012)}

The recent measurements of $\mathrm{CH}_{4}$ mixing ratios had a maximum measured value on 28 March 2012 which was $1891 \mathrm{ppb}$. After March, the atmospheric $\mathrm{CH}_{4}$ mixing ratio decreases and reaches the lowest value late July, $1823 \mathrm{ppb}$. During August, $\mathrm{CH}_{4}$ mixing ratio increases again to $1871 \mathrm{ppb}$. From these measured values, the amplitude of the cycle is $68 \mathrm{ppb}$, though a full season has not been measured. The tabulated data for the measurements is found in table A.6 in Appendix A. The phase of recent seasonal cycle in figure 3.15 confirms the phase obtained from measured values of archive air samples in figure 3.2 .

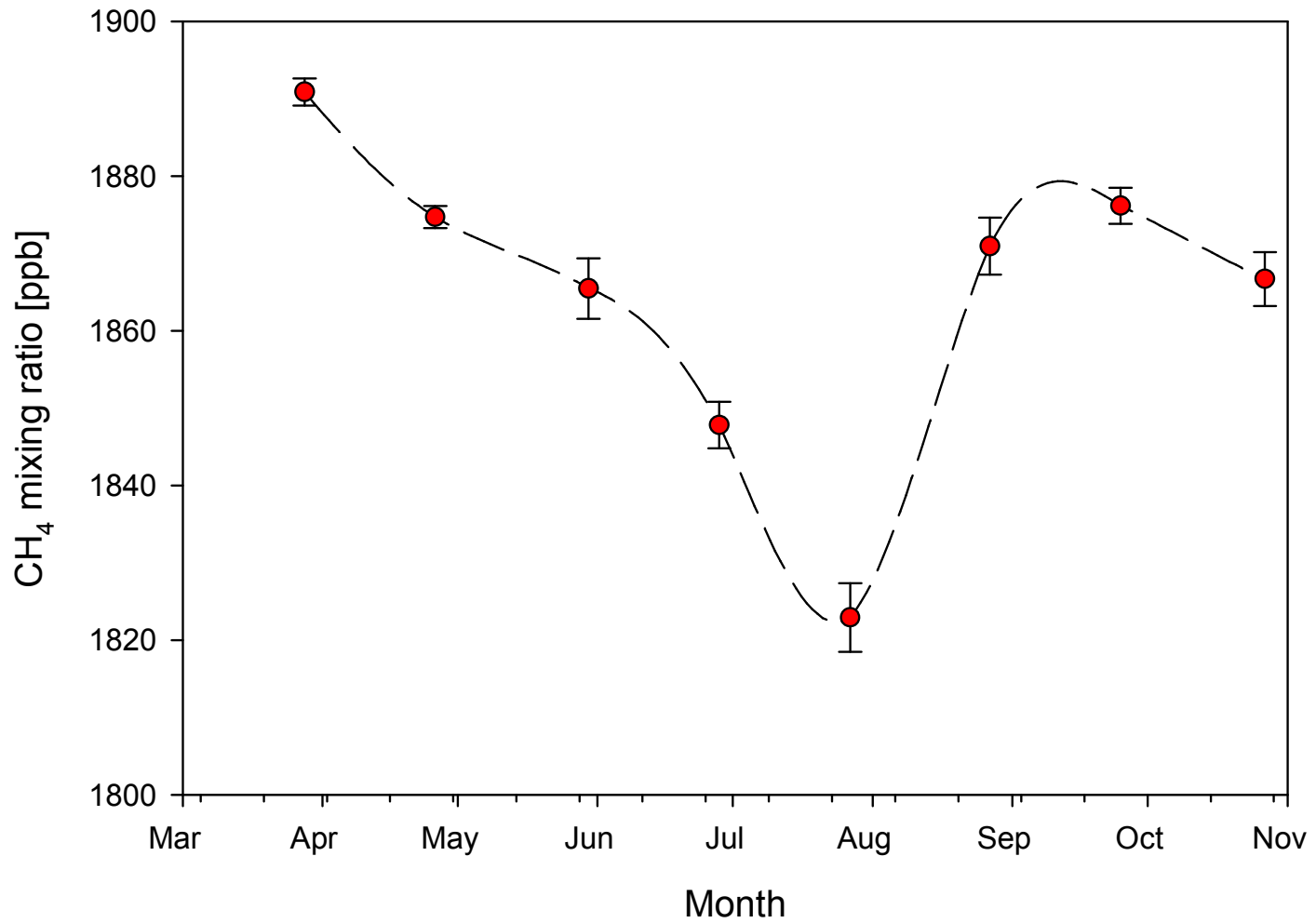

Figure 3.15. The seasonal trend of $\mathrm{CH}_{4}$ mixing ratio starting from 28 March 2012 to October 2012. The measured $\mathrm{CH}_{4}$ mixing ratio is on the NOAA04 scale. Error bars represent $\pm 1 \sigma$. 


\subsubsection{Isotope Ratios}

$\delta^{13} \mathrm{C}$ of recently collected air samples at Cape Meares were measured. The measured values are shown in figure $3.16 . \delta^{13} \mathrm{C}$ of atmospheric $\mathrm{CH}_{4}$ becomes gradually enriched after March and reaches its highest value (-47.14\%o) in July. Subsequently, $\delta^{13} \mathrm{C}$ becomes rapidly depleted and falling to its minimum value (-47.7\%o) during late September. From these measurements, the amplitude of the cycle is $0.56 \%$. From figure 3.10 and figure 3.16, the highest value of $\delta^{13} \mathrm{C}$ is shifted from May to July. However, the minimum values of $\delta^{13} \mathrm{C}$ occur in September as observed in the archive. The measured values are tabulated in table A.6 in Appendix A.

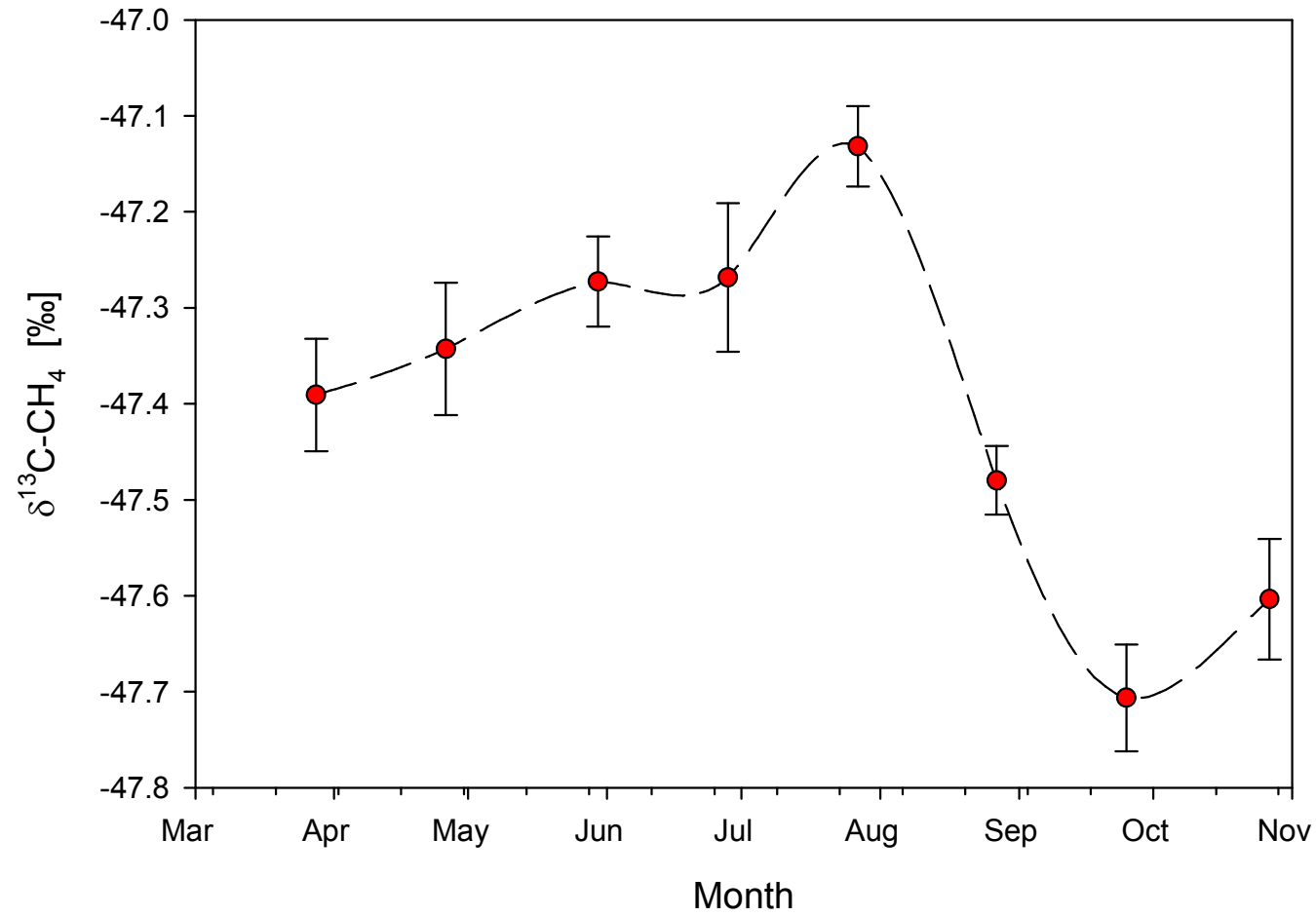

Figure 3.16. The seasonal trend of $\delta^{13} \mathrm{C}$ of atmospheric $\mathrm{CH}_{4}$ starting from 28 March 2012 to October 2012. Error bars represent \pm 1 standard error. 
$\delta \mathrm{D}$ of recently collected air samples at Cape Meares have yet to be measured. However, we plan to commence these measurements in the coming months which will confirm seasonal trend in $\delta \mathrm{D}$ from the archive.

\subsection{Archived samples from South Pole, Mauna Loa, and Samoa}

Additional samples collected at South Pole, Mauna Loa, and Samoa were available from the OGI archive and were measured for their $\mathrm{CH}_{4}$ mixing ratio, $\delta^{13} \mathrm{C}$ and $\delta \mathrm{D}$ at PSU. One complication regarding these samples was that, for each location and month, all the samples that were collected over the same month were mixed into one canister. In contrast to the Cape Meares archive, these samples represent a mix of air and could present a significant source of uncertainty. Further, the fractional weighting for each individual date is unknown. NOAA began reporting average mixing ratios at these locations in 1983 [Dlugokencky, et al., 2012]. However, $\delta^{13} \mathrm{C}$ measurements at these locations didn't start until 1998 [White and Vaughn, 2011]. Our measurements provide some information on $\delta^{13} \mathrm{C}$ and $\delta \mathrm{D}$ during these periods at these selected stations. Records of $\delta^{13} \mathrm{C}$ are available for Mauna Loa and Samoa by Quay et al. [1999]. However, there is no recorded data available for $\delta \mathrm{D}$ during the period of collection at any of these locations. 


\subsubsection{South Pole $\left(90^{\circ} \mathrm{S}\right)$}

There are 15 samples in the air archive collected from the South Pole during the period January 1992 to February 1995. Three of them had unknown collection dates. With the exception of discrete two samples, the samples are of mixed dates (i.e. samples are from different days during the month of collection are mixed in one canister). The measurements of $\mathrm{CH}_{4}$ mixing ratio, $\delta^{13} \mathrm{C}$, and $\delta \mathrm{D}$ are shown in figure 3.16. Tabulated values can also be found table A.7 in Appendix A.

The average value of mixing ratio of South Pole samples is $1689 \pm 22 \mathrm{ppb}$ with a minimum measured value of $1663 \mathrm{ppb}$ in March, 1992 and a maximum measured value of $1740 \mathrm{ppb}$ in October, 1992.

Although there are not full data for one year, the measurements during 1992 show that the seasonal trend in $\mathrm{CH}_{4}$ mixing ratio has a minimum value during March and reaches a maximum in October and their values mentioned above. A comparison between these measurements and measurements made by NOAA-ESRL [Dlugokencky et al., 2012] is shown in figure 3.17 (a). According to NOAA measurements, the maximum and minimum values of mixing ratio occur during September and October, respectively. During 1992, the maximum value of mixing ratio observed by NOAA is $1703 \mathrm{ppb}$, and the minimum value is $1672 \mathrm{ppb}$. Overall, our archived samples follow the seasonality of NOAA data with a few exceptions. The June 1992 and October 1992 samples are 23 ppb and $\sim 40 \mathrm{ppb}$ higher than expected, respectively. The cause of these deviations is 
unknown but may reflect differences in air masses sampled. All other samples are within $\pm 2 \sigma$ measurement error bars.

The $\delta^{13} \mathrm{C}$ of atmospheric $\mathrm{CH}_{4}$ record from South Pole archived samples is shown in figure $3.17(\mathrm{~b})$. The average value of these measurements is $-47.06 \pm 0.09(1 \sigma) \%$. From these measurements, the maximum observed value is in February, $1992(-46.88 \%)$ and the minimum observed value is in September, $1992(-47.22 \%)$. Measurements of $\delta^{13} \mathrm{C}$ of atmospheric $\mathrm{CH}_{4}$ at South Pole by NOAA didn't begin until 1998. However, the seasonal trend of $\delta^{13} \mathrm{C}$ for high latitude southern hemisphere locations has been discussed in the literature [Lowe et al., 1991; 1994; 1997; 2004; Miller et al., 2002]. Based on the measurements of atmospheric $\mathrm{CH}_{4}$ and its carbon isotope from 1989 to 1996 at Baring Head, New Zealand $\left(41^{\circ} \mathrm{S}\right.$ and $\left.174^{\circ} \mathrm{E}\right)$ and at a Scott Base, Antarctica $\left(77.85^{\circ} \mathrm{S}, 166.75^{\circ}\right.$ E), Lowe et al. [1997] found that the seasonal cycles of $\delta^{13} \mathrm{C}$ from both sites are approximately 6 months out of phase with mixing ratio [Lowe et al., 1997].

Miller et al. [2002] showed that, during $1998-1999, \delta^{13} \mathrm{C}$ seasonal cycle at South Pole (SPO) has a lower amplitude than those at Cape Grim (CGO) $\left(40.7^{\circ} \mathrm{S}, 144.7^{\circ} \mathrm{E}\right)$ and Samoa (SMO) $\left(13.8^{\circ} \mathrm{S}, 172^{\circ} \mathrm{W}\right)$. The amplitudes of seasonal cycles for SPO, CGO, and SMO during 1998 are $0.17 \%$, 0.28\%o, and 0.39\%, respectively. In case of South Pole, the seasonal amplitudes of $\mathrm{CH}_{4}$ and $\delta^{13} \mathrm{C}$ are thought to be completely controlled by $\mathrm{OH}$ destruction. During the summer in Southern hemisphere, the $\mathrm{OH}$ has the highest concentration and $\mathrm{CH}_{4}$ will decrease the $\mathrm{CH}_{4}$ concentration and enrich the ${ }^{13} \mathrm{CH}_{4}$ in the 
atmosphere. Therefore, the seasonal cycle of $\delta^{13} \mathrm{C}$ will have 6 months out of phase, $\mathrm{CH}_{4}$ will have maximum values in September and minimum values in February.

The $\delta \mathrm{D}$ of atmospheric $\mathrm{CH}_{4}$ for South Pole over the same period is shown in figure 3.17(c). The mean value of these results is $-90.4 \pm 3.2(1 \sigma) \%$. The minimum value is found to be $-96.5 \%$ during May 1992 and maximum value of $-84.2 \%$ is found during February 1995. From the measurements of $\delta \mathrm{D}$ during 1992, the most enriched value is during August (-88.1\%o) and the most depleted value occurs in May (-96.4\%).

Because the measurements of $\delta \mathrm{D}$ are not as common as $\delta^{13} \mathrm{C}$, there is no other data available to compare these results with. In fact, these are the only known measurements of $\delta \mathrm{D}$ of atmospheric $\mathrm{CH}_{4}$ from the southern hemisphere during this time. However, based on the sink-driven seasonality we anticipate $\delta \mathrm{D}$ to be in phase with $\delta^{13} \mathrm{C}$ with minimum values during September and maximum values during February. 

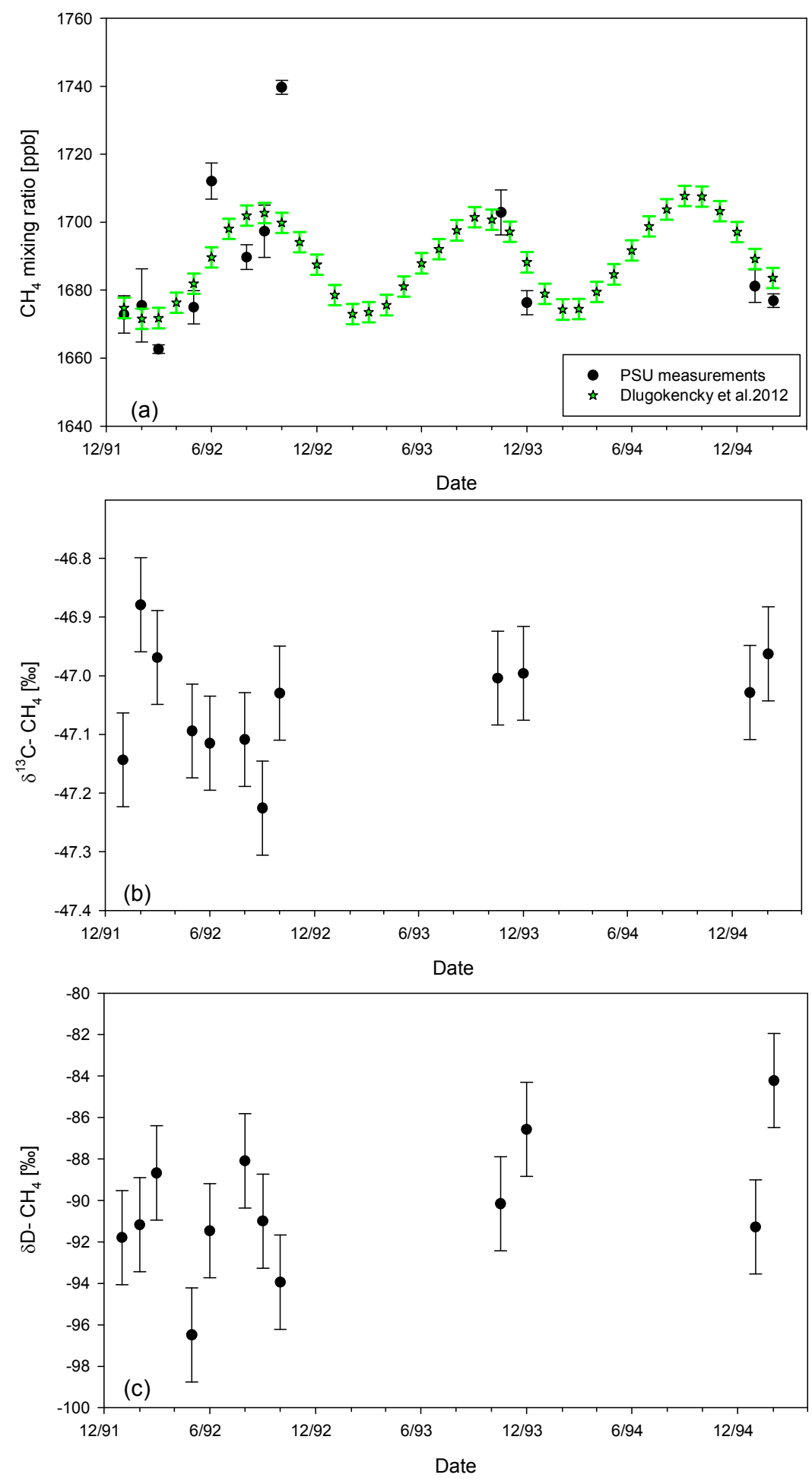

Figure 3.17 (a) $\mathrm{CH}_{4}$ mixing ratio (b) $\delta{ }^{13} \mathrm{C}_{-} \mathrm{CH}_{4}$, and (c) $\delta \mathrm{D}-\mathrm{CH}_{4}$ measurements for South Pole from January 1992 to February 1995. Error bars represent $\pm 1 \sigma . \mathrm{CH}_{4}$ mixing ratio measurements at PSU were adjusted to be in NOAA scale. 


\subsubsection{Samoa $\left(14.1^{\circ} \mathrm{S}, 170.6^{\circ} \mathrm{W}\right)$}

There are 14 samples from this location which were part of OGI archive and collected from March 1995 to April 1996, with few missing months during this period. Figure 3.18 shows the results obtained from Samoa archived samples measured at PSU. The measurements of $\mathrm{CH}_{4}$ mixing ratio and its isotopic composition for these samples are tabulated in table A.8 in Appendix A.

The average measured $\mathrm{CH}_{4}$ mixing ratio in Samoa over this period is $1698 \pm 8(1 \sigma)$ ppb. The $\mathrm{CH}_{4}$ mixing ratio changes from a minimum value of $1684 \mathrm{ppb}$ in March 1995 to a maximum value of $1710 \mathrm{ppb}$ in September 1995. The amplitude of the seasonal cycle is 26 ppb. Comparison between these measurements and others measured by NOAA [Dlugokencky et al., 2012] is shown in figure 3.18(a). Their data, from March 1995 to April 1996, show that there are two minimum values of the $\mathrm{CH}_{4}$ mixing ratio in March 1995 and April 1996 with values of 1698 ppb and 1699 ppb, respectively. Their maximum values of mixing ratio occur during September 1995 and February 1996 with values of $1714 \mathrm{ppb}$ and $1725 \mathrm{ppb}$, respectively. All measurements performed at PSU from the archive agree within $( \pm 2 \sigma)$ with NOAA measurements. However, there are 3 samples that are more than $10 \mathrm{ppb}$ lower than measured by NOAA. These samples were collected March 1995, August 1995, and January 1996. With the exception of two of these samples, the seasonal trend observed here in mixing ratio is consistent with the NOAA record. 
The $\delta^{13} \mathrm{C}$ results for Samoa over the period are shown in figure 3.18(b). The average value of these measurements is $-47.03 \pm 0.07( \pm 1 \sigma) \%$ with a minimum $-47.19 \%$ occurring January 1996 and a maximum value of $-46.93 \%$ occurring October 1995 . A comparison between these measurements and measurements done by Quay et al. [1999] is shown on the same figure. Their measurements show, from February 1995 and April 1996, the highest values $\delta^{13} \mathrm{C}$ occur during March 1995, September 1995, and April 1996 with values of $-47.2 \%$, $-47 \%$, and $-46.4 \%$, respectively. There are quite depleted values of $\delta^{13} \mathrm{C}$ from the Quay et al. dataset which occur during November 1995 and March 1996 with values of $-47.3 \%$ and $-47.5 \%$, respectively. However, we do not have samples during these months. All monthly values overlap within $\pm 2 \sigma$ error except one value during November, 1995. The seasonal cycle in our measurements has amplitude of $\sim 0.26 \%$ similar to the $0.2 \%$ based on the measurements at Samoa from 1988 to 1995 from Quay et al. [1999]. They also assumed that the primary reason for the $\delta^{13} \mathrm{C}$ seasonal trend of atmospheric $\mathrm{CH}_{4}$ could be explained by the primary destruction of $\mathrm{CH}_{4}$ by $\mathrm{OH}$. They found, based on the measurements from 1988 to 1995 , that the $\delta^{13} \mathrm{C}$ minimum value occurs in February with a value of $-47.29 \%$ and the $\delta^{13} \mathrm{C}$ maximum value occurs in October with a value of $-47.16 \%$. The $\delta^{13} \mathrm{C}$ measured at PSU for Samoa is on the Tyler $\delta^{13} \mathrm{C}$ of $\mathrm{CH}_{4}$ scale; however the Quay et al. [1999] data for Samoa is on the Quay $\delta^{13} \mathrm{C}$ of $\mathrm{CH}_{4}$ scale. Using a t-test, we compare between measured values of Samoa at PSU and Quay et. [1999] and find no high degree of statistical difference between both measurement sets suggesting that isotope scales are close. 
The $\delta \mathrm{D}$ results from Samoa archive samples are shown in figure 3.17(c). The mean value of these results is $-90.9 \pm 2.5( \pm 1 \sigma)$ \%o with a minimum value of $-94.3 \%$ during April 1995 and a maximum value of $-86.7 \%$ during May 1995. It is difficult to discern any seasonal behavior in the $\delta \mathrm{D}$ data. These are some of the only $\delta \mathrm{D}$ data known for the southern hemisphere during this decade. 

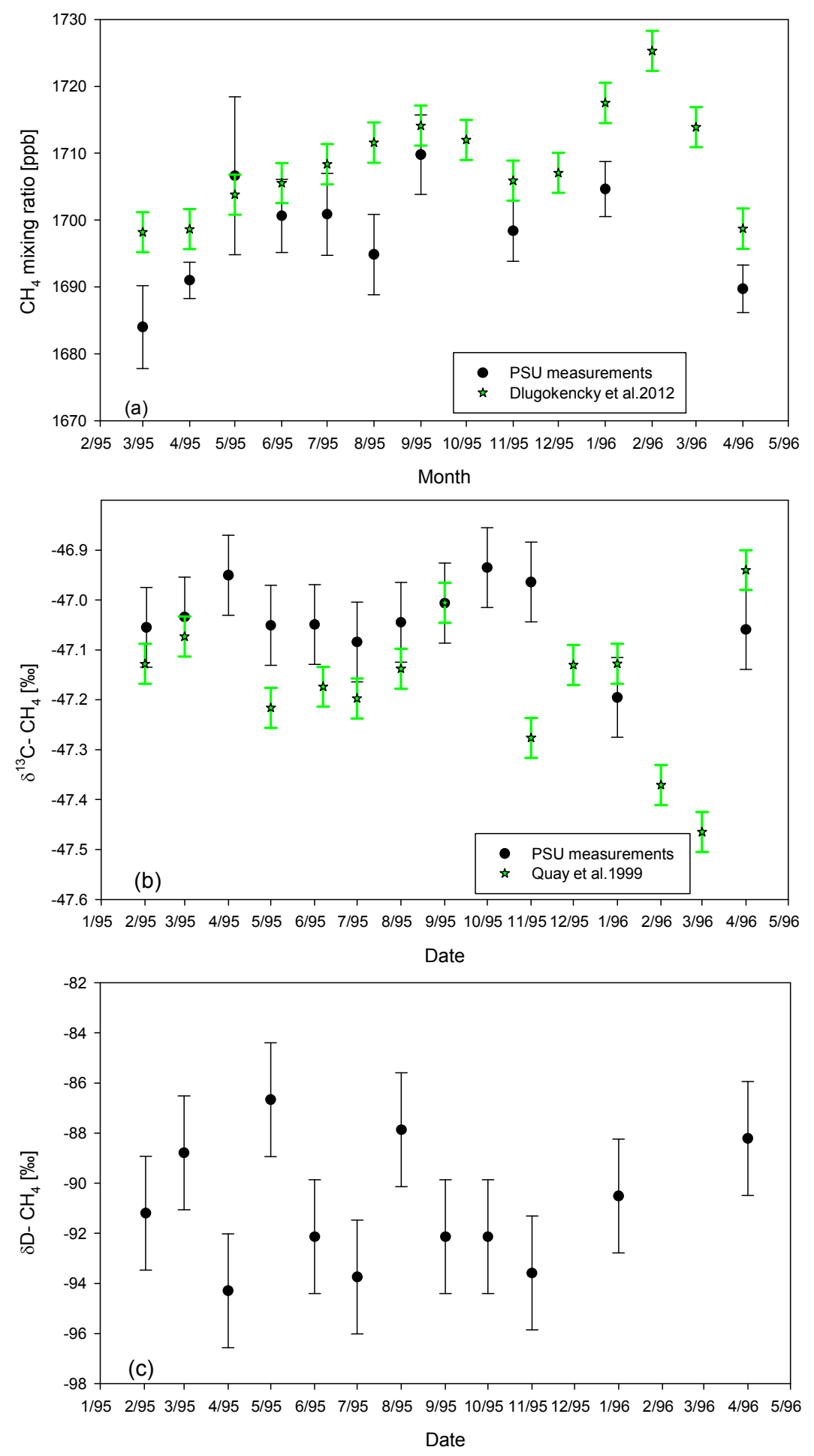

Figure 3.18 (a) $\mathrm{CH}_{4}$ mixing ratio (b) $\delta^{13} \mathrm{C}_{-} \mathrm{CH}_{4}$, and (c) $\delta \mathrm{D}-\mathrm{CH}_{4}$ measurements at Samoa from February 1995 to April 1996. Error bars in represent $\pm 1 \sigma . \mathrm{CH}_{4}$ mixing ratio (a) measurements at PSU were adjusted to be in NOAA scale. 


\subsubsection{Mauna Loa $\left(21.08^{\circ} \mathrm{N}, 157.2^{\circ} \mathrm{W}\right)$}

There were 11 samples as part of OGI archive from February, 1995 to December, 1995 collected from Mauna Loa, Hawaii. Figure 3.18 shows the results obtained from the Mauna Loa archive samples measured at PSU. The tabulated results of these samples are in table A.9 in Appendix A.

The results for $\mathrm{CH}_{4}$ mixing ratio at Mauna Loa are shown in figure 3.19(a). The average value of these results is $1758 \pm 9(1 \sigma)$ ppb with a minimum value (1747 ppb) in August and a maximum value (1775 ppb) in November. Figure 3.19(a) also shows measurements made by NOAA at Mauna Loa over the same period [Dlugokencky et al., 2012]. Their data show, during 1995, the mixing ratio reaches $1764 \mathrm{ppb}$ in March and starts to decrease in subsequent months and reaches the lowest value during July with a value of $1750 \mathrm{ppb}$. The mixing ratio increases and reaches to its maximum value through the year in December with a value of $1773 \mathrm{ppb}$. The PSU measurements overlap within $\pm 1 \sigma$ with these of NOAA except for two measurements: October and December which are lower at PSU.

The $\delta^{13} \mathrm{C}$ measurements at Mauna Loa during 1995 are shown in figure 3.19(b). The mean value of these measurements is $-47.2 \pm 0.1(1 \sigma) \%$ with a minimum of $-47.32 \%$ o in October and a maximum value -47.02\% in November. The data of Quay et al. [1999] are also shown in the same figure. Their data show, during $1995, \delta^{13} \mathrm{C}$ becomes enriched after January and reaches its highest value of $-47.1 \%$ during May-June. Subsequently, it becomes depleted in July $-47.3 \%$ o through the end of the year. The lowest of $\delta^{13} \mathrm{C}$ is 
observed during November -47.4\%o. Based on Quay et al. [1999] for Mauna Loa, during 1988-1995, the highest value of $\delta^{13} \mathrm{C}$ occurs during June-August, and the lowest values occurs in November. Overall, agreement with Quay et al data is quite good with values within $\pm 1 \sigma$ except in two cases. Our November data, in particular, appears quite enriched relative to data in October and December, and values from Quay et al.. In addition, our July value is enriched $0.2 \%$ compared that of Quay et al. However, it is consistent with overall annual trend and observed seasonality over a longer period by Quay et al. The significant difference between PSU measurements and Quay et al. [1999] has been checked using t-test. We found no statistical difference between the two datasets and scales ( $p$ - value is 0.4$)$.

The $\delta \mathrm{D}$ results from Mauna Loa archive samples are shown in figure 3.19(c). The mean value of these results is $-92.4 \pm 4.6(1 \sigma) \%$ with a minimum value $-99.6 \%$ o during December 1995 and a maximum value -82.5\%o during April 1995. As with South Pole and Samoa, these are the only $\delta \mathrm{D}$ of $\mathrm{CH}_{4}$ values reported from Mauna Loa

We can also compare our Mauna Loa data with that from Bergamashi et al. [2000] who measured $\mathrm{CH}_{4}, \delta^{13} \mathrm{C}$, and $\delta \mathrm{D}$ from late 1996 to the end of 1998 at Izaña, Tenerife $\left(26^{\circ} \mathrm{N}, 16^{\circ} \mathrm{W}\right)$. They found that $\delta^{13} \mathrm{C}$ and $\delta \mathrm{D}$ seasonal cycle have their maximum occurring in June and August while the minimum seasonal cycle of $\mathrm{CH}_{4}$ occurs in August. Similar to Izaña, Mauna Loa has a minimum $\mathrm{CH}_{4}$ mixing ratio in July while the maximum of seasonal cycles of both $\delta^{13} \mathrm{C}$ and $\delta \mathrm{D}$ are in between April to June, respectively. Therefore, the seasonal cycles of $\delta^{13} \mathrm{C}$ and $\delta \mathrm{D}$ of Mauna Loa are similarly 
controlled by both the effect of KIE of the sinks and the emission of sources. In particular, high values of $\delta^{13} \mathrm{C}$ and $\delta \mathrm{D}$ observed during spring indicate a biomass burning source signature and low values of $\delta^{13} \mathrm{C}$ and $\delta \mathrm{D}$ during October-November indicate a microbial $\mathrm{CH}_{4}$ source signature. This is similar to that observed at Cape Meares (section $3.3)$. 

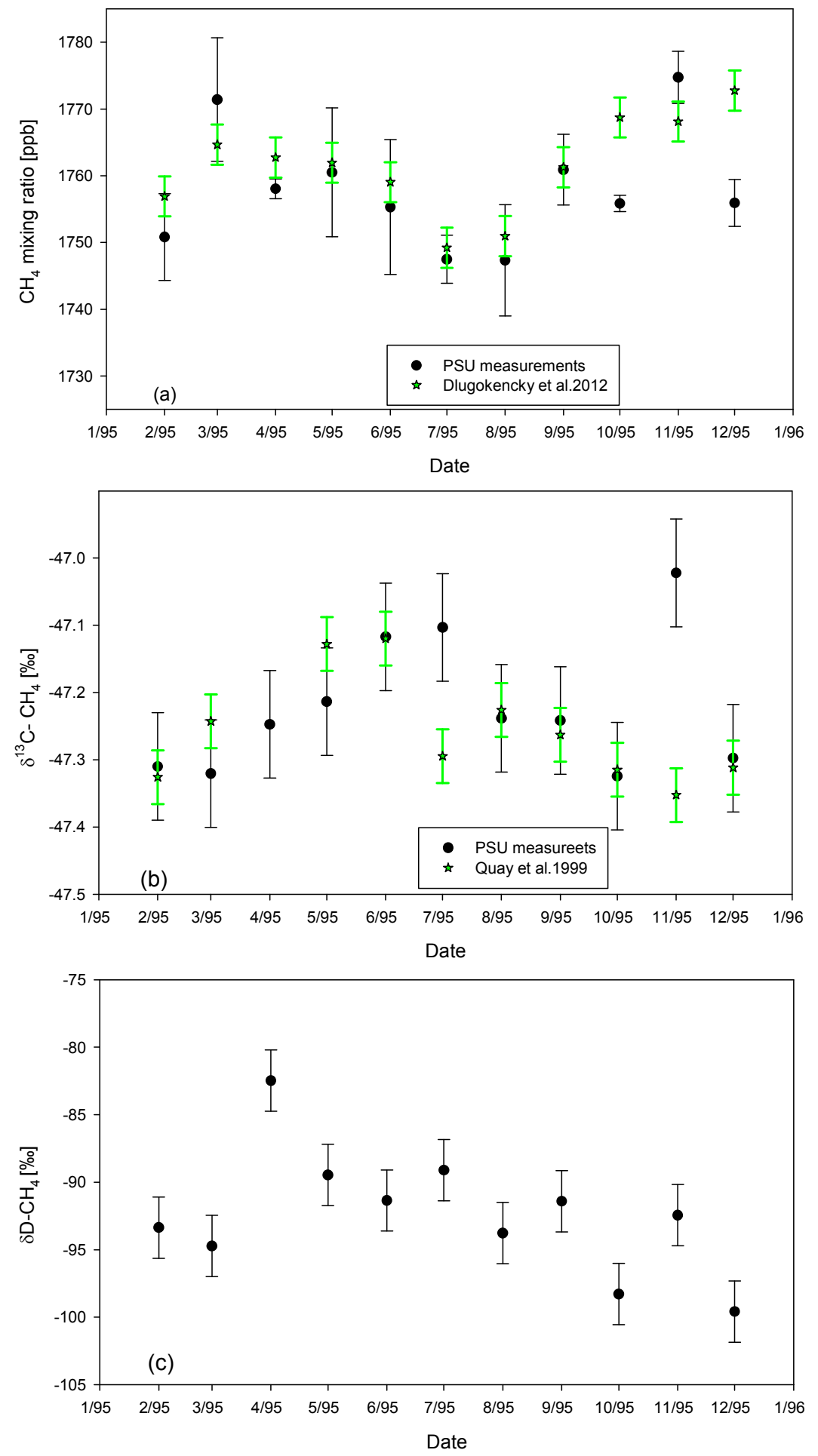

Figure 3.19 (a) $\mathrm{CH}_{4}$ mixing ratio (b) $\delta^{13} \mathrm{C}_{-} \mathrm{CH}_{4}$, and (c) $\delta \mathrm{D}-\mathrm{CH}_{4}$ measurements at Mauna Loa from February 1995 to December 1995. Error bars in represent $\pm 1 \sigma . \mathrm{CH}_{4}$ mixing ratio measurements at PSU were adjusted to be on the NOAA04 scale. 


\section{Chapter 4}

\section{Analysis and Discussions}

In this chapter, additional datasets from three mid-latitude sites are added to the Cape Meares dataset in order to describe the trend of $\mathrm{CH}_{4}$ and its isotopes from 1978 till 2010. Before including such data, some adjustments are done to match scales and to remove latitudinal-dependence. LOWESS and Bootstrap statistical methods are described briefly in section 4.2 . The seasonal cycles of $\mathrm{CH}_{4}, \delta^{13} \mathrm{C}$, and $\delta \mathrm{D}$ calculation from the composite dataset during 1978-2010 and the calculations of the hydrogen and carbon kinetic isotopic effects are described in section 4.3. After removing the seasonality from the measured variables, the secular and interannual variability are described in section 4.4 using LOWESS and Bootstrap methods. The growth rate of $\mathrm{CH}_{4}$ mixing ratio and the time rate of change of $\delta^{13} \mathrm{C}$ and $\delta \mathrm{D}$ of atmospheric $\mathrm{CH}_{4}$ are also obtained in this section. In section 4.5, we calculate the annual total emission of $\mathrm{CH}_{4}$ from 1978-2010 based on a $\mathrm{CH}_{4}$ lifetime 9.7 yrs. This section also includes the results of the average weighted $\delta^{13} \mathrm{C}$ and $\delta \mathrm{D}$ of $\mathrm{CH}_{4}$ sources. These calculations provide insight how $\mathrm{CH}_{4}$ sources have changed over the 30 year period 1978-2010. 


\subsection{Composite data from Cape Meares and other locations}

To understand the long trend of atmospheric $\mathrm{CH}_{4}$ from 1978 through 2010 in terms of its sources, a composite record from a single latitudinal zone of $\mathrm{CH}_{4}$ and its isotopes $\left(\delta^{13} \mathrm{C}\right.$ and $\left.\delta \mathrm{D}\right)$ for the northern hemisphere is created. In order to include data collected by different groups at different locations, it is important to ensure that:

1) All the measured data is on the same reference scale, e.g. in case of $\mathrm{CH}_{4}$ concentration, all the measured data should be on the NOAA04 scale. For $\delta^{13} \mathrm{C}$ calibrations are relative to VPDB and for $\delta \mathrm{D}$ calibrations are relative to VSMOW.

2) The dependence on latitude of each dataset is removed. In our case, this step is achieved by comparing between Cape Meares data and each other data set during the time period of intersection.

3) The seasonality from the datasets is removed which can reduce the fluctuations in $\mathrm{CH}_{4}$ and its isotope tracers that are regular.

Four locations were chosen here: Cape Meares, Oregon $\left(45.5^{\circ} \mathrm{N}, 124^{\circ} \mathrm{W}\right)$, Olympic Peninsula, Washington $\left(48^{\circ} \mathrm{N}, 123.62^{\circ} \mathrm{W}\right)$, Montaña de Oro, California $\left(35^{\circ} \mathrm{N}\right.$, $\left.121^{\circ} \mathrm{W}\right)$, and Niwot Ridge, Colorado $\left(40^{\circ} \mathrm{N}, 105^{\circ} \mathrm{W}\right)$. The main reasons for using these datasets are:

1) They have available measurements for $\mathrm{CH}_{4}$ mixing ratios, $\delta^{13} \mathrm{C}$ and/or $\delta \mathrm{D}$ over periods of several years that either intersect with Cape Meares measurements in 
time (such as Olympic Peninsula data) or give more details about the trends of these variables after 1999 (such as Montaña de Oro and Niwot Ridge).

2) All sites are mid-latitude northern hemisphere which minimize the effects of latitude on seasonality and interannual variability. Cape Meares, Olympic Peninsula, and Montaña de Oro are all coastal sites located in the continental US and receive similar airmasses. Niwot Ridge is a mid continental site, but has a well established record for $\mathrm{CH}_{4}$ mixing ratios and its isotopes which has been compared with the coastal sites (e.g. Tyler et al., 2007). Comparisons of $\mathrm{CH}_{4}$ mixing ratios, its isotopes, and their seasonal trends between Cape Meares and Niwot Ridge are shown from Figures B.1 to Figure B. 6 in Appendix B.

\subsubsection{Atmospheric $\mathrm{CH}_{4}$ mixing ratio}

The data we include in the $\mathrm{CH}_{4}$ mixing ratio are five datasets. The first record is from the Cape Meares archive (1977-1999) and was measured at Portland state University during 2010 and 2011. Samples were measured on the National Institute of Standards and Technology (NIST) scale (SRM 1659a). The second time series used is from Olympic Peninsula, Washington from 1985 to 1990 and measured on the Climate Monitoring and Diagnostics Laboratory 1983 scale (CMDL83) from Quay et al. [1999]. The third time series is from Montaña de Oro, California from 1996 to 2005 and is also measured on the CMDL83 scale from Tyler et al. in 2007 [Tyler et al., 2007]. Niwot Ridge, Colorado data from 1994-2005 is also taken from Tyler et al. and measured on the CMDL83 scale [Tyler et al., 2007]. The final set is also from Niowt Ridge, Colorado 
measured by the National Oceanic and Atmospheric Administration (NOAA) and reported on the NOAA04 scale and covers 1983 to 2010 [Dlugokencky et al.,2012]. The relations between NIST and CMDL83 scales with respect to NOAA04 scale are defined [Dlugokencky et al.,2005] as follows

$\left[\mathrm{CH}_{4}\right](\mathrm{NOAA04}$ scale $)=1.0124 *\left[\mathrm{CH}_{4}\right](\mathrm{CMDL} 83$ scale $)$

$\left[\mathrm{CH}_{4}\right]($ NOAA04 scale $)=0.998 *\left[\mathrm{CH}_{4}\right](\mathrm{NIST}$ scale $)$

Figure 4.1(a) represents the atmospheric $\mathrm{CH}_{4}$ mixing ratio trend from 1977 to 2010 from Cape Measres, Olympic Peninsula, Montaña de Oro, and Niwot Ridge datasets after adjusting them to be on the NOAA04 scale using equations (4.1) and (4.2).

The next step is to adjust all of these measurements to remove the latitudinal dependence. This process was done by comparing the $\mathrm{CH}_{4}$ mixing ratio measured at each location with the Cape Meares (CM) dataset during the collected time period of overlap. For example, figure 4.1(a) shows marginally higher concentrations observed at Olympic Peninsula consistent with known latitudinal trend in $\mathrm{CH}_{4}$ [Quay et al.,1999]. For Olympic Peninsula (OP) a comparison with Cape Meares during period of overlap (April 1985 to May 1990) finds that:

$\left[\mathrm{CH}_{4}\right](\mathrm{CM})=\frac{\left[\mathrm{CH}_{4}\right](\mathrm{OP})}{1.0038}$

The same procedures were used to get the ratios for Montaña de Oro and Niwot Ridge. These ratios are 1.0135 and 1.001 for and Montaña de Oro and Niwot Ridge, respectively. Figure 4.1(b) represents the $\mathrm{CH}_{4}$ mixing ratio of the four locations after making the latitude independent based on the $45^{\circ} \mathrm{CM}$ site. 

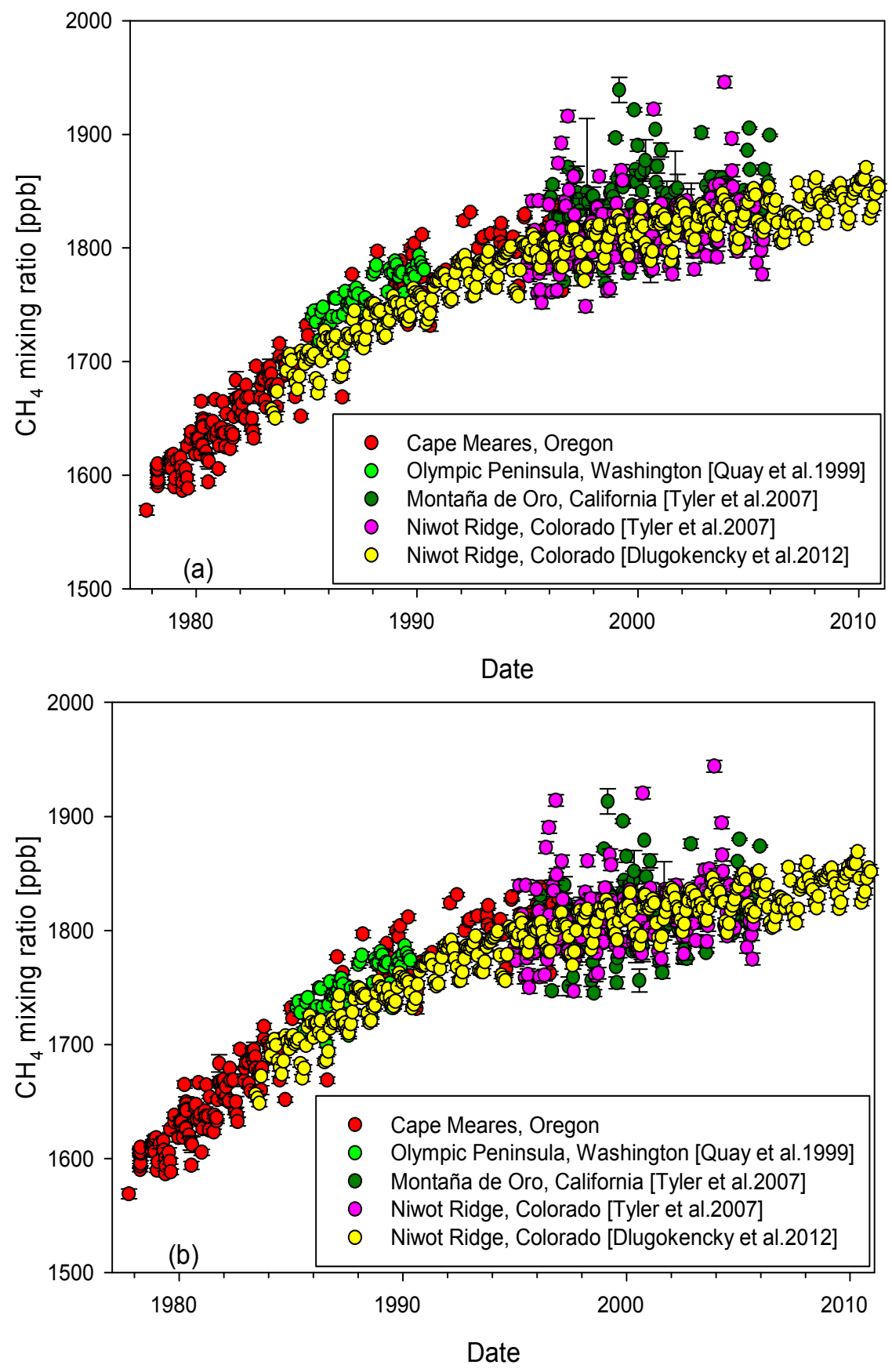

Figure 4.1 (a) atmospheric $\mathrm{CH}_{4}$ mixing ratios for mid-latitude Northern hemisphere sites (1977-2010) after adjusting them to NOAA04 scale. Error bars represent $\pm 1 \sigma$. (b) Atmospheric $\mathrm{CH}_{4}$ mixing ratios for midlatitude Northern hemisphere sites (1977-2010) after adjusting for the latitude of each dataset based on CM site. Error bars represent $\pm 1 \sigma$. 
The data set in figure 4.1(b) includes a long term trend which describes how the $\mathrm{CH}_{4}$ mixing ratio changes from 1977 to 2010 , seasonal trend which describes how the $\mathrm{CH}_{4}$ mixing ratio changes over one year from one season to another and inter-annual variability that spans one to several years. To isolate each trend, a smoothing technique based on LOWESS is used within the data analysis program MATLAB (2010a). This technique will be explained in section 4.2.

\subsubsection{Atmospheric $\delta^{13} \mathrm{C}-\mathrm{CH}_{4}$}

The data included in the composite record $\delta^{13} \mathrm{C}$ of atmospheric $\mathrm{CH}_{4}$ is from the same sites as our composite $\mathrm{CH}_{4}$ mixing ratio record from same locations. The first is from the Cape Meares (CM) archive was measured at Portland State University during 2009 to 2011 and described in section 3.2. The samples are from 1977 to 1999 . The second dataset is from Olympic Peninsula (OP), Washington from 1988 to 1996 [Quay et al., 1999]. The third dataset is from Montaña de Oro (MDO), California and spans 1996 to 2005 [Tyler et al., 2007]. Niwot Ridge (NWR), Colorado data from 1994-2005 is also taken from Tyler et al. [2007] .The final dataset is from to Niowt Ridge, Colorado and covers 1998 to 2010 [White and Vaughn, 2011]. All of these measurements were reported relative to Vienna Peedee Belemnite (VPDB). The measurements from CM, MDO and NWR are calibrated relative to the Tyler $\mathrm{CH}_{4}$ isotope scale (see e.g. Tyler et al., 2007). The difference between this scale and Quay et al. [1999] scale was not statistically significant based on the t-test on data for Samoa and Mauna Loa combined p-value is 0.07 [see sections 3.6.2 and 3.6.3]. 
Figure 4.2(a) represents the $\delta^{13} \mathrm{C}$ record of atmospheric $\mathrm{CH}_{4}$ from October 1977 to December 2010 from these datasets. To remove the dependence of the $\delta^{13} \mathrm{C}$ datasets on latitude and site, we compared the intersecting time periods between Cape Meares and each location separately. For Olympic Peninsula, the comparison extends from 1988 to 1995. To convert measurements from Olympic Peninsula to the Cape Meares latitude, a factor of $0.02 \%$ was added to Olympic Peninsula measurements. For Montaña de Oro and Niwot Ridge, the factors were $-0.02 \%$ and $-0.12 \%$, respectively.

Figure 4.2(b) represents the $\delta^{13} \mathrm{C}$ record shown in figure 4.2(a) after adjusting the datasets for latitude independence. The datasets in figure 4.2(b) will be used later to get the seasonal cycle, secular trend and inter-annual variability of $\delta^{13} \mathrm{C}$. 

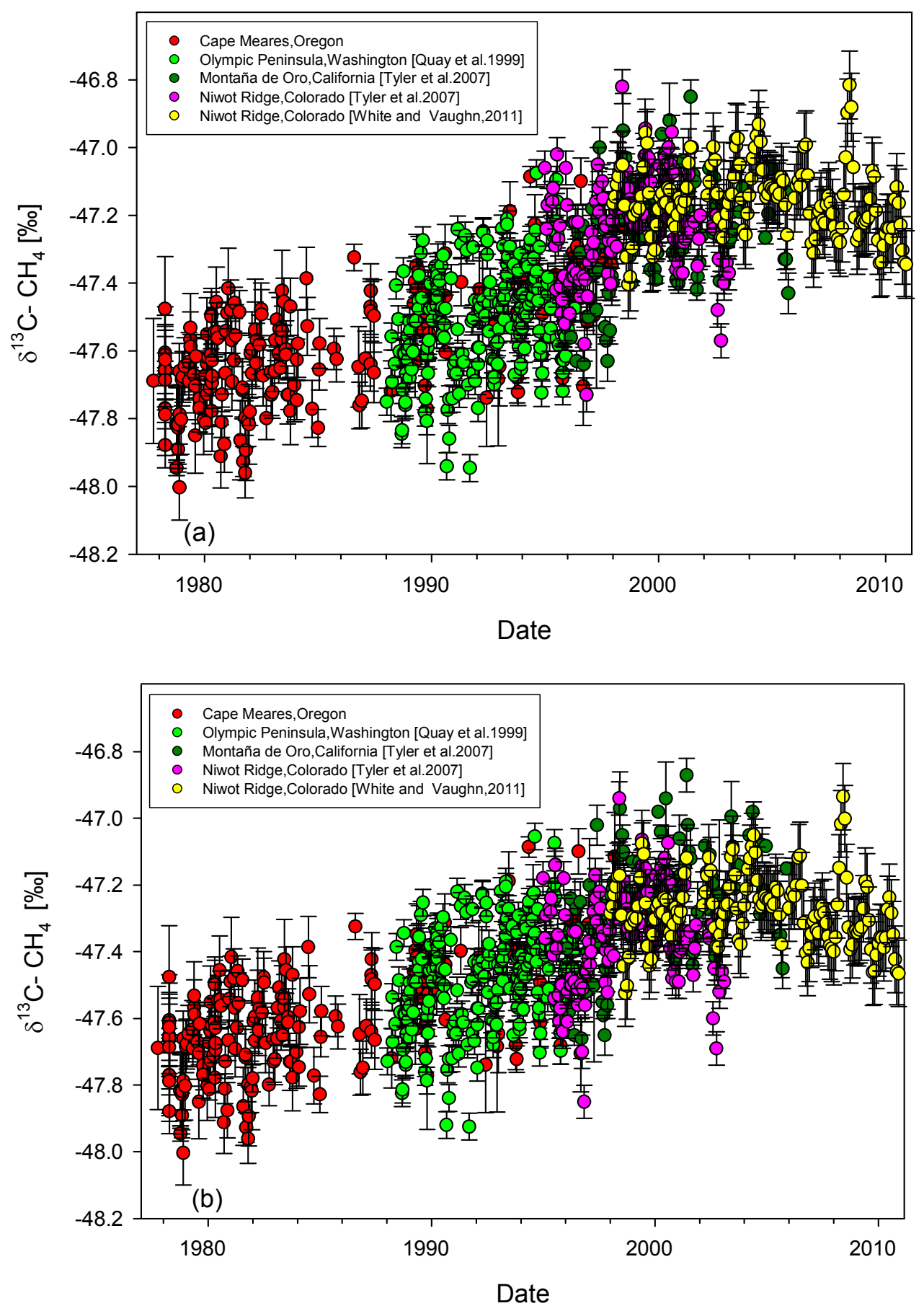

Figure 4.2 (a) $\delta^{13} \mathrm{C}$ record of atmospheric $\mathrm{CH}_{4}$ from datasets in the Northern hemisphere mid-latitudes (1977-2010). All of the results are reported relative to VPDB. Errors bars represent $\pm 1 \sigma$. (b) $\delta^{13} \mathrm{C}$ record of atmospheric $\mathrm{CH}_{4}$ from datasets in the Northern hemisphere mid-latitudes (1977-2010) after adjusting the latitude of each dataset based on the $\mathrm{CM}$ site. 


\subsubsection{Atmospheric $\delta \mathrm{D}-\mathrm{CH}_{4}$}

There is considerably less $\delta \mathrm{D}$ of atmospheric $\mathrm{CH}_{4}$ data to use in this composite dataset. Here, we use: $\delta \mathrm{D}$ data from Cape Meares archive measurements which extend from 1977 to 1999; $\delta \mathrm{D}$ data from Montaña de Oro, California from 2000 to 2005 from Tyler et al. [2007]; and $\delta \mathrm{D}$ data from Niwot Ridge, Colorado is from 1998-2005 also taken from Tyler et al. [2007]. No data is available from Olympic Peninsula and from the NOAA record. Calibration of each of these sites is on the Tyler $\mathrm{CH}_{4}$ isotope scale so few inter-calibration issues are assumed to exist. All of these measurements were reported relative to Vienna Standard Mean Ocean Water (VSMOW).

Figure 4.3(a) represents the $\delta \mathrm{D}$ record of atmospheric $\mathrm{CH}_{4}$ from October 1977 to

December 2005 from these datasets. As with $\delta^{13} \mathrm{C}$ and $\mathrm{CH}_{4}$ mixing ratio, to remove the dependence of the datasets in latitude we compared the intersection time period between Cape Meares and each location separately. For Niwot Ridge, the comparison was from 1998 to 1999 and to convert these measurements from the Niwot Ridge site to the Cape Meares site, a factor of $-0.408 \%$ is added to Niwot Ridge measurements. For Montaña de Oro (MDO), there is no time intersected with Cape Meares therefore a comparison with Niwot Ridge is made and then data is converted to the Cape Meares latitude. The resulting conversion factor between $\mathrm{MDO}$ and $\mathrm{CM}$ was $1.28 \%$. Figure 4.3(b) represents the $\delta \mathrm{D}$ record after adjusting the datasets for latitude and site independence. 

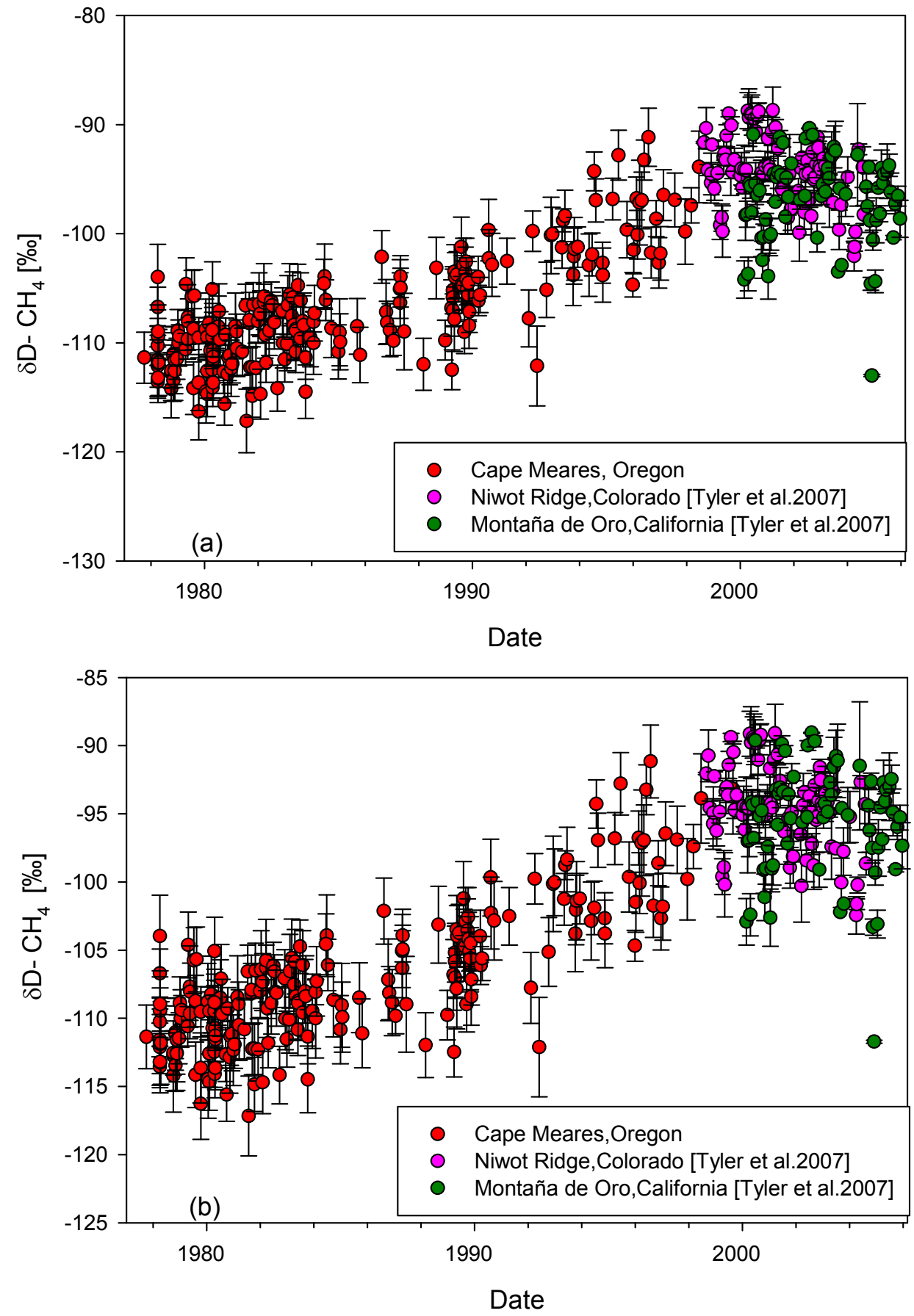

Figure 4.3 (a) $\delta \mathrm{D}$ record of atmospheric $\mathrm{CH}_{4}$ from datasets in the Northern hemisphere mid-latitudes (19772005). All of the results are reported relative to VSMOW. Errors bars represent $\pm 1 \sigma$. (b) $\delta \mathrm{D}$ record of atmospheric $\mathrm{CH}_{4}$ from datasets in the Northern hemisphere mid-latitudes (1977-2005) after adjusting both datasets based on CM site. 


\subsection{Statistical Methods}

To get the seasonal, secular, and inter-annual trends and their uncertainty, LOWESS and Bootstrap techniques are used. This section describes in some detail how these methods are applied to our analyses.

\subsubsection{LOWESS}

In 1988, Cleveland and Devlin introduced a procedure for fitting a regression surface to data through multivariate smoothing based on locally weighted regression (LOWESS) [Cleveland and Devlin, 1988]. In case of the datasets used here, we define the collected date (the independent variable) as $\mathrm{x}_{\mathrm{i}}$ and the corresponding variable as $\mathrm{y}_{\mathrm{i}}$ for $\mathrm{i}=1$ to $\mathrm{n}$, where $\mathrm{n}$ is the number of measurements. LOWESS regression curve, $\hat{g}(\mathrm{x})$, is a smoothing of $y$ at a given $x$. The estimation of $\hat{g}$ at $x$ uses the $q$ measurements, where $q$ is an integer where $1 \leq \mathrm{q} \leq \mathrm{n}$, whose $\mathrm{x}_{\mathrm{i}}$ values are closest to $\mathrm{x}$. Therefore, a neighborhood in the space of the independent variables $y_{i}$ is defined according to the weighting of each point. Points close to $\mathrm{x}$ have large weight while far points have smaller weight.

The weight function is defined as a tri-cube function [Cleveland et al.1990]

$$
W(u)=\left[\begin{array}{cl}
\left(1-u^{3}\right)^{3} & \text { for } 0 \leq u \leq 1 \\
0 & \text { for } u \geq 1
\end{array}\right.
$$

The weight for any measurement $\mathrm{x}_{\mathrm{i}}$ will be defined as

$$
\mathrm{w}_{\mathrm{i}}(\mathrm{x})=\mathrm{W}\left(\frac{\left|\mathrm{x}_{\mathrm{i}}-\mathrm{x}\right|}{\lambda_{\mathrm{q}}(\mathrm{x})}\right)
$$


where $\lambda_{q}(\mathrm{x})$ is the distance of the qth farthest $\mathrm{x}_{\mathrm{i}}$ from $\mathrm{x}$.

If the fitted function for the observations $\mathrm{x}_{\mathrm{i}}$ and $\mathrm{y}_{\mathrm{i}}$ is linear and defined as

$y=a+b x$

where $a$ is the intercept and $b$ is the slope of regression. In case of weighted least square in LOWESS, it does two jobs:

1- Determining these parameters by minimize the sum of squares between the observed and predicted

2- Weighting each observed point according to how it is far or close from the predicted value

These could be written as

$\mathrm{E}_{\mathrm{w}}=\sum_{\mathrm{i}} \mathrm{w}_{\mathrm{i}}\left(\mathrm{y}_{\mathrm{i}}-\mathrm{y}\right)^{2}=\sum_{\mathrm{i}} \mathrm{w}_{\mathrm{i}}\left[\left(\mathrm{y}_{\mathrm{i}}-\left(\mathrm{a}+\mathrm{bx}_{\mathrm{i}}\right)\right]^{2}\right.$

where $\mathrm{w}_{\mathrm{i}}$ is defined in equation 4.5 .

Therefore, $w_{i}(x)$ has a maximum weight for $x_{i}$ close to $x$ and decrease as $x_{i}$ far away from $\mathrm{x}$. The weight of any measurement $\mathrm{w}_{\mathrm{i}}(\mathrm{x})$ becomes 0 at the qth farthest point. Instead of $\mathrm{q}$, the number of points in the neighborhood, the fraction of points in the neighborhood $q / n$ is used. In MATLAB, $q / n$ is defined as a span, which in some versions define $q / n$ as a percentage (\%) and in others (as the one used in our calculations R2010a) define $q / n$ as a fraction that varies from 0 to 1 . As the span increases, the 
smoothing surface $\hat{\mathrm{g}}(\mathrm{x})$ becomes smoother. Reducing the span, however, makes the smoothing surface follow the data more closely and the hence amplifying data variability.

LOWESS is initially used in the current calculations to estimate the seasonal cycles of $\mathrm{CH}_{4}$ mixing ratio and its isotopes $\left(\delta^{13} \mathrm{C}\right.$ and $\left.\delta \mathrm{D}\right)$ by choosing a wide span. Therefore, the resulting datasets describe the trend of these variables without seasonality. The fitted values of LOWESS are given for each point in the datasets. The residuals of the measurements are calculated by subtracting the fitted value (resulting from LOWESS) from the measured ones. The averages of the residuals, their standard deviations, and their standard errors are calculated based on the month of collection to obtain the seasonal cycles in $\mathrm{CH}_{4}, \delta^{13} \mathrm{C}$, and $\delta \mathrm{D}$ (as discussed in section 4.3). Subsequently, after removing the seasonal trend LOWESS is again used with a smaller span to get the secular trend and interannual variability (as discussed in section 4.4).

\subsubsection{Bootstrap}

Bootstrap is one of the two techniques used in the analysis of the composite dataset for the $\mathrm{CH}_{4}$ mixing ratio, $\delta^{13} \mathrm{C}$, and $\delta \mathrm{D}$. In 1979, Erfon introduced the Bootstrap method [Efron, 1979]. Bootstrap is a method for estimating the sampling distribution of an estimator by re-sampling with replacement from the original sample [Diaconis and Erfon, 1983]. This can be done by creating an artificial list by randomly picking up elements from the original dataset. Some elements may be chosen more than once. This artificial list can be repeated for many times. Additionally, the mean, standard deviation, standard error, and confidence interval can be calculated from the distribution. Therefore, 
Bootstrap is a good method to get information about the distribution of a sample when the sample size is small or the distribution of the sample can't be described trivially.

Bootstrapping has been used to calculate the uncertainty of the $\mathrm{CH}_{4}$ growth rate over long time period since 1992 (e.g. Steele et al., 1992; Dlugokencky et. 1994; 2001; 2009; and 2011).

In our analysis, Bootstrap is used after LOWESS to calculate statistical parameters such as the standard deviation, standard error, median, and others for the distribution of each variable as described later.

\section{3. $\mathrm{CH}_{4}, \delta^{13} \mathrm{C}$, and $\delta \mathrm{D}$ Seasonal Cycles of $\mathrm{CH}_{4}$ of the composite datasets}

Initially, in order to look at the seasonality of $\mathrm{CH}_{4}$ and its isotopes $\left(\delta^{13} \mathrm{C}\right.$ and $\left.\delta \mathrm{D}\right)$, we use LOWESS to smooth data set with a wide span of 0.3 in the case of $\mathrm{CH}_{4}$ mixing ratio and $\delta^{13} \mathrm{C}$ and 0.34 in the case of $\delta \mathrm{D}$ (due to the shorter dataset).

In case of $\mathrm{CH}_{4}$ mixing ratio of the composite dataset for mid-latitude sites, the total number of points is 883 from 1977 to 2010 . Using span=0.3 in LOWESS smoothing method for this dataset means each smoothing region has $30 \%$ of the whole dataset. This presents 265 points in each region and covers a window $8.25 \pm 3$ years.

In case of $\delta^{13} \mathrm{C}$ of atmospheric $\mathrm{CH}_{4}$ from the composite dataset for mid-latitude sites, there are 815 points from 1977 to 2010 . Applying a LOWESS smoothing method with span $=0.3$ means the local regression is done for regions along the dataset. Each region contains 245 points and covers a window $8.3 \pm 3.7$ years. 
Since the measurements of $\delta \mathrm{D}$ of atmospheric $\mathrm{CH}_{4}$ stopped in 2005 and less data is available, there are 359 points included during 1977-2005. Running a LOWESS smoothing method with a span $=0.34$ means the regression is done through the whole datasets by dividing them into regions and each region includes 122 points and covers a window of time $9 \pm 4.32$ years.

The localized regression is estimated based on the method explained in section 4.2.1. Using MATLAB (version 7.10.0 R2010a), a predicted value for each measurement in the datasets is produced from LOWESS smoothing. The seasonal cycle for each variable is obtained by:

1) Calculating the residual of each point by getting the difference between the measured and predicted values

2) Organizing the residual according to the month of collection, regardless the year of collection

3) Calculating the average, standard deviation, and standard error of the residual over the month of collection

\subsubsection{Atmospheric $\mathrm{CH}_{4}$ seasonal cycle for the composite Northern hemisphere dataset}

The $\mathrm{CH}_{4}$ mixing ratio seasonal cycle based on steps $1-3$ in section 4.3 is represented in figure 4.4. It shows that the $\mathrm{CH}_{4}$ mixing ratio has a broad maximum value (10 ppb) from October to April. It starts to decrease after April and reaches to the lowest value (-23.6 ppb) between July and August. It rapidly rises again in August. Peak to peak 
amplitude is $34 \mathrm{ppb}$. Tabulated values of residual of $\mathrm{CH}_{4}$ shown in figure 4.4 are in table A.10 in Appendix A.

The $\mathrm{CH}_{4}$ seasonal cycles of composite datasets for the mid-latitudes in figure 4.4 and of Cape Meares in figure 3.2 have the same phase and close minimum and maximum amplitudes. In the case of Cape Meares, the seasonal cycle is similar with the maximum amplitude of $\mathrm{CH}_{4}$ mixing ratio occurring in March (8.5 ppb) and its minimum amplitude (-24.8 ppb) occurring in late of July. The peak to peak amplitude is $33 \mathrm{ppb}$.

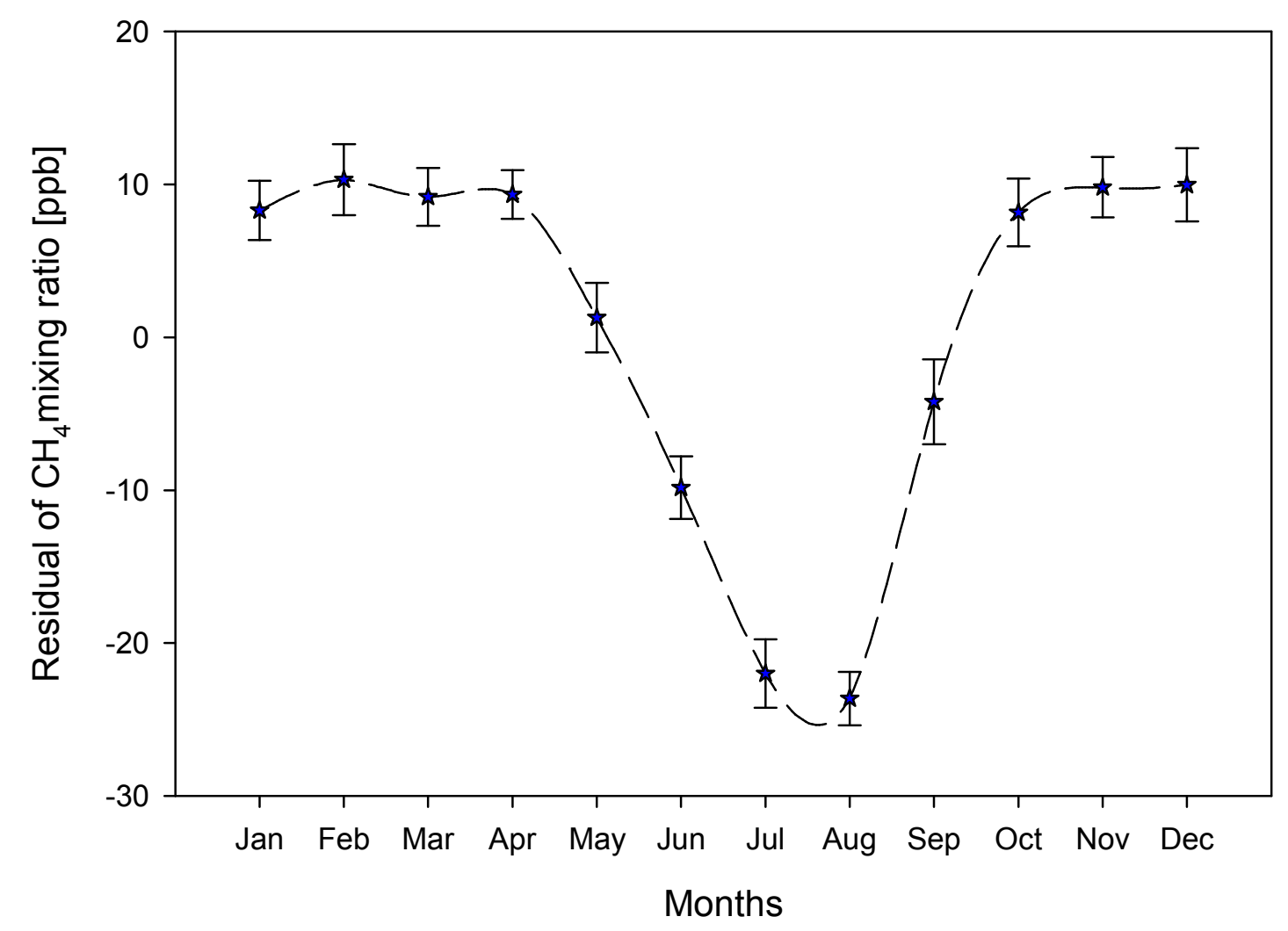

Figure 4.4 Seasonal trend of $\mathrm{CH}_{4}$ mixing ratio from datasets in the Northern hemisphere mid-latitudes (1977-2010) from data in figure 4.1(b). Error bars represent \pm one standard error. 


\subsubsection{Atmospheric $\delta^{13} \mathrm{C}-\mathrm{CH}_{4}$ seasonal cycle for the composite Northern hemisphere dataset}

The seasonal cycle in $\delta^{13} \mathrm{C}$ of atmospheric $\mathrm{CH}_{4}$ based on steps 1-3 in section 4.3 is represented in figure 4.5. This figure shows that the $\delta^{13} \mathrm{C}$ of atmospheric $\mathrm{CH}_{4}$ gradually increases in the atmosphere and reaches its highest level by June $(\sim 0.12 \%$ o). It decreases after June and reaches the most depleted values during September and October ( 0.12\%o). After October, it again increases through the end of year. Peak to peak amplitude is $0.24 \%$ o. $\delta^{13} \mathrm{C}$ seasonal values from figure 4.5 appear in table A.11 in Appendix A. The $\delta^{13} \mathrm{C}$ seasonal cycle resulting from the composite datasets in the mid-latitude sites has the same phase as $\delta^{13} \mathrm{C}$ seasonal cycle observed at Cape in figure 3.10 and close maximum (0.1\%o during June), minimum (-0.12\%o during October), and peak-to-peak seasonal amplitude (0.22\%o). 


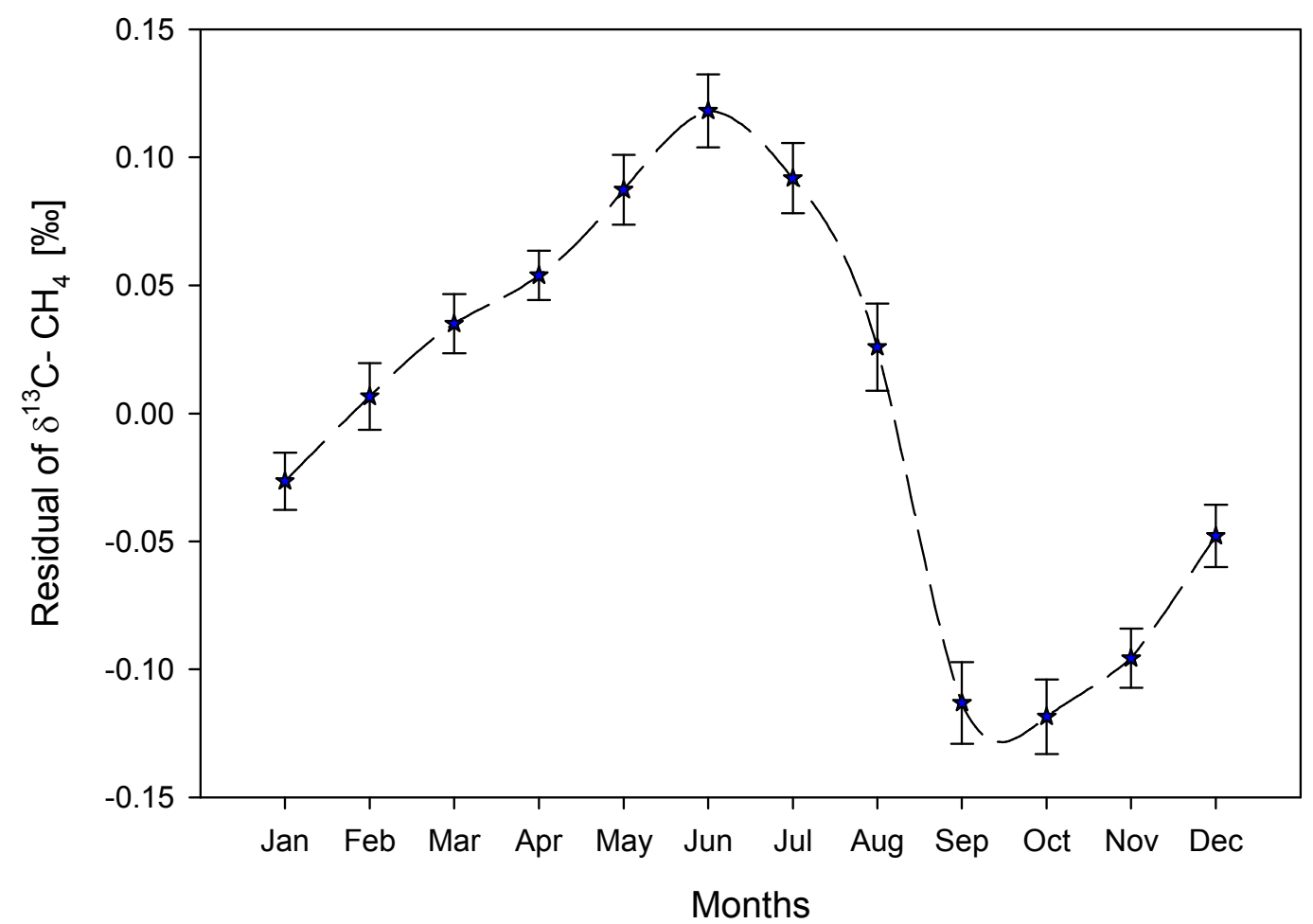

Figure $4.5 \delta^{13} \mathrm{C}$ seasonal trend from datasets in the Northern hemisphere mid-latitudes (1977-2010) from data in figure 4.2(b). Error bars represent \pm one standard error.

\subsubsection{Atmospheric $\delta \mathrm{D}-\mathrm{CH}_{4}$ seasonal cycle for the composite Northern hemisphere dataset}

The seasonal cycle in $\delta \mathrm{D}$ of atmospheric $\mathrm{CH}_{4}$ is shown in figure 4.6. Beginning in February, $\delta \mathrm{D}$ increases in the atmosphere gradually and reaches to the highest level around July with a value of $2.3 \%$ as shown in figure 4.6 . After July, it becomes depleted and reaches its lowest level November with a value of $-1.5 \%$. $\delta \mathrm{D}$ is approximately constant during October-November. Peak to peak amplitude of the seasonal cycle is 3.9\%. Table A.12 in Appendix A gives tabular $\delta \mathrm{D}$ seasonal values represented in figure 4.6. From figure 3.12 , the seasonal cycle of $\delta \mathrm{D}$ observed at Cape Meares has the same 
phase as the seasonal cycle from the composite datasets with a maximum value of $2.4 \%$ o during July, a minimum value of $-1.6 \%$ during November, and peak-to-peak seasonal amplitude of 4\%o. Table A.12 in Appendix A gives tabular $\delta \mathrm{D}$ seasonal values represented in figure 4.6 .

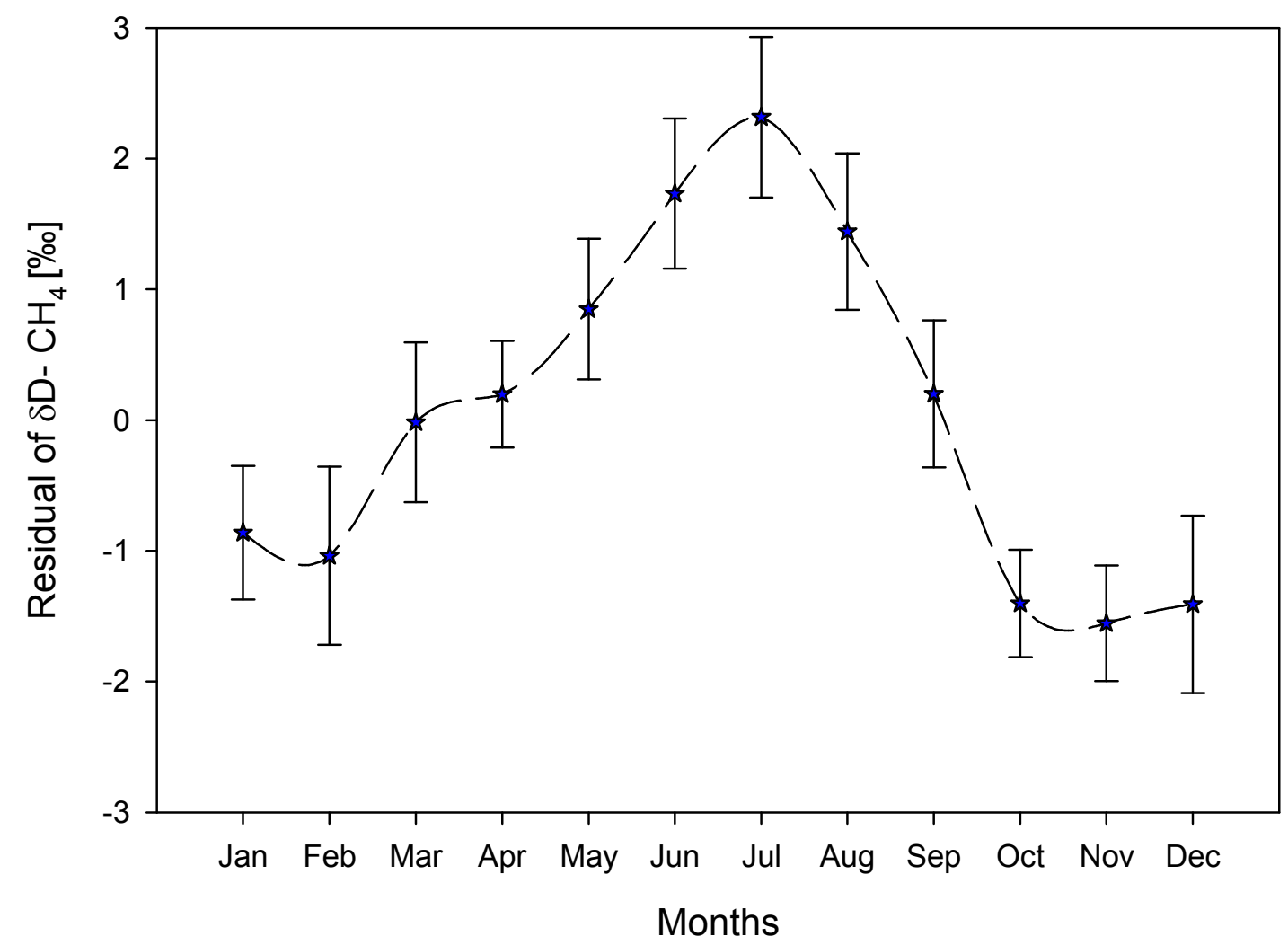

Figure 4.6 $\delta \mathrm{D}$ seasonal trend from datasets in the Northern hemisphere mid-latitudes (1977-2005) from data in figure 4.3(b). Error bars represent \pm one standard error.

\subsubsection{Discussion of seasonal cycles of $\mathrm{CH}_{4}$ mixing ratio, $\delta^{13} \mathrm{C}$ and $\delta \mathrm{D}$ for the composite mid-latitude datasets}

The seasonal cycles of $\mathrm{CH}_{4}$ mixing ratio, $\delta^{13} \mathrm{C}$, and $\delta \mathrm{D}$ from the composite dataset for the mid-latitude sites in the Northern hemisphere (as shown in figure 4.7) are very 
similar to the seasonal cycles of $\mathrm{CH}_{4}$ mixing ratio, $\delta^{13} \mathrm{C}$, and $\delta \mathrm{D}$ of the Cape Meares air archive samples (as represented in figure 3.13 and discussed in section 3.4).

The following two questions are addressed in this discussion are

1) How does $\mathrm{CH}_{4}$ seasonal cycle relate to the seasonal cycles of $\delta^{13} \mathrm{C}$ and $\delta \mathrm{D}$ ?

2) How do sinks and /or sources control the seasonal cycles of $\mathrm{CH}_{4}, \delta^{13} \mathrm{C}$, and $\delta \mathrm{D}$ ?

Figure 4.7 shows the behavior of $\mathrm{CH}_{4}$ and its isotopic species together, with enriched values occurring during periods where $\mathrm{CH}_{4}$ is lower in the atmosphere. The most enriched values in $\delta^{13} \mathrm{C}$ and $\delta \mathrm{D}$ occur in June and July, respectively and the lowest $\mathrm{CH}_{4}$ mixing ratio through the year occurs during July and August. The $\mathrm{CH}_{4}$ seasonal cycle is better correlated with the $\delta \mathrm{D}$ seasonal cycle than the $\delta^{13} \mathrm{C}$ seasonal cycle.

The changing of sources and sinks of atmospheric $\mathrm{CH}_{4}$ during the seasons causes the changes of $\delta^{13} \mathrm{C}$ and $\delta \mathrm{D}$ seasonal cycles. To understand how the sources and sinks control the seasonal cycles of $\mathrm{CH}_{4}, \delta^{13} \mathrm{C}$, and $\delta \mathrm{D}$, we examine correlation between $\mathrm{CH}_{4}$ and its isotopic species. The relation between the residual of $\mathrm{CH}_{4}$ mixing ratio with the residual of $\delta^{13} \mathrm{C}$ is represented in figure 4.8(a). This figure includes 581 points for $\mathrm{CM}$, MDO and NWR from Tyler et al. [2007] and NOAA data. The slope, corresponding to these points, is $(-0.0019 \pm 0.0002) \% \mathrm{p} / \mathrm{ppb}$ and has a correlation $\mathrm{r}^{2}=0.11$. 

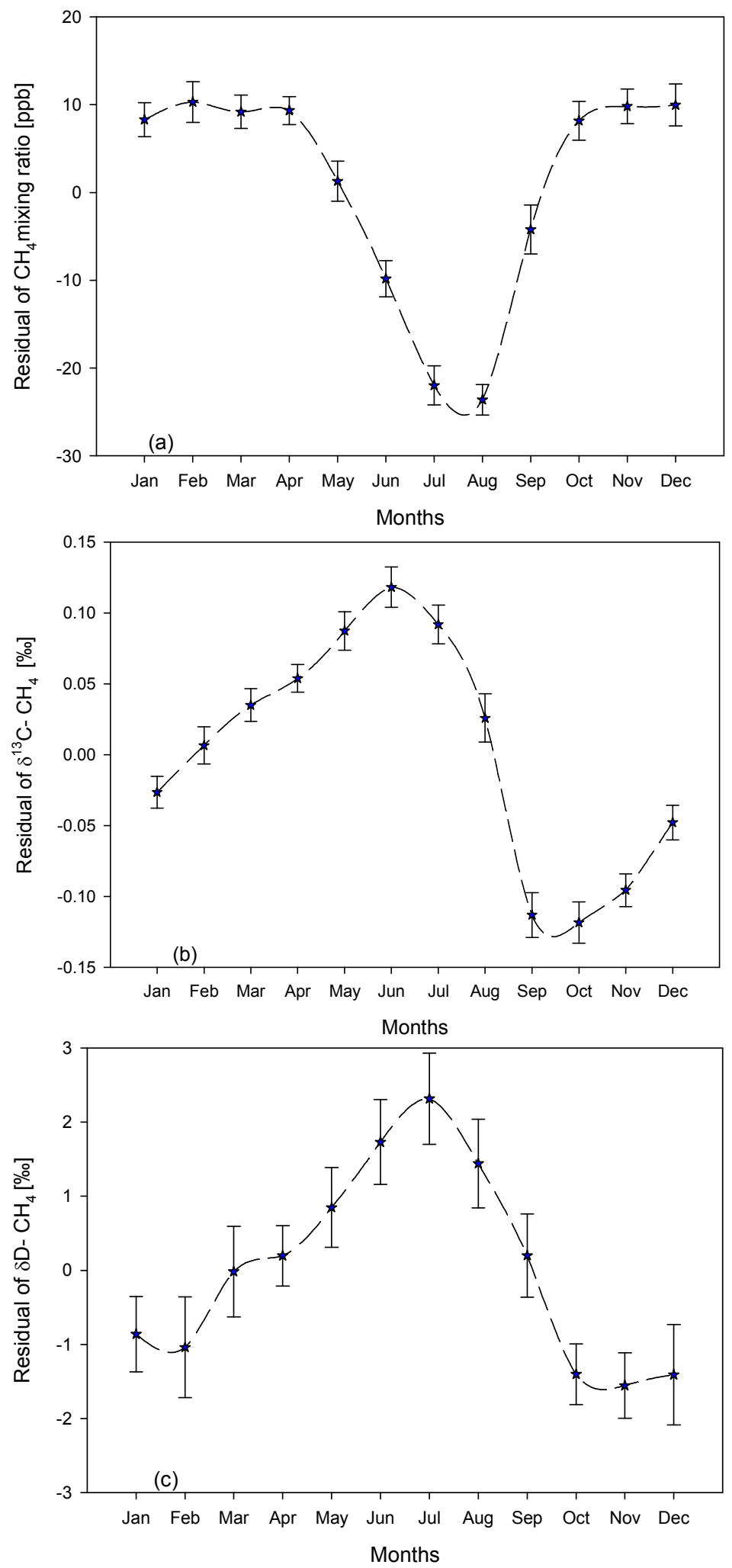

Figure 4.7 Seasonal cycles of (a) atmospheric $\mathrm{CH}_{4}$ mixing ratio,(b) $\delta^{13} \mathrm{C}$, and (c) $\delta \mathrm{D}$ from mid-latitude sites in the Northern hemisphere. Error bars represent \pm 1 standard error. 
The relation between the residual of $\mathrm{CH}_{4}$ mixing ratio with the residual of $\delta \mathrm{D}$ is represented in figure 4.8(b). This figure includes 347 points belong to CM, MDO and NWR from Tyler et al. [2007]. The slope, corresponding to these points, is ($0.086 \pm 0.0061) \% / \mathrm{ppb}$ and has a correlation coefficient $\mathrm{r}^{2}=0.36$. Therefore, $\delta \mathrm{D}$ has a stronger anti-correlation with $\mathrm{CH}_{4}$ mixing ratio than $\delta^{13} \mathrm{C}$.

Calculating mean atmospheric the KIE based on the mean of $\mathrm{CH}_{4}, \delta^{13} \mathrm{C}$, and $\delta \mathrm{D}$ in 2000 which are $1810 \mathrm{ppb},-47.25 \%$, and $-94.6 \%$, respectively gives ${ }^{13 \mathrm{C}} \alpha$ and ${ }^{\mathrm{D}} \alpha$ of $1.0036 \pm 0.0004$ and $1.21 \pm 0.02$, respectively. The \pm values are the KIE standard errors with a confidence interval $95 \%$. The calculated KIE values are lower than the values obtained for MDO and NWR by Tyler et al. [Tyler et al., 2007].

The change of the seasonal value of $\mathrm{CH}_{4}$ mixing ratio with that of its isotopes forms an ellipse as described in section 3.4. The more the seasonal change of the sources, the more eccentric the ellipse [Bergamaschi et al. 2000; and Allen et al., 2001; Tyler et al. 2007].

The comparison between the slope from the whole composite dataset with each set individually is shown in figure 4.9(a). Although NOAA began measurements of $\mathrm{CH}_{4}$ mixing ratio in $1983, \delta^{13} \mathrm{C}-\mathrm{CH}_{4}$ did not start until 1998. Therefore the data at NWR from NOAA represents the measurements during 1998-2010. Both slopes in figure 4.9(a), for CM and NWR (NOAA data), are very close in their values $\left(\mathrm{S}_{\mathrm{CM}}=-0.0033, \mathrm{~S}_{\mathrm{NWR}}=-0.0030\right)$. The carbon isotope effect at NWR (NOAA data) ${ }^{13 \mathrm{C}} \alpha$ is $1.0057 \pm 0.001$. Values of ${ }^{13 \mathrm{C}} \alpha$ from MDO and NWR (from Tyler et al., figure 4.9(a)) are lower $1.0025 \pm 0.008$ and $1.0026 \pm 0.009$, respectively 

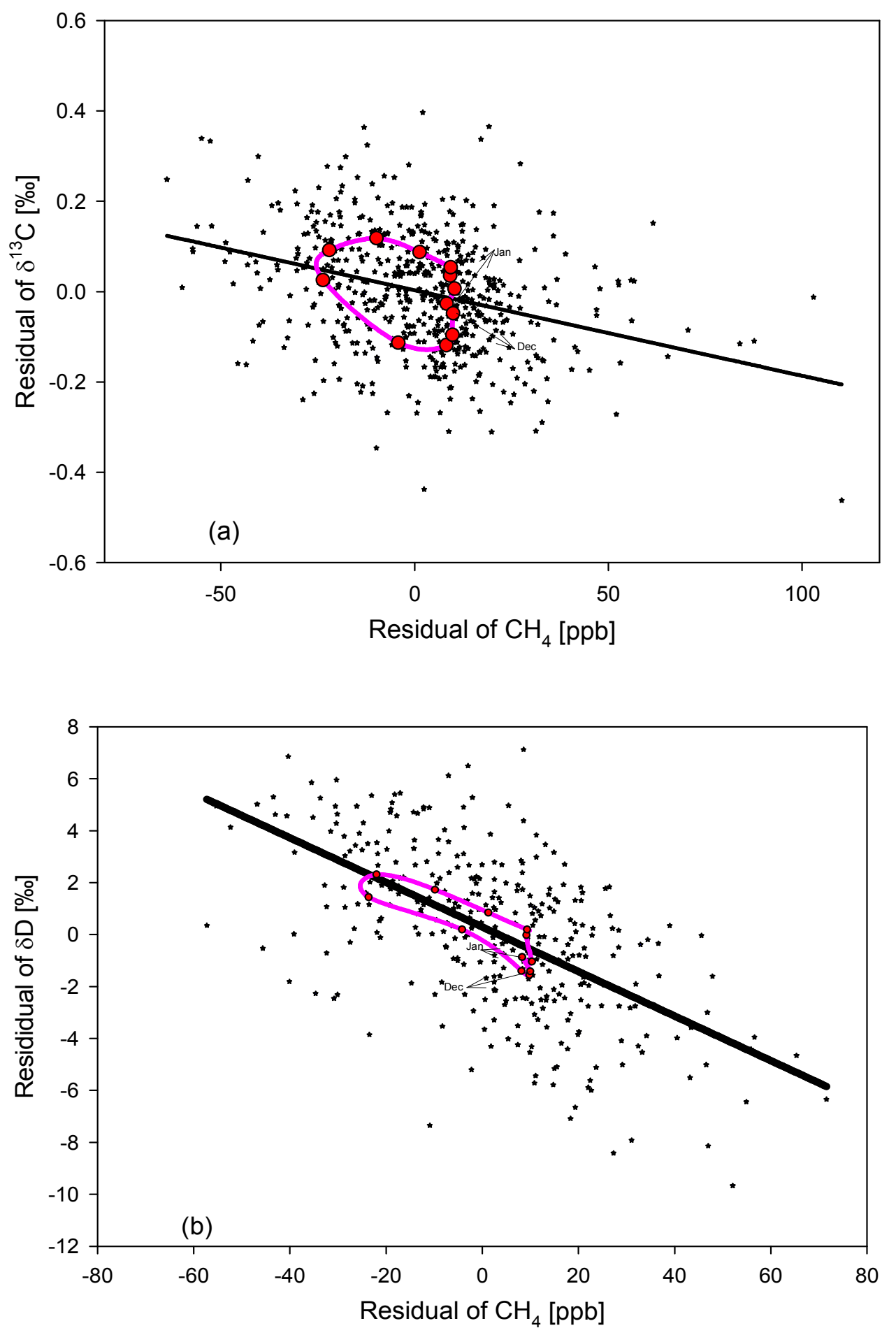

Figure 4.8 Phase ellipse for the composite datasets, made by plotting (a) residual of $\delta^{13} \mathrm{C}^{-\mathrm{CH}_{4}}$ versus residual of $\mathrm{CH}_{4}$ mixing ratio and (b) residual $\delta \mathrm{D}-\mathrm{CH}_{4}$ versus residual $\mathrm{CH}_{4}$ mixing ratio. The black stars are mean monthly residual values of $\mathrm{CH}_{4}, \delta^{13} \mathrm{C}$, and $\delta \mathrm{D}$. The results of KIE of both ${ }^{13 \mathrm{C}} \alpha$ and ${ }^{\mathrm{D}} \alpha_{\mathrm{j}}$ are $1.0036 \pm 0.0004$ and $1.21 \pm 0.02$, respectively 

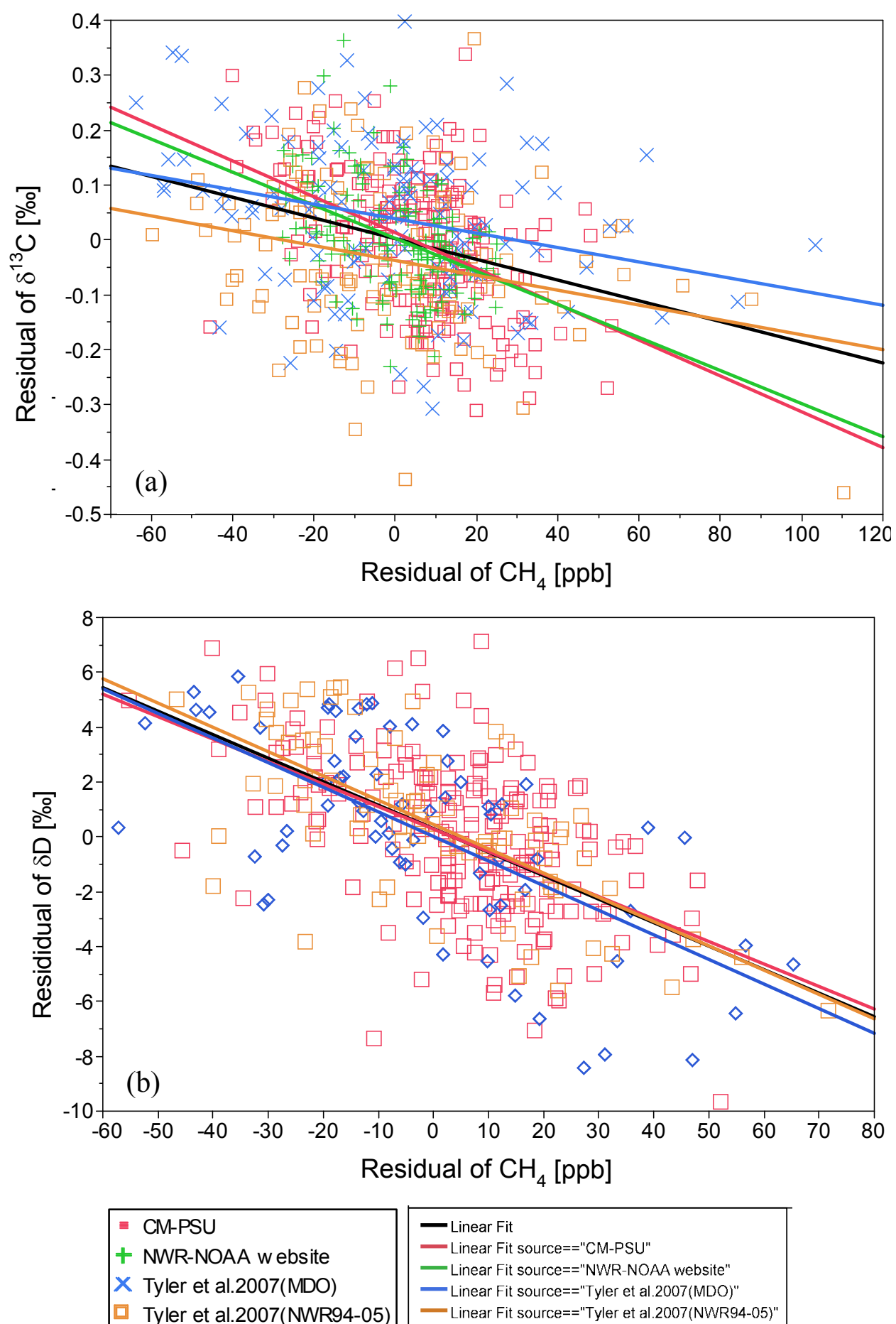

Figure 4.9 (a) Residual of $\delta^{13} \mathrm{C}_{-} \mathrm{CH}_{4}$ versus residual of $\mathrm{CH}_{4}$ mixing ratio as in figure 4.8(a) but with datasets individually and aggregated. (b) Residual of $\delta \mathrm{D}-\mathrm{CH}_{4}$ versus residual of $\mathrm{CH}_{4}$ mixing ratio as in figure $4.8(\mathrm{~b})$ with datasets individually and aggregated. 
In the case of $\delta \mathrm{D}$, the composite dataset has the same slopes from each individual site as represented in figure 4.9(b). Values of $\mathrm{D}_{\alpha}$ from MDO and NWR are $1.22 \pm 0.041 .22 \pm 0.03$, respectively, in agreement with CM.

Overall, this data is describing a significant enriched source of $\mathrm{CH}_{4}$ (such as biomass burning) causes increase of $\delta^{13} \mathrm{C}$ and $\delta \mathrm{D}$ of atmospheric $\mathrm{CH}_{4}$ during JanuaryMay. Depleted sources (such as microbial) cause a decrease in $\delta^{13} \mathrm{C}$ and $\delta \mathrm{D}$ during August-October (as discussed for Cape Meares in section 3.4).

\subsection{The secular trend and interannual variability in the composite dataset for $\mathrm{CH}_{4}$, $\delta^{13} \mathrm{C}$, and $\delta \mathrm{D}$}

After removing the latitude dependence in the composite data, the seasonality is removed from all trends. This step is accomplished by subtracting the average monthly residual of that variable during the month of collection from the measured value. For example, the equation (4.8) is used to deseasonalize the $\mathrm{CH}_{4}$ data

$\left[\mathrm{CH}_{4}\right]_{\text {desasonlized }}=\left[\mathrm{CH}_{4}\right]_{\text {measured }}-\left[\mathrm{CH}_{4}\right]_{\text {monthly residual }}$

where $\left[\mathrm{CH}_{4}\right]_{\text {measured }}$ is the value of $\mathrm{CH}_{4}$ defined by figure $4.1(\mathrm{~b})$ and $\left[\mathrm{CH}_{4}\right]_{\text {monthly residual }}$ is the value of the average residual based on month defined by figure 4.4.

Equation (4.8) is also used to deseasonalize the $\delta^{13} \mathrm{C}$ as well as $\delta \mathrm{D}$. Figure 4.10 represents the composite data of $\mathrm{CH}_{4}, \delta^{13} \mathrm{C}$, and $\delta \mathrm{D}$, respectively before and after removing the seasonal trends. The variables become more tightly distributed after removing the seasonality. 
After removing the latitude dependence and seasonal variability from the composite dataset as we discussed in section 4.1 and here, we describe the longer trends in measured variables change using LOWESS. The smoothing windows of time (span) chosen for these analysis were 3, 4, and 5 years. The reasons for choosing these windows of time are:

1) to reduce the effect of the noise through the datasets on observed trends

2) to describing both the secular trend and interannaul variability over the time period.

In case of $\mathrm{CH}_{4}$ and $\delta^{13} \mathrm{C}$, these windows of time period 3,4 , and 5 years are equivalent to spans $0.09,0.12$, and 0.15 , respectively. They are equivalent to spans 0.10 , 0.14 , and 0.17 , respectively for $\delta \mathrm{D}$ due to the shorter time period.

The smoothed data here are then bootstrapped. Bootstrap method, as explained in section 4.2.2., is used to calculate the uncertainty (standard deviation) and other statistical parameters of the distribution of each variable. The smoothed data and its uncertainty are then fit with a smoothing spine fit in MATLAB, to describe the resulting trends with regularly spaced points $1978-2010$. In case of $\delta D$, the resulting trend is $1978-2005$. This fitted function is then differentiated with respect to time to obtain a time rate of change. Using the Bootstrap technique with the same span we used for LOWESS, the averages and standard deviations of the smoothed data and time rate of change are calculated. The average yearly values for the 3 variables $\left(\mathrm{CH}_{4}, \delta^{13} \mathrm{C}, \delta \mathrm{D}\right)$ and their time rates of change are also calculated. We calculate an average annual value about mid-year. 

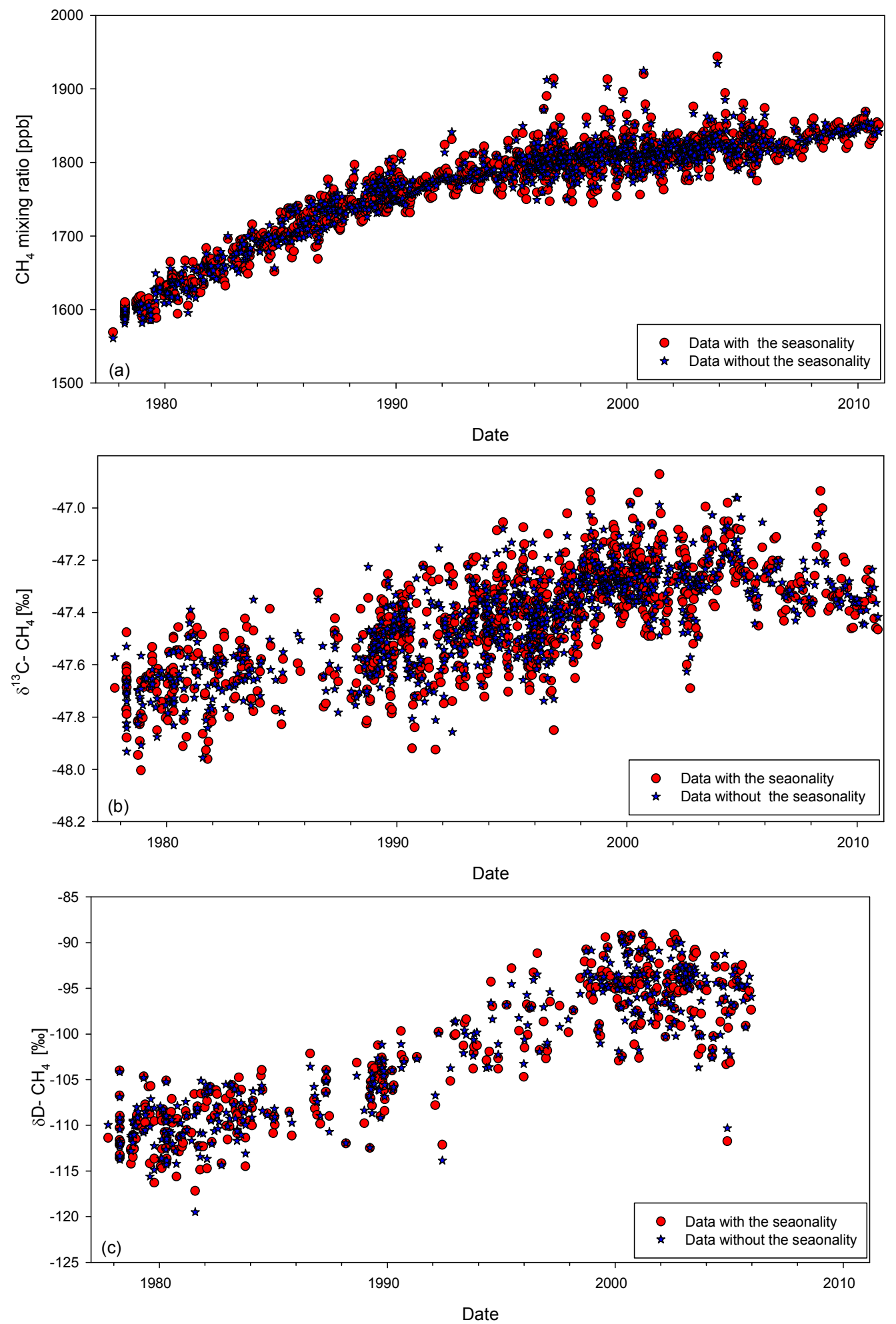

Figure 4.10 The composite data before and after removing the seasonal trend for (a) $\mathrm{CH}_{4}$ mixing ratio (b) $\delta^{13} \mathrm{C}_{-} \mathrm{CH}^{4}$ and $(\mathrm{C}) \delta \mathrm{D}-\mathrm{CH}_{4}$. 
In the next subsections, the figures produced using spans $0.09,0.09$, and 0.10 for $\mathrm{CH}_{4}, \delta^{13} \mathrm{C}$, and $\delta \mathrm{D}$, respectively are represented. Table 4.1 provides average annual values for $\mathrm{CH}_{4}, \delta^{13} \mathrm{C}$, and $\delta \mathrm{D}$, and their growth rates during 1978-2010. Tables and figures for other LOWESS span values are included in Appendices A, and B for comparison.

\subsubsection{Atmospheric $\mathrm{CH}_{4}$ and its growth rate}

The composite data (star points in figure 4.10(a)) are smoothed using LOWESS with spans equal to $0.09,0.12$, and 0.15 . These spans are equivalent to windows of times $3 \pm 1.1$ years, $4 \pm 1.4$ years, and $5 \pm 1.4$ years, respectively.

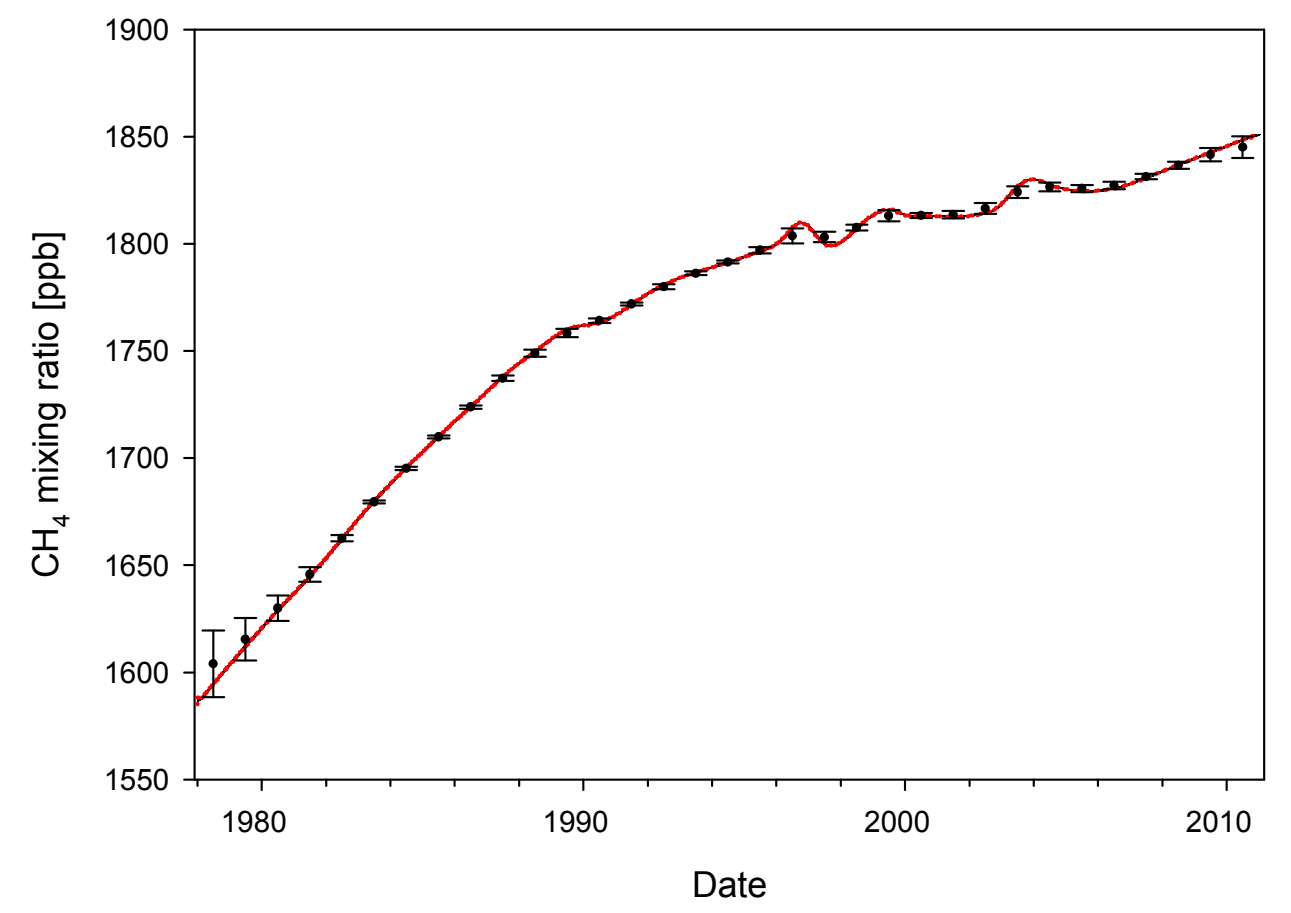

Figure 4.11 The instantaneous atmospheric $\mathrm{CH}_{4}$ mixing ratio (1978-2010) with mean values (black line), \pm $1 \sigma$ (red dots), and average yearly values (black circles) with $\pm 1 \sigma$ by smoothing the deseaonalize data in figure 4.10(a). 
Figure 4.11 represents the trend of atmospheric $\mathrm{CH}_{4}$ mixing ratio based on LOWESS and Bootstrap techniques with a span 0.09. Figure 4.12 shows the instantaneous and annual growth rate calculated from the slope of figure 4.11. The $\mathrm{CH}_{4}$ mixing ratio increased from $1590 \mathrm{ppb}$ in 1978 to $1800 \mathrm{ppb}$ in 1996 with an average rate of $12.1 \mathrm{ppb} / \mathrm{yr}$ during this period. The rate of increasing the $\mathrm{CH}_{4}$ in northern hemisphere sites measured by NOAA from 1983 to 1993 was 11.2 ppb/yr [Dlugokencky et al.1994]. The rate of increase slowed and from 1996 to 2010 it averaged 3 ppb/yr with significantly inter-annual variability. There are some main features of the trend during this time period. There are four peaks in 1991, 1996, 1999, and 2003. The 1996 peak is followed by a decrease in 1997. The mixing ratio was constant from 2000 to 2002. After the 2003 peak, the $\mathrm{CH}_{4}$ mixing ratio increased from $1820 \mathrm{ppb}$ to $1850 \mathrm{ppb}$ in 2010 . The growth rate of the $\mathrm{CH}_{4}$ mixing ratio doesn't change significantly during 1978-1983. Its growth rate during this time period is $16.9 \pm 0.5 \mathrm{ppb} / \mathrm{yr}$. After 1983, the $\mathrm{CH}_{4}$ growth rate decreases and reaches to a local minimum in 1990. Anomalously low growth rate occurs in 1990, 1997 , and 2004.

Some of these spikes are explained in the literature. For example, the sudden increase in the growth rate of atmospheric $\mathrm{CH}_{4}$ in 1991-1992 is attributed to $\mathrm{SO}_{2}$ emitted during the eruption of Mount Pinatubo. The resulting sulfate aerosol absorbed UV and the decreased UV flux is thought to have decreased the steady state of $[\mathrm{OH}]$ which caused the large growth rate observed in 1991-1992 [Dlugokencky et al., 1996]. For 1998, there were two main reasons for the anomalously large growth rate. First was the 
warmest year in the modern temperature record [Hansen et al., 1999]. Some $\mathrm{CH}_{4}$ sources, such as wetlands, increase their $\mathrm{CH}_{4}$ emission with increasing

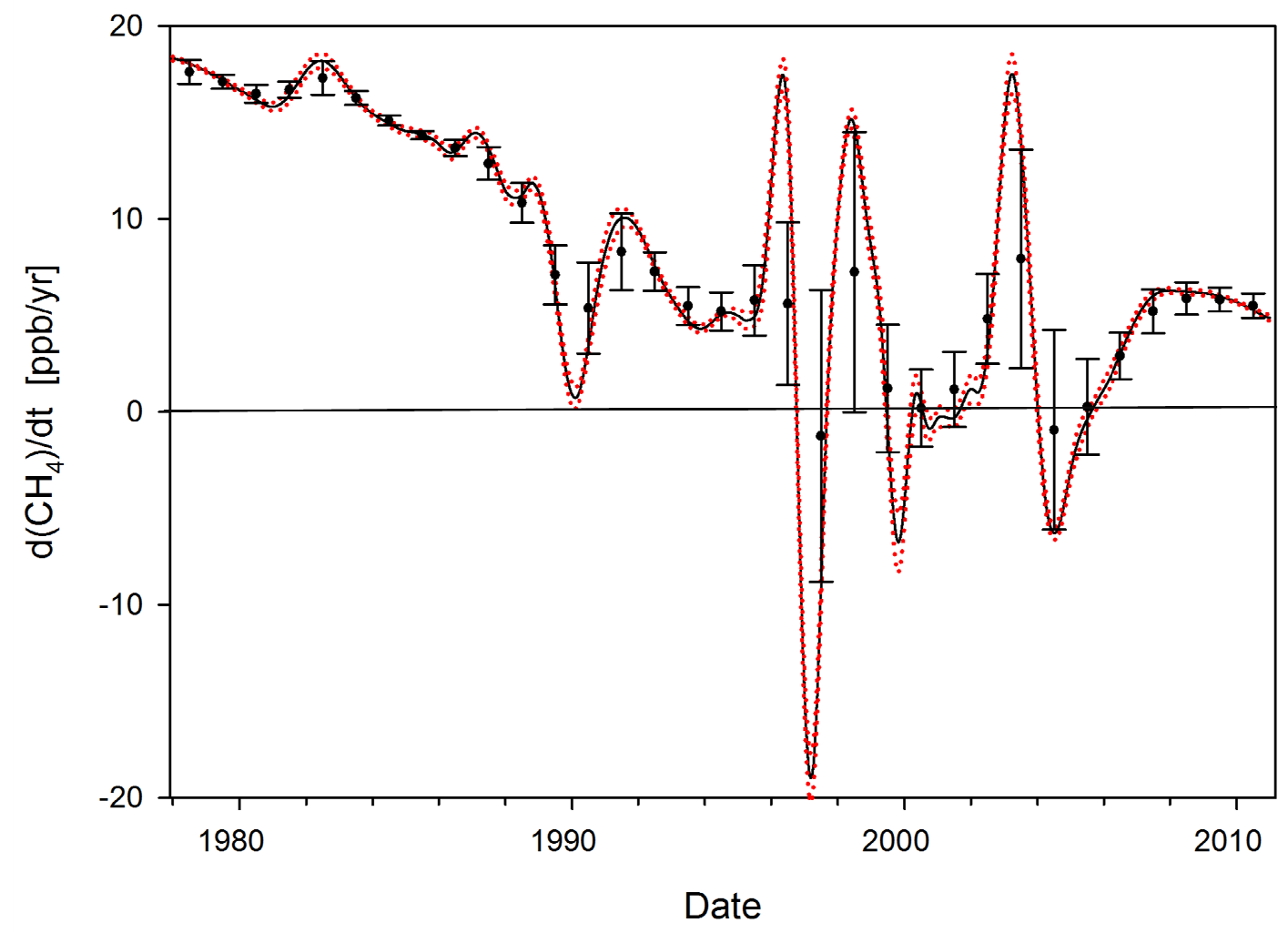

Figure 4.12 The instantaneous $\mathrm{CH}_{4}$ growth rate (1978-2010) calculated from the derivative of the black line in figure 4.11 with respect to time $\pm 1 \sigma$ (red dots), and average yearly values (black circles) with $\pm 1 \sigma$.

temperature. The second reason was the $\mathrm{CH}_{4}$ emissions from the large boreal fires, especially from Russia, Canada, and additional fires in Indonesia, which are thought to have contributed to this higher growth rate [Dlugokencky et al., 2001].

From figure 4.12, the $\mathrm{CH}_{4}$ growth rate decreases from $17.6 \mathrm{ppb} / \mathrm{yr}$ in 1978 to 5.4 ppb in 2010. The annual growth rate was constant during 1978-1983 and 2008-2010 with 
values of $16.9 \pm 0.5 \mathrm{ppb} / \mathrm{yr}$ and $5.7 \pm 0.2 \mathrm{ppb} / \mathrm{yr}$, respectively. Assuming the $\mathrm{CH}_{4}$ sources are constant during 1983-2008, the $\mathrm{CH}_{4}$ lifetime calculated from 1983 till 2008 is $(9.67 \pm 0.2)$ years, in a good agreement with a number of estimates [Prinn et al., 1987; 1995; Dlugokencky et al., 1998].

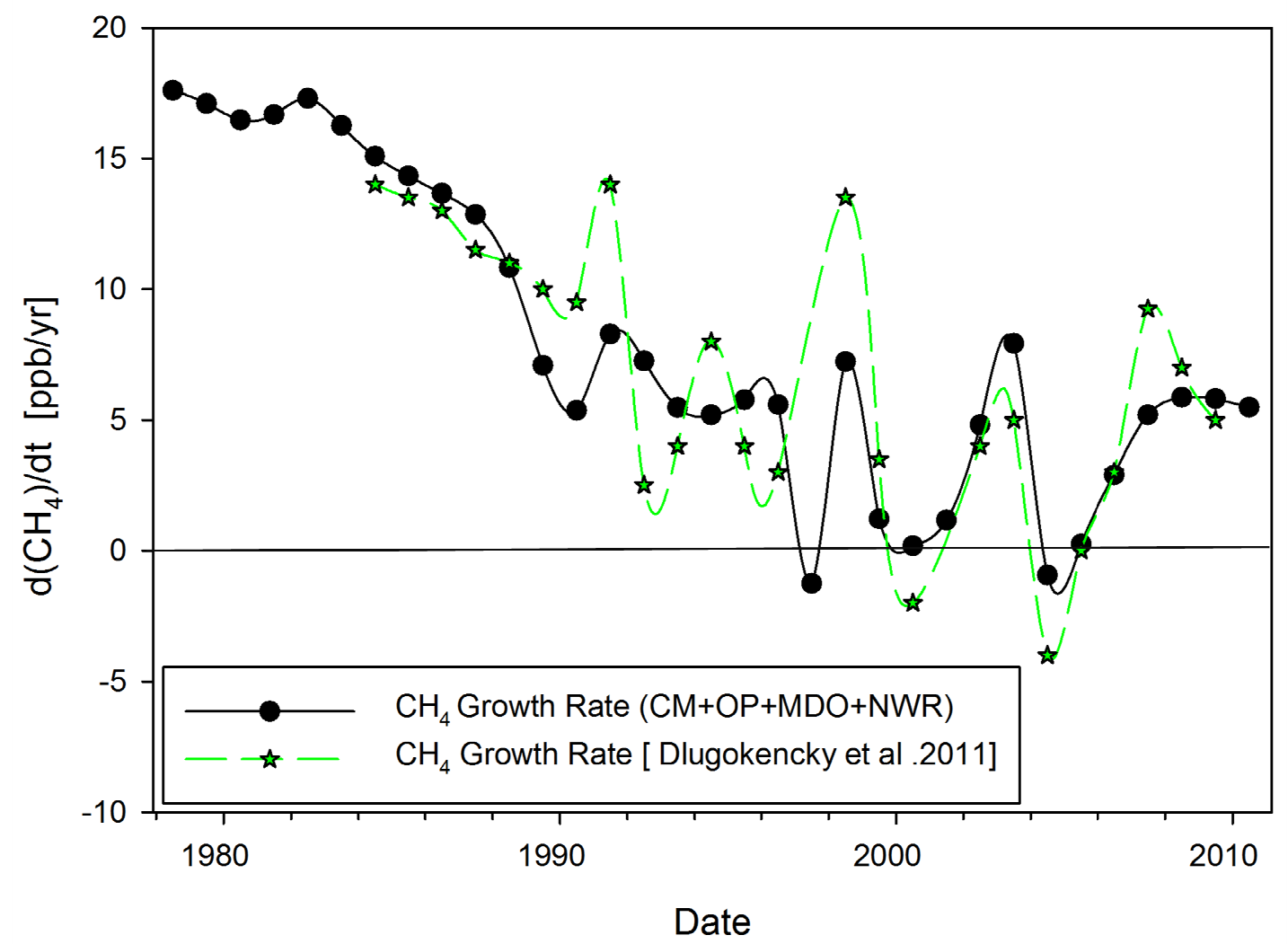

Figure 4.13 The annual increases $\mathrm{CH}_{4}$ growth rate for the composite data with black circles during 19782010 measured in ppb/yr. Green stars are the annual $\mathrm{CH}_{4}$ growth rate calculated from NOAA Global Cooperative Air Sampling Network measurements (values are taken from figure 1.(b) [Dlugokencky et al. 2011]).

A comparison of the annual growth rate of $\mathrm{CH}_{4}$ based on the results from the four-site composite dataset in the Northern hemisphere and more than 139 sites (26 of them have stopped collecting air) of the NOAA Global Cooperative Air Sampling Network [Dlugokencky et al., 2011] is shown in figure 4.13. There is agreement between 
both trends. Both the secular trend and much of the interannual variability is captured by the composite Northern hemisphere mid-latitude dataset. However, the values of the peaks are different. In most cases (e.g. 1991, 1998), the annual growth rate is larger for Dlugokencky et al. since their values are global. The correlation between Dlugokencky et al and composite data from 1984 to 2009 is highly significant $r^{2}=0.7$ (excluding 1997 and 2001 since their values of $\mathrm{CH}_{4}$ growth rate are not reported by Dlugokencky et al. [2011]).

The figures of the $\mathrm{CH}_{4}$ mixing ratio, its growth rate, and a comparison of the $\mathrm{CH}_{4}$ average yearly growth rate for composite data and Dlugokencky et al. are included in Appendix B for LOWESS smoothing of the data with spans of 0.12 and 0.15 . The $\mathrm{CH}_{4}$ lifetimes corresponding to these spans during $1983-2008$ are $9.9 \pm 0.1$ years and $10.5 \pm 0.1$ years, respectively. The correlations between the $\mathrm{CH}_{4}$ annual growth rate from the composite data and Dlugokencky et al. do not change significantly due to changing of the span in the analysis.

\subsubsection{Atmospheric $\delta^{13} \mathrm{C}-\mathrm{CH}_{4}$ and its time rate of change}

The composite data (star points in figure 4.10(b)) are smoothed using LOWESS with spans equal to $0.09,0.12$, and 0.15 . These spans are equivalent to windows of times $3 \pm 1.8$ years, $4 \pm 1.7$ years, and $5 \pm 1.7$ years, respectively. Using the Bootstrap technique, the uncertainties in the trend and its time rate of change are obtained. 


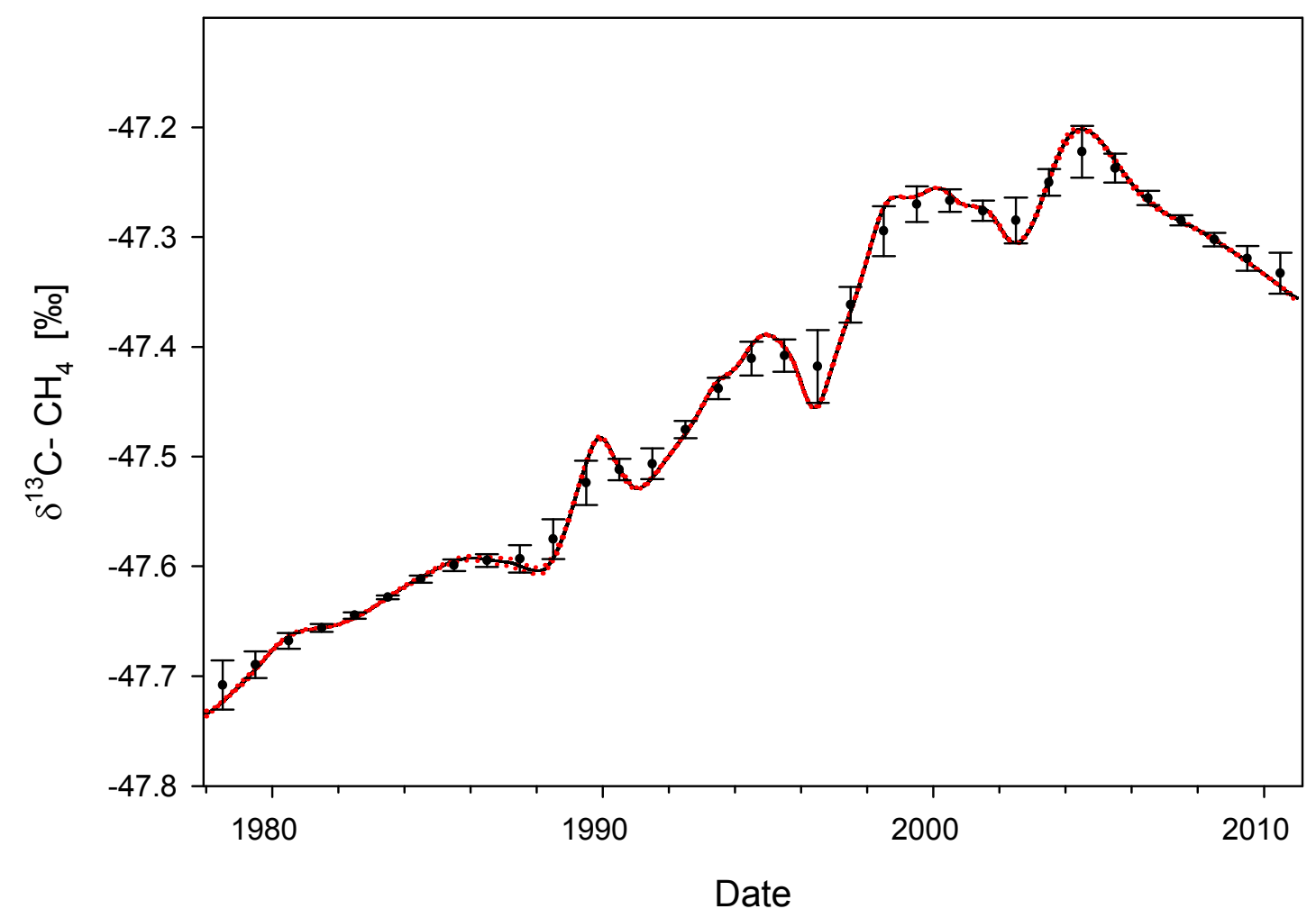

Figure 4.14 The instantaneous $\delta^{13} \mathrm{C}$ trend during 1978-2010 with mean values (black line), $\pm 1 \sigma$ (red dots), and average yearly values (black circles) with $\pm 1 \sigma$ calculate from 1 January in one year to 1 January in the next year by smoothing the deseasonalize data in figure 4.10 (b).

Figure 4.14 represents the trend of $\delta^{13} \mathrm{C}$ of atmospheric $\mathrm{CH}_{4}$ from the composite dataset after using a LOWESS smoother with a span of 0.09 and Bootstrapping uncertainties. Figure 4.15 shows the time rate of change of $\delta^{13} \mathrm{C}$ of atmospheric $\mathrm{CH}_{4}$ for the same period. Figure 4.14 shows that the atmospheric $\delta^{13} \mathrm{C}$ becomes gradually enriched with a slow rate from $-47.7 \%$ in 1978 to $-47.6 \%$ in 1987. From 1987 to 2005 , $\delta^{13} \mathrm{C}$ increases to $-47.2 \%$ with an average time rate of change of $0.02 \% / \mathrm{yr}$. This later period shows significant variability and characterized by periods with no annual increase in $\delta^{13} \mathrm{C}$ and large peaks. In contrast to the prior two and a half decades, the period 2005- 
2010 shows a depletion of $\delta^{13} \mathrm{C}$ at an average rate of $-0.02 \% / \mathrm{yr}$. The periods with no annual increase of $\delta^{13} \mathrm{C}$ occur 1989-1991, 1994-1996, and 1999-2002 with values of $47.5 \%,-47.4 \%$, and,$-47.3 \%$, respectively.

Positive spikes in the rate of change of $\delta^{13} \mathrm{C}$, as shown in figure 4.15 , occur in 1988-1989, 1992-1993, 1997, and 2003. Negative values in the trend of $\delta^{13} \mathrm{C}$ occur in $1990,1995,2000-2001$ and 2005. Overall the average rate of change of $\delta^{13} \mathrm{C}$ went from 0.03\%/yr during 1978-1980 to -0.02\%o/y during 2007-2010.

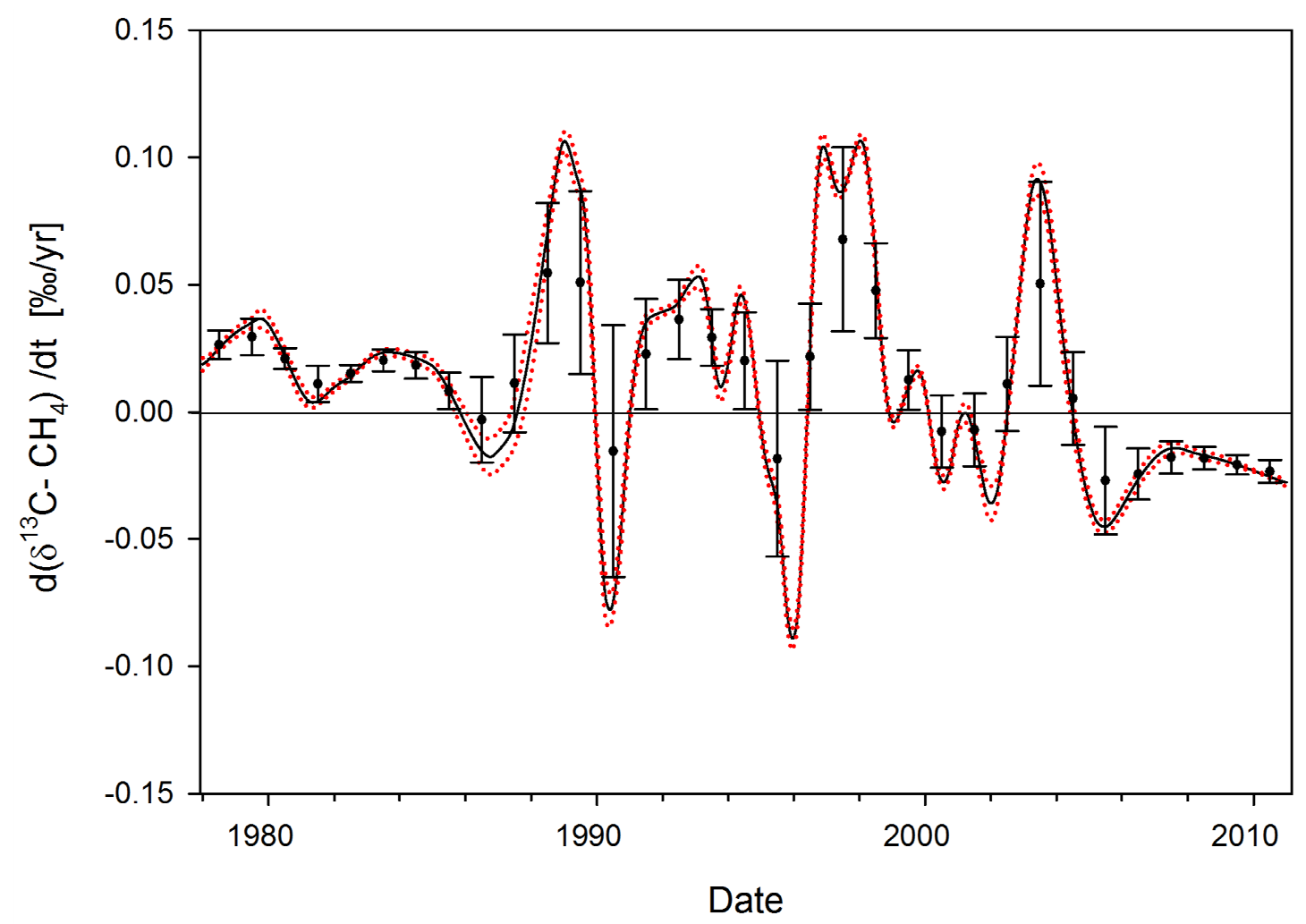

Figure 4.15 The instantaneous $\delta^{13} \mathrm{C}$ growth rate of composite data during 1978-2010. Red dots are \pm one standard deviation and black circles are the average yearly value calculated from 1 January in one year to 1 January in the next year. 
The relation between the changing of the growth rate of $\mathrm{CH}_{4}, \delta^{13} \mathrm{C}$, and $\delta \mathrm{D}$ will be discussed later in section 4.4.4. Changes in $\delta^{13} \mathrm{C}$ of atmospheric $\mathrm{CH}_{4}$ will be related to changes in sources in section 4.5 .

\subsubsection{Atmospheric $\delta \mathrm{D}-\mathrm{CH}_{4}$ and its time rate of change}

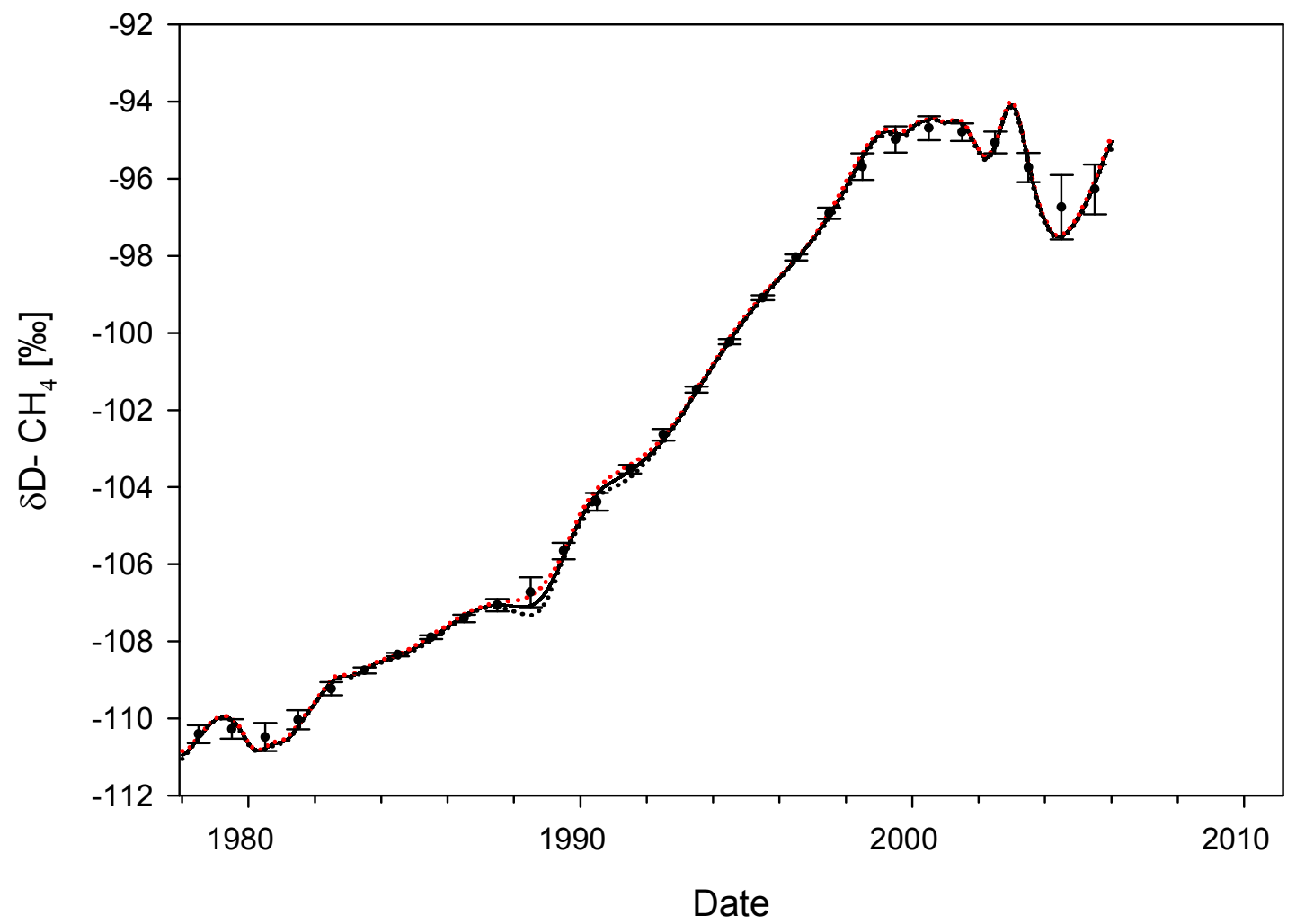

Figure 4.16 The instantaneous $\delta \mathrm{D}$ trend (1978-2005) with mean values (black line), $\pm 1 \sigma$ (red dots), and average yearly values (black circles) with $\pm 1 \sigma$ calculated from 1 January in one year to 1 January in the next year by smoothing deseasonalized data in figure $4.10(\mathrm{c})$

The instantaneous $\delta \mathrm{D}$ trend of the composite data is obtained by smoothing the data in figure 4.10(b) with LOWESS of a span of 0.10 and then using the Bootstrap 
technique to get the uncertainty in the trend. Figure 4.16 shows the smoothed $\delta \mathrm{D}$ trend during 1978-2005. It shows that $\delta \mathrm{D}$ becomes increasingly enriched in the atmosphere gradually at first from $-110 \%$ to $-100 \%$ in 1988 , then more rapidly from 1989 reaching its maximum of $-95 \%$ during 1999-2001. After 2002, $\delta$ D turns over and becomes more depleted through 2005. Unlike $\delta^{13} \mathrm{C}$, no data is available after 2005 so it is unclear if this trend towards more depleted values of $\delta \mathrm{D}$ continues.

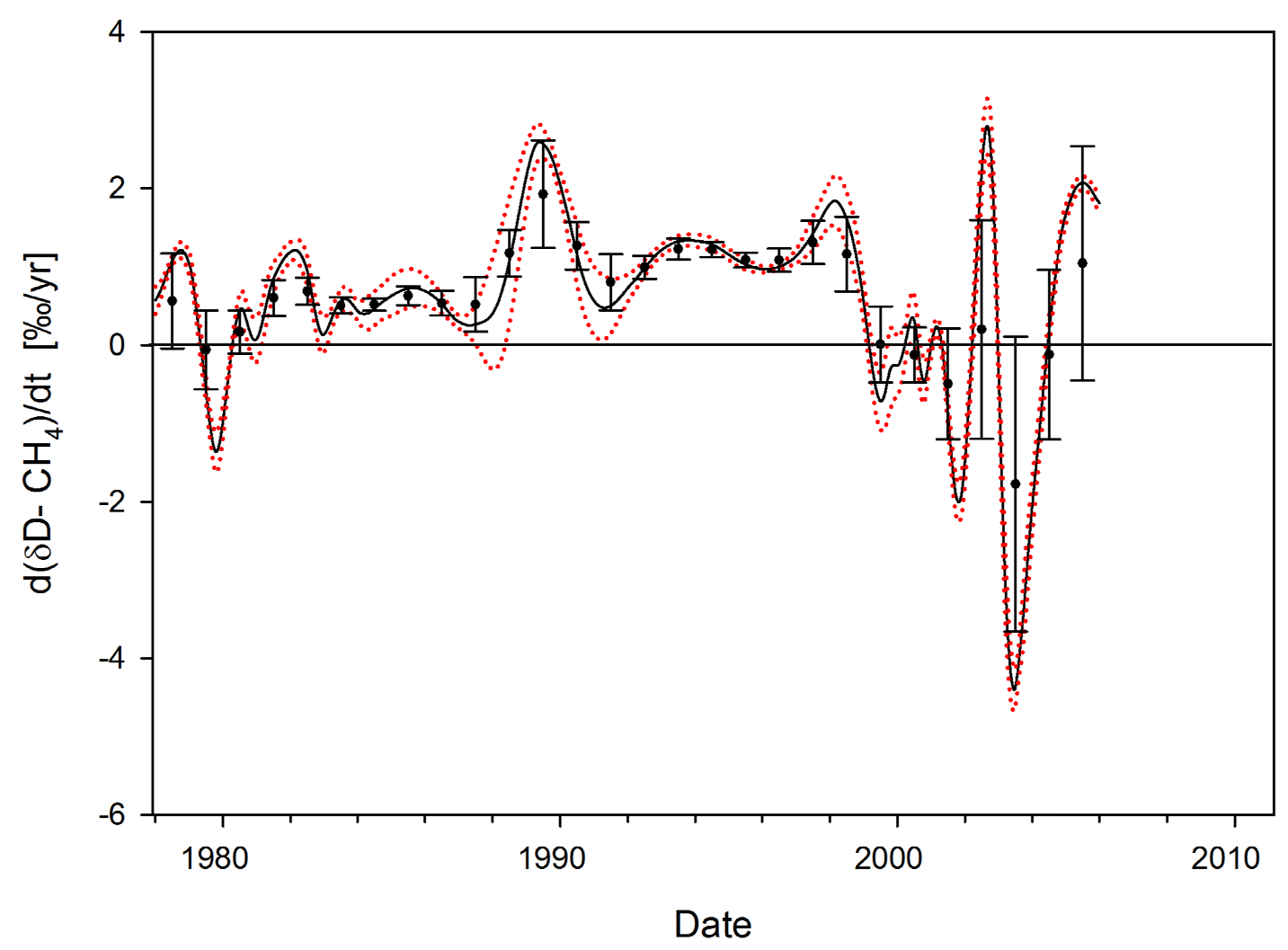

Figure 4.17 The instantaneous $\delta$ D time rate of change of composite data during 1978-2005. Red dots are \pm one standard deviation and black circles are the average yearly values calculated from 1 January in one year to 1 January in the next year.

The time rate of change of $\delta \mathrm{D}$ is obtained by differentiating the smoothed data (black line in figure 4.16) with respect to time. The rate of change of $\delta \mathrm{D}$ of atmospheric 
$\mathrm{CH}_{4}$ shows significant interannual variability similar to $\delta^{13} \mathrm{C}$ and $\mathrm{CH}_{4}$ mixing ratios. Periods where the time rate of change of $\delta \mathrm{D}$ is constant occur 1981-1987 and 1993-1995. Positive spikes for this change occur in 1989, 1997-1998, 2002, and 2005. Periods where the time rate of change is negative occur in 1979, 1999-2001, and 2003. The relation between the secular trends and interannual variability of $\delta \mathrm{D}, \mathrm{CH}_{4}, \delta^{13} \mathrm{C}$ will be discussed in section 4.4.4. The long-term trend and interannaul variability in $\delta \mathrm{D}$ of atmospheric $\mathrm{CH}_{4}$ are discussed in relation to changes in $\mathrm{CH}_{4}$ sources in section 4.5.

\subsubsection{Discussion of the time rates of change of $\mathrm{CH}_{4}, \delta^{13} \mathrm{C}$ and $\delta \mathrm{D}$ of the composite data $1977-2010$}

The growth rate of $\mathrm{CH}_{4}$ is the imbalance between sources and sinks [Khalil et al., 2007]. Therefore, when its growth rate increases the strength of sources is larger than its sinks. Similarly, a decrease in the growth rate of atmospheric $\mathrm{CH}_{4}$ is caused when sinks are larger than sources.

The positive spike of $\mathrm{CH}_{4}$ growth rate in 1991 is thought to be due to the decrease of $[\mathrm{OH}]$ in the atmosphere after Mt. Pinatubo erupted [Dlugokencky et al., 2001]. It was expected that the $\delta^{13} \mathrm{C}$ time rate of change would decrease due to the decrease of $\mathrm{OH}$ sink, however according to figure 4.18(b) its annual value becomes more enriched in the atmosphere during 1991-1993. From figure 4.18(c), the $\delta \mathrm{D}$ time rate of change is marginally lower by $0.8 \%$ than surrounding years then increases gradually during 1991 1994. $\delta \mathrm{D}$ should be particularly sensitive to changes in $\mathrm{OH}$ due to the large KIE in 
oxidation. That this departure is not particularly dramatic in $\delta \mathrm{D}$ and that it is opposite in sign for $\delta^{13} \mathrm{C}$ does not support the Pinatubo hypothesis. However, because $\delta^{13} \mathrm{C}$ shows a positive response and $\delta \mathrm{D}$ shows a negative response is somewhat ambiguous.

The 1998 spike of $\mathrm{CH}_{4}$ growth rate (as shown in figure 4.18(a)) was explained by the increase of $\mathrm{CH}_{4}$ emissions from wetlands and fires occur through this year [Dlugokencky et al., 2001]. From Figure 4.18(b), $\delta^{13} \mathrm{C}$ shows a positive response during 1997-1998 which is consistent with an increase in biomass burning during this period. Similarly, figure $4.18(\mathrm{c})$ shows a smaller positive anomaly in $\delta \mathrm{D}$, consistent with enhanced fire. Both isotopic tracers show a gradual decrease after this period during 1999-2001.

The 2003 spike of $\mathrm{CH}_{4}$ growth rate (as shown in figure 4.18(a)), as recorded in the composite dataset and in the NOAA record, suggests that $\mathrm{CH}_{4}$ sources increased during this year. During $2003, \delta^{13} \mathrm{C}$ time rate of change increased while $\delta \mathrm{D}$ time rate of change decreased (as shown in figure 4.18(b) and figure 4.18(c)). This is perplexing, but could require a change in $\mathrm{CH}_{4}$ sources and sinks.

The negative spike of $\mathrm{CH}_{4}$ growth rate during 1997 assumed $\mathrm{CH}_{4}$ sinks are larger than $\mathrm{CH}_{4}$ sources. There is less confidence in the trend in 1997 as it is not shown by the NOAA global dataset. 

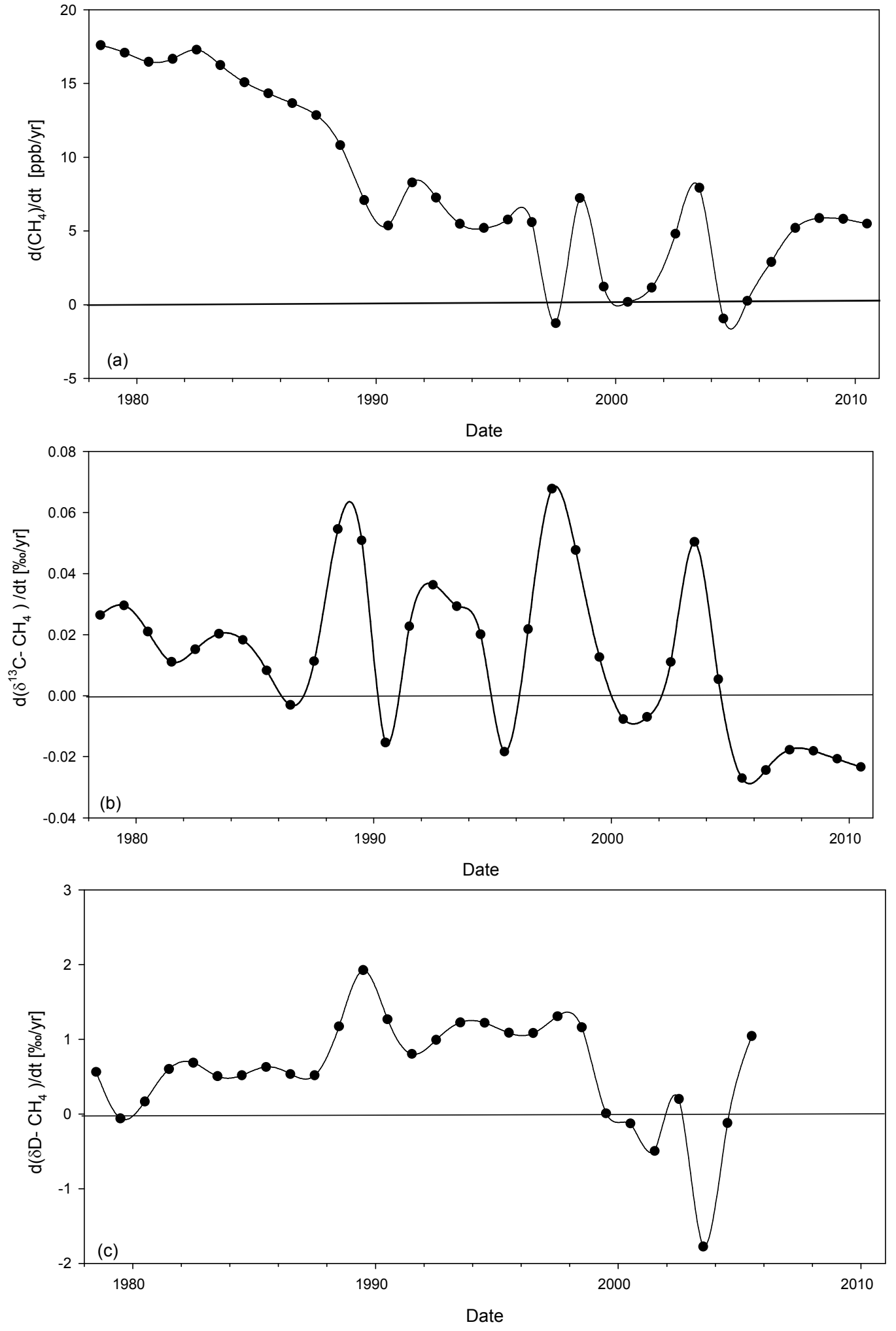

Figure 4.18 The annual time rate of change of (a) $\mathrm{CH}_{4}(\mathrm{~b}) \delta^{13} \mathrm{C}(\mathrm{c}) \delta \mathrm{D}$ of composite data. 
Table 4.1 Summary of the annual $\mathrm{CH}_{4}, \delta^{13} \mathrm{C}, \delta \mathrm{D}$ and their growth rates

\begin{tabular}{|c|c|c|c|c|c|c|c|c|c|c|c|c|}
\hline \multirow[t]{2}{*}{ Year } & \multicolumn{2}{|c|}{$\mathrm{CH}_{4}$ [ppb] } & \multicolumn{2}{|c|}{$\begin{array}{c}\mathrm{d}\left(\mathrm{CH}_{4}\right) / \mathrm{dt} \\
{[\mathrm{ppb} / \mathrm{yr}]}\end{array}$} & \multicolumn{2}{|c|}{$\delta^{13} \mathrm{C}[\%$} & \multicolumn{2}{|c|}{$\begin{array}{c}\mathrm{d}\left(\delta^{13} \mathrm{C}\right) / \mathrm{dt} \\
{[\% / \mathrm{yr}]}\end{array}$} & \multicolumn{2}{|c|}{$\delta \mathrm{D}[\% \mathrm{\%}]$} & \multicolumn{2}{|c|}{$\begin{array}{c}\mathrm{d}(\delta \mathrm{D}) / \mathrm{dt} \\
{[\% / \mathrm{yr}]}\end{array}$} \\
\hline & Ave. & $\begin{array}{c}\text { Std } \\
\text { Dev }\end{array}$ & Ave. & $\begin{array}{c}\text { Std } \\
\text { Dev }\end{array}$ & Ave. & $\begin{array}{c}\text { Std } \\
\text { Dev }\end{array}$ & Ave. & $\begin{array}{l}\text { Std } \\
\text { Dev }\end{array}$ & Ave. & $\begin{array}{c}\text { Std } \\
\text { Dev }\end{array}$ & Ave. & $\begin{array}{c}\text { Std } \\
\text { Dev }\end{array}$ \\
\hline 1978 & $1,604.0$ & 15.5 & 17.6 & 0.6 & -47.71 & 0.02 & 0.00 & 0.02 & -110.4 & 0.2 & 0.6 & 0.6 \\
\hline 1979 & $1,615.4$ & 9.9 & 17.1 & 0.4 & -47.70 & 0.01 & 0.03 & 0.02 & -110.3 & 0.3 & -0.1 & 0.5 \\
\hline 1980 & $1,629.9$ & 5.9 & 16.5 & 0.5 & -47.66 & 0.01 & 0.03 & 0.02 & -110.5 & 0.4 & 0.2 & 0.3 \\
\hline 1981 & $1,645.7$ & 3.3 & 16.7 & 0.4 & -47.65 & 0.01 & 0.00 & 0.02 & -110.0 & 0.2 & 0.6 & 0.2 \\
\hline 1982 & $1,662.6$ & 1.5 & 17.3 & 0.9 & -47.65 & 0.01 & 0.01 & 0.01 & -109.2 & 0.2 & 0.7 & 0.2 \\
\hline 1983 & $1,679.5$ & 0.8 & 16.2 & 0.4 & -47.63 & 0.01 & 0.02 & 0.01 & -108.8 & 0.1 & 0.5 & 0.1 \\
\hline 1984 & $1,695.2$ & 0.7 & 15.1 & 0.3 & -47.60 & 0.01 & 0.02 & 0.01 & -108.3 & 0.0 & 0.5 & 0.1 \\
\hline 1985 & $1,709.9$ & 0.6 & 14.3 & 0.2 & -47.59 & 0.01 & 0.00 & 0.01 & -107.9 & 0.0 & 0.6 & 0.1 \\
\hline 1986 & $1,723.8$ & 0.7 & 13.7 & 0.4 & -47.59 & 0.01 & -0.02 & 0.03 & -107.4 & 0.1 & 0.5 & 0.2 \\
\hline 1987 & $1,737.3$ & 1.3 & 12.9 & 0.8 & -47.60 & 0.02 & 0.01 & 0.02 & -107.1 & 0.2 & 0.5 & 0.3 \\
\hline 1988 & $1,749.0$ & 1.7 & 10.8 & 1.0 & -47.58 & 0.02 & 0.06 & 0.04 & -106.7 & 0.4 & 1.2 & 0.3 \\
\hline 1989 & $1,758.3$ & 2.0 & 7.1 & 1.5 & -47.52 & 0.02 & 0.06 & 0.06 & -105.7 & 0.2 & 1.9 & 0.7 \\
\hline 1990 & $1,764.1$ & 1.1 & 5.4 & 2.4 & -47.51 & 0.01 & -0.04 & 0.08 & -104.4 & 0.2 & 1.3 & 0.3 \\
\hline 1991 & $1,771.9$ & 0.7 & 8.3 & 2.0 & -47.51 & 0.01 & 0.03 & 0.04 & -103.5 & 0.1 & 0.8 & 0.4 \\
\hline 1992 & $1,780.0$ & 1.1 & 7.3 & 1.0 & -47.48 & 0.01 & 0.04 & 0.02 & -102.6 & 0.2 & 1.0 & 0.1 \\
\hline 1993 & $1,786.2$ & 0.9 & 5.5 & 1.0 & -47.43 & 0.01 & 0.03 & 0.01 & -101.5 & 0.1 & 1.2 & 0.1 \\
\hline 1994 & $1,791.4$ & 0.7 & 5.2 & 1.0 & -47.41 & 0.02 & 0.03 & 0.02 & -100.2 & 0.1 & 1.2 & 0.1 \\
\hline 1995 & $1,796.9$ & 1.4 & 5.8 & 1.8 & -47.41 & 0.02 & -0.02 & 0.04 & -99.1 & 0.1 & 1.1 & 0.1 \\
\hline 1996 & $1,803.7$ & 3.5 & 5.6 & 4.2 & -47.42 & 0.04 & 0.02 & 0.02 & -98.0 & 0.1 & 1.1 & 0.1 \\
\hline 1997 & $1,803.1$ & 2.5 & -1.3 & 7.6 & -47.36 & 0.02 & 0.07 & 0.04 & -96.9 & 0.1 & 1.3 & 0.3 \\
\hline 1998 & $1,807.6$ & 1.4 & 7.2 & 7.2 & -47.29 & 0.03 & 0.05 & 0.02 & -95.7 & 0.3 & 1.2 & 0.5 \\
\hline 1999 & $1,813.0$ & 2.6 & 1.2 & 3.3 & -47.27 & 0.02 & 0.01 & 0.01 & -95.0 & 0.3 & 0.0 & 0.5 \\
\hline 2000 & $1,813.2$ & 1.2 & 0.2 & 2.0 & -47.27 & 0.01 & -0.01 & 0.02 & -94.7 & 0.3 & -0.1 & 0.4 \\
\hline 2001 & $1,813.6$ & 1.8 & 1.2 & 1.9 & -47.27 & 0.01 & 0.01 & 0.02 & -94.8 & 0.2 & -0.5 & 0.7 \\
\hline 2002 & $1,816.5$ & 2.5 & 4.8 & 2.3 & -47.29 & 0.03 & 0.00 & 0.04 & -95.1 & 0.3 & 0.2 & 1.4 \\
\hline 2003 & $1,824.2$ & 2.7 & 7.9 & 5.7 & -47.25 & 0.02 & 0.08 & 0.07 & -95.7 & 0.4 & -1.8 & 1.9 \\
\hline 2004 & $1,826.5$ & 2.0 & -0.9 & 5.2 & -47.20 & 0.05 & 0.00 & 0.03 & -96.7 & 0.8 & -0.1 & 1.1 \\
\hline 2005 & $1,825.7$ & 1.6 & 0.3 & 2.5 & -47.24 & 0.02 & -0.06 & 0.05 & -96.3 & 0.6 & 1.0 & 1.5 \\
\hline 2006 & $1,827.2$ & 1.8 & 2.9 & 1.2 & -47.28 & 0.02 & -0.03 & 0.02 & & & & \\
\hline 2007 & $1,831.3$ & 1.3 & 5.2 & 1.1 & -47.29 & 0.01 & 0.00 & 0.02 & & & & \\
\hline 2008 & $1,836.6$ & 1.6 & 5.9 & 0.8 & -47.29 & 0.01 & -0.01 & 0.01 & & & & \\
\hline 2009 & $1,841.6$ & 3.1 & 5.8 & 0.6 & -47.31 & 0.01 & -0.03 & 0.01 & & & & \\
\hline 2010 & $1,845.1$ & 5.0 & 5.5 & 0.6 & -47.34 & 0.03 & -0.04 & 0.02 & & & & \\
\hline
\end{tabular}

\subsection{The $\mathrm{CH}_{4}$ sources $1978-2010$}

In this section, calculations, which estimate the total $\mathrm{CH}_{4}$ sources and the $\delta^{13} \mathrm{C}$ and $\delta \mathrm{D}$ signatures of the combined $\mathrm{CH}_{4}$ sources are given based on observations from our composite time series. 


\subsubsection{Total $\mathrm{CH}_{4}$ emissions 1978-2010}

From measured $\mathrm{CH}_{4}$ mixing ratio and its growth rate, we can calculate an estimate of $\mathrm{CH}_{4}$ emissions. Treating the atmosphere as a single box, from the mass balance equation

$\frac{\mathrm{d}\left[\mathrm{CH}_{4}\right]}{\mathrm{dt}}=\mathrm{S}-\frac{\left[\mathrm{CH}_{4}\right]}{\tau}$

where $\frac{\mathrm{d}\left[\mathrm{CH}_{4}\right]}{\mathrm{dt}}$ is the $\mathrm{CH}_{4}$ growth rate measured in parts per billion per year $[\mathrm{ppb} / \mathrm{yr}], \mathrm{S}$ is the total $\mathrm{CH}_{4}$ emission measured in teragram/year $[\mathrm{Tg} / \mathrm{yr}],\left[\mathrm{CH}_{4}\right]$ is the $\mathrm{CH}_{4}$ mixing ratio measured in parts per billion [ppb], and $\tau$ is the $\mathrm{CH}_{4}$ lifetime measured in years [yr]. To convert from [ppb/yr] to [Tg/yr], a factor of 2.75 is used [Khalil et al., 2007]. Both $\left[\mathrm{CH}_{4}\right]$ and are $\mathrm{d}\left[\mathrm{CH}_{4}\right] / \mathrm{dt}$ are known and the lifetime is taken to be 9.7 years which is calculated from our data and the approximate middle of the range of lifetimes as discussed in section 1.3.2. To calculate the $\mathrm{CH}_{4}$ emission from 1978 to 2010 , we consider the $\mathrm{CH}_{4}$ lifetime to be constant.

Under these assumptions, the $\mathrm{CH}_{4}$ emission can be obtained as

$\mathrm{S}=2.75 *\left(\frac{\mathrm{d}\left[\mathrm{CH}_{4}\right]}{\mathrm{dt}}+\frac{\left[\mathrm{CH}_{4}\right]}{\tau}\right)$

The results of the total emission during 1978-2010 are shown in figure 4.19. Tabulated values for annual $\mathrm{CH}_{4}$ emissions are given in table 4.2. 
Table 4.2 The annual total $\mathrm{CH}_{4}$ total emissions, $\delta^{13} \mathrm{C}$ and $\delta \mathrm{D}$ of $\mathrm{CH}_{4}$ sources

\begin{tabular}{|c|c|c|c|c|c|}
\hline Year & $\mathrm{CH}_{4}$ [ppb] & $\mathrm{d}\left(\mathrm{CH}_{4}\right) / \mathrm{dt}[\mathrm{ppb} / \mathrm{yr}]$ & $S_{9.7 \mathrm{yr}}(\mathrm{Tg} / \mathrm{yr})$ & $\delta^{13} \mathrm{C}$-sources [\%] & $\delta \mathrm{D}$-sources [\%o] \\
\hline 1978 & $1,604.0$ & 17.6 & 503.1 & -52.36 & -282.8 \\
\hline 1979 & $1,615.4$ & 17.1 & 505.0 & -52.35 & -283.3 \\
\hline 1980 & $1,629.9$ & 16.5 & 507.4 & -52.35 & -284.2 \\
\hline 1981 & $1,645.7$ & 16.7 & 512.4 & -52.34 & -283.8 \\
\hline 1982 & $1,662.6$ & 17.3 & 518.9 & -52.32 & -282.7 \\
\hline 1983 & $1,679.5$ & 16.2 & 520.8 & -52.33 & -283.4 \\
\hline 1984 & $1,695.2$ & 15.1 & 522.1 & -52.35 & -284.3 \\
\hline 1985 & $1,709.9$ & 14.3 & 524.2 & -52.36 & -284.8 \\
\hline 1986 & $1,723.8$ & 13.7 & 526.3 & -52.37 & -285.1 \\
\hline 1987 & $1,737.3$ & 12.9 & 527.9 & -52.39 & -285.7 \\
\hline 1988 & $1,749.0$ & 10.8 & 525.6 & -52.43 & -287.4 \\
\hline 1989 & $1,758.3$ & 7.1 & 518.0 & -52.47 & -290.2 \\
\hline 1990 & $1,764.1$ & 5.4 & 514.9 & -52.51 & -290.9 \\
\hline 1991 & $1,771.9$ & 8.3 & 525.1 & -52.43 & -287.4 \\
\hline 1992 & $1,780.0$ & 7.3 & 524.6 & -52.42 & -287.7 \\
\hline 1993 & $1,786.2$ & 5.5 & 521.5 & -52.43 & -288.5 \\
\hline 1994 & $1,791.4$ & 5.2 & 522.2 & -52.41 & -287.8 \\
\hline 1995 & $1,796.9$ & 5.8 & 525.3 & -52.40 & -286.4 \\
\hline 1996 & $1,803.7$ & 5.6 & 526.7 & -52.41 & -285.8 \\
\hline 1997 & $1,803.1$ & -1.3 & 507.7 & -52.54 & -291.8 \\
\hline 1998 & $1,807.6$ & 7.2 & 532.3 & -52.25 & -282.3 \\
\hline 1999 & $1,813.0$ & 1.2 & 517.3 & -52.38 & -287.8 \\
\hline 2000 & $1,813.2$ & 0.2 & 514.6 & -52.41 & -288.6 \\
\hline 2001 & $1,813.6$ & 1.2 & 517.4 & -52.39 & -287.7 \\
\hline 2002 & $1,816.5$ & 4.8 & 528.2 & -52.30 & -284.2 \\
\hline 2003 & $1,824.2$ & 7.9 & 539.0 & -52.19 & -281.7 \\
\hline 2004 & $1,826.5$ & -0.9 & 515.2 & -52.39 & -291.4 \\
\hline 2005 & $1,825.7$ & 0.3 & 518.3 & -52.37 & -289.8 \\
\hline 2006 & $1,827.2$ & 2.9 & 526.0 & -52.33 & \\
\hline 2007 & $1,831.3$ & 5.2 & 533.5 & -52.29 & \\
\hline 2008 & $1,836.6$ & 5.9 & 536.8 & -52.29 & \\
\hline 2009 & $1,841.6$ & 5.8 & 538.1 & -52.31 & \\
\hline 2010 & $1,845.1$ & 5.5 & 538.2 & -52.33 & \\
\hline
\end{tabular}




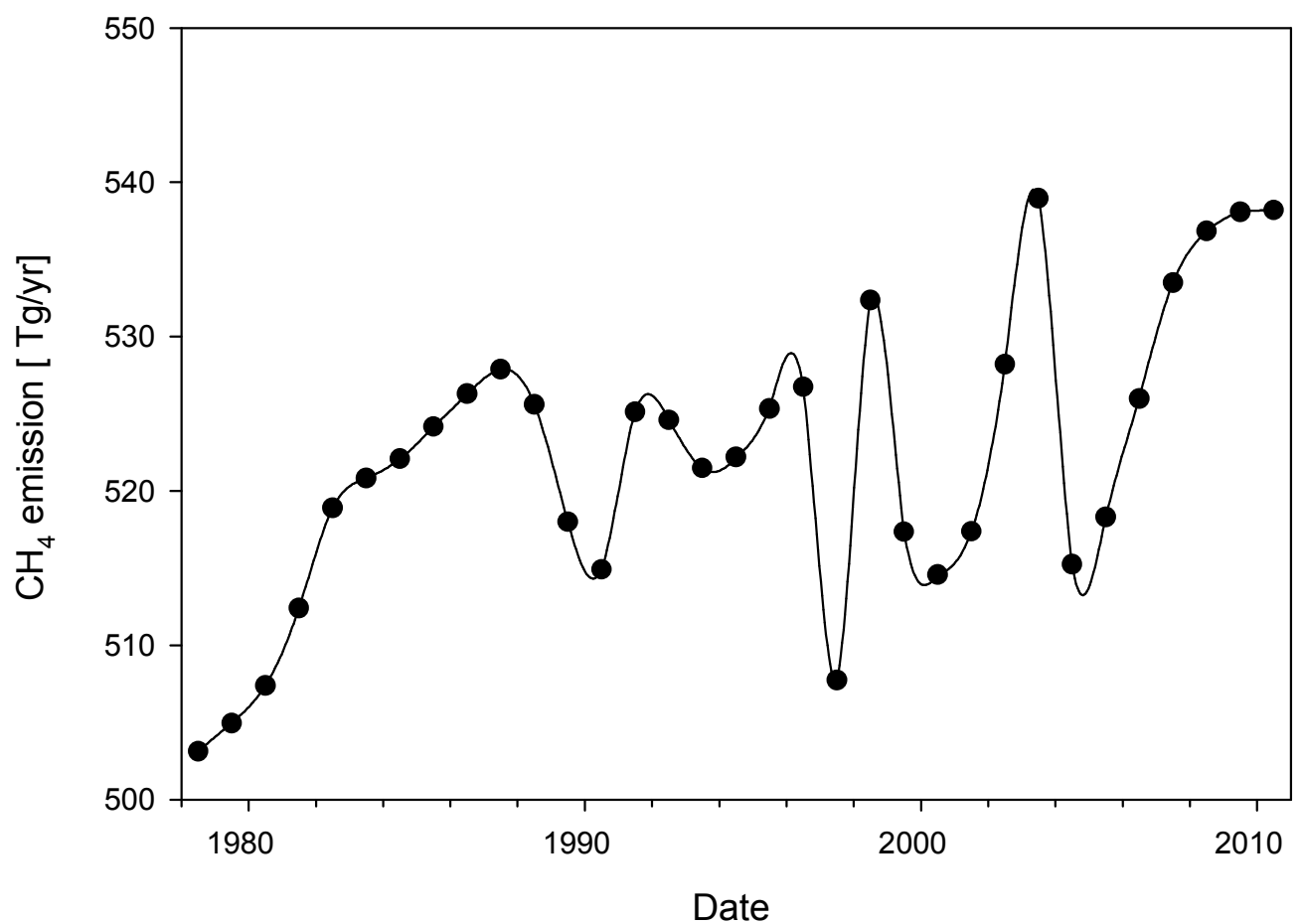

Figure 4.19 Annual $\mathrm{CH}_{4}$ emission during 1978-2010 using the mass balance equation (4.10) and based on a $\mathrm{CH}_{4}$ lifetime of $9.7 \mathrm{yrs}$.

The average $\mathrm{CH}_{4}$ emission during $1978-2010$ is $522 \pm 9 \mathrm{Tg} / \mathrm{yr}$ with a minimum value of $503 \mathrm{Tg} / \mathrm{yr}$ in 1978 and a maximum value of $539 \mathrm{Tg} / \mathrm{yr}$ in 2003 (as shown in table 4.2 and figure 4.19). The highest $\mathrm{CH}_{4}$ emission during 2003 was the reason of anomalously large growth rate in $\mathrm{CH}_{4}$ (as described in section 4.4.4).

Figure 4.19 shows that $\mathrm{CH}_{4}$ emissions increased rapidly from 1978 with a value of $503 \mathrm{Tg} / \mathrm{yr}$ to 1983 with a value of $520 \mathrm{Tg} / \mathrm{yr}$ and slowed down from 1983 to 1987 with a value of $528 \mathrm{Tg} / \mathrm{yr}$. After 1987, $\mathrm{CH}_{4}$ emissions decreased from $538 \mathrm{Tg} / \mathrm{yr}$ and reached $515 \mathrm{Tg} / \mathrm{yr}$ during 1990. A rapid return to increased $\mathrm{CH}_{4}$ emissions followed during 1991, at $525 \mathrm{Tg} / \mathrm{yr}$. In 1991-1996, $\mathrm{CH}_{4}$ emissions changed slowly. During 1997, $\mathrm{CH}_{4}$ emissions decreased sharply to $508 \mathrm{Tg} / \mathrm{yr}$. The high $\mathrm{CH}_{4}$ emissions during 1998 with a value of 532 
$\mathrm{Tg} / \mathrm{yr}$ from wetlands and fires appear as a sharp increase in figure 4.19 and a sharp increase in the $\mathrm{CH}_{4}$ growth rate in figure $4.18(\mathrm{a}) . \mathrm{CH}_{4}$ emissions decreased again after 1998 and reached $514 \mathrm{Tg} / \mathrm{yr}$ during 2000. After 2001, $\mathrm{CH}_{4}$ emissions increased again and spiked during 2003 with a value of $539 \mathrm{Tg} / \mathrm{yr}$. They decreased again during 2004 with a value of $515 \mathrm{Tg} / \mathrm{yr}$ and $518 \mathrm{Tg} / \mathrm{yr}$ in 2005. Emissions increased rapidly 2000-2005 and leveled off 2008-2010 which explains the increase of $\mathrm{CH}_{4}$ growth rate during 20052010.

Decreasing the lifetime of $\mathrm{CH}_{4}$ in the atmosphere from 9.7 yrs to 8.7 yrs ( and fixing the $\mathrm{CH}_{4}$ mixing ratio and its growth rate), the effect of sinks will increase and therefore $\mathrm{CH}_{4}$ emissions are increased from $503 \mathrm{Tg} / \mathrm{yr}$ in 1978 (as calculated from equation 4.8 with a $\mathrm{CH}_{4}$ lifetime $=9.7 \mathrm{yrs}$ ) to $555 \mathrm{Tg} / \mathrm{yr}$ in 1978 . The maximum value of emission occurs in 2003 with a value $560 \mathrm{Tg} / \mathrm{yr}$. Contrastingly, increasing the $\mathrm{CH}_{4}$ lifetime means a decrease of the atmospheric sink. Therefore, an increase $\mathrm{CH}_{4}$ lifetime to 10.7 yrs changes minimum and maximum annual emission strengths to be $460 \mathrm{Tg} / \mathrm{yr}$ and $491 \mathrm{Tg} / \mathrm{yr}$, respectively. A figure B.21 in Appendix B shows the difference of $\mathrm{CH}_{4}$ emission when the $\mathrm{CH}_{4}$ lifetime is $8.7 \mathrm{yrs}, 9.7 \mathrm{yrs}$ and $10.7 \mathrm{yrs}$.

\subsubsection{The $\delta^{13} \mathrm{C}$ of the $\mathrm{CH}_{4}$ sources $1978-2010$}

Recall equation (4.9), the total emission of $\mathrm{CH}_{4}$ can be defined as

$$
\mathrm{S}=\frac{\mathrm{d}\left[\mathrm{CH}_{4}\right]}{\mathrm{dt}}+\frac{\left[\mathrm{CH}_{4}\right]}{\tau}
$$


where $\left[\mathrm{CH}_{4}\right]$ is the total mixing ratio of $\mathrm{CH}_{4}$ in the atmosphere which includes all isotopologues, $\mathrm{CH}_{4}={ }^{12} \mathrm{CH}_{4}+{ }^{13} \mathrm{CH}_{4}+\mathrm{CH}_{3} \mathrm{D}$

considering isotopologues ${ }^{12} \mathrm{CH}_{4}$ and ${ }^{13} \mathrm{CH}_{4}$ and how our measurements of $\delta^{13} \mathrm{C}$ are made, contributions from other isotopologues are not important. As in equation (4.11), the mass balance equations for ${ }^{12} \mathrm{CH}_{4},{ }^{13} \mathrm{CH}_{4}$ can be written as

$\mathrm{S}_{12 \mathrm{CH} 4}=\frac{\mathrm{d}}{\mathrm{dt}}\left[{ }^{12} \mathrm{CH}_{4}\right]+\frac{\left[{ }^{12} \mathrm{CH}_{4}\right]}{\tau_{12 \mathrm{CH} 4}}$
$\mathrm{~S}_{13 \mathrm{CH} 4}=\frac{\mathrm{d}}{\mathrm{dt}}\left[{ }^{13} \mathrm{CH}_{4}\right]+\frac{\left[{ }^{13} \mathrm{CH}_{4}\right]}{\tau_{13 \mathrm{CH} 4}}$

Dividing equation (4.13) by (4.12), the isotopic ratio of the source has the form

$\mathrm{R}_{\text {source }}=\left[\frac{\frac{\mathrm{d}}{\mathrm{dt}}\left[{ }^{13} \mathrm{CH}_{4}\right]+\frac{{ }^{13} \mathrm{CH}_{4}}{\tau_{13 \mathrm{CH} 4}}}{\frac{\mathrm{d}}{\mathrm{dt}}\left[{ }^{12} \mathrm{CH}_{4}\right]+\frac{{ }^{12} \mathrm{CH}_{4}}{\tau_{12 \mathrm{CH} 4}}}\right]_{\text {air }}$

Multiplying the right hand side of equation (4.14) with $\frac{\tau_{13 \mathrm{CH}_{4}}}{\tau_{13 \mathrm{CH}_{4}}}$ and using

$$
\tau_{13 \mathrm{CH}_{4}}=\alpha \tau_{12 \mathrm{CH}_{4}}
$$

we obtain

$$
\begin{aligned}
& \mathrm{R}_{\text {source }}=\left[\frac{\tau_{13 \mathrm{CH} 4} \frac{\mathrm{d}}{\mathrm{dt}}\left[{ }^{13} \mathrm{CH}_{4}\right]+{ }^{13} \mathrm{CH}_{4}}{\tau_{13 \mathrm{CH} 4} \frac{\mathrm{d}}{\mathrm{dt}}\left[{ }^{12} \mathrm{CH}_{4}\right]+\alpha^{12} \mathrm{CH}_{4}}\right]_{\text {air }} \\
& \text { since } \mathrm{R}=\frac{{ }^{13} \mathrm{CH}_{4}}{{ }^{12} \mathrm{CH}_{4}} \text { therefore } \\
& { }^{13} \mathrm{CH}_{4}=\mathrm{R}^{12} \mathrm{CH}_{4}
\end{aligned}
$$

and its time derivative has the form

$\frac{\mathrm{d}}{\mathrm{dt}}\left[{ }^{13} \mathrm{CH}_{4}\right]=\mathrm{R}^{\prime}{ }^{12} \mathrm{CH}_{4}+\mathrm{R} *\left[{ }^{12} \mathrm{CH}_{4}\right]^{\prime}$

where $\mathrm{R}^{\prime}$ and $\left[{ }^{12} \mathrm{CH}_{4}\right]$ ' are the time derivatives of $\mathrm{R}$ and $\left[{ }^{12} \mathrm{CH}_{4}\right]$ and will be defined here. 
From Equations (4.15),(4.16), (4.17), and (4.18) and after some simplification, equation (4.14) can be re- written simply as

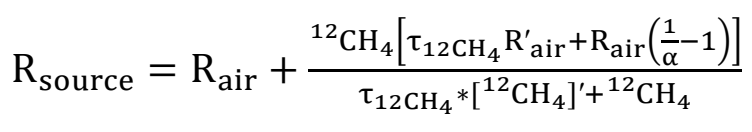

The terms in the right hand side of equation (4.19) can be calculated from measured parameters as follows

$$
\begin{aligned}
& \mathrm{R}_{\mathrm{air}}=\mathrm{R}_{\mathrm{VPDB}}\left(\frac{\delta^{13} \mathrm{C}_{\mathrm{air}}}{1000}+1\right) \\
& \mathrm{R}_{\mathrm{air}}^{\prime}=\frac{\mathrm{R}_{\mathrm{VPDB}}}{1000} \frac{\mathrm{d}}{\mathrm{dt}} \delta^{13} \mathrm{C}_{\mathrm{air}} \\
& { }^{12} \mathrm{CH}_{4}=\frac{\mathrm{CH}_{4}}{1+\mathrm{R}_{\mathrm{air}}} \\
& { }^{12} \mathrm{CH}_{4}{ }_{4}=\frac{\left.{ }^{12} \mathrm{CH}_{4} \mathrm{CH}_{4}^{\prime}-\mathrm{R}^{\prime} \text { air }{ }^{12} \mathrm{CH}_{4}\right)^{2}}{\mathrm{CH}_{4}}
\end{aligned}
$$

The carbon kinetic isotopic effect (KIE) $\alpha$ is taken as 1.0054 based on the calculations from equation (3.2). $\tau_{12 \mathrm{CH}_{4}}$ is the lifetime of ${ }^{12} \mathrm{CH}_{4}$ in the atmosphere and will be taken as the lifetime of $\mathrm{CH}_{4} 9.7$ yrs. Finally, $\delta^{13} \mathrm{C}_{\text {source }}$ can be obtained from

$\delta^{13} \mathrm{C}_{\text {source }}=\left[\frac{\mathrm{R}_{\text {source }}}{\mathrm{R}_{\mathrm{VPDB}}}-1\right] 1000$

where $\mathrm{R}_{\mathrm{VPDB}}=0.0112372$ for carbon isotope ratios [ Coplen, 1995]. 


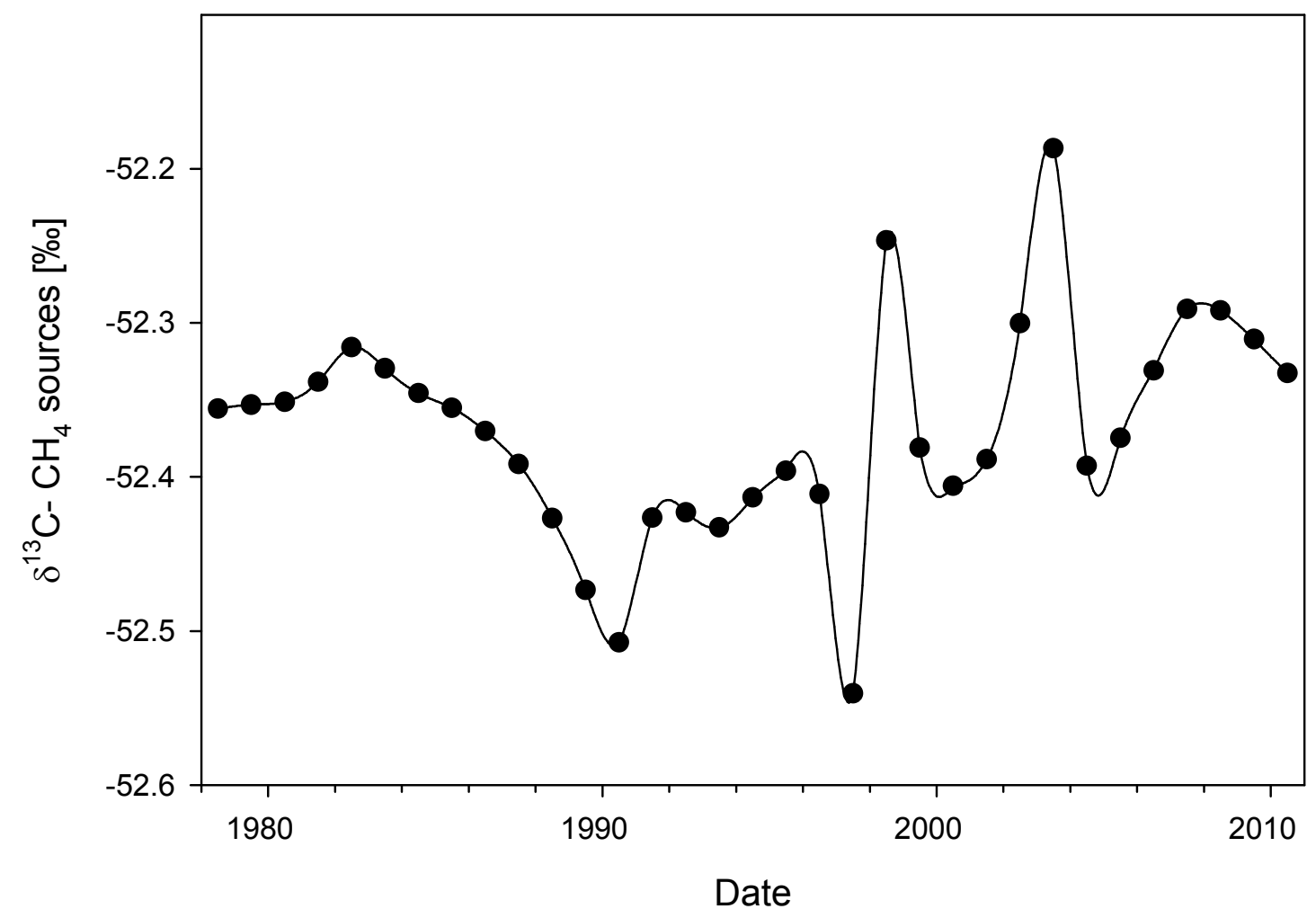

Figure 4.20 The annual $\delta^{13} \mathrm{C}$ of the $\mathrm{CH}_{4}$ sources during 1978-2010.

The flux weighted average $\delta^{13} \mathrm{C}$ of the global $\mathrm{CH}_{4}$ source based on our composite data is represented in figure 4.20. Values are represented in figure 4.20 are tabulated in table 4.2. The average value during $1978-2010$ is $-52.4 \pm 0.1 \%$. The most depleted value of the $\delta^{13} \mathrm{C}_{\text {of }} \mathrm{CH}_{4}$ sources during 1978-2010 occurred in 1997 with a value of $-52.5 \%$ while the most enriched of the $\delta^{13} \mathrm{C}_{\text {of }} \mathrm{CH}_{4}$ sources occurred in 2003 with a value of $52.2 \%$, a range of $0.3 \%$.

Figure 4.20 shows that $\delta^{13} \mathrm{C}$ of $\mathrm{CH}_{4}$ sources increases slowly during 1978-1982 from an annual value of $-52.4 \%$ in 1978 to be $-52.3 \%$ in 1982 . It then decreases rapidly and reaches a depleted value of $-52.5 \%$ in 1990. During $1991-1996, \delta^{13} \mathrm{C}_{\text {of }} \mathrm{CH}_{4}$ sources is constant with a value of $-52.4 \%$. A sharp decrease in $\mathrm{CH}_{4}$ emission during 1997 (as 
shown in figure 4.19) may be explained by a decrease in enriched source emissions (as shown in figure 4.20) such as biomass burning or fossil fuel. Therefore, $\delta^{13} \mathrm{C}$ of the $\mathrm{CH}_{4}$ sources become more depleted value during this period. The large spike of $\mathrm{CH}_{4}$ emissions (as shown in figure 4.19) during 1998 due to the increase in $\mathrm{CH}_{4}$ emissions from wetlands and boreal fires is also observed in figure 4.20 . This spike (-52.25\%o) confirms that the effect of boreal fires on atmospheric $\mathrm{CH}_{4}\left(\delta^{13} \mathrm{C} \sim-25 \%\right)$. $\delta^{13} \mathrm{C}$ of $\mathrm{CH}_{4}$ sources returns to $-52.4 \%$ after 1998 till 2001. This is followed by a sharp increase of $\delta^{13} \mathrm{C}$ of $\mathrm{CH}_{4}$ sources reaching to an enriched value of $-52.2 \%$ during 2003 . This may be the result of wildfires which occurred across Europe during August 2003 due to the extremely hot and dry weather conditions [Hodzic et al. 2007]. There were also Southern California wildfires which occurred in 2003 between October 20th and November 3rd [http://www.nws.noaa.gov/os/assessments/pdfs/Signed-Wildfire.pdf;

http://map.sdsu.edu/fireweb/]. A sharp dip to $-52.4 \%$ occurs in 2004 followed by a gradual increase through 2007. $\mathrm{CH}_{4}$ emission from sources increases rapidly from 2004 to 2008 and slows during 2008-2010 (as shown in figure 4.19). During this period, the $\delta^{13} \mathrm{C}$ of the $\mathrm{CH}_{4}$ sources increases gradually during 2004-2007 and decreases slowly during 2008-2010. This may occur due to an increase in emissions from enriched sources (such as fossil fuel with $\delta^{13} \mathrm{C} \sim-38 \%$ or biomass burning with $\delta^{13} \mathrm{C} \sim-25 \%$ ) during 20042007. The gradual depletion of $\delta^{13} \mathrm{C}$ of sources may be explained from increased emission from microbial sources $\left(\delta^{13} \mathrm{C} \sim-60 \%\right.$ ) during 2008-2010 or the decrease in emissions from an enriched source such as biomass burning or fossil fuel. 


\subsubsection{The $\delta \mathrm{D}$ of $\mathrm{CH}_{4}$ sources $1978-2005$}

The same procedures are followed to calculate the hydrogen isotope of methane sources $\delta \mathrm{D}_{\mathrm{s}}$. The mass balance equations for $\mathrm{CH}_{4}$ and $\mathrm{CH}_{3} \mathrm{D}$ can be written as in equation

$\mathrm{S}_{\mathrm{CH}_{4}}=\left[\mathrm{CH}_{4}\right]^{\prime}+\frac{\left[\mathrm{CH}_{4}\right]}{\tau_{\mathrm{CH}_{4}}}$

$\mathrm{S}_{\mathrm{CH}_{3} \mathrm{D}}=\left[\mathrm{CH}_{3} \mathrm{D}\right]^{\prime}+\frac{\left[\mathrm{CH}_{3} \mathrm{D}\right]}{\tau_{\mathrm{CH}_{3} \mathrm{D}}}$

Dividing equation (4.26) by (4.25), the ratio of the source has the form

$\frac{\mathrm{S}_{\mathrm{CH} 3 \mathrm{D}}}{\mathrm{S}_{\mathrm{CH} 4}}=4 \mathrm{R}_{\mathrm{D} . \text { source }}=\left[\frac{\left[\mathrm{CH}_{3} \mathrm{D}\right]^{\prime}+\frac{\left[\mathrm{CH}_{3} \mathrm{D}\right]}{\tau_{\mathrm{CH}_{3} \mathrm{D}}}}{\left[\mathrm{CH}_{4}\right]^{\prime}+\frac{\left[\mathrm{CH}_{4}\right]}{\tau_{\mathrm{CH}_{4}}}}\right]_{\text {air }}$

Multiplying the right hand side of equation (4.27) with $\frac{\tau_{C H_{3} D}}{\tau_{C_{3} D}}$ and using

$\tau_{C H_{3} D}=\alpha \tau_{C H_{4}}$

we got

$\mathrm{R}_{\text {source }}=\frac{1}{4}\left[\frac{\tau_{\mathrm{CH} 3 \mathrm{D}} \frac{\mathrm{d}}{\mathrm{dt}}\left[\mathrm{CH}_{3} \mathrm{D}\right]+\mathrm{CH}_{3} \mathrm{D}}{\tau_{\mathrm{CH} 3 \mathrm{D}} \frac{\mathrm{d}}{\mathrm{dt}}\left[\mathrm{CH}_{4}\right]+\alpha * \mathrm{CH}_{4}}\right]_{\text {air }}$

In case of hydrogen $\mathrm{R}=\frac{1}{4} \frac{\mathrm{CH}_{3} \mathrm{D}}{\mathrm{CH}_{4}}$ therefore

$\mathrm{CH}_{3} \mathrm{D}=4 \mathrm{R} \mathrm{CH}_{4}$

and its time derivative has the form

$\frac{\mathrm{d}}{\mathrm{dt}}\left[\mathrm{CH}_{3} \mathrm{D}\right]=4 \mathrm{R}^{\prime} \mathrm{CH}_{4}+\mathrm{R}\left[\mathrm{CH}_{4}\right]^{\prime}$

where $\mathrm{R}^{\prime}$ and $\left[\mathrm{CH}_{4}\right]^{\prime}$ are the time derivatives of $\mathrm{R}$ and $\left[\mathrm{CH}_{4}\right]$.

From Equations (4.28), (4.30), and (4.31) and after some simplifications, equation (4.29) can be re- written simply as 
$\mathrm{R}_{\text {source }}=\mathrm{R}_{\mathrm{air}}+\frac{\mathrm{CH}_{4}\left[\tau_{\mathrm{CH}_{4}} \mathrm{R}_{\text {air }}+\mathrm{R}_{\mathrm{air}}\left(\frac{1}{\alpha}-1\right)\right]}{\tau_{\mathrm{CH}_{4}} \mathrm{CH}_{4}{ }_{4}+\mathrm{CH}_{4}}$

The terms in the right hand side of equation (4.32) can be calculated from measured parameters as follows

$\mathrm{R}_{\mathrm{air}}=\mathrm{R}_{\mathrm{VSMOW}}\left(\frac{\delta \mathrm{D}_{\mathrm{air}}}{1000}+1\right)$

$\mathrm{R}_{\text {air }}^{\prime}=\frac{\mathrm{R}_{\mathrm{VSMOW}}}{1000} \frac{\mathrm{d}}{\mathrm{dt}} \delta \mathrm{D}_{\mathrm{air}}$

Here $\alpha$ is the hydrogen kinetic isotopic effect (KIE) which can be taken as 1.27 based on the calculations from equation (3.4) and the $\mathrm{CH}_{4}$ lifetime is taken as $9.7 \mathrm{yrs}$.

$\delta \mathrm{D}_{\text {source }}$ can be obtained from equation (4.32) as

$\delta \mathrm{D}_{\text {source }}=\left[\frac{\mathrm{R}_{\text {source }}}{\mathrm{R}_{\text {VSMOW }}}-1\right] * 1000$

where $\mathrm{R}_{\mathrm{VSMOW}}=0.00015574$ for hydrogen isotope ratios [Coplen, 1995].

The annual flux weighted average $\delta \mathrm{D}$ of $\mathrm{CH}_{4}$ sources during 1978-2005 is shown in figure 4.21. Values in this figure are included in table 4.2. During 1978-2005, $\delta$ D of the $\mathrm{CH}_{4}$ sources has an average value of $-286 \pm 3 \%$ with a minimum value of $-292 \%$ o occurring in 1997 and a maximum value of $-282 \%$ in 2003 . $\delta \mathrm{D}$ of the $\mathrm{CH}_{4}$ sources decreases slowly from $-283 \%$ in 1978 to $-284 \%$ in 1980 . It increases gradually from $284 \%$ in 1981 to $-283 \%$ in 1982 . Another slow decrease in $\delta \mathrm{D}$ of the $\mathrm{CH}_{4}$ sources begins in 1982 to a value of $-286 \%$ in 1987 and is followed by a more rapid decrease to $-291 \%$ o in $1990 . \delta \mathrm{D}$ of the $\mathrm{CH}_{4}$ sources increases after 1990 and reaches to a value of $-286 \%$ in 1996. A sharp dip occurs in 1997 with a value of $-292 \%$ followed by a large peak in 
1998 with a value $-282 \%$. This large 1998 peak in figure 4.21 is consistent with a large peak in $\mathrm{CH}_{4}$ emission (as in figure 4.19) and with a large peak $\delta^{13} \mathrm{C}_{\text {of }} \mathrm{CH}_{4}$ sources (as in figure 4.20). The main reason for this peak during 1998, as mentioned before, is $\mathrm{CH}_{4}$ emissions from boreal fires. Clearly, the effect of large spike during 1998 in both $\delta^{13} \mathrm{C}$ and $\delta \mathrm{D}$ of $\mathrm{CH}_{4}$ sources supports the hypothesis, that $\mathrm{CH}_{4}$ emissions from fires was greater than $\mathrm{CH}_{4}$ emission from wetlands. After the large spike in $1998, \delta \mathrm{D}$ of $\mathrm{CH}_{4}$ sources decreases sharply and reaches $-289 \%$ in 2000 . The sources become enriched in $\delta \mathrm{D}$ again in 2002-2003 with a value of $-282 \%$ during 2003. This large peak in $\delta \mathrm{D}$ of $\mathrm{CH}_{4}$ sources (as shown in figure 4.21) is consistent with a large peak in $\mathrm{CH}_{4}$ emission (see figure 4.19) and with a large peak in $\delta^{13} \mathrm{C}$ of $\mathrm{CH}_{4}$ sources (see figure 4.20). Therefore, these results suggest the 2003 spike in $\mathrm{CH}_{4}$ was caused by enriched sources, likely fire. A sharp decrease in $\delta \mathrm{D}$ of $\mathrm{CH}_{4}$ sources occurs after 2003 and reaches to $-291 \%$ in 2004 and $-290 \%$ in 2005. Since there are no available measurements of $\delta \mathrm{D}$ of atmospheric $\mathrm{CH}_{4}$ 2005-2010, a continued description is not feasible. 


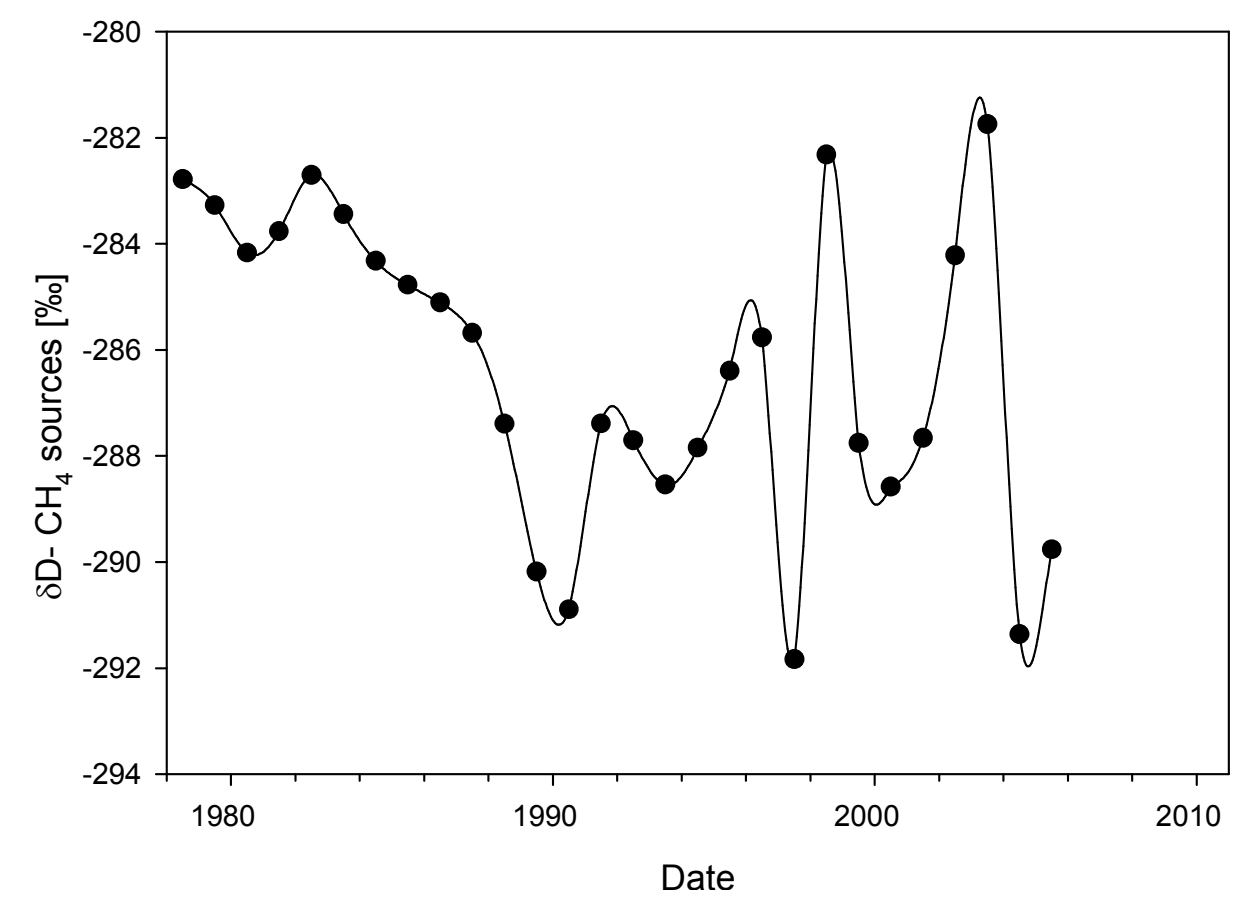

Figure 4.21. The annual $\delta \mathrm{D}$ of the $\mathrm{CH}_{4}$ sources during 1978-2005.

A classification of the $\mathrm{CH}_{4}$ emitted from sources has been discussed according to $\mathrm{CH}_{4}$ emitted from natural sources or anthropogenic sources [Khalil, 2000; IPCC2007]. Another classification was described according to their $\delta^{13} \mathrm{C}$ and $\delta \mathrm{D}$ values [Quay et al.1991; 1999]. In 1991, Quay et al. divided the $\mathrm{CH}_{4}$ emitted sources into three categories: biogenic sources such as wetlands, lakes, rice paddies; fossil fuel sources such as coal and natural gas; and biomass burning sources [Quay et al., 1999]. The biogenic sources are characterized by a depleted value of $\delta^{13} \mathrm{C}$ which ranges from $-65 \%$ for tundra to $-50 \%$ for landfills. The biogenic sources also have depleted values in $\delta \mathrm{D}$ and range from $-380 \%$ for termites to $-293 \%$ for landfills. Fossil fuel sources are characterized by with higher values of $\delta^{13} \mathrm{C}$ than biogenic sources. Their $\delta^{13} \mathrm{C}$ values range from -37 to -38 
$\%$. However, their $\delta \mathrm{D}$ values are the most enriched sources of these categories at $-175 \%$. Biomass burning sources are the most enriched value of $\delta^{13} \mathrm{C}$ between -24 to $-26 \%$ and their $\delta \mathrm{D}$ values are approximately $-210 \%$. For more information on isotopic signatures of $\mathrm{CH}_{4}$ sources see table 1.1.

Figure 4.22 shows the three main categories of $\mathrm{CH}_{4}$ emission sources. Using figure 4.20 and figure 4.21 , we can plot the annual values of $\delta^{13} \mathrm{C}$ of $\mathrm{CH}_{4}$ sources versus the annual values of $\delta \mathrm{D}$ of $\mathrm{CH}_{4}$ sources and correlate the resulting plot with the three categories of $\mathrm{CH}_{4}$ sources as shown in figure 4.23. This approach shows effect of three distinct source categories on the isotopic composition of $\mathrm{CH}_{4}$. This figure shows a decreasing contribution from fossil fuel emissions occurring during 1978-1980. This is followed by an increase in the emissions of biomass burning from 1981-1982. After 1982, (1983-1990) the fractional contributions from biomass burning and /or fossil sources gradually decrease while the fractional contributions from microbial sources increases. From 1991-1996, the prior $\mathrm{CH}_{4}$ trend in emissions between microbial and enriched sources reverses and enriched sources increase relative to microbial sources. The decrease in emissions from biomass burning and fossil fuel show up in 1997 as a dramatic anomaly in figure 4.23. The high $\mathrm{CH}_{4}$ emissions from boreal fires during 1998 appears as an increase in the biomass burning component. Another increase of biomass emission occurs during 2003. After 2003, the microbial emission increases relative to fossil fuel and biomass burning. 


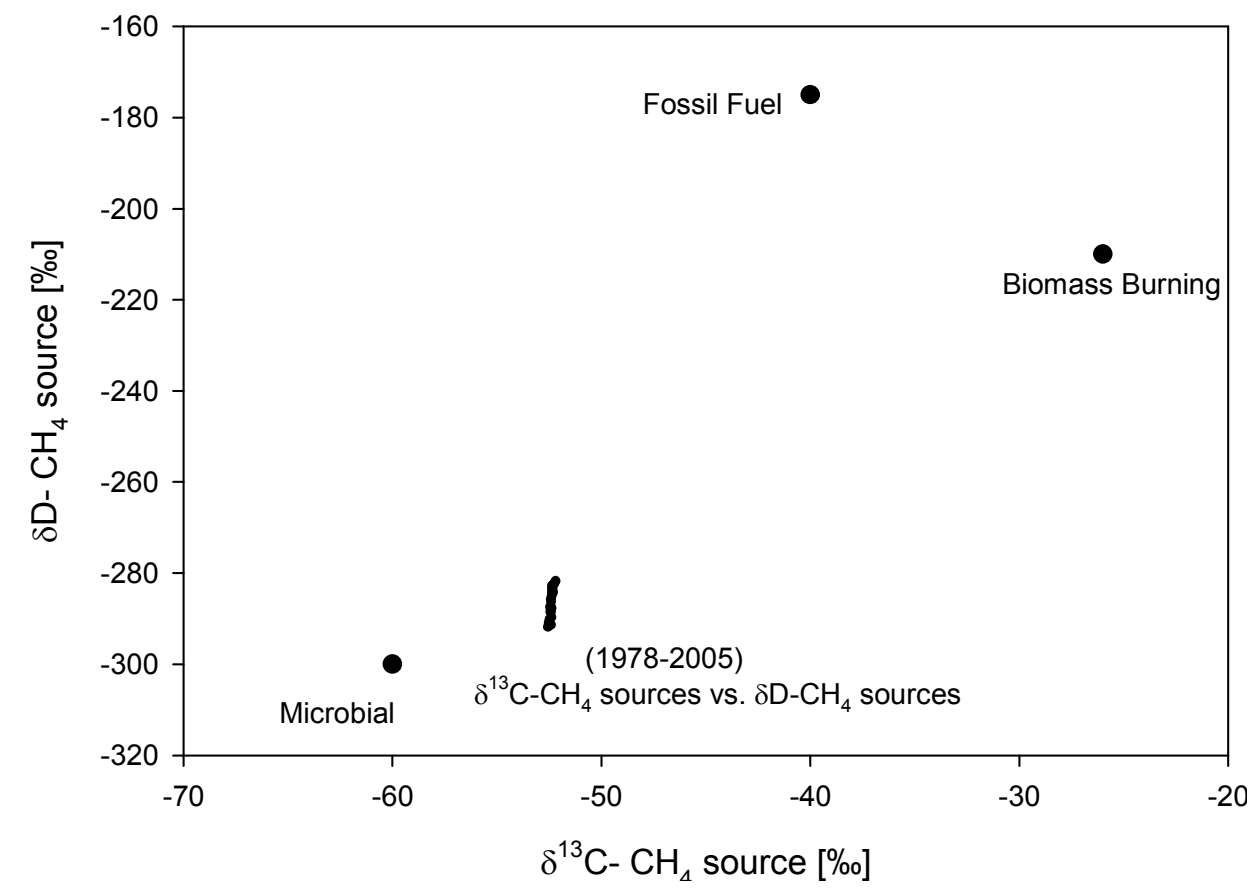

Figure 4.22. $\delta^{13} \mathrm{C}_{-} \mathrm{CH}_{4}$ source vs. $\delta \mathrm{D}-\mathrm{CH}_{4}$ source for Microbial, Fossil Fuel, and Biomass Burning with the results obtained from figure 4.20 and figure 4.21 during 1978-2005.

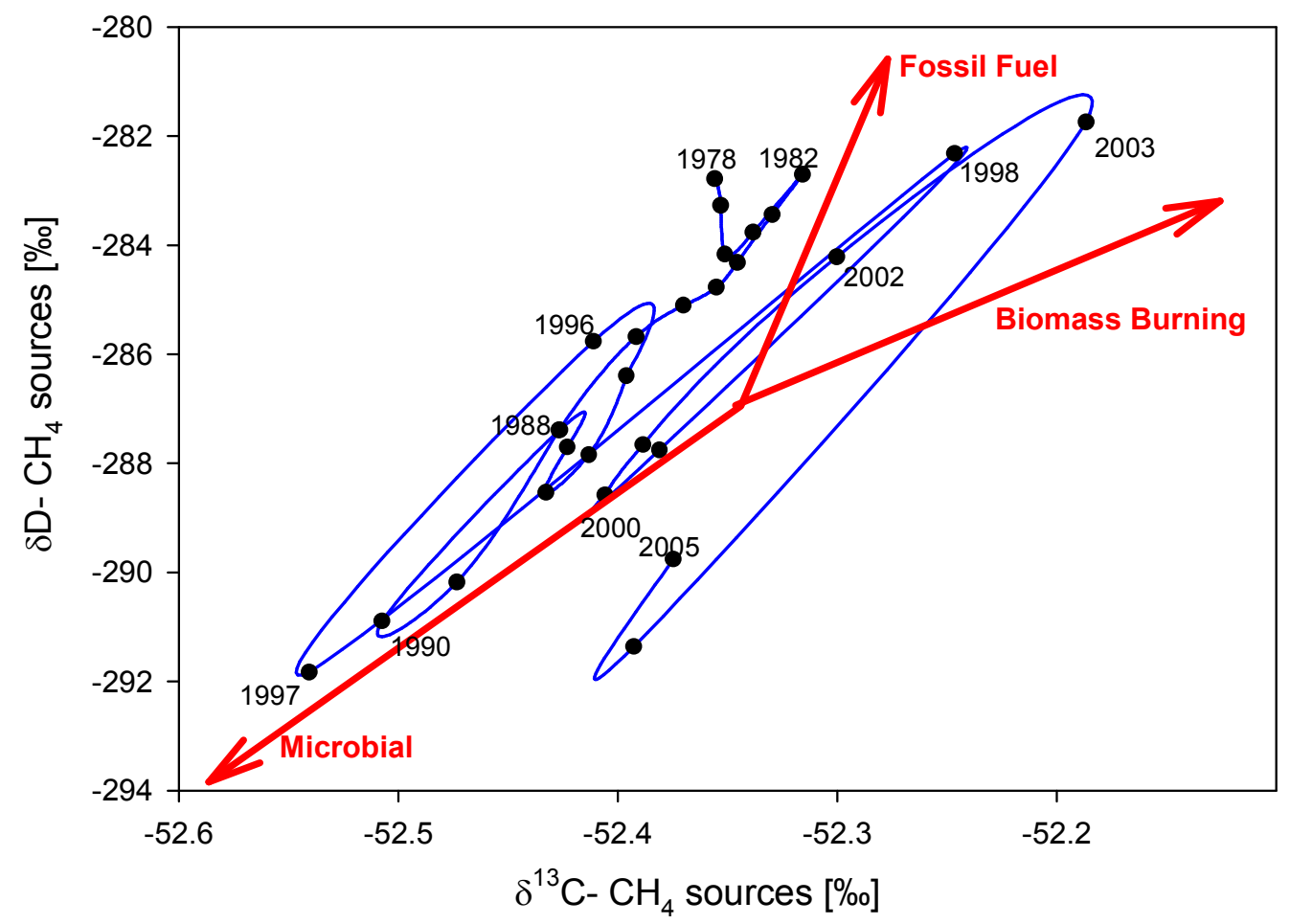

Figure 4.23. The annual values of $\delta^{13} \mathrm{C}-\mathrm{CH}_{4}$ sources vs. the annual values $\delta \mathrm{D}-\mathrm{CH}_{4}$ sources from figure 4.20 and figure 4.21 during 1978-2005. 


\section{Chapter 5}

\section{Summary and Conclusion}

Methane $\left(\mathrm{CH}_{4}\right)$, one of the most important greenhouse gases after water vapor and carbon dioxide, has a global warming potential 25 times than that of $\mathrm{CO}_{2}$ (based on a 100 year time horizon). Its atmospheric concentration has been increased more than double from the preindustrial era due to the anthropogenic human activities such as rice cultivation, biomass burning, and fossil fuel production. The rate of increase of atmospheric $\mathrm{CH}_{4}$ (or the growth rate) slowed from 1980 till present day. The main reason of these fluctuations is the interaction between $\mathrm{CH}_{4}$ sources and sinks.

This research focuses on the temporal changes in the isotopic composition of atmospheric $\mathrm{CH}_{4}$ over the last three decades. Isotopes can provide a better way to

estimate the $\mathrm{CH}_{4}$ budget and its change in time because of the distinct values of $\delta^{13} \mathrm{C}$ and $\delta \mathrm{D}$ for $\mathrm{CH}_{4}$ sources and characteristic isotopic fractionation effects in sinks.

For this work, we use four sets of archive samples brought from the Oregon Graduate Institute to Portland State University. The first and the longest air archive samples from Cape Meares, Oregon extended from 1977 to 1999. This archive includes 211 samples. The other three air archive sets are from South Pole, Samoa, and Mauna Loa. For South Pole air samples, they extended from January 1992 to February 1996 and include 15 samples. The Samoa air archive samples were collected from March 1995 to April 1996 and include 14 samples. The last air archive samples, Mauna Loa, Hawaii were collected from February 1995 to December 1995 and includes 11 samples. One of 
the uncertainties for the values obtained for these three air archive sets (other than Cape Meares) is most of these samples represent a mix of air samples collected over the same month during a year combined without knowing the fractional weighting for each date.

We developed a gas chromatography isotopic ratio mass spectrometer (GCIRMS) technique to measure the $\delta^{13} \mathrm{C}$ and $\delta \mathrm{D}$ for these samples as discussed in detail in section 2.2. We have calibrated it with isotopic standards measured by Professor Tyler at the University of California, Irvine relative to VPDB and VSMOW. Each archive sample was measured between 3 to 4 times for each analysis. The average precision for $\delta^{13} \mathrm{C}$ and $\delta \mathrm{D}$ are $0.08 \%$ and $2.3 \%$, respectively, when all uncertainties are accounted for. Also constructed and tested was an analytical method to measure $\mathrm{CH}_{4}$ mixing ratios using gas chromatography with a flame ionization detector (GC-FID) as presented in section 2.3. The calibrated gas used is synthetic air sample traceable to NIST SRM 1659a. The average precision of the GC measurements is $6 \mathrm{ppb}$ including uncertainty in the reference gas.

The results of measured values of $\mathrm{CH}_{4}$ mixing ratio, $\delta^{13} \mathrm{C}$, and $\delta \mathrm{D}$ from archive samples at Cape Meares were presented in sections 3.1, 3.2, and 3.3. For $\mathrm{CH}_{4}$ mixing ratio, we compared the measured values at PSU with continuous measurements at Cape Meares during 1979-1992 [Khalil et al., 1993] and NOAA measurements at Cape Meares during 1983-1998 [Dlugokencky et al., 2012]. We also compared our measured values at PSU with the measured values at OGI and found good sample stability over time. We also calculated the seasonal cycle of each dataset (PSU measured values, [Khalil et al., 
1993] and [Dlugokencky et al., 2012]) using a local weighted regression (LOWESS) and obtained a good agreement among the seasonal cycle trends of all of these datasets. The seasonal cycle of $\mathrm{CH}_{4}$ mixing ratio shows it has a broad maximum between October and April with a value of $8.5 \mathrm{ppb}$ and the lowest value occurs between July and August with a value of $-24.8 \mathrm{ppb} . \delta^{13} \mathrm{C}$ seasonal cycle shows that maximum values occur in May with a value of $0.1 \%$, and minimum values occur between September and October with a value of $-0.12 \%$. $\delta \mathrm{D}$ reaches its seasonal maximum in July with a value of $2.3 \%$ and a minimum in October with a value of $-1.7 \%$. Using the relation between the $\mathrm{CH}_{4}$-residual with $\delta^{13} \mathrm{C}$-residual and $\mathrm{CH}_{4}$-residual with $\delta \mathrm{D}$-residual, we obtained the kinetic isotopic effects of carbon and hydrogen in the $\mathrm{CH}_{4}$ sink reactions. The values obtained for ${ }^{13 \mathrm{C}} \alpha$ and ${ }^{\mathbf{D}} \alpha$ are $1.006 \pm 0.0007$ and $1.19 \pm 0.02$, respectively. We also found that $\delta \mathrm{D}$ seasonal cycle has a stronger anticorrelation with $\mathrm{CH}_{4}$ mixing ratio seasonal cycle than $\delta^{13} \mathrm{C}$ seasonal cycle. Additionally, we found that during January-May a significant enriched source is more prevalent (such as biomass burning and fossil fuel therefore $\delta^{13} \mathrm{C}$ and $\delta \mathrm{D}$ are increased) and during August-September a more depleted source is more prevalent. The measured values of recent mixing ratios for air samples collected at Cape Meares during March, 2012-September, 2012 were also presented. These data show similar features to the Cape Meares archive.

The measured values of $\mathrm{CH}_{4}$ mixing ratio, $\delta^{13} \mathrm{C}$ and $\delta \mathrm{D}$ at South Pole, Samoa, and Mauna Loa archives were presented in section 3.6. For $\mathrm{CH}_{4}$ mixing ratio, measured values at PSU were compared with those measured by NOAA [Dlugokencky et al., 2012] 
for three sites. For Samoa and Mauna Loa, their $\delta^{13} \mathrm{C}$ measured values at PSU were compared with those measured by Quay et al. [1999] during the same period. The $\delta \mathrm{D}$ measurements represent some of the only measurements for these sites during their time periods.

Additional datasets from three mid-latitude sites (Olympic Peninsula (OP), Montaña de Oro (MDO), Niwot Ridge (NWR)) were added to the Cape Meares (CM) dataset in order to describe the trend of $\mathrm{CH}_{4}$ and its isotopes from 1978 till 2010. Before using these datasets, we adjusted the three variables to the same scale, removed the latitudinal-dependence, and removed the seasonality. For $\mathrm{CH}_{4}$ mixing ratio, all the measured values were converted to the NOAA04 scale. For $\delta^{13} \mathrm{C}$ and $\delta \mathrm{D}$ at $\mathrm{CM}, \mathrm{MDO}$, and NWR, all the measured value were on the Tyler scale [Tyler et al., 2007]. For OP dataset, we compared between Samoa and Mauna Loa measured values at PSU with those measured by Quay et al. [1999] and found no significant difference between each of these datasets for these locations (i.e., there is no significant difference between the two scales). We removed the latitude-dependence by comparing the dataset for each variable at each site with Cape Meares during the intersection of collected time. To remove the seasonality from the corrected data (after adjusting their scales and making them latitudinal independent), we used LOWESS regression and calculated the average of the residuals based on the month of collection for each variable. The resulting seasonal cycles of $\mathrm{CH}_{4}$ mixing ratio, $\delta^{13} \mathrm{C}$, and $\delta \mathrm{D}$ show a good agreement for those determined for Cape Meares in chapter 3. The carbon and hydrogen isotopic effects were 
also obtained based on the residual values of $\mathrm{CH}_{4}, \delta^{13} \mathrm{C}$ and $\delta \mathrm{D}$ in the composite dataset. The values obtained for ${ }^{13 C} \alpha$ and ${ }^{\mathbf{D}} \alpha$ are $1.0036 \pm 0.0004$ and $1.21 \pm 0.02$, respectively.

After removing the seasonality from the composite data, we used LOWESS and Bootstrap techniques to obtain the secular trend and interannual variability for each variable and their uncertainties. The time rate of change of each variable is also obtained by fitting the smoothed data then differentiating it with respect to time. A comparison of the annual value of the growth rate of $\mathrm{CH}_{4}$ mixing ratio from the composite dataset with the annual value of the growth rate of $\mathrm{CH}_{4}$ mixing ratio from NOAA sites [Dlugokencky et. al, 2011] in the Northern and Southern hemisphere sites shows a high degree of correlation, $\mathrm{r}^{2}=0.7$. Using the annual values of $\mathrm{CH}_{4}$ mixing ratio, their growth rates, and a lifetime of 9.7 yrs, we calculated the total $\mathrm{CH}_{4}$ emissions during 1978-2010. We then developed equations to calculate the average $\delta^{13} \mathrm{C}$ and $\delta \mathrm{D}$ of $\mathrm{CH}_{4}$ sources based on measured values as the annual values $\mathrm{CH}_{4}$, their growth rates, $\delta^{13} \mathrm{C}$ and $\delta \mathrm{D}$ of atmospheric $\mathrm{CH}_{4}$, their time rates of change, the carbon and hydrogen kinetic isotopic effects, and $\mathrm{CH}_{4}$ lifetime. Results of this analysis suggest that no one source dominated the decrease in the $\mathrm{CH}_{4}$ trend. The period 1978-1980 shows a relative decrease of fossil fuel emission; 1980-1982 shows the fractional contributions from fossil fuel and/or biomass burning increases; 1982-1990 shows the fractional contribution from fossil fuel sources decrease while the fractional contribution from the microbial sources increase; 1990-1996 shows the fossil sources increase relative to the microbial sources; 1997 shows a dramatic decrease of fossil and biomass emissions relative to the microbial emissions. In 1998, the fire emissions show up as a large peak in the biomass burning 
relative to the fossil and microbial emissions. After 1998, the fractional contribution from the biomass burning decreases while the fractional contribution from microbial increases till 2000. During 2002-2003, there is another increase of biomass burning sources relative to the microbial sources reaching maximum in 2003. After 2003, the microbial emission increases relative to fossil and biomass burning. The spikes observed in 1998 and 2003 were due to the wildfires in boreal area in Northern hemisphere and Europe, respectively.

Beyond what is presented here, future work will use the data of each site and composite $\mathrm{CH}_{4}, \delta^{13} \mathrm{C}$, and $\delta \mathrm{D}$ datasets to calculate the global emissions of the three categories of $\mathrm{CH}_{4}$ sources: microbial, fossil fuel, and biomass burning during the time period 1978-2010. The knowledge of $\delta^{13} \mathrm{C}$ and $\delta \mathrm{D}$ from additional sites will improve these calculations by adding information on $\mathrm{CH}_{4}$ sources. For this work, we are collaborating with Dr. Chris Butenhoff and his graduate student Florain Roeger, who are using the GEOS- Chem (chemistry transport model) model. This model is developed by Harvard and has a resolution of $4^{\circ}$ (lat) $x 5^{\circ}$ (long) with 47 vertical layers. GEOS-Chem is a global 3-D chemical transport model (CTM) for atmospheric composition driven by meteorological input (such as temperature and pressure) from the Goddard Earth Observing System (GEOS) of the NASA Global Modeling and Assimilation Office. 


\section{References}

- Allan, W. H., H. Struthers, and D. Lowe, Methane carbon isotope effects caused by atomic chlorine in the marine boundary layer: Global results compared with Southern Hemisphere measurements, J. Geophys.Res., 2007. 112, (D04306), doi:10.1029/2006JD007369.

- Allan, W., M. R. Manning, K. R. Lassey, D. C. Lowe, and A. J. Gomez, Modeling the variation of $\delta^{13} \mathrm{C}$ in the atmospheric methane: Phase ellipses and kinetic isotope effect, Global Biogeochem. Cycles,2001. 15,p:467-481.

- Allan W., D.C. Lowe, and J.M. Cainey, Active chlorine in the remote marine boundary layer: Modeling anomalous measurements of $\delta^{13} \mathrm{C}$ in methane, Geophys.Res. Lett., 2001(a).28:p.3239-3242.

- Bartlett, K. B., and R. C. Harriss, reviewed and assessment of methane emission from wetlands, Chemosphere, 1993. 26:p.261-320.

- Bates, T. S., K. C. Kelly, J.E.Johnson, and R.H.Gammon, A reevaluation of the open ocean source of methane to the atmosphere. J. Geophys. Res., 1996, 101:p. 69536961.

- Bergamaschi,P., M. Braunlich,T. Marik, and C.A.M. Brenninkmeijer, Measurements of the carbon and hydrogen isotopes of atmospheric methane at Izafia, Tenerife: Seasonal cycles and synoptic-scale variations, J. Geophys. Res., 2000.105(D11):p.14, $531-14,546$. 
- Blake, D.R., and F.S. Rowland, Continuing worldwide increase in tropospheric methane 1978 to 1987, Science, 1988, 239(4844): p. 1129-1131,

- Blunier, T., J. Chappellaz, J.Schwander , J . Barnola,T. Desperts, B.Stauffer, , D. Raynaud, Atmospheric methane, record from a Greenland ice core over the last 1000 years. Geophys. Res. Lett., 1993, 20:p. 2219- 2222.

- Bousquet, P., P. Ciais, J. B. Miller, E. J. Dlugokencky, D. A. Hauglustaine, C. Prigent, G. R. Van der Werf, P. Peylin, E.-G. Brunke, C. Carouge, R. L. Langenfelds, J. Lathie`re,

- F. Papa, M. Ramonet, M. Schmidt, L. P. Steele, S. C. Tyler and J. White, contribution of anthoropogenic and natural sources of atmospheric methane variability. Nature, 2006, 443:p.doi:10. 1038/nature 05132.

- Brass, M. and T. R_ckmann, Continuous-flow isotope mass spectrometry method for carbon and hydrogen isotope measurements on atmospheric methane, Atmo. Meas. Tech Discuss., 2010. 3:p-24333-2476.

- Bräunlich, M., O. Aballain,T. Marik,P. Jöckel,C. A. M. Brenninkmeijer,J. Chappellaz,, J. Barnola,R. Mulvaney, and W. T. Sturges, Changes in the global atmospheric methane budget over the last decades inferred from $13 \mathrm{C}$ and $\mathrm{D}$ isotopic analysis of Antarctic firn air. J. Geophys. Res., 2001.106(D17): p. 20,465-20,481.

- Brook, E. J., T. Sowers, J. Orchardo, Rapid variations in atmospheric methane concentration during the past 110,000 years, Science, 1996, (273):p.1087-1091.

- Cantrell, C.A., R.E. Shetter, A.H. McDaniel, J.G.Calvert, J.A. Davidson, D.C. Lowe, S.C. Tyler, R.J. Cicerone, and J.P. Greenberg, Carbon kinetic isotope effect in the 
oxidation of methane by hydroxyl radicals. J. Geophys. Res., 1990.95:p.2245522462.

- Cao, M, K. Gregson, S. Marshall, J. B. Dent, and O. W. Heal, Global methane emission from rice paddies.Chemosphere, 1996, (33):p.879-897.

- Chappellaz,J .A., I.Y. Fung, and A.M. Thompson, The atmospheric $\mathrm{CH}_{4}$ increase since the last glacial maximum,1, Source estimates, Tellus, Ser. B, 1993.45:p. 228241.

- Cicerone, R.J., R.S. Oremland., Biogeochemical aspects of atmospheric methane, Global Biogeochem., 1988. 2:p. 299- 327.

- Cleveland, W.S., S.J. Devlin, Locally Weighted Regression: An Approach to Regression Analysis by Local fitting, J. Americ. Statis. Asso.,1988.83(403):p. 596610. doi: $10.2307 / 2289282$.

- Cleveland, R. B.,W.S. Cleveland, J.E. McRae, and I. Terpenning, STL: A seasonaltrend decomposition procedure based on loess, J. Off. Stat.,1990.6:p.3-73.

- Coplen, T.B., Reporting of stable carbon, hydrogen, and oxygen isotopic abundances, IAEA Tec,DOC825,1995.p:31-34.

- Craig, H., C.C. Chou, Methane: the record in polar ice cores. Geophys. Res. Lett. 1982, 9:p. 1221- 1224.

- Crutzen, P., I. Aselmann., and W. Seiler, Methane production by domestic animals, wild ruminants, and other herbivorous fauna and humans, Tellus, 1986. (38B):p. 271284. 
- Crutzen, P.J., and M. O. Andreae, Biomass burning in the tropics: impact on the atmospheric chemistry and biogeochemical cycles, Science, 1990. 250 (4988):p. 1669-1678.

- Diaconis, P. and B.Erfon, Computer intensive methods in statistics, Technic. Rep. no.83,1983. Stanford University.

- Dlugokencky, E. J., L. Bruhwiler, J. W. C. White,L. K. Emmons,P. C. Novelli,S. A. Montzka,K. A. Masarie, P. M. Lang, A. M. Crotwell,J. B. Miller, and L. V. Gatti, Observational constraints on recent increases in the atmospheric $\mathrm{CH} 4$ burden. Geophys, Res. Lett. 2009.36(L18803): p.doi:10.1029/2009GL039780.

- Dlugokencky, E. J., R. C. Myers, P. M. Lang, K. A. Masarie, A. M. Crotwell, K. W. Thoning, B. D. Hall, J. W. Elkins, and L.P. Steele, Conversion of NOAA atmospheric dry air $\mathrm{CH} 4$ mole fractions to a gravimetrically prepared standard scale, J. Geophys. Res., 2005. 110(D18306), doi: 10.1029/2005JD006035.

- Dlugokencky, E. J., S. Houweling, L. Bruhwiler, K. A. Masarie, P. M. Lang, J. B. Miller, and P. P. Tans, Atmospheric methane levels off: Temporary pause or a new steady state?, Geophys. Res. Lett. , 2003, 30 (19): p.doi: 10.1029/2003GL018126.

- Dlugokencky, E., K. Masarie, P. Lang, and P. Tans, Continuing decline in the growth rate of the atmospheric methane burden. Nature, 1998, 393: p-447-450.

- Dlugokencky, E.J., L. P. Steele, P. M. Lang and K. M. Masarie, The growth rate and distribution of atmospheric $\mathrm{CH}_{4}$. J. Geophys. Res., 1994, 99(D8):p.17, 021-17,043. 
- Dlugokencky, E.J., L.P. Steele, P.M.Lange and K. M. Masarie, Atmospheric methane at Mauna Loa and Barrow observatories: Presentation and analysis of in situ measurements. J. Geophys. Res., 1995, 100(D11):p. 23103-23113.

- Dlugokencky, E.J., P.M. Lang, A.M. Crotwell, and K.A. Masarie 2012, Atmospheric Methane Dry Air Mole Fractions from the NOAA ESRL Carbon Cycle Cooperative Global Air Sampling Network, 1983-2011, Version: 2012-09-24, Path: ftp://ftp.cmdl.noaa.gov/ccg/ch4/flask/event/.

- Dlugokencky, E.J.,B.P. Walter, K.A. Masarie P.M. Lang, and E.S. Kasischke, Measurements of an anomalous global methane increase during 1998, Geophy. Res. Lett., 2001.28(3):p.499-502.

- Dlugokencky, E.J., E.G. Nisbet, R. Fisher, and D. Lowry, Global atmospheric methane: budget, changes and dangers, Phil. Trans. R. Soc. A2011.369:p-2058-2072.

- Dlugokencky, E. J., S. Houweling, L. Bruhwiler, K.A. Masarie, P.M. Lang, J.B. Miller, and P.P. Tans, Atmospheric methane levels off: temporary pause or a new steady-state? Geophys. Res. Lett., 2003.30( 1992) doi:10.1029/2003GL018126.

- Dlugokencky, E. J., K.A. Masarie, P.M. Lang, P. M., P.P. Tans, P. P., P.L. Steele, and E.G. Nisbet, A dramatic decrease in the growth rate of atmospheric methane in the northern hemisphere during 1992. Geophys. Res. Lett., 1994(a). 21:p. 4548(doi:10.1029/93GL03070).

- Dlugokencky, E. J., E.G.Dutton, P.C. Novelli, P.P. Tans, K.A. Masarie, K.O. Lantz, and $\mathrm{S}$. Madronich, Changes in $\mathrm{CH}_{4}$ and $\mathrm{CO}$ growth rates after the eruption of $\mathrm{Mt}$. 
Pinatubo and their link with changes in tropical tropospheric UV flux. Geophys. Res. Lett., 1996. 23:p. 2761-2764 (doi:10.1029/96GL02638).

- Donner, L., and V. Ramanathan, Methane and nitrous oxide: Their effects on the terrestrial climate, J. Atmos. Sci., 1980. 37: p.119-124.

- Draxler, R.R. and G.D.Rolph, 2012. HYSPLIT(HYbird Single-Particle Largrangian Integrated Trajectory) Model access via NOAA ARL READY Website ( http://ready.arl.noaa.gov/HYSPLIT.php) NOAA Air Resources Laborartory, Silver Spring, MD.

- Ehhalt, D. H, The atmospheric cycle of methane, Tellus, 1974. (26):p.58-70.

- Efron, B., Bootstrap methods: Another look at the jackknife, Ann. Statist., 1979. 7(1):p. 1-26.

- Etheridge, D. M., L. P. Steele, R. J. Francey, and R. L. Langenfelds, Atmospheric methane between 1000 A.D. and present: Evidence of anthropogenic emissions and climatic variability,J. Geophys. Res., 1998. 103(D13):p. 15,979-15,993.

- Ferretti, D. F., J.B. Miller, J. W.C. White, D.M.Etheridge, K.R. Lassey, D.C. Lowe, C. M. MacFarling Meure, C. M., M.F.Dreier,, C,M. Trudinger, T.D.V.Ommen, and R. L. Langenfelds, Unexpected changes to the global methane budget over the last 2000 years, Science, 2005.309:p.1714-1717.

- Francey, R., M. Manning, C. Allison, S. Coram, D. Etheridge, R. Langenfelds, D. Lowe, L. Steele, A history of $\delta^{13} \mathrm{C}$ in atmospheric $\mathrm{CH} 4$ from the Cape Grim Air Archive and Antarctic firn air. J. Geophys. Res., 1999. 104: p. 23631- 43643. 
- Fung, I., J. John, J. Lerner, E. Matthews, M. Prather, L. Steele, L., and P.Fraser, P., Three-dimensional model synthesis of the global methane cycle. J. Geophys. Res., 1991, 96:p.13033- 13065.

- Goody, R. M., and G. D. Robinson, Radiation in the troposphere and lower stratosphere, Quart. J. R. M. Soc., 1951. 77(332):p.151-187.

- George, L.A.,T.M. Hard and R.J. O'Brien, Measurements of Free Radicals OH and $\mathrm{HO}_{2}$ in Los Angeles Smog, J. Geophys. Res.-Atmo.,1999.104(D9):p.11643-11656.

- Hard, T.M., A.A. Mehrabzadeh, C.Y. Chan and R. J. O'Brien, FAGE measurements of tropospheric $\mathrm{HO}$ with measurements and model interferences, J. Geophys.Res.1992.97(D9):p.9795-9817.

- Hodzic, A., S. Madronich, B. Bohn, S. Massie, L. Menut, and C. Wiedinmyer, Atmos.Chem.Phys.Discuss., 2007.7:p.4705-4760.

- Houweling, S., G. R. van der Werf, K. K. Goldewijk, T. Rockmann, and I. Aben, Early anthropogenic $\mathrm{CH}_{4}$ emissions and the variation of $\delta^{13} \mathrm{CH}_{4}$ over the last millennium, Global Biogeochem. Cyc., 2008. 22(GB1002):p. doi:10.1029/2007GB002961.

- International Atomic Energy Agency, References and intercomparison material for stable isotopes of light elements(IAEA-TECDOC-825).

- IPCC, Climate Change 2007: The Physical Science Basis. Contribution of Working Group I to the Fourth Assessment Report of the Intergovernmental Panel on Climate Change (Chapter2), Cambridge University Press, Cambridge, United Kingdom and New York, NY, USA, 2007. 
- Jacobson, M. Z., Atmospheric pollution: history, science, and regulation. 2002, Camber. Univ. Press.

- Johnson, D. E., K.A. Johnson, G.M. Ward, and M. E. Branine, Ruminants and other animals, Atmospheric methane :its role in the global environment in :Khalil ,M.(Ed.), Atmospheric Methane: Its Role in the Global Environment, Springer-Verlag, New York, NY, 2000:p.112-133.

- Judd, A.G., Geological sources of methane. In: Khalil, M.(Ed.), Atmospheric Methane: Its Role in the Global Environment. Springer-Verlag, New York, NY, 2000:p. 280-303.

- Kasischke, E. S., and L. P. Bruhwiler, Emissions of carbon dioxide, carbon monoxide, and methane from boreal forest fires in 1998, J. Geophys. Res., 2003. 108(D1), doi:10.1029/2001JD000461.

- Khalil, M. A. K., and R. A. Rasmussen, Sources, sinks, and seasonal cycles of atmospheric methane. J. Geophys. Res., 1983, 88:p. 5131-5144.

- Khalil, M. A. K, C. L. Butenhoff, and R. A. Rasmussen, Atmospheric Methane: Trends and Cycles of Sources and Sinks. Environ. Sci. Technol., 2007. 41:p. 21312137.

- Khalil, M., M. J. Shearer, Sources of methane: an overview. In: Khalil, M. (Ed.), Atmospheric Methane: Its Role in the Global Environment, 2000, Springer-Verlag, New York, NY: p. 98-111. 
- Khalil, M., M.J. Shearer, Sources of methane: an overview. In: Khalil, M. (Ed.), Atmospheric Methane: Its Role in the Global Environment, 2000. Springer-Verlag, New York, NY: p. 98-111.

- $\quad$ Khalil, M., R. Rasmussen, M. Shearer, R. Dalluge, L. Ren, C. Duan, Factors affecting methane emissions from rice fields. J. Geophys. Res., 1998.103: p. 25219-25231.

- Khalil, M., and R. Rasmussen, Atmospheric methane: trends over the last 10,000 years, Atmos. Environ., 1987. 21: p. 2445- 2452.

- Khalil, M.A.K, R.A. Rasmussen, M.J. Shearer, S. Ge, and J. A. Rau, methane from coal burning, Chemosphere, 1993(a).(26):p. 473-477.

- Khalil, M.A.K., Atmospheric methane: An introduction, Atmospheric methane: its role in the global environment (M. A. K. Khalil, Ed.), Springer, 2000.

- Khalil, M.A.K., R.A. Rasmussen, and F. Moraes, Atmospheric Methane at Cape Meares: Analysis of a High Resolution Data Base and its Environmental Implications. J. Geophys. Res., 1993. 98(D8):p. 14,753-14,770.

- Lashof, D. A. and D. R. Ahuja, Relative contributions of greenhouse gas emissions to global warming. Nature, 1990.344: p 529 - 531 .

- Lassey, K. R., D.C. Lowe, and M.R. Manning, The trend in atmospheric methane $\delta^{13} \mathrm{C}$ and implications for isotopic constraints on the global methane budget, Global Biogeochem. Cyc., 2000.14:p.41-49.

- Lassey, K.R., D.C. Lowe, C.A.M. Brenninkmeijer, and A.J. Gomez, Atmospheric methane and its carbon isotopes in the Southern Hemisphere: their time series and an instructive model. Chemosp., 1993. 26:p. 95- 109. 
- Legrand, M., C. LORIUS, N. I. BARKOV and V. N. PETROV, Vostok (Antarctic ice core): atmospheric chemistry changes over the last climatic cycle (160,000 years). Atmos. Environ., 1988.22:p. 317-33.

- Lelieveld, J.,P. Crutzen, and F. Dentener, Changing concentration, lifetime and climate forcing of atmospheric methane. Tellus, 1998.50B:p.128-150.

- Lowe, D. C., C. A. M. Brenninkmeijer, S. C. Tyler, and E. J. Dlugokencky, Determination of the isotopic composition of atmospheric methane and its application in the Antarctic, J. Geophys. Res., 1991. 96(D8):p.15, 455-15,467.

- Lowe, D. C., M. R. Manning, G. W. Brailsford, and A. M. Bromley, The 1991-1992 atmospheric methane anomaly: Southern Hemisphere13C decrease and growth rate fluctuations, Geophys. Res. Lett., 1997.24(8):p.857-860.

- Lowe, D. C.,K. Koshy, T. Bromley, W. Allan, H. Struthers, F. Mani, and M. Maata, Seasonal cycles of mixing ratio and $13 \mathrm{C}$ in atmospheric methane at Suva, Fiji, J. Geophys. Res., 2004, 109(D23308), doi: 10.1029/2004JD005166.

- Lowe, D.C., C. A. M. Brenninkmeijer, G. W. Brailsford, K.R. Lassey ,A.J.Gomez, and E.G. Nisbet, Concentration and ${ }^{13} \mathrm{C}$ record of atmospheric methane in New Zealand and Antarctica: Evidence for changes in methane sources, J. Geophys. Res., 1994, 99(D8), p: 16,913-16,925.

- Matthews, D. E., and J. M. Hayes, Isotope-ratio-monitoring gas chromatographymass spectrometry, Anal. Chem., 1978. 50 (11): p. 1465-1473. 
- Merritt, D. A., J.M. Hayes, and D.J. Des Marais, Carbon isotopic analysis of atmospheric methane by isotope-ratio-monitoring gas chromatography-mass spectrometry, J. Geophys. Res., 1995. 100(D1), 1317-1326, doi: 10.1029/94JD02689.

- Miller, J. B., K. A. Mack, R. Dissly, J. W.C. White, E.J. Dlugokencky and P. P. Tans, Development of analytical methods and measurements of $13 \mathrm{C} / 12 \mathrm{C}$ in atmospheric $\mathrm{CH}_{4}$ from NOAA Climating Monitoring and Diagnostics Laboratory Global Air Sampling Network, J. Geophys. Res., 2002, 107(D13):p. doi: 10. 1029/2002JD00630.

- Miller. J.B., The carbon Isotopes composition of Atmospheric methane and its constraint on the global methane budget, Ch.16 in Stable isotopes and biosphereatmosphere interactions: processes and biological controls (Ed: L. B. Flanagan., J. R. Ehleringer, and D. E. Pataki) Elsevier Academic Press, 2005.

- Mischler, J.A.,T. A. Sowers,R. B. Alley,M. Battle,J. R. McConnell, L. Mitchell, T. Popp, E. Sofen, and M. K. Spencer, Carbon and hydrogen isotopic composition of methane over the last 1000 years, Global Biogeochem. Cy., 2009. 23(GB4024) doi:10.1029/2009GB003460.

- Morimoto,S., S. Aoki, T. Nakazawa, and T. Yamanouchi, Temporal variations of the carbon isotopic ratio of atmospheric methane observed at Ny Ålesund, Svalbard from 1996 to 2004, J. Geophys. Res., 2006. 33(L01807), doi: 10.1029/2005GL024648.

- Nelson, R. C., E. K. Plyer, and W. S. Benedict, Absorption spectrum of $\mathrm{CH}_{4}$ in the Near Infrared, Journal of research of the national Bureau of Standards, 1948, 41: p615-621. 
- Poppe, D., J. Zimmerman and H. Dorn, Field data and model calculations for the hydroxyl radical. J. Atmos. Sci., 1995.52: p. 3402-3407.

- Prather, M. J., Time scales in atmospheric chemistry: Theory, GWPs for $\mathrm{CH}_{4}$ and CO, and runaway growth, Geophys. Res. Lett., 1996. 23:p.2597-2600.

- Prinn, R.G., R.F.Weiss,B.R. Miller, J.Huang, F.N. Alyea, D.M.Cunnold,P.J. Fraser, D.E. Hartley, and P.G. Simmonds, Atmospheric trends and lifetime of $\mathrm{CH} 3 \mathrm{CCl} 3$ and global OH concentrations. Science, 1995. 269:p. 187- 198.

- Prinn,R., D. Cunnold, P. Simmonds, F. Alyea, R.Boldi, A. Crawford, P. Freaser, D. Gutzl, D. Hartley, R. Rosen, and R. Rasmussen, Global average concentration and trend for hydroxyl radicals deduced from ALE/GAGE trichloroethane (Methyl Chloroform) data for 1978-1990. J. Geophy. Res., 1992.97(D2): p- 2445-2461.

- Prinn, R., D. Cunnold, R. Rasmussen, P. Simmonds, F. Alyea, A. Crawford, P. Fraser, and R. Rosen, Atmospheric Trends in Methyl chloroform and the global average for the hydroxyl radical. Science, 1987, 238(4829):p. 945-950.

- Prinn,R.G., J. Huang, R. F. Weiss, D. M. Cunnold,P. J. Fraser, P. G. Simmonds, A. McCulloch,C. Harth, P. Salameh, S. O’Doherty,R. H. J. Wang, L. Porter, and B. R. Miller, Evidence for substantial variations of Atmospheric hydroxyl radicals in the past two decades. Science, 2001. (292). doi: 10.1126/science.1058673.

- Quay, P., J. Stutsman, D. Wilbur,A. Snover, E. Dlugokencky, T. Brown, The isotopic composition of atmospheric methane. Glob. Biogeochem. Cyc., 1999, 13(2): p. 445461 
- Quay, P.D., S.L. King, J. Stutsman,D.O. Wilbur, L.P. Steele, I. Fung, R.H. Gammon, T.A. Brown, G.W. Farwell, P.M. Grootes, and F.H. Schmidt, Carbon isotopic composition of atmospheric $\mathrm{CH}_{4}$ : fossil and biomass burning source strengths. Global Biogeochem. Cyc., 1991. 5:p. 25- 47.

- Ramanathan, V., R.J. Cicerone, H.B. Singh, and J.T. Kiehl, Trace gas trends and their potential role in climate change, J. Geophy. Res., 1985, 80(D3): p.6647-6688.

- Rasmussen, R.M. and M.A.K. Khalil, Atmospheric Methane $\left(\mathrm{CH}_{4}\right)$ : Trends and Seasonal Cycles. J. Geophys. Res., 1981. 86(C10):p.9826-9832.

- Rice, A. L., A. A. Gotoh, H.O. Ajie, and S.C Tyler, High-precision continuous-flow measurement of $\delta^{13} \mathrm{C}$ and $\delta \mathrm{D}$ of atmospheric $\mathrm{CH}_{4}$, Anal. Chem., 2001.73(17):p.41044110.

- Rice, A.L., S.C. Tyler, M.C. McCarthy and E. Atlas, The Carbon and hydrogen isotopic compositions of startospheric methane:1 High-precision Observations from NASA ER-2 aircraft, J. Geophys. Res., 2003. 108(D15), 4460, doi:10.1029/2002JD003042.

- Rigby, M., R. G. Prinn, P. J. Fraser, P. G. Simmonds, R. L. Langenfelds,J. Huang, D. M. Cunnold, L. P. Steele, P. B. Krummel, R. F. Weiss, S. O'Doherty, P. K. Salameh, H. J. Wang, C. M. Harth, J. Mu"hle, and L. W. Porter, Renewed growth of $\begin{array}{llll}\text { atmospheric methane. J. } & \text { Geophy.Res., }\end{array}$ doi:10.1029/2008GL036037.

- Sanderson, M.G., Biomass of termites and their emissions of methane and carbon dioxide: a global database. Global Biogeochem. Cyc., 1996. 10: p- 543-557. 
- Santrock, J., S. A. Studley, and J. M. Hayes, Isotopic analyses based on the mass spectrum of carbon dioxide, Anal. Chem., 1985, 57: p7444-1448.

- Saueressig, G.,J. Crowley, P. Bergamaschi, C. Brühl, C. Brenninkmeijer, and H. Fischer.Carbon-13 and D kinetic isotope effects in the reactions of $\mathrm{CH}_{4}$ with $\mathrm{O}(1 \mathrm{D})$ and $\mathrm{OH}$ : New laboratory measurements and their implications for the isotopic composition of stratospheric methane. J. Geophys. Res., 2001.106(D19):p. 23,12723,138 .

- Seiler,W. and P.J.Crutzen, Estimates of gross and net fluxes of carbon between the biosphere and atmosphere from biomass burning, Clim. Change, 1980.2:p. 207-247.

- Snover, A., and P. Quay. Hydrogen and carbon kinetic isotope effects during soil uptake of atmospheric methane. Global Biogeochem. Cyc., 2000. 14(1):p. 25-39.

- Sowers, T., S. Bernard, O. Aballain, J. Chappellaz, J.M. Barnola, and T. Marik, Records of the $\delta^{13} \mathrm{C}$ of atmospheric $\mathrm{CH}_{4}$ over the last 2 centuries as recorded in Antarctic snow and ice, Global Biogeochem. Cy., 2005. 19(GB2002):p. doi:2010.1029/2004GB002408.

- Stauffer, B. , E. Lochbronner, H. Oeschger and J . Schwander, Methane concentration in the glacial atmosphere was only half that of the preindustrial Holocene, Nature, 1988. 332:p. 812-814.

- Steele, L.P., E. J. Dlugokencky, P.M. Lang, P.P. Tans, R.C. Martin, and K.A. Masarie, Slowing down of the global accumulation atmospheric methane during the 1980's, Nature, 1992. 358:p. 313-316. 
- Steele, L.P., P.J. Fraser, R.A. Rasmussen, M.A.K. Khalil, T.J. Conway, A.J. Crawford, R.H. Gammon, K.A. Masarie, and K.W. Thoning, The global distribution of methanein the troposphere, J. Atmos. Chem., 1987, 5:p. 125-171.

- Stevens, C. M., and F. E. Rust, The Carbon Isotopic Composition of Atmospheric M ethane, J. Geophys. Res., 1982, 87(C7):p. 4879-4882.

- Stevens, C. M., Atmospheric Methane. Chemic. Geol., 1988.71:p.11-21.

- Stevens, C. M., and M. Whalen, The isotopic composition of atmospheric methane and its sources, Atmospheric methane: its role in the global environment (Khalil, M. Ed.), Springer, 2000.

- Stolarski, R. S. and R. J. Cicerone, Stratospheric Chlorine: a Possible Sink for Ozone. Can. J. Chem., 1974 .52: p-1610-1615.

- Tans, P.P., A note on isotopic ratios and the global atmospheric methane budget, Global Biogeochem. Cyc., 1997. 11(1):p. 77-81.

- Thompson, A., The oxidizing capacity of the Earth's atmosphere: probable past and future changes. Science, 1992. 256:p.1157-1165.

- Thorneloe, S.A., M. A. Barlaz, R. Peer, L. C. Huff, L. Davis, and J. Mangino, Waste Mangement, Atmospheric methane: its role in the global environment (Khalil, M., Ed.), Springer, 2000.

- Tyler, S.C., A. L. Rice and H.O. Ajie, Stable isotope ratios in atmospheric $\mathrm{CH}_{4}$ : implications for seasonal sources and sinks. J. Geophys. Res., 2007.112(D03303): p.doi:10.1029/2006JD007231. 
- Tyler, S.C., G.W. Broilsford, K. Ykigi, K. Minami and R.J .Cicerone, Seasonal variations in methane flux and $\delta^{13} \mathrm{CH}_{4}$ values for rice paddies in Japan and their implications. Glob. Biogeochem. Cycl., 1994. 8(1):p. 1-12.

- Tyler, S.C., H.O.Ajie, A. L. Rice, R.J. Cicerone, and E. C. Tuazon, Experimentally determined kinetic isotope effects in the reaction of $\mathrm{CH}_{4}$ with $\mathrm{Cl}$ implications for atmospheric $\mathrm{CH}_{4}$.Geophys. Res. Let. , 2000. 27:p. 1715- 1718.

- Tyler, S.C., Stable Carbon Isotope Ratios in Atmospheric Methane and Some of Its Sources. J. Geophys. Res., 1986. 91(D12):p. 13,232-13,238.

- Vaghijani, G.L., and A.R. Ravishankara, New measurement of the rate coefficient for the reaction of $\mathrm{OH}$ with methane, Nature, 1991.350:p.406-409.

- Wennberg, P. O, Atmospheric chemistry: Radicals follow the Sun, Nature, 2006. 442:p.145-146.

- White, J.W.C. and B.H. Vaughn (2011), University of Colorado, Institute of Arctic and Alpine Research (INSTAAR), Stable Isotopic Composition of Atmospheric Methane (13C) from the NOAA ESRL Carbon Cycle Cooperative Global Air Sampling Network, 1998-2010, Version: 2011-11-09, Path: ftp://ftp.cmdl.noaa.gov/ccg/ch4c13/flask/event/.

- Whiticar, M.J., Can stable isotopes and global budget be used to constrain atmospheric methane budget? Atmospheric methane: its role in the global environment (Khalil, M., Ed.), Springer, 2000.

- Wolfsberg, M., Theoretical evaluation of experimentally observed isotope effects. Acco. Chem. Res., 1972.5(7):p.225-233. 
- Wubbles, D. J. and K. Hayhoe, Atmospheric methane and global change. EarthScience Rev, 2002.57:p.177-210.

- Yamada,K., Y. Ozaki, F. Nakagawa, M. Tanaka,N. Yoshid, An improved method for measurement of the hydrogen isotope ratio of atmospheric methane and its application to a Japanese urban atmosphere, Atmos. Envi., 2003. 37:p. 1975-1982.

- Zellner, R., and D. Ehhalt, Global aspects of atmospheric chemistry, Springer, 1999. 


\section{Appendix A}

\section{Tables}

Table A.1. Summary of the measured values of $\mathrm{CH}_{4}$ mixing ratio, $\delta{ }^{13} \mathrm{C}$, and $\delta \mathrm{D}$ for each tank in the Cape Meares air archived samples. The $\mathrm{CH} 4$ mixing ratio has been calculated using the Peak Area (P.A.) and Peak Height (P.H.) from equation (2.12)

\begin{tabular}{|c|c|c|c|c|c|c|c|c|c|c|c|}
\hline \multirow[t]{2}{*}{$\begin{array}{l}\text { Collected } \\
\text { date }\end{array}$} & \multirow[t]{2}{*}{ Tank \# } & \multicolumn{2}{|c|}{$\begin{array}{c}\text { PSU mixing ratio via } \\
\text { P.A.[ppb] }\end{array}$} & \multicolumn{2}{|c|}{$\begin{array}{c}\text { PSU mixing ratio via } \\
\text { P.H.[ppb] }\end{array}$} & \multicolumn{2}{|c|}{$\begin{array}{l}\text { OGI mixing } \\
\text { ratio[ppb] }\end{array}$} & \multicolumn{2}{|c|}{$\delta^{13} \mathrm{C}[\% \circ]$} & \multicolumn{2}{|c|}{$\delta \mathrm{D}[\%$} \\
\hline & & Ave. & Std. dev & Ave. & Std. dev & Ave. & $\begin{array}{l}\text { Std. } \\
\text { dev }\end{array}$ & Ave. & $\begin{array}{l}\text { Std. } \\
\text { dev }\end{array}$ & Ave. & $\begin{array}{l}\text { Std. } \\
\text { dev }\end{array}$ \\
\hline $10 / 1 / 1977$ & BY-1 & 1563.8 & 6.3 & 1572.2 & 4.3 & 1574.1 & 1.1 & -47.69 & 0.18 & -111.4 & 2.3 \\
\hline $4 / 3 / 1978$ & $\mathrm{O}-031$ & 1591.4 & 1.9 & 1593.6 & 1.8 & 1594.8 & 0.7 & -47.77 & 0.12 & -111.6 & 1.2 \\
\hline $4 / 4 / 1978$ & $\mathrm{O}-032$ & 1609.4 & 7.8 & 1609.8 & 2.3 & 1615 & & -47.61 & 0.14 & -112.1 & 2.8 \\
\hline $4 / 4 / 1978$ & $\mathrm{O}-036$ & 1598.1 & 4.0 & 1596.8 & 2.1 & 1602.9 & 1 & -47.48 & 0.15 & -106.7 & 1.8 \\
\hline $4 / 4 / 1978$ & O-029 & 1602.3 & 4.2 & 1609.9 & 1.7 & 1607.4 & 1.5 & -47.61 & 0.09 & -104.0 & 3.0 \\
\hline $4 / 6 / 1978$ & $\mathrm{O}-030$ & 1584.0 & 5.7 & 1608.1 & 2.8 & 1611.3 & 0.9 & -47.77 & 0.11 & -113.6 & 1.5 \\
\hline $4 / 6 / 1978$ & O-026 & 1607.6 & 4.7 & 1611.9 & 1.0 & 1610 & 1.5 & -47.65 & 0.09 & -110.3 & 1.8 \\
\hline $4 / 7 / 1978$ & $\mathrm{O}-004$ & 1604.3 & 4.3 & 1603.8 & 2.4 & 1607.7 & 1.8 & -47.88 & 0.07 & -109.5 & 1.7 \\
\hline $4 / 7 / 1978$ & O-028 & 1605.0 & 6.3 & 1606.7 & 1.9 & 1609 & 0.5 & -47.66 & 0.17 & -113.3 & 1.7 \\
\hline $4 / 7 / 1978$ & $\mathrm{O}-035$ & 1607.8 & 11.1 & 1599.1 & 2.2 & 1605.7 & 2.4 & -47.66 & 0.12 & -111.9 & 2.2 \\
\hline $4 / 7 / 1978$ & $\mathrm{O}-017$ & 1604.6 & 2.9 & 1608.1 & 2.5 & 1605.2 & 1.4 & -47.69 & 0.08 & -111.8 & 3.0 \\
\hline $4 / 7 / 1978$ & $\mathrm{O}-022$ & 1608.7 & 5.6 & 1608.9 & 1.4 & 1610 & 3.1 & -47.63 & 0.10 & -109.0 & 2.4 \\
\hline $4 / 7 / 1978$ & $\mathrm{O}-020$ & 1608.6 & 3.7 & 1613.2 & 1.0 & 1606.6 & 1.5 & -47.79 & 0.12 & -113.2 & 2.3 \\
\hline $10 / 5 / 1978$ & $\mathrm{O}-010$ & 1609.1 & 9.3 & 1611.4 & 5.3 & 1605.3 & 3.2 & -47.81 & 0.11 & -114.2 & 2.7 \\
\hline $10 / 5 / 1978$ & $\mathrm{O}-016$ & 1604.3 & 9.9 & 1610.0 & 4.6 & 1608.2 & 13 & -47.82 & 0.11 & -112.8 & 2.6 \\
\hline $10 / 5 / 1978$ & $\mathrm{O}-021$ & 1613.7 & 6.3 & 1615.3 & 2.0 & 1613.2 & 1.6 & -47.95 & 0.02 & -112.5 & 1.6 \\
\hline $11 / 3 / 1978$ & $\mathrm{O}-041$ & 1615.5 & 3.8 & 1615.1 & 3.5 & 1620.6 & 1.5 & -47.89 & 0.07 & -113.5 & 1.9 \\
\hline $11 / 3 / 1978$ & $\mathrm{O}-043$ & 1614.3 & 7.9 & 1615.6 & 2.3 & 1615 & 1.5 & -47.83 & 0.12 & -111.0 & 1.9 \\
\hline $11 / 3 / 1978$ & $\mathrm{O}-044$ & 1612.9 & 2.9 & 1618.0 & 1.8 & 1613.2 & 1.6 & -47.82 & 0.12 & -111.2 & 2.6 \\
\hline $11 / 22 / 1978$ & O-046 & 1617.2 & 4.4 & 1620.6 & 2.7 & 1623.2 & 1.9 & -47.66 & 0.08 & -112.5 & 2.8 \\
\hline $11 / 22 / 1978$ & O-048 & 1619.3 & 5.4 & 1620.2 & 3.0 & 1620 & 1.7 & -47.79 & 0.09 & -111.6 & 3.1 \\
\hline $11 / 22 / 1978$ & $\mathrm{O}-045$ & 1601.7 & 5.0 & 1609.5 & 1.9 & 1602.6 & 1.3 & -48.00 & 0.10 & -112.6 & 1.5 \\
\hline $12 / 20 / 1978$ & $\mathrm{O}-052$ & 1626.0 & 10.5 & 1621.5 & 3.4 & 1621.8 & 0.9 & -47.80 & 0.10 & -111.5 & 1.9 \\
\hline $1 / 3 / 1979$ & $\mathrm{O}-054$ & 1592.7 & 4.4 & 1593.0 & 1.7 & 1594 & 1.1 & -47.68 & 0.08 & -108.9 & 1.9 \\
\hline $1 / 16 / 1979$ & $\mathrm{O}-057$ & 1601.7 & 5.3 & 1600.4 & 1.5 & 1603.5 & 2.1 & -47.68 & 0.07 & -110.0 & 2.1 \\
\hline $2 / 16 / 1979$ & $\mathrm{O}-059$ & 1613.9 & 11.9 & 1616.0 & 4.2 & 1618.5 & 1.8 & -47.65 & 0.08 & -109.4 & 1.1 \\
\hline $4 / 20 / 1979$ & O-061 & 1618.4 & 5.1 & 1618.6 & 4.0 & 1615.5 & 1 & -47.63 & 0.09 & -110.6 & 1.4 \\
\hline $4 / 25 / 1979$ & O-064 & 1615.3 & 2.5 & 1610.4 & 2.3 & 1616.5 & 2.4 & -47.69 & 0.06 & -104.6 & 2.4 \\
\hline $5 / 18 / 1979$ & O-066 & 1592.2 & 4.9 & 1589.8 & 2.5 & 1597.5 & & -47.57 & 0.08 & -109.7 & 1.8 \\
\hline $5 / 18 / 1979$ & O-067 & 1604.4 & 9.1 & 1603.8 & 2.9 & 1609.2 & 1.9 & -47.53 & 0.10 & -107.7 & 3.0 \\
\hline $5 / 23 / 1979$ & O-068 & 1594.2 & 4.5 & 1596.9 & 1.6 & 1598.8 & 1.8 & -47.59 & 0.04 & -108.1 & 2.1 \\
\hline $7 / 12 / 1979$ & $\mathrm{O}-073$ & 1612.4 & 8.6 & 1608.5 & 4.2 & 1608.2 & 2.4 & -47.67 & 0.11 & -105.8 & 2.4 \\
\hline $8 / 3 / 1979$ & $\mathrm{O}-074$ & 1630.6 & 2.7 & 1629.1 & 2.8 & 1628.5 & 1.2 & -47.85 & 0.11 & -114.2 & 2.4 \\
\hline $8 / 3 / 1979$ & $\mathrm{O}-075$ & 1601.6 & 7.1 & 1600.9 & 2.5 & 1607.2 & 0.6 & -47.70 & 0.10 & -108.7 & 1.9 \\
\hline $8 / 17 / 1979$ & O-076 & 1585.9 & 4.1 & 1591.6 & 2.3 & 1592.8 & 1.9 & -47.62 & 0.06 & -105.7 & 2.4 \\
\hline $10 / 12 / 1979$ & $\mathrm{O}-078$ & 1633.8 & 10.3 & 1635.5 & 3.6 & 1643 & 3 & -47.74 & 0.07 & -116.3 & 2.6 \\
\hline $10 / 12 / 1979$ & O-079 & 1644.3 & 3.6 & 1641.4 & 2.7 & 1643.2 & 1.1 & -47.77 & 0.07 & -113.6 & 2.6 \\
\hline $12 / 19 / 1979$ & $\mathrm{O}-083$ & 1624.9 & 6.3 & 1621.6 & 3.8 & 1626.1 & 1.1 & -47.80 & 0.10 & -109.5 & 1.8 \\
\hline $1 / 17 / 1980$ & O-084 & 1636.7 & 6.8 & 1635.9 & 4.0 & 1637.6 & 1.3 & -47.67 & 0.11 & -108.8 & 2.8 \\
\hline $1 / 21 / 1980$ & O-086 & 1621.2 & 1.9 & 1634.3 & 2.3 & 1632.8 & 0.6 & -47.81 & 0.03 & -114.5 & 2.9 \\
\hline $2 / 7 / 1980$ & $\mathrm{O}-089$ & 1629.6 & 4.0 & 1637.0 & 2.7 & 1642.8 & 1.2 & -47.64 & 0.04 & -114.7 & 2.1 \\
\hline $2 / 8 / 1980$ & $\mathrm{O}-070$ & 1627.9 & 7.2 & 1632.4 & 6.6 & 1634.5 & 2.4 & -47.55 & 0.11 & -109.5 & 1.8 \\
\hline $2 / 8 / 1980$ & $\mathrm{O}-090$ & 1634.6 & 3.1 & 1635.3 & 2.5 & 1634.3 & 0.8 & -47.73 & 0.06 & -112.6 & 2.5 \\
\hline $3 / 3 / 1980$ & $\mathrm{O}-085$ & 1625.5 & 9.8 & 1621.8 & 5.6 & 1630.7 & 1.2 & -47.62 & 0.07 & -108.3 & 2.8 \\
\hline $3 / 25 / 1980$ & $\mathrm{O}-091$ & 1664.6 & 4.9 & 1668.2 & 3.1 & 1640 & 6 & -47.71 & 0.08 & -110.7 & 2.4 \\
\hline $4 / 15 / 1980$ & $\mathrm{O}-093$ & 1646.2 & 6.7 & 1647.3 & 2.6 & 1649.1 & 0.7 & -47.61 & 0.07 & -112.5 & 2.6 \\
\hline $4 / 15 / 1980$ & O-096 & 1639.6 & 7.6 & 1645.8 & 3.2 & 1649.2 & 2.2 & -47.69 & 0.09 & -109.5 & 2.7 \\
\hline $4 / 18 / 1980$ & O-098 & 1625.6 & 6.7 & 1630.5 & 2.6 & 1637.6 & 0.9 & -47.49 & 0.07 & -105.1 & 2.5 \\
\hline $4 / 18 / 1980$ & O-099 & 1625.1 & 3.6 & 1629.4 & 1.5 & 1638.2 & 1.5 & -47.50 & 0.08 & -108.8 & 1.6 \\
\hline $4 / 22 / 1980$ & O-102 & 1652.3 & 10.1 & 1652.9 & 4.6 & 1661.6 & 1.8 & -47.78 & 0.05 & -114.1 & 1.7 \\
\hline $4 / 29 / 1980$ & $\mathrm{O}-087$ & 1638.6 & 10.3 & 1650.9 & 3.5 & 1665.4 & 1.2 & -47.69 & 0.20 & -111.6 & 1.6 \\
\hline $4 / 29 / 1980$ & $\mathrm{O}-050$ & 1654.4 & 16.3 & 1646.6 & 3.6 & 1646.6 & 1.2 & -47.67 & 0.10 & -110.7 & 2.4 \\
\hline $4 / 29 / 1980$ & $\mathrm{O}-104$ & 1647.4 & 4.7 & 1645.5 & 2.1 & 1650.9 & 1.6 & -47.63 & 0.09 & -111.3 & 2.4 \\
\hline $6 / 10 / 1980$ & $\mathrm{O}-110$ & 1623.0 & 8.4 & 1623.8 & 2.7 & 1629.5 & 2.3 & -47.54 & 0.07 & -108.9 & 1.6 \\
\hline $7 / 8 / 1980$ & $\mathrm{O}-114$ & 1623.2 & 14.7 & 1616.9 & 6.3 & 1614.9 & 2 & -47.46 & 0.10 & -108.5 & 2.8 \\
\hline
\end{tabular}




\begin{tabular}{|c|c|c|c|c|c|c|c|c|c|c|c|}
\hline 7/17/1980 & O-115 & 1594.5 & 8.5 & 1597.3 & 3.4 & 1606.3 & 0.7 & -47.54 & 0.09 & -107.1 & 2.5 \\
\hline $7 / 30 / 1980$ & O-120 & 1632.9 & 25.1 & 1615.5 & 6.9 & 1613.1 & 1 & -47.56 & 0.05 & -109.7 & 2.6 \\
\hline $9 / 17 / 1980$ & $\mathrm{O}-113$ & 1647.4 & 3.4 & 1648.2 & 3.1 & 1654.6 & 1.2 & -47.91 & 0.09 & -112.7 & 2.0 \\
\hline $10 / 1 / 1980$ & O-109 & 1646.4 & 4.9 & 1650.7 & 1.8 & 1652.2 & 0.9 & -47.81 & 0.04 & -115.6 & 1.9 \\
\hline $10 / 15 / 1980$ & O-124 & 1641.7 & 12.8 & 1637.8 & 2.4 & 1641.9 & 0.6 & -47.73 & 0.05 & -109.3 & 1.6 \\
\hline $11 / 12 / 1980$ & O-125 & 1673.5 & 13.1 & 1669.9 & 2.7 & 1669.2 & 1.1 & -47.88 & 0.08 & -112.9 & 2.6 \\
\hline $11 / 26 / 1980$ & O-127 & 1631.7 & 4.1 & 1637.9 & 4.6 & 1638.6 & 0.8 & -47.67 & 0.06 & -111.3 & 2.1 \\
\hline $12 / 10 / 1980$ & O-129 & 1645.0 & 8.4 & 1642.1 & 2.8 & 1643.4 & 0.9 & -47.54 & 0.09 & -111.2 & 2.7 \\
\hline $12 / 31 / 1980$ & O-132 & 1599.2 & 3.6 & 1608.7 & 2.7 & 1610.8 & 1.6 & -47.49 & 0.08 & -112.3 & 2.6 \\
\hline $1 / 15 / 1981$ & $\mathrm{O}-133$ & 1619.7 & 6.1 & 1629.3 & 2.2 & 1607 & & -47.42 & 0.12 & $\begin{array}{l}-111.9 \\
\end{array}$ & 1.8 \\
\hline $2 / 25 / 1981$ & O-136 & 1641.0 & 6.2 & 1645.0 & 3.6 & 1651.9 & 1.7 & -47.48 & 0.09 & -108.5 & 3.0 \\
\hline $3 / 11 / 1981$ & O-138 & 1637.6 & 3.3 & 1640.4 & 2.2 & 1659.6 & 0.8 & -47.57 & 0.06 & -109.0 & 1.6 \\
\hline $3 / 18 / 1981$ & O-140 & 1663.2 & 4.0 & 1667.9 & 2.4 & 1669 & 1.9 & -47.69 & 0.08 & -110.5 & 2.6 \\
\hline $4 / 17 / 1981$ & O-158 & 1642.7 & 14.2 & 1640.5 & 3.4 & 1643 & 0.9 & -47.63 & 0.09 & -108.8 & 2.4 \\
\hline $4 / 29 / 1981$ & $\mathrm{O}-160$ & 1619.5 & 7.1 & 1628.2 & 3.9 & 1630.9 & 0.9 & -47.46 & 0.05 & -113.6 & 1.6 \\
\hline $5 / 13 / 1981$ & O-163 & 1650.7 & 3.5 & 1657.4 & 1.4 & 1659 & 1.2 & -47.55 & 0.09 & -110.8 & 2.2 \\
\hline $7 / 15 / 1981$ & $\mathrm{O}-170$ & 1622.6 & 2.6 & 1626.6 & 2.2 & 1634.6 & 1.6 & -47.48 & 0.06 & -106.6 & 2.0 \\
\hline $7 / 29 / 1981$ & O-171 & 1624.8 & 4.0 & 1641.3 & 2.8 & 1644.1 & 0.6 & -47.86 & 0.12 & -117.2 & 2.9 \\
\hline $9 / 2 / 1981$ & O-176 & 1637.6 & 5.5 & 1636.3 & 2.1 & 1643.6 & 2.5 & -47.72 & 0.08 & -108.2 & 2.2 \\
\hline $9 / 2 / 1981$ & O-177 & 1630.5 & 8.4 & 1639.1 & 2.8 & 1644.7 & 2 & -47.71 & 0.09 & -107.9 & 2.5 \\
\hline $9 / 16 / 1981$ & O-179 & 1651.5 & 4.1 & 1654.9 & 2.3 & 1662.6 & 1.7 & -47.93 & 0.04 & -112.3 & 1.9 \\
\hline $10 / 14 / 1981$ & O-183 & 1660.6 & 4.7 & 1670.5 & 1.9 & 1676.9 & 2.1 & -47.80 & 0.05 & -114.9 & 2.0 \\
\hline $10 / 14 / 1981$ & O-184 & 1689.5 & 10.8 & 1686.9 & 7.6 & 1681.6 & 0.8 & -47.96 & 0.07 & -112.3 & 1.9 \\
\hline $10 / 28 / 1981$ & O-185 & 1668.6 & 16.2 & 1671.0 & 4.2 & 1678.5 & 1.3 & -47.89 & 0.09 & -106.5 & 2.0 \\
\hline $12 / 2 / 1981$ & O-190 & 1654.1 & 5.6 & 1662.2 & 2.2 & 1666.6 & 0.8 & -47.81 & 0.08 & -112.3 & 2.3 \\
\hline $12 / 16 / 1981$ & O-192 & 1670.8 & 4.0 & 1671.1 & 2.6 & 1625 & 1 & -47.82 & 0.12 & $*$ & $*$ \\
\hline $12 / 30 / 1981$ & O-194 & 1668.2 & 6.0 & 1672.6 & 3.2 & 1675 & 1.5 & -47.78 & 0.04 & -108.0 & 1.9 \\
\hline $1 / 13 / 1982$ & O-196 & 1653.9 & 3.8 & 1655.4 & 2.1 & 1662.2 & 1 & -47.61 & 0.05 & -106.4 & 2.9 \\
\hline $2 / 3 / 1982$ & O-199 & 1653.1 & 3.2 & 1658.0 & 1.6 & 1663.4 & 2.1 & -47.59 & 0.11 & -107.3 & 2.1 \\
\hline $2 / 3 / 1982$ & $\mathrm{O}-200$ & 1667.1 & 4.1 & 1666.6 & 1.2 & 1672 & 2.5 & -47.67 & 0.07 & -114.7 & 2.3 \\
\hline $3 / 24 / 1982$ & $\mathrm{O}-205$ & 1650.0 & 3.2 & 1653.1 & 2.0 & 1657.8 & 0.8 & -47.55 & 0.09 & -106.3 & 1.7 \\
\hline $3 / 24 / 1982$ & O-206 & 1652.9 & 5.3 & 1653.8 & 2.5 & 1641 & 2 & -47.54 & 0.15 & -105.8 & 3.0 \\
\hline $4 / 7 / 1982$ & $\mathrm{O}-207$ & 1677.9 & 3.7 & 1682.4 & 0.9 & 1683.3 & 0.3 & -47.64 & 0.08 & -109.3 & 2.1 \\
\hline $4 / 21 / 1982$ & $\mathrm{O}-210$ & 1666.1 & 3.8 & 1671.9 & 1.9 & 1674.2 & 0.5 & -47.57 & 0.05 & -111.8 & 1.8 \\
\hline $6 / 2 / 1982$ & $\mathrm{O}-215$ & 1677.6 & 6.9 & 1672.1 & 5.6 & 1676 & 2.3 & -47.58 & 0.09 & -108.9 & 2.3 \\
\hline $6 / 30 / 1982$ & $\mathrm{O}-218$ & 1643.0 & 5.0 & 1644.6 & 2.6 & 1652.8 & 1.4 & -47.48 & 0.08 & -106.2 & 1.7 \\
\hline $7 / 14 / 1982$ & $\mathrm{O}-220$ & 1651.8 & 6.4 & 1653.0 & 4.7 & 1656.4 & 0.9 & -47.49 & 0.07 & -106.6 & 1.2 \\
\hline $7 / 28 / 1982$ & $\mathrm{O}-222$ & 1636.6 & 3.2 & 1641.6 & 2.6 & 1634 & 1.2 & -47.67 & 0.09 & -108.1 & 1.6 \\
\hline $8 / 11 / 1982$ & $\mathrm{O}-223$ & 1630.8 & 7.2 & 1635.8 & 3.9 & 1644.3 & 1.1 & -46.78 & 0.11 & -108.1 & 2.4 \\
\hline $9 / 22 / 1982$ & $\mathrm{O}-228$ & 1695.5 & 4.5 & 1699.1 & 3.2 & 1699 & 2.3 & -47.80 & 0.06 & -114.2 & 2.1 \\
\hline $11 / 30 / 1982$ & $\mathrm{O}-235$ & 1667.6 & 6.2 & 1671.6 & 3.1 & 1678.6 & 0.9 & -47.66 & 0.06 & -107.1 & 2.1 \\
\hline $12 / 8 / 1982$ & $\mathrm{O}-238$ & 1682.0 & 7.5 & 1682.7 & 1.4 & 1701.9 & 2.9 & -47.73 & 0.06 & -110.0 & 2.3 \\
\hline $12 / 29 / 1982$ & O-239 & 1693.5 & 8.7 & 1687.4 & 2.9 & 1692.7 & 1.8 & -47.72 & 0.08 & -111.5 & 2.1 \\
\hline $1 / 31 / 1983$ & $\mathrm{O}-243$ & 1689.0 & 9.9 & 1688.0 & 4.1 & 1689.1 & 1.3 & -47.66 & 0.06 & -110.1 & 2.5 \\
\hline $2 / 11 / 1983$ & $\mathrm{O}-246$ & 1671.3 & 4.9 & 1669.0 & 3.9 & 1674 & 1.2 & -47.57 & 0.06 & -106.6 & 2.7 \\
\hline $3 / 9 / 1983$ & O-249 & 1658.6 & 7.0 & 1662.8 & 1.5 & 1667.6 & 2.6 & -47.51 & 0.08 & -105.6 & 2.9 \\
\hline $4 / 6 / 1983$ & $\mathrm{O}-254$ & 1691.2 & 6.7 & 1697.5 & 2.6 & 1700.6 & 2 & -47.61 & 0.09 & -107.5 & 2.1 \\
\hline $4 / 20 / 1983$ & $\mathrm{O}-256$ & 1685.3 & 4.2 & 1690.0 & 1.8 & 1695.2 & 0.8 & -47.54 & 0.09 & -105.9 & 2.4 \\
\hline $5 / 4 / 1983$ & $\mathrm{O}-258$ & 1688.1 & 7.7 & 1698.6 & 6.7 & 1700.3 & 2.1 & -47.65 & 0.03 & -108.4 & 2.6 \\
\hline $5 / 28 / 1983$ & $\mathrm{O}-253$ & 1693.1 & 8.6 & 1692.4 & 3.3 & 1697 & 0.9 & -47.57 & 0.04 & -110.8 & 1.9 \\
\hline $6 / 1 / 1983$ & O-261 & 1685.2 & 2.8 & 1682.8 & 2.7 & 1685.1 & 0.6 & -47.54 & 0.07 & -108.7 & 2.9 \\
\hline $6 / 1 / 1983$ & $\mathrm{O}-262$ & 1680.3 & 6.3 & 1682.1 & 2.6 & 1690.1 & 2.3 & -47.42 & 0.12 & -108.9 & 2.6 \\
\hline $6 / 29 / 1983$ & $\mathrm{O}-265$ & 1653.7 & 7.1 & 1662.3 & 3.6 & 1668 & 1.7 & -47.46 & 0.07 & -104.8 & 2.0 \\
\hline $8 / 3 / 1983$ & O-269 & 1674.4 & 3.0 & 1678.1 & 2.4 & 1678.6 & 1.1 & -47.60 & 0.08 & -106.1 & 2.5 \\
\hline $8 / 3 / 1983$ & $\mathrm{O}-270$ & 1685.5 & 6.2 & 1679.6 & 3.1 & 1684.7 & 1.1 & -47.61 & 0.05 & -109.6 & 1.9 \\
\hline $8 / 31 / 1983$ & $\mathrm{O}-272$ & 1663.7 & 8.1 & 1663.4 & 3.9 & 1667.1 & 2.2 & -47.73 & 0.09 & -108.0 & 2.3 \\
\hline $9 / 14 / 1983$ & $\mathrm{O}-274$ & 1683.1 & 7.4 & 1682.8 & 2.4 & 1687.4 & 1.3 & -47.73 & 0.04 & -108.4 & 3.0 \\
\hline $10 / 12 / 1983$ & O-277 & 1706.7 & 1.3 & 1708.3 & 2.4 & 1711.2 & 1.2 & -47.78 & 0.10 & -111.4 & 2.0 \\
\hline $10 / 12 / 1983$ & $\mathrm{O}-278$ & 1711.2 & 2.8 & 1719.3 & 2.8 & 1721 & 0.7 & -47.47 & 0.08 & -114.5 & 2.4 \\
\hline $12 / 14 / 1983$ & $\mathrm{O}-285$ & 1702.8 & 2.9 & 1704.7 & 2.3 & 1713 & 1.8 & -47.70 & 0.11 & -109.5 & 2.7 \\
\hline $1 / 25 / 1984$ & $\mathrm{O}-287$ & 1697.6 & 4.1 & 1701.1 & 3.8 & 1703.3 & 0.6 & -47.63 & 0.06 & -110.0 & 2.9 \\
\hline $1 / 25 / 1984$ & $\mathrm{O}-288$ & 1696.9 & 7.0 & 1701.3 & 2.1 & 1706.4 & 2.4 & -47.75 & 0.06 & -108.1 & 0.9 \\
\hline $2 / 10 / 1984$ & O-289 & 1691.8 & 2.7 & 1692.0 & 1.0 & 1698.3 & 1.4 & -47.58 & 0.10 & -107.3 & 2.6 \\
\hline $6 / 27 / 1984$ & $\mathrm{O}-302$ & 1668.0 & 4.9 & 1672.3 & 3.0 & 1675.8 & 1.6 & -47.39 & 0.09 & $\begin{array}{l}-103.9 \\
\end{array}$ & 3.0 \\
\hline $7 / 11 / 1984$ & $\mathrm{O}-303$ & 1696.5 & 5.3 & 1695.9 & 1.1 & 1701.6 & 1 & -47.53 & 0.09 & -106.1 & 1.9 \\
\hline $9 / 26 / 1984$ & O-308 & 1647.5 & 4.5 & 1655.1 & 2.4 & 1658.8 & 1.2 & -47.77 & 0.08 & -108.7 & 2.7 \\
\hline $12 / 30 / 1984$ & O-311 & 1721.3 & 3.7 & 1735.5 & 2.3 & 1741.8 & 1.2 & -47.83 & 0.05 & -110.8 & 2.5 \\
\hline $1 / 17 / 1985$ & O-316 & 1697.4 & 3.6 & 1708.0 & 1.0 & 1709.8 & 1 & -47.66 & 0.06 & -109.1 & 3.1 \\
\hline $1 / 24 / 1985$ & O-317 & 1715.7 & 7.2 & 1726.3 & 3.9 & 1728.4 & 1.6 & -47.58 & 0.07 & -109.9 & 2.6 \\
\hline 9/13/1985 & O-286 & 1730.4 & 2.7 & 1736.5 & 1.5 & 1741.2 & 1.9 & -47.59 & 0.06 & -108.5 & 2.6 \\
\hline $10 / 24 / 1985$ & $\mathrm{O}-323$ & 1703.6 & 6.3 & 1708.2 & 3.4 & 1716.4 & 2 & -47.62 & 0.07 & -111.1 & 2.5 \\
\hline $8 / 14 / 1986$ & $\mathrm{O}-330$ & 1674.5 & 6.0 & 1672.2 & 2.9 & 1680 & 1.9 & -47.32 & 0.04 & -102.1 & 2.4 \\
\hline
\end{tabular}




\begin{tabular}{|c|c|c|c|c|c|c|c|c|c|c|c|}
\hline $10 / 14 / 1986$ & O-331 & 1730.1 & 1.7 & 1745.0 & 3.1 & 1752.1 & 0.8 & -47.65 & 0.12 & -107.2 & 3.0 \\
\hline $10 / 28 / 1986$ & O-332 & 1746.3 & 4.7 & 1747.1 & 2.6 & 1755.1 & 1.4 & -47.76 & 0.07 & -108.2 & 2.0 \\
\hline $12 / 4 / 1986$ & O-333 & 1750.6 & 5.0 & 1757.1 & 3.5 & 1759.5 & 1.3 & -47.75 & 0.08 & -108.8 & 2.4 \\
\hline $1 / 23 / 1987$ & O-335 & 1771.6 & 6.5 & 1780.4 & 2.1 & 1781.5 & 0.7 & -47.62 & 0.08 & -109.8 & 1.3 \\
\hline $4 / 23 / 1987$ & O-339 & 1757.2 & 6.4 & 1757.4 & 2.9 & 1764.8 & 1.4 & -47.64 & 0.08 & -106.3 & 2.8 \\
\hline $4 / 23 / 1987$ & O-338 & 1764.6 & 4.2 & 1766.6 & 2.0 & 1767.2 & 1 & -47.47 & 0.08 & -105.1 & 2.7 \\
\hline $4 / 28 / 1987$ & $\mathrm{O}-340$ & 1739.6 & 4.8 & 1745.1 & 2.5 & 1752.1 & 1.6 & -47.42 & 0.08 & -103.9 & 1.9 \\
\hline $4 / 28 / 1987$ & O-341 & 1740.9 & 4.8 & 1749.3 & 3.4 & 1751.9 & 0.7 & -47.48 & 0.09 & -104.9 & 1.8 \\
\hline $6 / 16 / 1987$ & $\mathrm{O}-345$ & 1743.6 & 3.5 & 1751.9 & 0.6 & 1758.1 & 1.2 & -47.66 & 0.09 & -109.0 & 3.5 \\
\hline $6 / 16 / 1987$ & $\mathrm{O}-344$ & 1738.2 & 4.5 & 1746.9 & 2.3 & 1749.2 & 0.3 & -47.50 & 0.11 & -104.6 & 2.2 \\
\hline $3 / 17 / 1988$ & $\mathrm{O}-361$ & 1799.0 & 8.7 & 1800.5 & 3.3 & 1803.1 & 2 & -47.72 & 0.09 & -112.0 & 2.4 \\
\hline $8 / 29 / 1988$ & O-369 & 1749.0 & 7.5 & 1749.6 & 4.6 & 1756.5 & 1.1 & -47.61 & 0.12 & -103.1 & 2.8 \\
\hline $12 / 28 / 1988$ & R 348B & 1751.8 & 5.8 & 1772.2 & 4.1 & 1780.7 & 0.6 & -47.59 & 0.08 & -109.8 & 1.8 \\
\hline $1 / 17 / 1989$ & R 346B & 1769.8 & 5.2 & 1770.2 & 1.7 & 1782.2 & 1.2 & -47.54 & 0.05 & -106.2 & 1.9 \\
\hline $3 / 21 / 1989$ & RSP 371 & 1769.3 & 4.6 & 1771.8 & 2.3 & 1776 & 0.6 & -47.46 & 0.06 & -106.8 & 2.6 \\
\hline $3 / 29 / 1989$ & RSP 373 & 1783.3 & 9.8 & 1776.5 & 5.1 & 1779.9 & 1.7 & -47.51 & 0.09 & -112.5 & 1.8 \\
\hline $4 / 11 / 1989$ & RSP 379 & 1749.7 & 13.3 & 1759.3 & 3.6 & 1766 & 1.6 & -47.40 & 0.06 & -107.0 & 1.5 \\
\hline $4 / 12 / 1989$ & RSP 380 & 1805.1 & 21.0 & 1786.9 & 6.1 & 1791.8 & 1.5 & -47.53 & 0.11 & -105.2 & 2.2 \\
\hline $4 / 12 / 1989$ & RSP 381 & 1792.3 & 3.1 & 1792.1 & 1.6 & 1795.2 & 1.2 & -47.63 & 0.10 & -105.9 & 2.6 \\
\hline $5 / 3 / 1989$ & RSP 383 & 1784.8 & 13.7 & 1779.6 & 4.6 & 1779.5 & 1.3 & -47.35 & 0.09 & -107.8 & 3.0 \\
\hline $5 / 3 / 1989$ & RSP384 & 1779.8 & 8.4 & 1774.1 & 1.6 & 1780.9 & 1.5 & -47.42 & 0.10 & -103.5 & 2.5 \\
\hline $5 / 10 / 1989$ & RSP385 & 1774.7 & 3.8 & 1779.9 & 3.1 & 1780.6 & 1.2 & -47.52 & 0.09 & -104.0 & 2.3 \\
\hline $6 / 6 / 1989$ & RSP 386 & 1761.3 & 4.2 & 1769.9 & 0.9 & 1770.5 & 2.1 & -47.37 & 0.10 & -103.8 & 2.1 \\
\hline $8 / 4 / 1989$ & $\begin{array}{c}\text { CORSP } \\
387 \\
\end{array}$ & 1735.5 & 8.2 & 1735.9 & 1.0 & 1741.2 & 1.1 & -47.44 & 0.06 & -101.2 & 2.7 \\
\hline 8/10/1989 & $\begin{array}{c}\text { CORSP } \\
355 \\
\end{array}$ & 1756.9 & 8.5 & 1754.4 & 2.9 & 1761.2 & 2.1 & -47.54 & 0.09 & -104.6 & 2.6 \\
\hline $8 / 25 / 1989$ & $\begin{array}{c}\text { CORSP } \\
388\end{array}$ & 1773.8 & 7.4 & 1764.7 & 4.8 & 1770 & 1.4 & -47.54 & 0.09 & -104.8 & 2.3 \\
\hline $9 / 1 / 1989$ & $\begin{array}{c}\text { CORSP } \\
389 \\
\end{array}$ & 1738.8 & 1.9 & 1740.6 & 1.5 & 1742.4 & 1.1 & -47.42 & 0.05 & -102.9 & 2.5 \\
\hline $9 / 14 / 1989$ & $\begin{array}{c}\text { CORSP } \\
390\end{array}$ & 1807.0 & 9.1 & 1803.2 & 3.1 & 1809.3 & 1 & -47.70 & 0.07 & -109.0 & 2.0 \\
\hline $9 / 29 / 1989$ & $\begin{array}{c}\text { CORSP } \\
391\end{array}$ & 1764.9 & 5.6 & 1766.4 & 5.2 & 1769 & 1.2 & -47.49 & 0.10 & -103.6 & 2.3 \\
\hline $10 / 6 / 1989$ & RSP 392 & 1780.6 & 12.9 & 1771.5 & 4.9 & 1775.2 & 1.3 & -47.61 & 0.07 & -102.6 & 2.2 \\
\hline $10 / 12 / 1989$ & RSP 393 & 1771.4 & 4.5 & 1775.5 & 2.4 & 1779.4 & 0.8 & -47.61 & 0.04 & -104.2 & 2.0 \\
\hline $10 / 19 / 1989$ & RSP394 & 1801.0 & 8.6 & 1797.9 & 3.6 & 1792.2 & 1.5 & -47.77 & 0.16 & -105.1 & 1.4 \\
\hline $11 / 7 / 1989$ & $\begin{array}{c}\text { CORSP3 } \\
96 \\
\end{array}$ & 1763.3 & 5.9 & 1768.4 & 4.5 & 1768.3 & 0.3 & -47.47 & 0.10 & -105.6 & 2.3 \\
\hline $11 / 10 / 1989$ & $\begin{array}{c}\text { CORSP } \\
397\end{array}$ & 1754.5 & 13.6 & 1761.8 & 5.6 & 1766.4 & 0.9 & -47.53 & 0.09 & -104.5 & 2.0 \\
\hline $11 / 19 / 1989$ & $\begin{array}{c}\text { CORSP } \\
398\end{array}$ & 1799.3 & 2.9 & 1807.8 & 3.5 & 1809.3 & 2.2 & -47.56 & 0.09 & -108.4 & 2.1 \\
\hline $11 / 21 / 1989$ & $\begin{array}{c}\text { CORSP } \\
399\end{array}$ & 1758.9 & 6.2 & 1760.6 & 2.6 & 1768.2 & 1.8 & -47.55 & 0.07 & -107.1 & 1.9 \\
\hline $3 / 20 / 1990$ & $\begin{array}{c}\text { CORSP } \\
402 \\
\end{array}$ & 1781.9 & 6.4 & 1778.2 & 3.5 & 1784.5 & 1.5 & -47.43 & 0.05 & -104.0 & 1.9 \\
\hline $3 / 27 / 1990$ & $\begin{array}{c}\text { CORSP } \\
403\end{array}$ & 1812.6 & 1.9 & 1815.3 & 2.8 & 1814.8 & 1.4 & -47.51 & 0.08 & -106.1 & 1.4 \\
\hline $4 / 14 / 1990$ & $\begin{array}{c}\text { CORSP } \\
405 \\
\end{array}$ & 1745.3 & 6.9 & 1763.9 & 2.2 & 1769.5 & 0.9 & -47.37 & 0.09 & -105.6 & 1.6 \\
\hline $8 / 9 / 1990$ & $\begin{array}{c}\text { CORSP } \\
406\end{array}$ & 1733.5 & 5.6 & 1735.1 & 4.9 & 1736.3 & 1.5 & -47.31 & 0.09 & -99.7 & 2.8 \\
\hline $8 / 15 / 1990$ & $\begin{array}{c}\text { CORSP } \\
407\end{array}$ & 1749.7 & 6.9 & 1749.5 & 2.5 & 1755.5 & 1.5 & -47.44 & 0.06 & -102.3 & 2.6 \\
\hline $9 / 25 / 1990$ & $\begin{array}{c}\text { CORSP } \\
408\end{array}$ & 1771.0 & 6.0 & 1775.3 & 3.9 & 1776.5 & 1.1 & -47.60 & 0.02 & -102.9 & 2.9 \\
\hline $4 / 22 / 1991$ & $\begin{array}{c}\text { CORSP } \\
409\end{array}$ & 1779.6 & 4.5 & 1784.0 & 3.3 & 1786.3 & 0.5 & -47.40 & 0.07 & -102.5 & 2.1 \\
\hline $2 / 10 / 1992$ & SPO 9 & 1827.3 & 12.8 & 1827.6 & 4.0 & 1829.5 & 0.3 & -47.42 & 0.11 & -107.8 & 2.6 \\
\hline $4 / 2 / 1992$ & $\begin{array}{c}\text { CORSP } \\
417\end{array}$ & 1793.8 & 7.8 & 1789.9 & 1.9 & 1791.4 & 0.4 & -47.46 & 0.13 & -99.8 & 1.8 \\
\hline $6 / 2 / 1992$ & SPO-298 & 1832.1 & 3.7 & 1835.1 & 1.8 & NA & NA & -47.74 & 0.14 & -112.1 & 3.7 \\
\hline 10/7/1992 & $\begin{array}{c}\text { CORSP } \\
418\end{array}$ & 1794.2 & 6.9 & 1803.6 & 2.8 & 1808.1 & 1 & -47.53 & 0.09 & -105.1 & 2.5 \\
\hline $12 / 8 / 1992$ & $\mathrm{CO} 419$ & 1805.1 & 7.0 & 1811.9 & 3.4 & 1812.7 & 0.5 & -47.68 & 0.20 & -100.2 & 3.5 \\
\hline $12 / 29 / 1992$ & $\mathrm{CO} 420$ & 1803.0 & 5.1 & 1813.2 & 2.0 & 1819.4 & 0.7 & -47.65 & 0.12 & -100.0 & 2.5 \\
\hline $5 / 6 / 1993$ & $\mathrm{CO} 426$ & 1828.1 & 21.6 & 1816.2 & 4.3 & 1820 & 1.4 & -47.37 & 0.07 & -101.3 & 1.9 \\
\hline $5 / 21 / 1993$ & $\mathrm{CO} 427$ & 1786.7 & 7.9 & 1793.4 & 7.4 & 1799.3 & 2.1 & -47.41 & 0.09 & -98.8 & 1.1 \\
\hline $6 / 17 / 1993$ & CO 428 & 1781.6 & 6.4 & 1784.6 & 2.7 & 1788.3 & 1.1 & -47.19 & 0.09 & -98.4 & 2.4 \\
\hline $10 / 8 / 1993$ & $\mathrm{CO} 433$ & 1819.6 & 7.4 & 1816.9 & 4.3 & 1825 & 0.9 & -47.68 & 0.07 & -103.8 & 2.8 \\
\hline $10 / 15 / 1993$ & CO 434 & 1806.8 & 11.6 & 1808.3 & 3.3 & 1809.6 & 0.4 & -47.48 & 0.09 & -102.1 & 2.6 \\
\hline
\end{tabular}




\begin{tabular}{|c|c|c|c|c|c|c|c|c|c|c|c|}
\hline $10 / 25 / 1993$ & $\mathrm{CO} 435$ & 1826.6 & 4.9 & 1825.3 & 2.3 & 1835.6 & 1.3 & -47.72 & 0.04 & -101.4 & 2.9 \\
\hline $12 / 8 / 1993$ & CO 438 & 1804.1 & 3.4 & 1804.9 & 4.7 & 1808.1 & 1.5 & -47.39 & 0.08 & -101.2 & 1.8 \\
\hline $5 / 10 / 1994$ & $\mathrm{CO} 442$ & 1815.4 & 11.7 & 1813.1 & 4.0 & 1825 & 2 & -47.09 & 0.03 & -102.9 & 2.9 \\
\hline $6 / 22 / 1994$ & $\begin{array}{c}\text { CORSP } \\
443\end{array}$ & 1798.4 & 6.1 & 1800.3 & 3.9 & 1804.7 & 3.7 & -47.35 & 0.12 & -101.9 & 2.0 \\
\hline $7 / 20 / 1994$ & $\begin{array}{c}\text { CORSP } \\
444\end{array}$ & 1764.8 & 3.9 & 1766.7 & 2.5 & NA & NA & -47.23 & 0.09 & -94.3 & 1.8 \\
\hline $8 / 12 / 1994$ & $\mathrm{CO} 445$ & 1769.3 & 7.3 & 1769.9 & 4.4 & NA & NA & -47.29 & 0.09 & -97.0 & 2.0 \\
\hline $11 / 11 / 1994$ & $\mathrm{CO} 447$ & 1809.6 & 3.3 & 1830.7 & 1.5 & NA & NA & -47.49 & 0.12 & -102.7 & 1.9 \\
\hline $11 / 14 / 1994$ & $\mathrm{CO} 448$ & 1833.0 & 6.9 & 1833.1 & 2.7 & NA & NA & -47.61 & 0.08 & -103.8 & 2.5 \\
\hline $3 / 30 / 1995$ & $\mathrm{CO} 450$ & 1809.9 & 6.0 & 1817.9 & 3.6 & NA & NA & -47.49 & 0.17 & -96.8 & 1.9 \\
\hline $6 / 16 / 1995$ & $\mathrm{CO} 452$ & 1800.7 & 8.1 & 1798.7 & 3.3 & NA & NA & -47.38 & 0.03 & -92.8 & 2.3 \\
\hline $10 / 11 / 1995$ & $\mathrm{CO} 453$ & 1819.2 & 5.3 & 1820.0 & 3.5 & NA & NA & -47.68 & 0.06 & -99.6 & 2.6 \\
\hline $12 / 28 / 1995$ & $\mathrm{CO} 454$ & 1819.4 & 4.6 & 1826.7 & 4.0 & NA & NA & -47.50 & 0.10 & -104.7 & 1.1 \\
\hline $1 / 10 / 1996$ & $\mathrm{CO} 455$ & 1821.9 & 10.5 & 1816.8 & 2.8 & NA & NA & -47.47 & 0.08 & -101.5 & 2.2 \\
\hline $2 / 16 / 1996$ & $\mathrm{CO} 456$ & 1816.8 & 2.9 & 1818.7 & 4.0 & NA & NA & -47.37 & 0.06 & -96.8 & 2.0 \\
\hline $2 / 29 / 1996$ & $\mathrm{CO} 457$ & 1834.4 & 11.8 & 1841.6 & 5.7 & NA & NA & -47.38 & 0.07 & -100.1 & 2.2 \\
\hline $3 / 29 / 1996$ & CO 458 & 1817.2 & 3.2 & 1820.8 & 1.2 & NA & NA & -47.31 & 0.09 & -97.1 & 3.9 \\
\hline $4 / 29 / 1996$ & CO 459 & 1819.3 & 6.7 & 1820.6 & 3.0 & NA & NA & -47.32 & 0.08 & -97.0 & 2.6 \\
\hline $5 / 31 / 1996$ & $\mathrm{CO} 460$ & 1813.8 & 3.7 & 1811.2 & 2.6 & NA & NA & -47.29 & 0.11 & -93.2 & 1.8 \\
\hline $7 / 2 / 1996$ & CO 461 & 1803.7 & 3.9 & 1804.2 & 1.9 & NA & NA & -47.34 & 0.03 & $*$ & $*$ \\
\hline $7 / 31 / 1996$ & $\mathrm{CO} 462$ & 1762.1 & 1.2 & 1766.0 & 1.5 & NA & NA & -47.10 & 0.07 & -91.2 & 2.7 \\
\hline $9 / 5 / 1996$ & $\mathrm{CO} 463$ & 1821.4 & 4.4 & 1826.8 & 1.4 & NA & NA & -47.70 & 0.12 & -101.7 & 2.3 \\
\hline $11 / 11 / 1996$ & $\mathrm{CO} 464$ & 1812.2 & 6.8 & 1818.9 & 0.7 & NA & NA & -47.51 & 0.08 & -98.6 & 1.7 \\
\hline $12 / 17 / 1996$ & O-051 & 1832.4 & 4.4 & 1831.7 & 3.1 & NA & NA & -47.45 & 0.08 & -102.7 & 2.3 \\
\hline $1 / 9 / 1997$ & $\mathrm{O}-278$ & 1818.0 & 2.9 & 1818.5 & 1.4 & NA & NA & -47.32 & 0.08 & -101.8 & 2.5 \\
\hline $2 / 20 / 1997$ & $\mathrm{O}-202$ & 1819.7 & 5.3 & 1820.3 & 2.7 & NA & NA & -47.50 & 0.05 & -96.5 & 2.3 \\
\hline $7 / 25 / 1997$ & $\mathrm{O}-027$ & 1798.6 & 11.2 & 1796.8 & 5.2 & NA & NA & -47.33 & 0.08 & -96.9 & 2.5 \\
\hline $12 / 12 / 1997$ & No Tag & 1818.6 & 8.7 & 1822.9 & 3.3 & NA & NA & -47.35 & 0.12 & -99.8 & 3.0 \\
\hline $3 / 13 / 1998$ & $\begin{array}{c}\text { WSCO- } \\
21\end{array}$ & 1810.5 & 5.7 & 1825.3 & 3.2 & NA & NA & -47.11 & 0.13 & -97.4 & 1.6 \\
\hline $6 / 19 / 1998$ & $\mathrm{CO} 343$ & 1811.3 & 8.9 & 1811.9 & 3.8 & NA & NA & -47.23 & 0.06 & -93.9 & 3.3 \\
\hline $8 / 24 / 1999$ & O-329 & 1783.0 & 7.7 & 1790.8 & 3.8 & NA & NA & -47.27 & 0.15 & -93.2 & 3.3 \\
\hline
\end{tabular}

Notes:

* We lost the air inside Tanks \# O-192 and CO 461. Therefore, there are not measured values of $\delta \mathrm{D}$ for both tanks. 
Table A.2. The seasonal value of $\mathrm{CH}_{4}$ mixing ratio based on the Cape Meares air archive samples collected during 1977-1999. These values are expressed on NIST scale

\begin{tabular}{|c|c|c|c|c|}
\cline { 3 - 5 } \multicolumn{1}{c|}{} & \multicolumn{3}{c|}{ CH $_{4}$-Resi [ppb] } \\
\hline Month & \# Rows & Ave. & Std Dev & Std Err \\
\hline Jan & 15 & 3.5 & 13.8 & 3.6 \\
\hline Feb & 13 & 6.7 & 12.1 & 3.4 \\
\hline Mar & 15 & 8.3 & 18.5 & 4.8 \\
\hline Apr & 39 & 5.1 & 10.5 & 1.7 \\
\hline May & 13 & 0.1 & 14.3 & 4.0 \\
\hline Jun & 15 & -5.3 & 16.2 & 4.2 \\
\hline Jul & 13 & -22.1 & 13.5 & 3.7 \\
\hline Aug & 16 & -24.9 & 18.0 & 4.5 \\
\hline Sep & 13 & -2.7 & 22.4 & 6.2 \\
\hline Oct & 24 & 8.5 & 12.9 & 2.6 \\
\hline Nov & 16 & 6.3 & 14.1 & 3.5 \\
\hline Dec & 19 & 7.6 & 12.6 & 2.9 \\
\hline
\end{tabular}

Table A.3. The seasonal value of $\mathrm{CH}_{4}$ mixing ratio at Cape Meares from continuous measurements during 1979-1992 [Khalil et al.1992], NOAA samples collected during 1983-1998 [Dlugokencky et al., 2012], and PSU measurements of air archive samples collected during [1977-1999]. All of three datasets are on the NOAA04 scale.

\begin{tabular}{|c|c|c|c|c|c|c|}
\cline { 2 - 7 } \multicolumn{1}{c|}{} & \multicolumn{7}{c|}{$\mathbf{C H}_{4}$ mixing ratio- Cape Meares [ppb] } \\
\hline & \multicolumn{2}{|c|}{ OGI continuous meas. } & \multicolumn{2}{c|}{ NOAA measurements } & \multicolumn{2}{c|}{ PSU archive } \\
\hline & Ave. & Std Err & Ave. & Std Err & Ave. & Std Err \\
\hline Jan & 4.0 & 2.4 & 7.7 & 1.9 & 3.5 & 3.6 \\
\hline Feb & 2.9 & 2.2 & 3.5 & 1.8 & 6.7 & 3.3 \\
\hline Mar & 5.0 & 1.7 & 8.8 & 1.6 & 8.3 & 4.8 \\
\hline Apr & 9.8 & 1.1 & 10.5 & 1.9 & 5.1 & 1.7 \\
\hline May & 5.4 & 1.3 & 3.9 & 1.0 & 0.1 & 4.0 \\
\hline Jun & -8.6 & 0.9 & -9.4 & 1.7 & -5.3 & 4.2 \\
\hline Jul & -21.0 & 1.6 & -25.8 & 2.3 & -22.1 & 3.7 \\
\hline Aug & -20.3 & 2.8 & -24.2 & 1.8 & -24.8 & 4.5 \\
\hline Sep & 1.3 & 1.7 & -1.0 & 2.8 & -2.7 & 6.2 \\
\hline Oct & 9.9 & 2.3 & 10.5 & 2.4 & 8.5 & 2.6 \\
\hline Nov & 6.2 & 1.5 & 8.6 & 2.2 & 6.3 & 3.5 \\
\hline Dec & 7.9 & 2.1 & 11.5 & 1.5 & 7.6 & 2.9 \\
\hline
\end{tabular}

Table A.4. The $\delta^{13} \mathrm{C}$ seasonal value based on the Cape Meares air archive samples collected during 19771999.

\begin{tabular}{|c|c|c|c|c|}
\cline { 3 - 5 } \multicolumn{2}{c|}{} & \multicolumn{3}{c|}{$\delta^{\mathbf{1 3}}$ C- Resi [\%o] } \\
\hline Month & \# Rows & Ave. & Std Dev & Std Err \\
\hline Jan & 15 & 0.00 & 0.09 & 0.02 \\
\hline Feb & 13 & 0.03 & 0.08 & 0.02 \\
\hline Mar & 15 & 0.04 & 0.09 & 0.02 \\
\hline Apr & 39 & 0.05 & 0.09 & 0.01 \\
\hline May & 13 & 0.11 & 0.10 & 0.03 \\
\hline Jun & 15 & 0.09 & 0.13 & 0.03 \\
\hline Jul & 13 & 0.09 & 0.12 & 0.03 \\
\hline
\end{tabular}




\begin{tabular}{|c|c|c|c|c|} 
Aug & 15 & 0.03 & 0.11 & 0.03 \\
\hline Sep & 13 & -0.12 & 0.13 & 0.04 \\
\hline Oct & 24 & -0.12 & 0.11 & 0.02 \\
\hline Nov & 16 & -0.09 & 0.10 & 0.02 \\
\hline Dec & 19 & -0.08 & 0.10 & 0.02 \\
\hline
\end{tabular}

Table A.5. The $\delta \mathrm{D}$ seasonal value baesd on the Cape Meares air archive samples collected during 19771999.

\begin{tabular}{|c|c|c|c|c|}
\hline & & \multicolumn{3}{|c|}{ SD- Resi [\%]] } \\
\hline Month & \# Rows & Ave. & Std Dev & Std Err \\
\hline Jan & 15 & -0.9 & 2.1 & 0.6 \\
\hline Feb & 13 & -0.4 & 2.8 & 0.8 \\
\hline Mar & 15 & 0.2 & 3.1 & 0.8 \\
\hline Apr & 39 & 0.6 & 2.5 & 0.4 \\
\hline May & 13 & 0.9 & 2.3 & 0.6 \\
\hline Jun & 15 & 1.1 & 3.8 & 1.0 \\
\hline Jul & 12 & 2.3 & 3.6 & 1.0 \\
\hline Aug & 16 & 2.0 & 2.3 & 0.6 \\
\hline Sep & 13 & -0.6 & 2.5 & 0.7 \\
\hline Oct & 24 & -1.7 & 2.5 & 0.5 \\
\hline Nov & 16 & -1.3 & 1.5 & 0.4 \\
\hline Dec & 18 & -1.5 & 2.3 & 0.5 \\
\hline
\end{tabular}

Table A.6. The recent $\mathrm{CH}_{4}$ mixing ratio at Cape Meares from air sampling collected during March,2012Septemebr,2012.

\begin{tabular}{|c|c|c|c|c|c|c|c|c|c|c|}
\hline \multirow[b]{3}{*}{ Collected date } & \multirow[b]{3}{*}{ Can \# } & \multicolumn{4}{|c|}{$\mathrm{CH}_{4}$ mixing ratio } & \multirow[b]{3}{*}{ Can \# } & \multicolumn{4}{|c|}{$\mathrm{CH}_{4}$ mixing ratio } \\
\hline & & \multicolumn{2}{|c|}{ on NIST scale } & \multicolumn{2}{|c|}{ on NOAA04 scale } & & \multicolumn{2}{|c|}{ on NIST scale } & \multicolumn{2}{|c|}{ on NOAA04 scale } \\
\hline & & Ave. & Std Err & Ave. & Std Err & & Ave. & Std Err & Ave. & Std Err \\
\hline $3 / 28 / 2012$ & ST-433 & 1894.7 & 1.8 & 1890.9 & 1.8 & $\mathrm{~B} 13059$ & 1898.0 & 2.6 & 1894.2 & 2.6 \\
\hline $4 / 26 / 2012$ & ST-434 & 1878.5 & 1.4 & 1874.7 & 1.4 & $\mathrm{~B} \mid 3062$ & 1883.0 & 4.4 & 1879.3 & 4.4 \\
\hline $5 / 30 / 2012$ & SMO-400 & 1869.2 & 3.9 & 1865.5 & 3.9 & B13057 & 1872.9 & 2.3 & 1869.1 & 2.3 \\
\hline $6 / 28 / 2012$ & ST-430 & 1851.5 & 3.0 & 1847.8 & 3.0 & $\mathrm{~B} 13037$ & 1844.8 & 2.0 & 1841.1 & 2.0 \\
\hline $7 / 27 / 2012$ & SMO-283 & 1826.6 & 4.5 & 1822.9 & 4.5 & $\mathrm{~B} 13052$ & 1824.9 & 0.9 & 1821.2 & 0.9 \\
\hline $8 / 27 / 2012$ & MLO 136 & 1874.7 & 3.7 & 1870.9 & 3.7 & $\mathrm{~B} 13098$ & 1872.4 & 2.0 & 1868.7 & 2.0 \\
\hline $9 / 25 / 2012$ & SMO355 & 1879.9 & 2.4 & 1876.2 & 2.4 & B959 & 1881.8 & 3.2 & 1878.1 & 3.2 \\
\hline
\end{tabular}

Table A.7. $\mathrm{CH}_{4}$ mixing ratio, $\delta^{13} \mathrm{C}$, and $\delta \mathrm{D}$ measured values of South Pole air archive samples at PSU.

\begin{tabular}{|c|c|c|c|c|c|}
\hline Collected date & Tank \# & \multicolumn{2}{|c|}{$\mathbf{C H}_{\mathbf{4}}$ mxing ratio [ppb] } & $\boldsymbol{\delta}^{\mathbf{1 3}} \mathbf{C}[\% \mathbf{~}$ & $\boldsymbol{\delta}$ [\% [\%] \\
\hline & & Ave. & Std Dev & & \\
\hline Jan.1992 & SPO 220 & 1672.8 & 5.5 & -47.14 & -91.8 \\
\hline Feb.1992 & SPO 212 & 1675.5 & 10.8 & -46.88 & -91.2 \\
\hline Mar.1992 & SPO 209 & 1662.6 & 1.2 & -46.97 & -88.7 \\
\hline May. 1992 & SPO 147 & 1675.0 & 4.9 & -47.09 & -96.5 \\
\hline Jun.1992 & SPO 263 & 1712.1 & 5.3 & -47.12 & -91.5 \\
\hline Aug.1992 & SPO 235 & 1689.7 & 3.6 & -47.11 & -88.1 \\
\hline
\end{tabular}




\begin{tabular}{|c|c|c|c|c|c|} 
Sep.1992 & SPO 151 & 1697.4 & 7.7 & -47.23 & -91.0 \\
\hline Oct.1992 & SPO 287 & 1739.7 & 2.1 & -47.03 & -93.9 \\
\hline 17 Oct.1993 & SPO 299 & 1702.9 & 6.6 & -47.00 & -90.2 \\
\hline Dec.1993 & SPO 346 & 1676.3 & 3.5 & -47.00 & -86.6 \\
\hline Jan.1995 & SPO 328 & 1681.2 & 4.8 & -47.03 & -91.3 \\
\hline 2 Feb.1995 & SPO 319 & 1676.9 & 2.0 & -46.96 & -84.2 \\
\hline
\end{tabular}

Table.A.8. . $\mathrm{CH}_{4}$ mixing ratio, $\delta^{13} \mathrm{C}$, and $\delta \mathrm{D}$ measured values of Samoa air archive samples at PSU.

\begin{tabular}{|c|c|c|c|c|c|}
\hline Collected date & Tank \# & \multicolumn{2}{|c|}{$\mathrm{CH}_{4}$ mixing ratio [ppb] } & $\delta^{13} \mathrm{C}[\% 0]$ & $\delta \mathrm{D}[\% 0]$ \\
\hline & & Ave. & & & \\
\hline 2 Feb.1995 & SMO282 & . & & -47.054667 & -91.192333 \\
\hline Mar. & SMO 283 & 83.992987 & 6.21175347 & -47.034 & -88.782 \\
\hline & & 169 & & -46.95 & \\
\hline $\mathrm{Ma}$ & 13 & 1706.62 & & -47.050667 & \\
\hline & SN & 1700.62 & 5.4 & -47.049 & \\
\hline & 0 & 1700 & & -47.084 & \\
\hline $\mathrm{Au}$ & 31 & 1694.85 & & -47.0445 & 655 \\
\hline & 46 & 1709.78648 & 5.9 & -47.006 & 1667 \\
\hline & 55 & $*$ & & -46.935 & 1667 \\
\hline Nov. 1995 & & 1698.37 & 4.5 & -46.964 & -93.584 \\
\hline & & 1704.64286 & 4.09 & -47.195333 & -90.5115 \\
\hline Apr.1996 & SMO 409 & 1689.703647 & 3.543505702 & -47.059 & -88.212 \\
\hline
\end{tabular}

* we lost air of theses samples

Table A.9. $\mathrm{CH}_{4}$ mixing ratio, $\delta^{13} \mathrm{C}$, and $\delta \mathrm{D}$ measured values of Mauna Loa air archive samples at PSU.

\begin{tabular}{|c|c|c|c|c|c|}
\hline Collected date & Tank \# & \multicolumn{2}{|c|}{$\mathbf{C H}_{\mathbf{4}}$ mixing ratio [ppb] } & $\boldsymbol{\delta}^{\mathbf{1 3}} \mathbf{C}[\% \mathbf{~}]$ & $\boldsymbol{\delta}$ D [\%o] \\
\hline & & Ave. & Std Dev & & \\
\hline Feb.1995 & MLO 324 & 1750.8 & 6.5 & -47.31 & -93.4 \\
\hline Mar.1995 & MLO 319 & 1771.4 & 9.3 & -47.32 & -94.7 \\
\hline Apr.1995 & MLO 350 & 1758.0 & 1.5 & -47.25 & -82.5 \\
\hline May.1995 & MLO 360 & 1760.5 & 9.7 & -47.21 & -89.5 \\
\hline Jun.1995 & MLO 368 & 1755.3 & 10.1 & -47.12 & -91.4 \\
\hline Jul.1995 & MLO 379 & 1747.5 & 3.6 & -47.10 & -89.1 \\
\hline Aug.1995 & MLO 388 & 1747.3 & 8.3 & -47.24 & -93.8 \\
\hline Sep.1995 & MLO 406 & 1760.9 & 5.3 & -47.24 & -91.4 \\
\hline Oct.1995 & MLO 418 & 1755.8 & 1.2 & -47.32 & -98.3 \\
\hline Nov.1995 & MLO 433 & 1774.7 & 3.9 & -47.02 & -92.4 \\
\hline Dec.1995 & MLO 445 & 1755.9 & 3.5 & -47.30 & -99.6 \\
\hline
\end{tabular}

Table A.10. $\mathrm{CH}_{4}$ seasonal value based on the composite dataset (CM+OP+MDO+NWR) during 1978-2010

\begin{tabular}{|c|c|c|c|c|}
\hline & & \multicolumn{3}{|c|}{ CH $_{\mathbf{4}}$-Resi [ppb] } \\
\hline Month & \# Rows & Ave. & Std Dev & Std Err \\
\hline Jan & 66 & 8.3 & 15.8 & 1.9 \\
\hline Feb & 67 & 10.3 & 19.0 & 2.3 \\
\hline Mar & 62 & 9.2 & 14.9 & 1.9 \\
\hline Apr & 102 & 9.3 & 16.1 & 1.6 \\
\hline May & 72 & 1.3 & 19.3 & 2.3 \\
\hline
\end{tabular}




\begin{tabular}{|c|c|c|c|c|} 
Jun & 74 & -9.8 & 17.7 & 2.1 \\
\hline Jul & 71 & -22.0 & 18.9 & 2.2 \\
\hline Aug & 74 & -23.6 & 15.1 & 1.8 \\
\hline Sep & 71 & -4.2 & 23.4 & 2.8 \\
\hline Oct & 78 & 8.2 & 19.6 & 2.2 \\
\hline Nov & 71 & 9.8 & 16.6 & 2.0 \\
\hline Dec & 75 & 10.0 & 20.8 & 2.4 \\
\hline
\end{tabular}

$\mathrm{CM}=$ Cape Meares, $\mathrm{OP}=$ Olympic Peninsula, $\mathrm{MDO}=$ Montaña de Oro, NWR= Niwot Ridge

Table A.11. $\delta^{13} \mathrm{C}$ seasonal value based on the composite dataset (CM+OP+MDO+NWR) during 1978-2010

\begin{tabular}{|c|c|c|c|c|}
\hline & & \multicolumn{3}{|c|}{$\delta^{\mathbf{1 3}}$ C- Resi [\%o] } \\
\hline Month & \# Rows & Ave. & Std Dev & Std Err \\
\hline Feb & 65 & 0.01 & 0.11 & 0.01 \\
\hline Mar & 58 & 0.04 & 0.09 & 0.01 \\
\hline Apr & 92 & 0.05 & 0.09 & 0.01 \\
\hline May & 67 & 0.09 & 0.11 & 0.01 \\
\hline Jun & 67 & 0.12 & 0.12 & 0.01 \\
\hline Jul & 67 & 0.09 & 0.11 & 0.01 \\
\hline Aug & 59 & 0.03 & 0.13 & 0.02 \\
\hline Sep & 61 & -0.11 & 0.12 & 0.02 \\
\hline Oct & 77 & -0.12 & 0.13 & 0.01 \\
\hline Nov & 68 & -0.10 & 0.10 & 0.01 \\
\hline Dec & 74 & -0.05 & 0.11 & 0.01 \\
\hline
\end{tabular}

Table A.12. $\delta$ D seasonal value based on the composite dataset (CM+MDO+NWR) during 1978-2005

\begin{tabular}{|c|c|c|c|c|}
\hline & & \multicolumn{3}{|c|}{ SD- Resi [\%]] } \\
\hline Month & \# Rows & Ave. & Std Dev & Std Err \\
\hline Jan & 27 & -0.9 & 2.7 & 0.5 \\
\hline Feb & 21 & -1.0 & 3.1 & 0.7 \\
\hline Mar & 25 & 0.0 & 3.1 & 0.6 \\
\hline Apr & 57 & 0.2 & 3.1 & 0.4 \\
\hline May & 25 & 0.8 & 2.7 & 0.5 \\
\hline Jun & 31 & 1.7 & 3.2 & 0.6 \\
\hline Jul & 24 & 2.3 & 3.0 & 0.6 \\
\hline Aug & 27 & 1.4 & 3.1 & 0.6 \\
\hline Sep & 27 & 0.2 & 2.9 & 0.6 \\
\hline Oct & 38 & -1.4 & 2.5 & 0.4 \\
\hline Nov & 29 & -1.6 & 2.4 & 0.4 \\
\hline Dec & 28 & -1.4 & 3.6 & 0.7 \\
\hline
\end{tabular}

Table A.13. The annual $\mathrm{CH}_{4}$ mixing ratio and its growth rate of the composite dataset using a LOWESS and Bootstrap with different spans.

\begin{tabular}{|c|c|c|c|c|c|c|c|c|c|c|c|c|}
\hline \multirow{3}{*}{ Year } & \multicolumn{4}{|c|}{ span $=0.09$} & \multicolumn{4}{|c|}{$\operatorname{span}=0.12$} & \multicolumn{4}{|c|}{ span $=0.15$} \\
\hline & \multicolumn{2}{|c|}{$\mathrm{CH}_{4}$ [ppb] } & \multicolumn{2}{|c|}{$\begin{array}{c}\mathrm{d}\left(\mathrm{CH}_{4}\right) / \mathrm{dt} \\
{[\mathrm{ppb} / \mathrm{yr}]}\end{array}$} & \multicolumn{2}{|c|}{$\mathrm{CH}_{4}$ [ppb] } & \multicolumn{2}{|c|}{$\begin{array}{c}\mathrm{d}\left(\mathrm{CH}_{4}\right) / \mathrm{dt} \\
{[\mathrm{ppb} / \mathrm{yr}]}\end{array}$} & \multicolumn{2}{|c|}{$\mathrm{CH}_{4}[\mathrm{ppb}]$} & \multicolumn{2}{|c|}{$\begin{array}{c}\mathrm{d}\left(\mathrm{CH}_{4}\right) / \mathrm{dt} \\
{[\mathrm{ppb} / \mathrm{yr}]}\end{array}$} \\
\hline & Ave. & $\begin{array}{l}\text { Std } \\
\text { Dev }\end{array}$ & Ave. & $\begin{array}{l}\text { Std } \\
\text { Dev }\end{array}$ & Ave. & $\begin{array}{l}\text { Std } \\
\text { Dev }\end{array}$ & Ave. & $\begin{array}{l}\text { Std } \\
\text { Dev }\end{array}$ & Ave. & $\begin{array}{l}\text { Std } \\
\text { Dev }\end{array}$ & Ave. & $\begin{array}{l}\text { Std } \\
\text { Dev }\end{array}$ \\
\hline 1978 & $1,604.0$ & 15.5 & 17.6 & 0.6 & $1,604.4$ & 14.3 & 16.9 & 0.1 & $1,604.3$ & 14.4 & 16.9 & 0.1 \\
\hline 1979 & $1,615.4$ & 9.9 & 17.1 & 0.4 & $1,614.9$ & 8.8 & 16.8 & 0.1 & $1,614.8$ & 8.8 & 16.9 & 0.1 \\
\hline
\end{tabular}




\begin{tabular}{|c|c|c|c|c|c|c|c|c|c|c|c|c|}
\hline 1980 & $1,629.9$ & 5.9 & 16.5 & 0.5 & $1,629.6$ & 4.8 & 16.8 & 0.1 & $1,629.5$ & 4.8 & 16.9 & 0.1 \\
\hline 1981 & $1,645.7$ & 3.3 & 16.7 & 0.4 & $1,645.9$ & 2.5 & 16.8 & 0.2 & $1,645.6$ & 2.6 & 16.8 & 0.1 \\
\hline 1982 & $1,662.6$ & 1.5 & 17.3 & 0.9 & $1,662.6$ & 1.3 & 16.8 & 0.3 & $1,662.7$ & 1.4 & 16.7 & 0.2 \\
\hline 1983 & $1,679.5$ & 0.8 & 16.2 & 0.4 & $1,679.3$ & 0.8 & 16.3 & 0.4 & $1,679.8$ & 1.0 & 16.3 & 0.3 \\
\hline 1984 & $1,695.2$ & 0.7 & 15.1 & 0.3 & $1,695.0$ & 0.7 & 15.2 & 0.2 & $1,695.5$ & 0.9 & 15.4 & 0.1 \\
\hline 1985 & $1,709.9$ & 0.6 & 14.3 & 0.2 & $1,709.8$ & 0.6 & 14.4 & 0.2 & $1,709.9$ & 0.6 & 14.5 & 0.1 \\
\hline 1986 & $1,723.8$ & 0.7 & 13.7 & 0.4 & $1,723.9$ & 0.8 & 13.8 & 0.3 & $1,724.1$ & 0.8 & 13.6 & 0.3 \\
\hline 1987 & $1,737.3$ & 1.3 & 12.9 & 0.8 & $1,737.1$ & 1.3 & 12.7 & 0.6 & $1,737.6$ & 1.4 & 12.4 & 0.5 \\
\hline 1988 & $1,749.0$ & 1.7 & 10.8 & 1.0 & $1,748.8$ & 1.8 & 10.6 & 0.8 & $1,749.4$ & 1.9 & 10.3 & 0.4 \\
\hline 1989 & $1,758.3$ & 2.0 & 7.1 & 1.5 & $1,757.9$ & 1.5 & 7.3 & 1.5 & $1,758.6$ & 2.0 & 7.9 & 0.9 \\
\hline 1990 & $1,764.1$ & 1.1 & 5.4 & 2.4 & $1,764.9$ & 0.7 & 6.8 & 1.1 & $1,764.6$ & 1.1 & 7.1 & 0.6 \\
\hline 1991 & $1,771.9$ & 0.7 & 8.3 & 2.0 & $1,772.2$ & 0.5 & 7.7 & 0.9 & $1,772.0$ & 1.0 & 7.2 & 0.3 \\
\hline 1992 & $1,780.0$ & 1.1 & 7.3 & 1.0 & $1,779.8$ & 0.7 & 7.0 & 0.6 & $1,780.6$ & 1.5 & 6.7 & 0.3 \\
\hline 1993 & $1,786.2$ & 0.9 & 5.5 & 1.0 & $1,786.1$ & 0.7 & 5.7 & 0.7 & $1,786.5$ & 0.9 & 5.9 & 0.5 \\
\hline 1994 & $1,791.4$ & 0.7 & 5.2 & 1.0 & $1,791.5$ & 0.6 & 5.2 & 1.1 & $1,791.4$ & 1.0 & 5.8 & 0.7 \\
\hline 1995 & $1,796.9$ & 1.4 & 5.8 & 1.8 & $1,797.2$ & 1.1 & 6.5 & 2.2 & $1,796.9$ & 1.8 & 6.4 & 1.8 \\
\hline 1996 & $1,803.7$ & 3.5 & 5.6 & 4.2 & $1,803.2$ & 2.6 & 4.1 & 2.6 & $1,804.3$ & 4.1 & 3.4 & 1.6 \\
\hline 1997 & $1,803.1$ & 2.5 & -1.3 & 7.6 & $1,803.9$ & 1.7 & -0.3 & 5.7 & $1,803.1$ & 3.0 & 1.4 & 3.2 \\
\hline 1998 & $1,807.6$ & 1.4 & 7.2 & 7.2 & $1,807.6$ & 1.2 & 6.4 & 5.6 & $1,807.6$ & 1.7 & 5.4 & 3.5 \\
\hline 1999 & $1,813.0$ & 2.6 & 1.2 & 3.3 & $1,812.6$ & 2.2 & 2.2 & 2.4 & $1,813.3$ & 3.0 & 2.6 & 1.6 \\
\hline 2000 & $1,813.2$ & 1.2 & 0.2 & 2.0 & $1,813.1$ & 1.1 & 0.0 & 2.2 & $1,813.0$ & 1.4 & 0.1 & 2.2 \\
\hline 2001 & $1,813.6$ & 1.8 & 1.2 & 1.9 & $1,813.8$ & 1.6 & 1.4 & 1.9 & $1,813.4$ & 1.8 & 1.8 & 1.6 \\
\hline 2002 & $1,816.5$ & 2.5 & 4.8 & 2.3 & $1,816.8$ & 1.9 & 5.4 & 2.4 & $1,816.0$ & 3.0 & 5.4 & 2.2 \\
\hline 2003 & $1,824.2$ & 2.7 & 7.9 & 5.7 & $1,823.3$ & 2.1 & 5.5 & 2.9 & $1,824.3$ & 3.3 & 4.8 & 1.8 \\
\hline 2004 & $1,826.5$ & 2.0 & -0.9 & 5.2 & $1,826.2$ & 1.9 & 0.1 & 2.8 & $1,826.9$ & 2.8 & 1.3 & 1.7 \\
\hline 2005 & $1,825.7$ & 1.6 & 0.3 & 2.5 & $1,826.1$ & 1.3 & -0.2 & 2.2 & $1,825.3$ & 1.8 & 0.5 & 1.7 \\
\hline 2006 & $1,827.2$ & 1.8 & 2.9 & 1.2 & $1,827.6$ & 1.5 & 2.8 & 1.0 & $1,826.2$ & 2.0 & 2.4 & 0.7 \\
\hline 2007 & $1,831.3$ & 1.3 & 5.2 & 1.1 & $1,831.8$ & 1.0 & 4.9 & 1.0 & $1,830.5$ & 1.3 & 4.3 & 0.7 \\
\hline 2008 & $1,836.6$ & 1.6 & 5.9 & 0.8 & $1,836.7$ & 1.6 & 5.7 & 0.8 & $1,835.9$ & 1.7 & 5.1 & 0.7 \\
\hline 2009 & $1,841.6$ & 3.1 & 5.8 & 0.6 & $1,841.6$ & 3.0 & 5.7 & 0.6 & $1,841.2$ & 3.2 & 5.3 & 0.6 \\
\hline 2010 & $1,845.1$ & 5.0 & 5.5 & 0.6 & $1,845.3$ & 4.9 & 5.4 & 0.6 & $1,845.0$ & 5.2 & 5.0 & 0.5 \\
\hline
\end{tabular}

Table A.14. The annual $\delta^{13} \mathrm{C}$ of atmospheric $\mathrm{CH}_{4}$ and its time rate of change of the composite dataset using a LOWESS and Bootstrap with different spans.

\begin{tabular}{|c|c|c|c|c|c|c|c|c|c|c|c|c|}
\hline & \multicolumn{4}{|c|}{ span $=0.09$} & \multicolumn{4}{|c|}{ span $=0.12$} & \multicolumn{4}{|c|}{ span $=0.15$} \\
\hline Year & \multicolumn{2}{|c|}{$\delta^{13} \mathrm{C}[\% 0]$} & \multicolumn{2}{|c|}{$\begin{array}{c}\mathrm{d}\left(\delta^{13} \mathrm{C}\right) / \mathrm{dt} \\
{[\% / \mathrm{yr}]}\end{array}$} & \multicolumn{2}{|c|}{$\delta^{13} \mathrm{C}[\% 0]$} & \multicolumn{2}{|c|}{$\begin{array}{c}\mathrm{d}\left(\delta^{13} \mathrm{C}\right) / \mathrm{dt} \\
{[\% / \mathrm{yr}]}\end{array}$} & \multicolumn{2}{|c|}{$\delta^{13} \mathrm{C}[\% 0]$} & \multicolumn{2}{|c|}{$\begin{array}{c}\mathrm{d}\left(\delta^{13} \mathrm{C}\right) / \mathrm{dt} \\
{[\% / \mathrm{yr}]} \\
\end{array}$} \\
\hline & Ave. & $\begin{array}{l}\text { Std } \\
\text { Dev }\end{array}$ & Ave. & $\begin{array}{l}\text { Std } \\
\text { Dev }\end{array}$ & Ave. & $\begin{array}{l}\text { Std } \\
\text { Dev }\end{array}$ & Ave. & $\begin{array}{l}\text { Std } \\
\text { Dev }\end{array}$ & Ave. & $\begin{array}{l}\text { Std } \\
\text { Dev }\end{array}$ & Ave. & $\begin{array}{l}\text { Std } \\
\text { Dev }\end{array}$ \\
\hline 1978 & -47.71 & 0.02 & 0.00 & 0.02 & -47.71 & 0.02 & 0.02 & 0.01 & -47.71 & 0.01 & 0.03 & 0.00 \\
\hline 1979 & -47.70 & 0.01 & 0.03 & 0.02 & -47.69 & 0.01 & 0.03 & 0.01 & -47.69 & 0.01 & 0.02 & 0.00 \\
\hline 1980 & -47.66 & 0.01 & 0.03 & 0.02 & -47.66 & 0.01 & 0.02 & 0.00 & -47.67 & 0.00 & 0.02 & 0.00 \\
\hline 1981 & -47.65 & 0.01 & 0.00 & 0.02 & -47.65 & 0.00 & 0.01 & 0.01 & -47.66 & 0.00 & 0.02 & 0.00 \\
\hline 1982 & -47.65 & 0.01 & 0.01 & 0.01 & -47.65 & 0.01 & 0.01 & 0.00 & -47.64 & 0.00 & 0.01 & 0.00 \\
\hline 1983 & -47.63 & 0.01 & 0.02 & 0.01 & -47.63 & 0.01 & 0.02 & 0.01 & -47.63 & 0.00 & 0.01 & 0.00 \\
\hline 1984 & -47.60 & 0.01 & 0.02 & 0.01 & -47.61 & 0.01 & 0.02 & 0.01 & -47.61 & 0.01 & 0.01 & 0.00 \\
\hline 1985 & -47.59 & 0.01 & 0.00 & 0.01 & -47.59 & 0.01 & 0.00 & 0.01 & -47.60 & 0.01 & 0.01 & 0.01 \\
\hline 1986 & -47.59 & 0.01 & -0.02 & 0.03 & -47.59 & 0.01 & -0.01 & 0.02 & -47.60 & 0.01 & 0.01 & 0.01 \\
\hline 1987 & -47.60 & 0.02 & 0.01 & 0.02 & -47.60 & 0.02 & 0.02 & 0.02 & -47.59 & 0.02 & 0.04 & 0.01 \\
\hline 1988 & -47.58 & 0.02 & 0.06 & 0.04 & -47.58 & 0.02 & 0.06 & 0.03 & -47.57 & 0.01 & 0.06 & 0.02 \\
\hline 1989 & -47.52 & 0.02 & 0.06 & 0.06 & -47.52 & 0.02 & 0.05 & 0.04 & -47.52 & 0.02 & 0.03 & 0.02 \\
\hline 1990 & -47.51 & 0.01 & -0.04 & 0.08 & -47.51 & 0.01 & -0.02 & 0.06 & -47.51 & 0.01 & -0.01 & 0.03 \\
\hline 1991 & -47.51 & 0.01 & 0.03 & 0.04 & -47.51 & 0.02 & 0.02 & 0.02 & -47.51 & 0.02 & 0.01 & 0.02 \\
\hline 1992 & -47.48 & 0.01 & 0.04 & 0.02 & -47.48 & 0.01 & 0.04 & 0.02 & -47.48 & 0.01 & 0.04 & 0.02 \\
\hline 1993 & -47.43 & 0.01 & 0.03 & 0.01 & -47.43 & 0.01 & 0.04 & 0.01 & -47.44 & 0.01 & 0.03 & 0.01 \\
\hline 1994 & -47.41 & 0.02 & 0.03 & 0.02 & -47.41 & 0.02 & 0.02 & 0.02 & -47.41 & 0.02 & 0.02 & 0.02 \\
\hline 1995 & -47.41 & 0.02 & -0.02 & 0.04 & -47.40 & 0.02 & -0.02 & 0.04 & -47.40 & 0.02 & -0.02 & 0.04 \\
\hline 1996 & -47.42 & 0.04 & 0.02 & 0.02 & -47.42 & 0.04 & 0.02 & 0.02 & -47.42 & 0.04 & 0.02 & 0.02 \\
\hline 1997 & -47.36 & 0.02 & 0.07 & 0.04 & -47.36 & 0.02 & 0.08 & 0.04 & -47.36 & 0.02 & 0.08 & 0.04 \\
\hline
\end{tabular}




\begin{tabular}{|c|c|c|c|c|c|c|c|c|c|c|c|c|}
\hline 1998 & -47.29 & 0.03 & 0.05 & 0.02 & -47.29 & 0.03 & 0.05 & 0.02 & -47.29 & 0.03 & 0.05 & 0.02 \\
\hline 1999 & -47.27 & 0.02 & 0.01 & 0.01 & -47.27 & 0.02 & 0.01 & 0.01 & -47.27 & 0.02 & 0.01 & 0.01 \\
\hline 2000 & -47.27 & 0.01 & -0.01 & 0.02 & -47.27 & 0.01 & -0.01 & 0.02 & -47.27 & 0.01 & -0.01 & 0.01 \\
\hline 2001 & -47.27 & 0.01 & 0.01 & 0.02 & -47.28 & 0.01 & 0.00 & 0.01 & -47.28 & 0.01 & -0.01 & 0.02 \\
\hline 2002 & -47.29 & 0.03 & 0.00 & 0.04 & -47.29 & 0.03 & 0.01 & 0.02 & -47.29 & 0.02 & 0.01 & 0.01 \\
\hline 2003 & -47.25 & 0.02 & 0.08 & 0.07 & -47.25 & 0.02 & 0.06 & 0.04 & -47.25 & 0.01 & 0.04 & 0.03 \\
\hline 2004 & -47.20 & 0.05 & 0.00 & 0.03 & -47.21 & 0.04 & 0.02 & 0.02 & -47.22 & 0.03 & 0.02 & 0.01 \\
\hline 2005 & -47.24 & 0.02 & -0.06 & 0.05 & -47.23 & 0.02 & -0.04 & 0.03 & -47.23 & 0.02 & -0.02 & 0.01 \\
\hline 2006 & -47.28 & 0.02 & -0.03 & 0.02 & -47.27 & 0.02 & -0.04 & 0.02 & -47.26 & 0.01 & -0.03 & 0.01 \\
\hline 2007 & -47.29 & 0.01 & 0.00 & 0.02 & -47.29 & 0.01 & -0.02 & 0.01 & -47.29 & 0.01 & -0.03 & 0.01 \\
\hline 2008 & -47.29 & 0.01 & -0.01 & 0.01 & -47.30 & 0.01 & -0.02 & 0.01 & -47.30 & 0.01 & -0.03 & 0.00 \\
\hline 2009 & -47.31 & 0.01 & -0.03 & 0.01 & -47.32 & 0.01 & -0.02 & 0.01 & -47.32 & 0.01 & -0.02 & 0.00 \\
\hline 2010 & -47.34 & 0.03 & -0.04 & 0.02 & -47.34 & 0.02 & -0.03 & 0.01 & -47.34 & 0.02 & -0.02 & 0.01 \\
\hline
\end{tabular}

Table A.15. The annual $\delta \mathrm{D}$ of atmospheric $\mathrm{CH}_{4}$ and its time rate of change of the composite dataset using a LOWESS and Bootstrap with different spans.

\begin{tabular}{|c|c|c|c|c|c|c|c|c|c|c|c|c|}
\hline \multirow{3}{*}{ Year } & \multicolumn{4}{|c|}{ span $=0.103$} & \multicolumn{4}{|c|}{$\operatorname{span}=0.138$} & \multicolumn{4}{|c|}{ span $=0.172$} \\
\hline & \multicolumn{2}{|c|}{$\delta \mathrm{D}[\% \mathrm{o}]$} & \multicolumn{2}{|c|}{$\begin{array}{c}d(\delta D) / d t \\
{[\% o / y r]}\end{array}$} & \multicolumn{2}{|c|}{$\delta \mathrm{D}[\% \mathrm{c}]$} & \multicolumn{2}{|c|}{$\begin{array}{c}d(\delta D) / d t \\
{[\% / y r]}\end{array}$} & \multicolumn{2}{|c|}{$\delta D[\%]$} & \multicolumn{2}{|c|}{$\begin{array}{c}d(\delta D) / d t \\
{[\% / y r]}\end{array}$} \\
\hline & Ave. & $\begin{array}{l}\text { Std } \\
\text { Dev }\end{array}$ & Ave. & $\begin{array}{l}\text { Std } \\
\text { Dev }\end{array}$ & Ave. & $\begin{array}{l}\text { Std } \\
\text { Dev }\end{array}$ & Ave. & $\begin{array}{l}\text { Std } \\
\text { Dev }\end{array}$ & Ave. & $\begin{array}{l}\text { Std } \\
\text { Dev }\end{array}$ & Ave. & $\begin{array}{l}\text { Std } \\
\text { Dev }\end{array}$ \\
\hline 1978 & -110.4 & 0.2 & 0.6 & 0.6 & -110.4 & 0.2 & 0.4 & 0.4 & -110.4 & 0.2 & 0.2 & 0.3 \\
\hline 1979 & -110.3 & 0.3 & -0.1 & 0.5 & -110.3 & 0.2 & -0.1 & 0.4 & -110.4 & 0.2 & 0.0 & 0.3 \\
\hline 1980 & -110.5 & 0.4 & 0.2 & 0.3 & -110.4 & 0.4 & 0.2 & 0.3 & -110.4 & 0.3 & 0.1 & 0.3 \\
\hline 1981 & -110.0 & 0.2 & 0.6 & 0.2 & -110.0 & 0.2 & 0.7 & 0.3 & -110.0 & 0.2 & 0.7 & 0.3 \\
\hline 1982 & -109.2 & 0.2 & 0.7 & 0.2 & -109.3 & 0.1 & 0.7 & 0.2 & -109.3 & 0.1 & 0.6 & 0.2 \\
\hline 1983 & -108.8 & 0.1 & 0.5 & 0.1 & -108.7 & 0.1 & 0.5 & 0.1 & -108.8 & 0.1 & 0.5 & 0.1 \\
\hline 1984 & -108.3 & 0.0 & 0.5 & 0.1 & -108.3 & 0.0 & 0.5 & 0.1 & -108.3 & 0.0 & 0.4 & 0.1 \\
\hline 1985 & -107.9 & 0.0 & 0.6 & 0.1 & -107.9 & 0.0 & 0.5 & 0.0 & -107.8 & 0.0 & 0.5 & 0.0 \\
\hline 1986 & -107.4 & 0.1 & 0.5 & 0.2 & -107.4 & 0.1 & 0.5 & 0.0 & -107.3 & 0.1 & 0.6 & 0.0 \\
\hline 1987 & -107.1 & 0.2 & 0.5 & 0.3 & -106.8 & 0.1 & 0.6 & 0.0 & -106.8 & 0.1 & 0.6 & 0.0 \\
\hline 1988 & -106.7 & 0.4 & 1.2 & 0.3 & -106.2 & 0.1 & 0.7 & 0.0 & -106.1 & 0.1 & 0.7 & 0.0 \\
\hline 1989 & -105.7 & 0.2 & 1.9 & 0.7 & -105.4 & 0.1 & 0.8 & 0.0 & -105.4 & 0.1 & 0.8 & 0.0 \\
\hline 1990 & -104.4 & 0.2 & 1.3 & 0.3 & -104.5 & 0.1 & 0.9 & 0.0 & -104.5 & 0.1 & 0.9 & 0.0 \\
\hline 1991 & -103.5 & 0.1 & 0.8 & 0.4 & -103.6 & 0.1 & 0.9 & 0.0 & -103.5 & 0.1 & 1.0 & 0.0 \\
\hline 1992 & -102.6 & 0.2 & 1.0 & 0.1 & -102.5 & 0.1 & 1.0 & 0.0 & -102.4 & 0.0 & 1.0 & 0.0 \\
\hline 1993 & -101.5 & 0.1 & 1.2 & 0.1 & -101.4 & 0.0 & 1.1 & 0.0 & -101.4 & 0.0 & 1.1 & 0.0 \\
\hline 1994 & -100.2 & 0.1 & 1.2 & 0.1 & -100.3 & 0.0 & 1.1 & 0.0 & -100.2 & 0.0 & 1.1 & 0.0 \\
\hline 1995 & -99.1 & 0.1 & 1.1 & 0.1 & -99.1 & 0.0 & 1.2 & 0.0 & -99.1 & 0.0 & 1.1 & 0.0 \\
\hline 1996 & -98.0 & 0.1 & 1.1 & 0.1 & -98.0 & 0.1 & 1.2 & 0.1 & -97.9 & 0.1 & 1.2 & 0.1 \\
\hline 1997 & -96.9 & 0.1 & 1.3 & 0.3 & -96.8 & 0.1 & 1.3 & 0.2 & -96.8 & 0.1 & 1.2 & 0.2 \\
\hline 1998 & -95.7 & 0.3 & 1.2 & 0.5 & -95.7 & 0.2 & 1.1 & 0.3 & -95.7 & 0.2 & 1.1 & 0.2 \\
\hline 1999 & -95.0 & 0.3 & 0.0 & 0.5 & -94.9 & 0.3 & 0.3 & 0.3 & -95.0 & 0.3 & 0.6 & 0.1 \\
\hline 2000 & -94.7 & 0.3 & -0.1 & 0.4 & -94.6 & 0.3 & 0.0 & 0.2 & -94.7 & 0.3 & 0.1 & 0.1 \\
\hline 2001 & -94.8 & 0.2 & -0.5 & 0.7 & -94.8 & 0.2 & -0.4 & 0.4 & -94.8 & 0.2 & -0.3 & 0.2 \\
\hline 2002 & -95.1 & 0.3 & 0.2 & 1.4 & -95.1 & 0.3 & -0.1 & 0.7 & -95.0 & 0.3 & -0.3 & 0.4 \\
\hline 2003 & -95.7 & 0.4 & -1.8 & 1.9 & -95.7 & 0.3 & -1.2 & 1.1 & -95.7 & 0.2 & -1.0 & 0.6 \\
\hline 2004 & -96.7 & 0.8 & -0.1 & 1.1 & -96.5 & 0.7 & -0.1 & 0.6 & -96.4 & 0.5 & -0.4 & 0.4 \\
\hline 2005 & -96.3 & 0.6 & 1.0 & 1.5 & -96.3 & 0.5 & 0.7 & 1.0 & -96.4 & 0.4 & 0.1 & 0.6 \\
\hline
\end{tabular}


Table A.16. Total $\mathrm{CH}_{4}$ emissions for three different $\mathrm{CH}_{4}$ lifetimes

\begin{tabular}{|c|c|c|c|c|c|}
\hline Year & $\mathrm{CH}_{4}[\mathrm{ppb}]$ & $\mathrm{d}\left(\mathrm{CH}_{4}\right) / \mathrm{dt}[\mathrm{ppb} / \mathrm{yr}]$ & $\mathrm{S}_{8.7 \mathrm{yr}}(\mathrm{Tg} / \mathrm{yr})$ & $\mathrm{S}_{9.7 \mathrm{yr}}(\mathrm{Tg} / \mathrm{yr})$ & $\mathrm{S}_{10.7 \mathrm{yr}}(\mathrm{Tg} / \mathrm{yr})$ \\
\hline 1978 & $1,604.0$ & 17.6 & 555.4 & 503.1 & 460.6 \\
\hline 1979 & $1,615.4$ & 17.1 & 557.6 & 505.0 & 462.2 \\
\hline 1980 & $1,629.9$ & 16.5 & 560.5 & 507.4 & 464.2 \\
\hline 1981 & $1,645.7$ & 16.7 & 566.0 & 512.4 & 468.8 \\
\hline 1982 & $1,662.6$ & 17.3 & 573.1 & 518.9 & 474.8 \\
\hline 1983 & $1,679.5$ & 16.2 & 575.6 & 520.8 & 476.3 \\
\hline 1984 & $1,695.2$ & 15.1 & 577.3 & 522.1 & 477.2 \\
\hline 1985 & $1,709.9$ & 14.3 & 579.9 & 524.2 & 478.9 \\
\hline 1986 & $1,723.8$ & 13.7 & 582.5 & 526.3 & 480.6 \\
\hline 1987 & $1,737.3$ & 12.9 & 584.5 & 527.9 & 481.8 \\
\hline 1988 & $1,749.0$ & 10.8 & 582.6 & 525.6 & 479.3 \\
\hline 1989 & $1,758.3$ & 7.1 & 575.3 & 518.0 & 471.4 \\
\hline 1990 & $1,764.1$ & 5.4 & 572.4 & 514.9 & 468.2 \\
\hline 1991 & $1,771.9$ & 8.3 & 582.9 & 525.1 & 478.2 \\
\hline 1992 & $1,780.0$ & 7.3 & 582.6 & 524.6 & 477.4 \\
\hline 1993 & $1,786.2$ & 5.5 & 579.7 & 521.5 & 474.1 \\
\hline 1994 & $1,791.4$ & 5.2 & 580.6 & 522.2 & 474.7 \\
\hline 1995 & $1,796.9$ & 5.8 & 583.9 & 525.3 & 477.7 \\
\hline 1996 & $1,803.7$ & 5.6 & 585.5 & 526.7 & 479.0 \\
\hline 1997 & $1,803.1$ & -1.3 & 566.5 & 507.7 & 460.0 \\
\hline 1998 & $1,807.6$ & 7.2 & 591.3 & 532.3 & 484.5 \\
\hline 1999 & $1,813.0$ & 1.2 & 576.4 & 517.3 & 469.3 \\
\hline 2000 & $1,813.2$ & 0.2 & 573.6 & 514.6 & 466.5 \\
\hline 2001 & $1,813.6$ & 1.2 & 576.5 & 517.4 & 469.3 \\
\hline 2002 & $1,816.5$ & 4.8 & 587.4 & 528.2 & 480.1 \\
\hline 2003 & $1,824.2$ & 7.9 & 598.4 & 539.0 & 490.6 \\
\hline 2004 & $1,826.5$ & -0.9 & 574.8 & 515.2 & 466.8 \\
\hline 2005 & $1,825.7$ & 0.3 & 577.8 & 518.3 & 469.9 \\
\hline 2006 & $1,827.2$ & 2.9 & 585.5 & 526.0 & 477.6 \\
\hline 2007 & $1,831.3$ & 5.2 & 593.2 & 533.5 & 485.0 \\
\hline 2008 & $1,836.6$ & 5.9 & 596.7 & 536.8 & 488.2 \\
\hline 2009 & $1,841.6$ & 5.8 & 598.1 & 538.1 & 489.3 \\
\hline 2010 & $1,845.1$ & 5.5 & 598.3 & 538.2 & 489.3 \\
\hline & & & & & \\
\hline
\end{tabular}


Table A.17. The annual $\delta^{13} \mathrm{C}$ and $\delta \mathrm{D}$ of $\mathrm{CH}_{4}$ sources based on the atmospheric annual $\mathrm{CH}_{4}, \delta^{13} \mathrm{C}, \delta \mathrm{D}$, and their time rate of changes from the composite dataset.

\begin{tabular}{|c|c|c|c|c|c|c|c|c|}
\hline Year & $\begin{array}{c}\mathrm{CH}_{4} \\
{[\mathrm{ppb}]}\end{array}$ & $\begin{array}{c}\mathrm{d}\left(\mathrm{CH}_{4}\right) / \mathrm{dt} \\
{[\mathrm{ppb} / \mathrm{yr}]}\end{array}$ & $\delta^{13} \mathrm{C}[\%$ & $\begin{array}{c}\mathrm{d}\left(\delta^{13} \mathrm{C}\right) / \mathrm{dt} \\
{[\% 0 / \mathrm{yr}]}\end{array}$ & $\delta \mathrm{D}[\% 0]$ & $\begin{array}{c}\mathrm{d}(\delta \mathrm{D}) / \mathrm{dt} \\
{[\% / \mathrm{yr}]}\end{array}$ & $\begin{array}{c}\delta^{13} \mathrm{C}- \\
\text { sources [\%o] }\end{array}$ & $\begin{array}{c}\text { SD-sources } \\
{[\%]}\end{array}$ \\
\hline 1978 & $1,604.0$ & 17.6 & -47.71 & 0.00 & -110.4 & 0.6 & -52.36 & -282.8 \\
\hline 1979 & $1,615.4$ & 17.1 & -47.70 & 0.03 & -110.3 & -0.1 & -52.35 & -283.3 \\
\hline 1980 & $1,629.9$ & 16.5 & -47.66 & 0.03 & -110.5 & 0.2 & -52.35 & -284.2 \\
\hline 1981 & $1,645.7$ & 16.7 & -47.65 & 0.00 & -110.0 & 0.6 & -52.34 & -283.8 \\
\hline 1982 & $1,662.6$ & 17.3 & -47.65 & 0.01 & -109.2 & 0.7 & -52.32 & -282.7 \\
\hline 1983 & $1,679.5$ & 16.2 & -47.63 & 0.02 & -108.8 & 0.5 & -52.33 & -283.4 \\
\hline 1984 & $1,695.2$ & 15.1 & -47.60 & 0.02 & -108.3 & 0.5 & -52.35 & -284.3 \\
\hline 1985 & $1,709.9$ & 14.3 & -47.59 & 0.00 & -107.9 & 0.6 & -52.36 & -284.8 \\
\hline 1986 & $1,723.8$ & 13.7 & -47.59 & -0.02 & -107.4 & 0.5 & -52.37 & -285.1 \\
\hline 1987 & $1,737.3$ & 12.9 & -47.60 & 0.01 & -107.1 & 0.5 & -52.39 & -285.7 \\
\hline 1988 & $1,749.0$ & 10.8 & -47.58 & 0.06 & -106.7 & 1.2 & -52.43 & -287.4 \\
\hline 1989 & $1,758.3$ & 7.1 & -47.52 & 0.06 & -105.7 & 1.9 & -52.47 & -290.2 \\
\hline 1990 & $1,764.1$ & 5.4 & -47.51 & -0.04 & -104.4 & 1.3 & -52.51 & -290.9 \\
\hline 1991 & $1,771.9$ & 8.3 & -47.51 & 0.03 & -103.5 & 0.8 & -52.43 & -287.4 \\
\hline 1992 & $1,780.0$ & 7.3 & -47.48 & 0.04 & -102.6 & 1.0 & -52.42 & -287.7 \\
\hline 1993 & $1,786.2$ & 5.5 & -47.43 & 0.03 & -101.5 & 1.2 & -52.43 & -288.5 \\
\hline 1994 & $1,791.4$ & 5.2 & -47.41 & 0.03 & -100.2 & 1.2 & -52.41 & -287.8 \\
\hline 1995 & $1,796.9$ & 5.8 & -47.41 & -0.02 & -99.1 & 1.1 & -52.40 & -286.4 \\
\hline 1996 & $1,803.7$ & 5.6 & -47.42 & 0.02 & -98.0 & 1.1 & -52.41 & -285.8 \\
\hline 1997 & $1,803.1$ & -1.3 & -47.36 & 0.07 & -96.9 & 1.3 & -52.54 & -291.8 \\
\hline 1998 & $1,807.6$ & 7.2 & -47.29 & 0.05 & -95.7 & 1.2 & -52.25 & -282.3 \\
\hline 1999 & $1,813.0$ & 1.2 & -47.27 & 0.01 & -95.0 & 0.0 & -52.38 & -287.8 \\
\hline 2000 & $1,813.2$ & 0.2 & -47.27 & -0.01 & -94.7 & -0.1 & -52.41 & -288.6 \\
\hline 2001 & $1,813.6$ & 1.2 & -47.27 & 0.01 & -94.8 & -0.5 & -52.39 & -287.7 \\
\hline 2002 & $1,816.5$ & 4.8 & -47.29 & 0.00 & -95.1 & 0.2 & -52.30 & -284.2 \\
\hline 2003 & $1,824.2$ & 7.9 & -47.25 & 0.08 & -95.7 & -1.8 & -52.19 & -281.7 \\
\hline 2004 & $1,826.5$ & -0.9 & -47.20 & 0.00 & -96.7 & -0.1 & -52.39 & -291.4 \\
\hline 2005 & $1,825.7$ & 0.3 & -47.24 & -0.06 & -96.3 & 1.0 & -52.37 & -289.8 \\
\hline 2006 & $1,827.2$ & 2.9 & -47.28 & -0.03 & & & -52.33 & \\
\hline 2007 & $1,831.3$ & 5.2 & -47.29 & 0.00 & & & -52.29 & \\
\hline 2008 & $1,836.6$ & 5.9 & -47.29 & -0.01 & & & -52.29 & \\
\hline 2009 & $1,841.6$ & 5.8 & -47.31 & -0.03 & & & -52.31 & \\
\hline 2010 & $1,845.1$ & 5.5 & -47.34 & -0.04 & & & -52.33 & \\
\hline
\end{tabular}




\section{Appendix B}

\section{Figures}

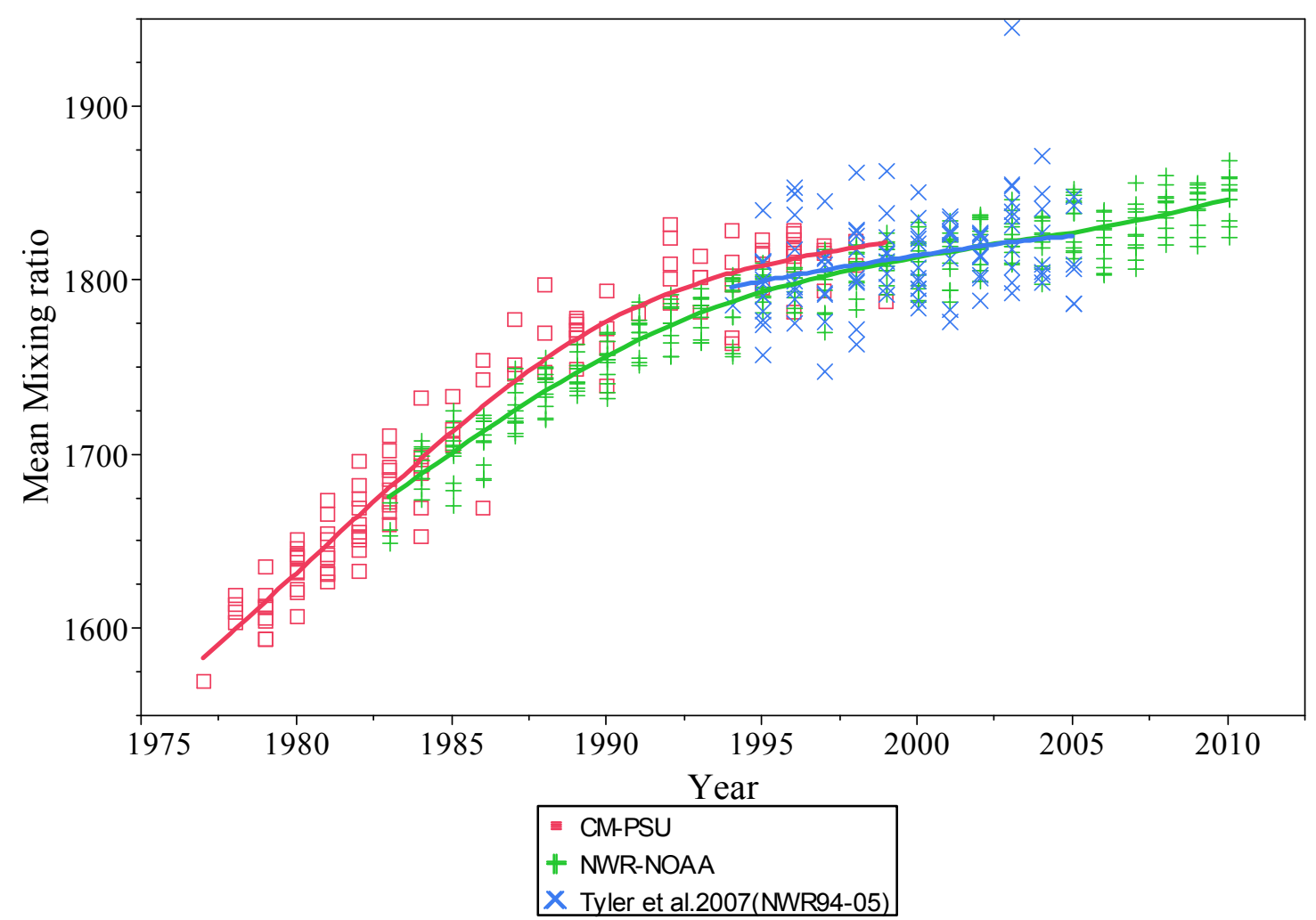

Figure B.1. The atmospheric $\mathrm{CH}_{4}$ mixing ratio of Cape Meares, Oregon during (1977-1999) measured at PSU and Niwot Ridge, Colorado measured by Tyler et al.,2007 during (1994-2005) and NOAA during (1983-2010) 

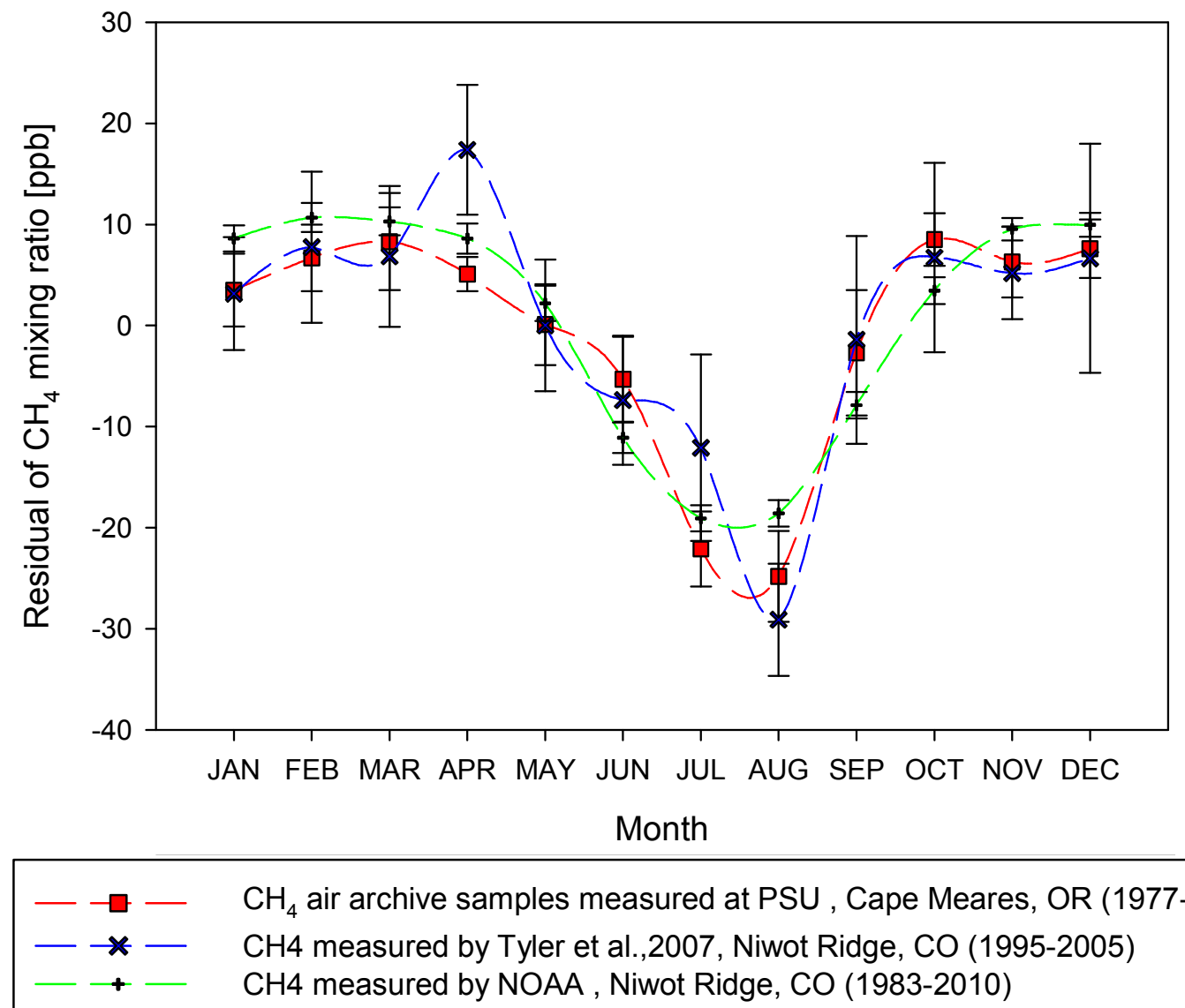

$\mathrm{CH}_{4}$ air archive samples measured at PSU , Cape Meares, OR (1977-1999) CH4 measured by Tyler et al.,2007, Niwot Ridge, CO (1995-2005) CH4 measured by NOAA, Niwot Ridge, CO (1983-2010)

Figure B.2. Seasonal trend of atmospheric $\mathrm{CH}_{4}$ at Cape Meares (red circle) and Niwot Ridge (blue cross) and (plus green). Error bars are \pm 1 standard error. 


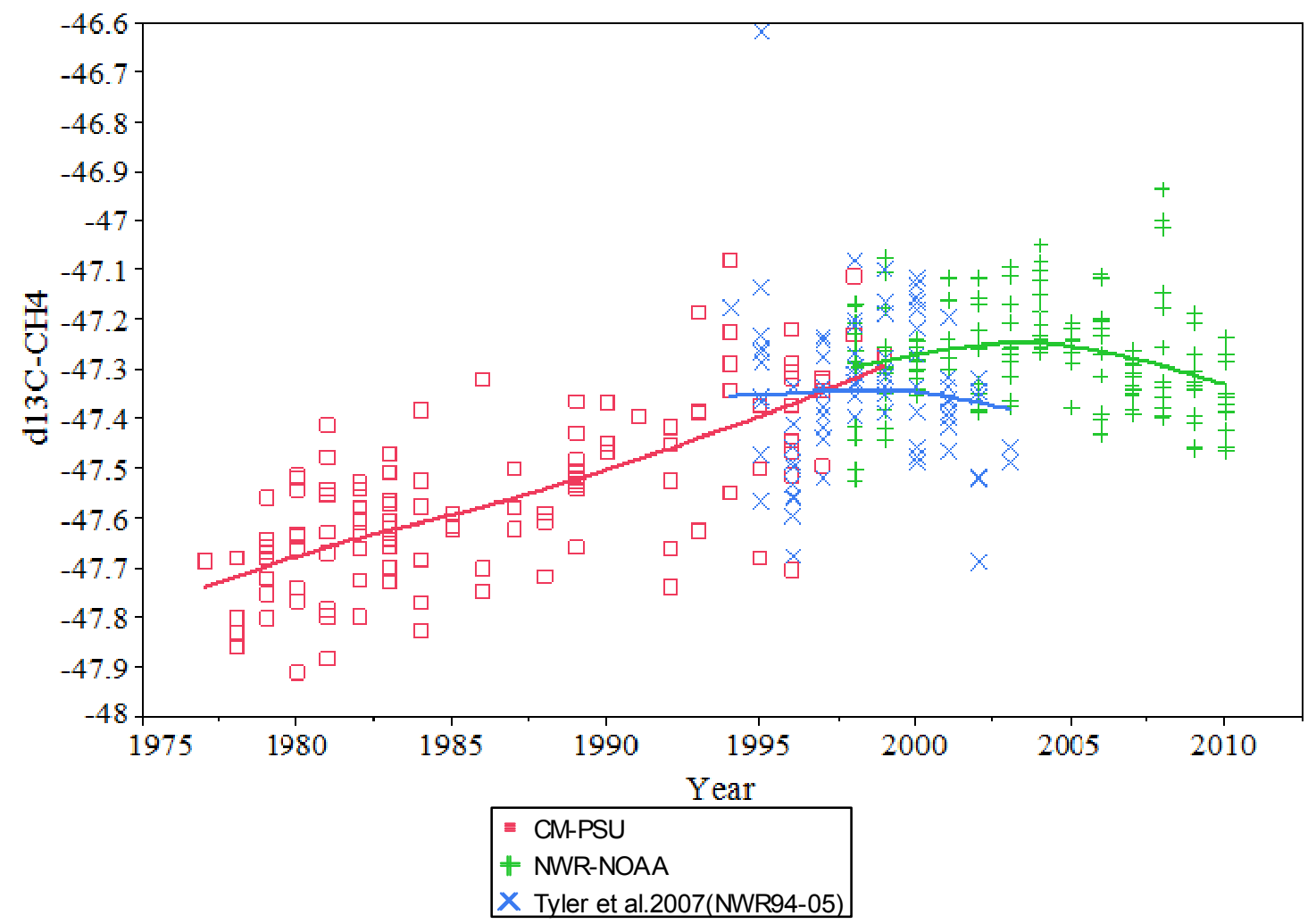

Figure B.3. The $\delta^{13} \mathrm{C}$ of atmospheric $\mathrm{CH}_{4}$ at Cape Meares, Oregon during (1977-1999) measured at PSU and Niwot Ridge, Colorado measured by Tyler et al.,2007 during (1994-2005) and NOAA during (19832010) 


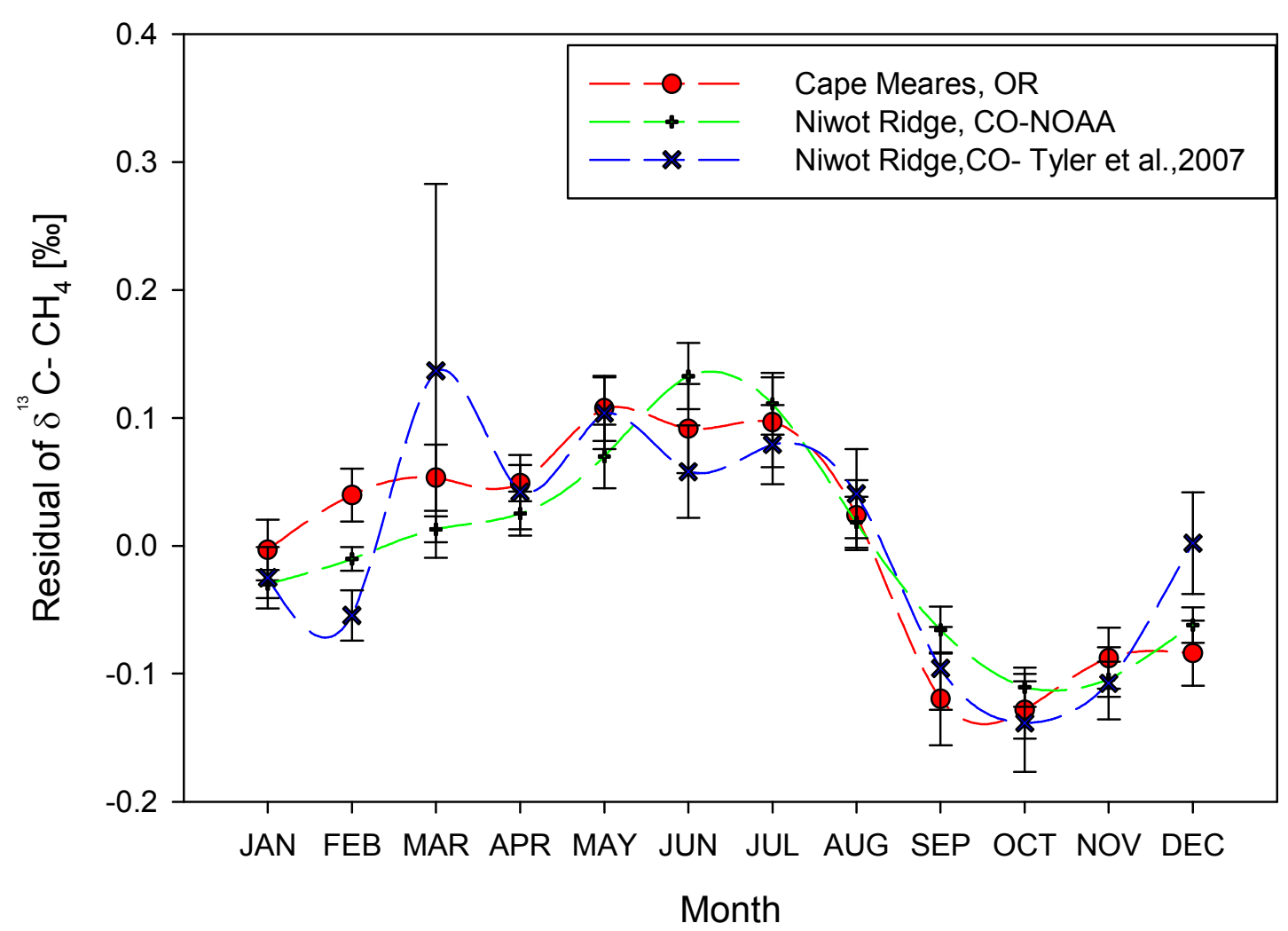

Figure B.4. Seasonal trend of $\delta^{13} \mathrm{C}$ of atmospheric $\mathrm{CH}_{4}$ at Cape Meares (red circle) and Niwot Ridge (blue cross) and (plus green). Error bars are \pm 1 standard error. 


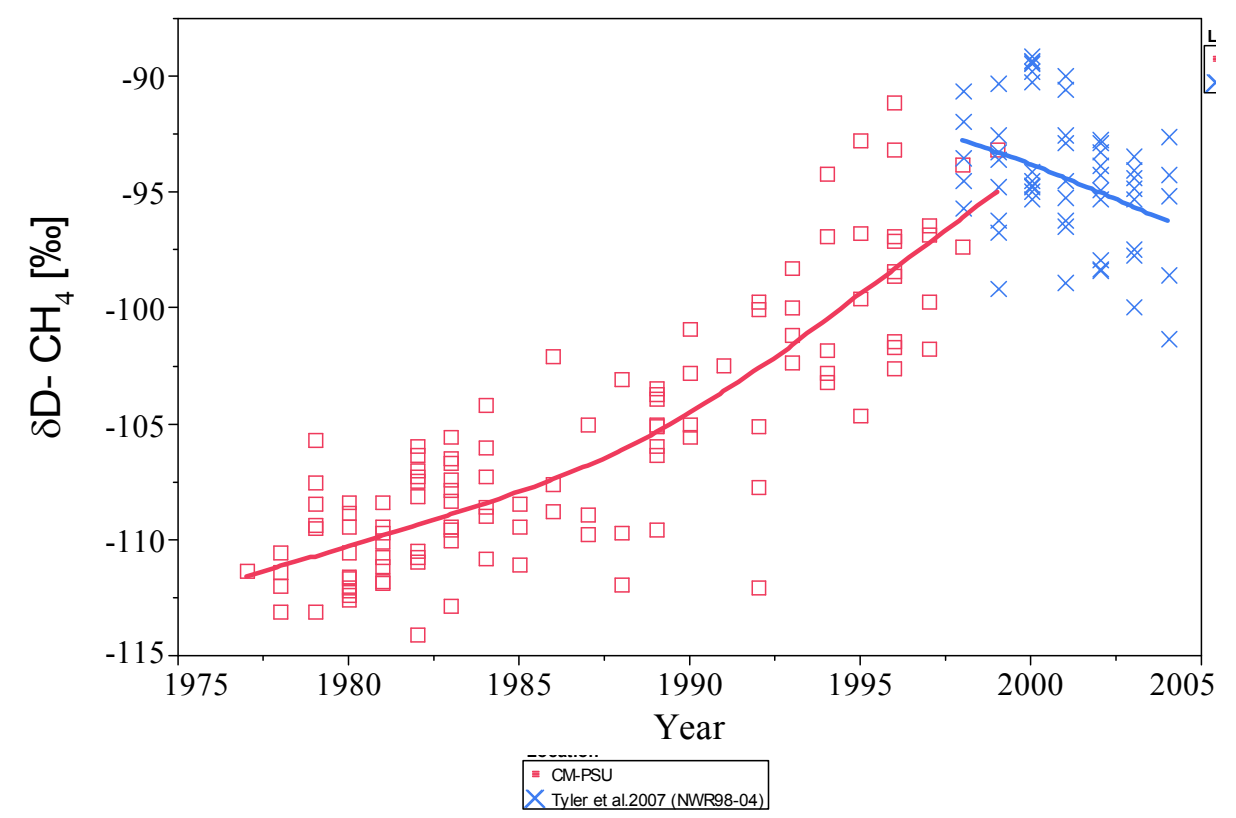

Figure B.5. The $\delta \mathrm{D}$ of atmospheric $\mathrm{CH}_{4}$ at Cape Meares, Oregon during (1977-1999) measured at PSU and Niwot Ridge, Colorado measured by Tyler et al.,2007 during (1998-2004). 


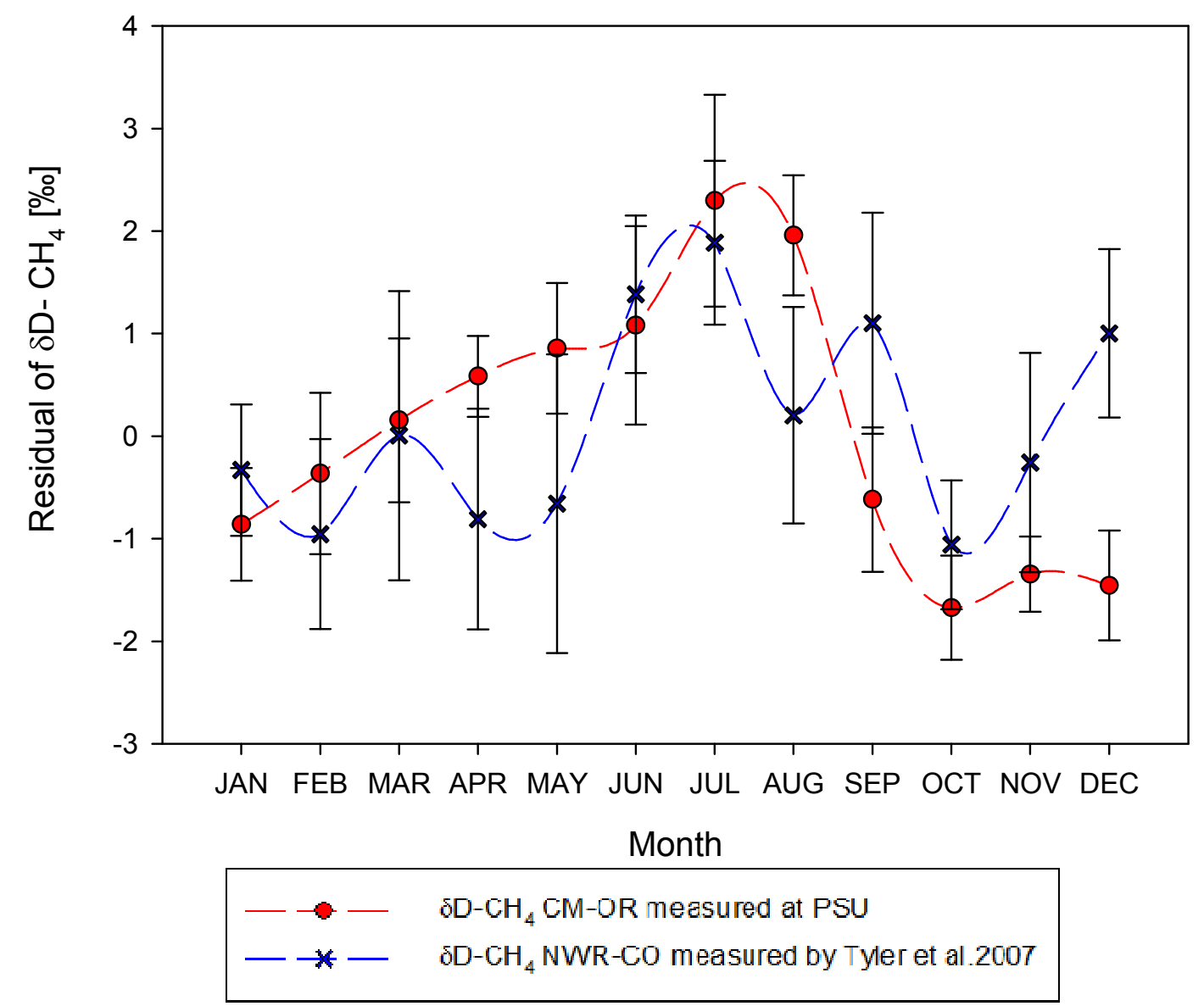

Figure B.6. Seasonal trend of $\delta \mathrm{D}$ of atmospheric $\mathrm{CH}_{4}$ at Cape Meares (red circle) and Niwot Ridge (blue cross). Error bars are \pm 1 standard error. 


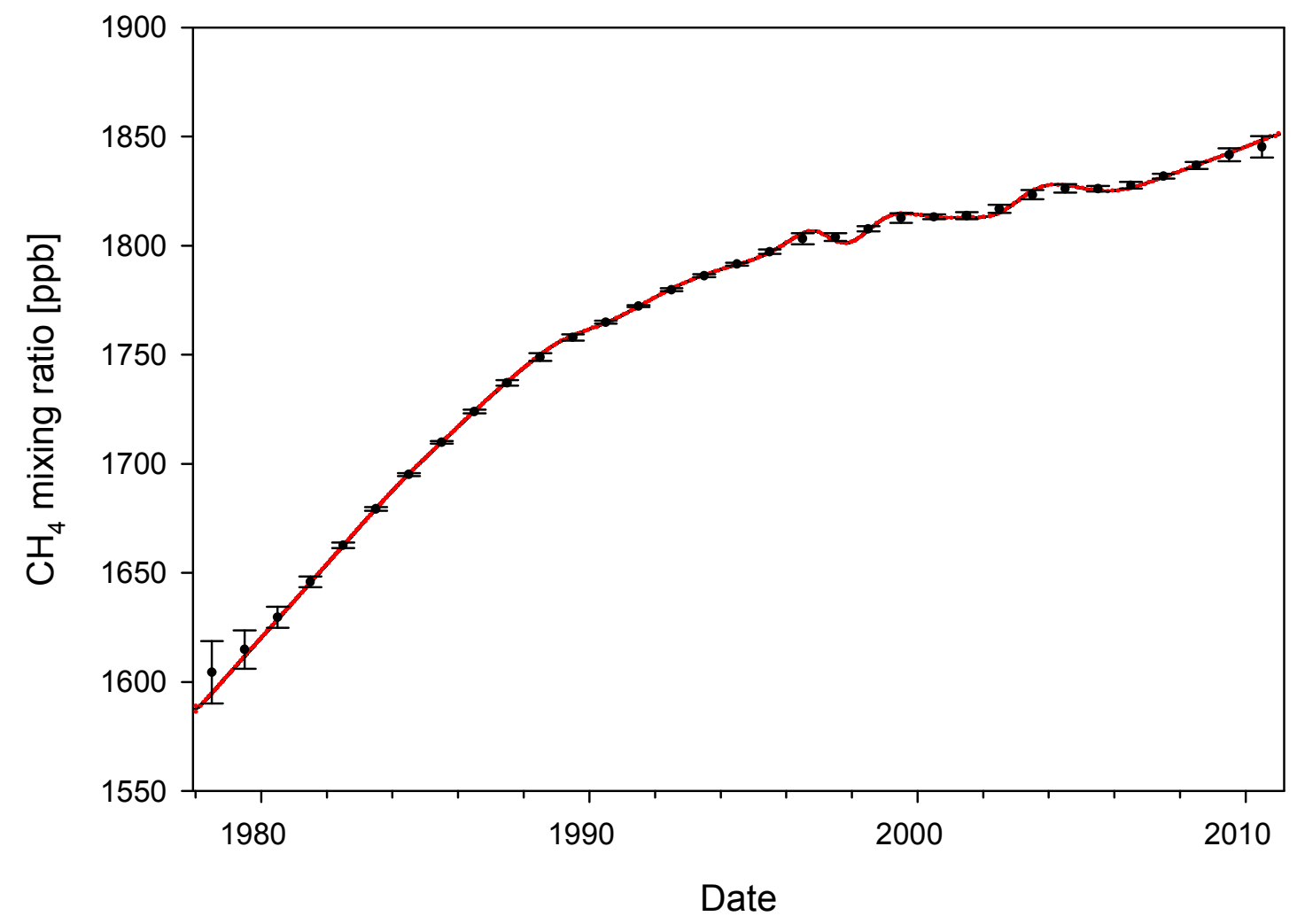

Figure B.7. The instantaneous atmospheric $\mathrm{CH}_{4}$ mixing ratio (1978-2010) with mean values (black line), $\pm 1 \sigma$ (red dots), and average yearly values (black circles) with $\pm 1 \sigma$ by smoothing the deseanonlize data for a span $=0.12$. 


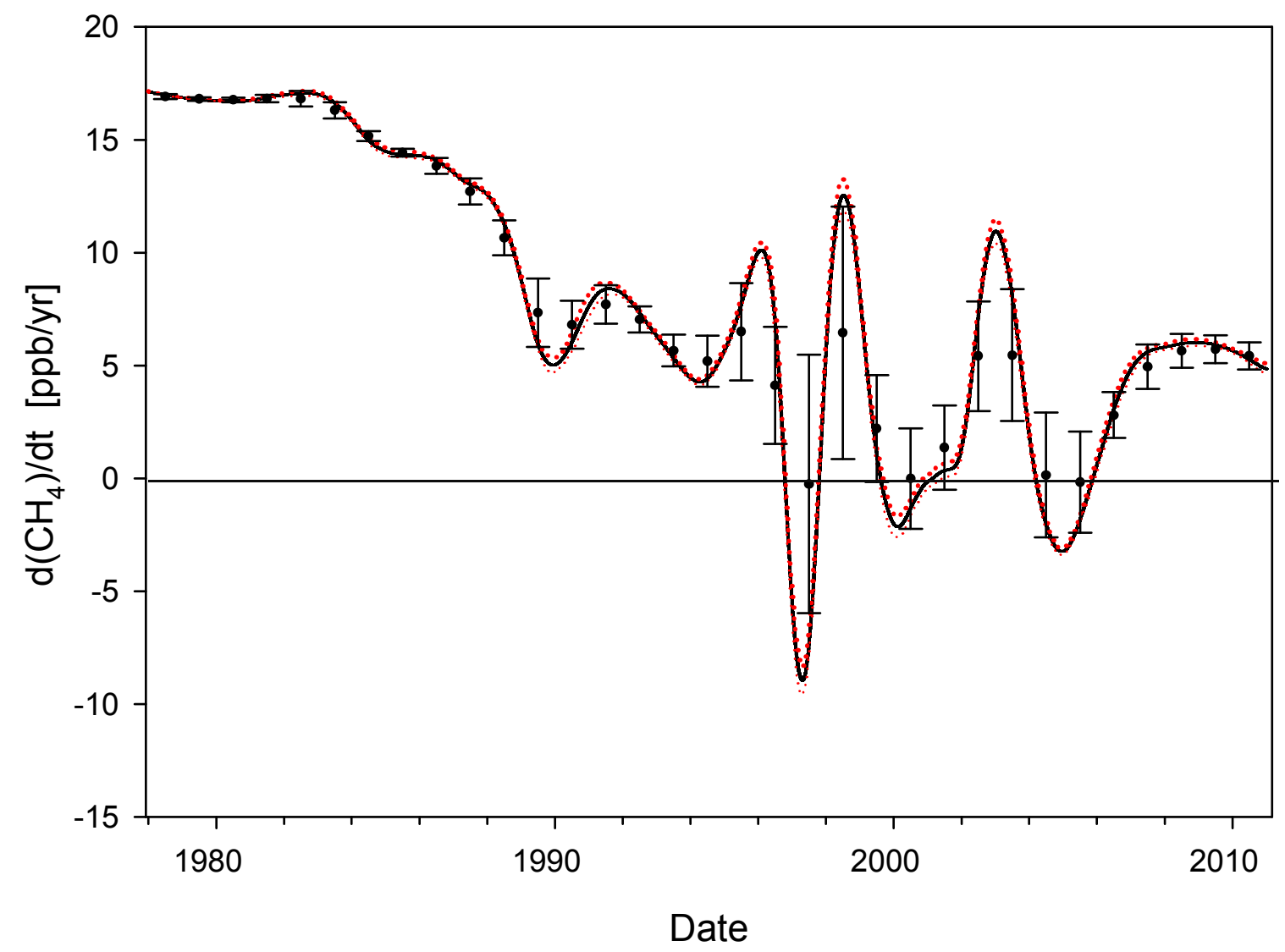

Figure B.8. The instantaneous $\mathrm{CH}_{4}$ growth rate (1978-2010) calculated from the derivative of the black line in figure B.7 with respect to time $\pm 1 \sigma$ (red dots), and average yearly values ( black circles) with $\pm 1 \sigma$. 


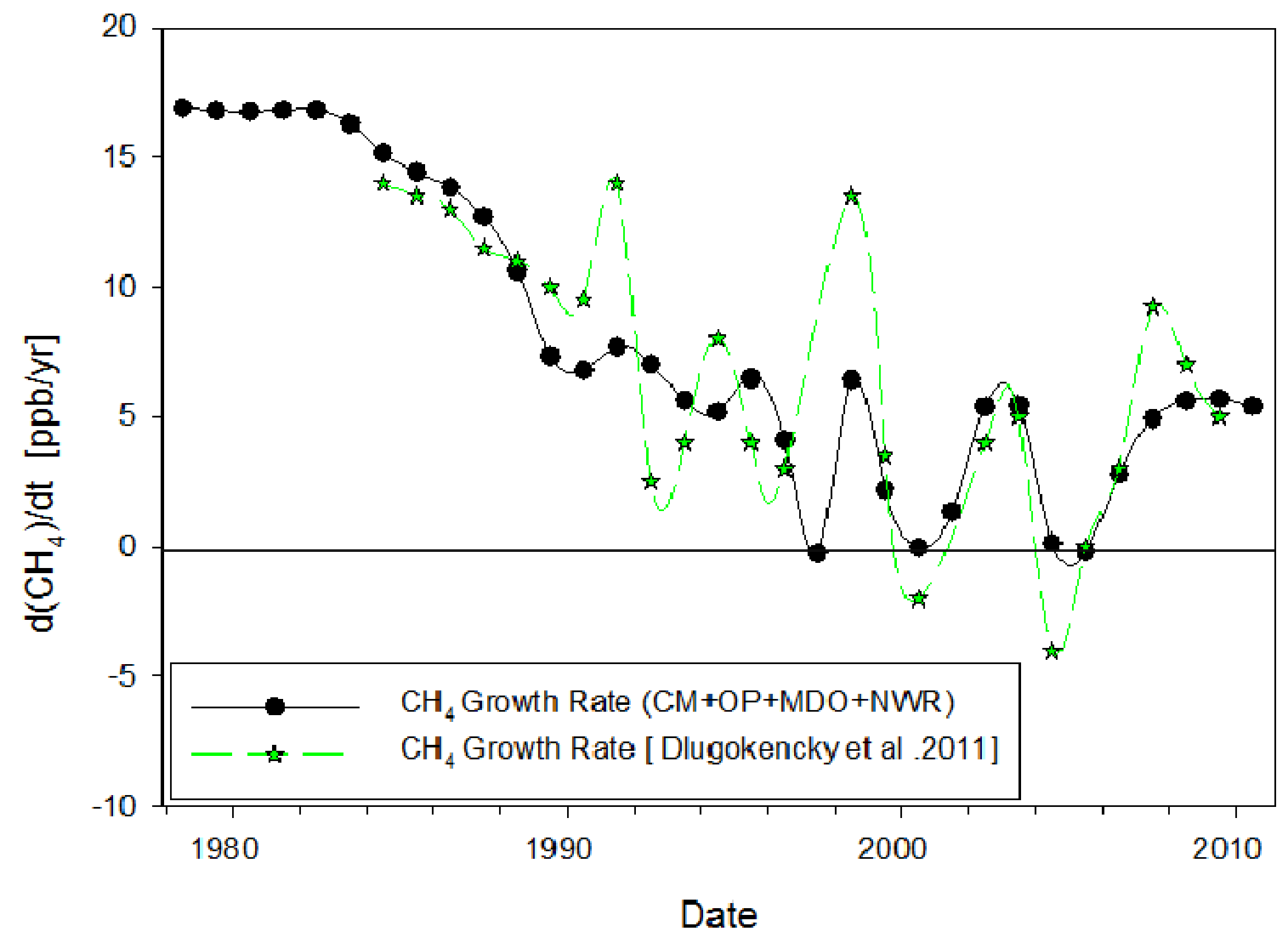

Figure B.9. The annual increases $\mathrm{CH}_{4}$ growth rate for the composite data with black circles during 19782010 measured in ppb/yr represented in figure B.8 as black circles. Green stars are the annual $\mathrm{CH}_{4}$ growth rate calculated from NOAA Global Cooperative Air Sampling Network measurements (values are taken from figure 1(b) [Dlugokencky et al. 2011]) 


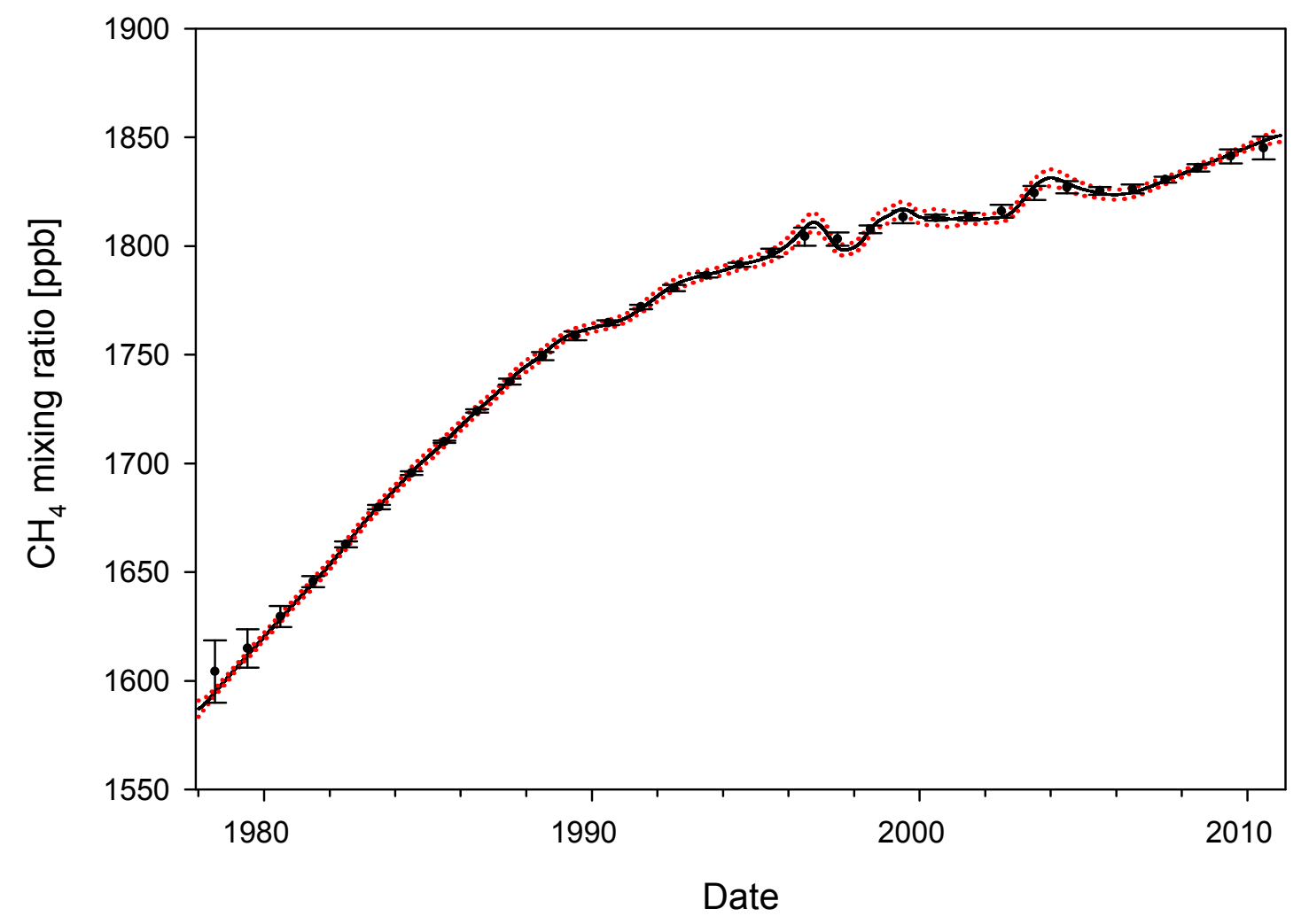

Figure B.10. The instantaneous atmospheric $\mathrm{CH}_{4}$ mixing ratio (1978-2010) with mean values (black line), $\pm 1 \sigma$ (red dots), and average yearly values (black circles) with $\pm 1 \sigma \sigma$ by smoothing the deseanonlize data for a span $=0.15$. 


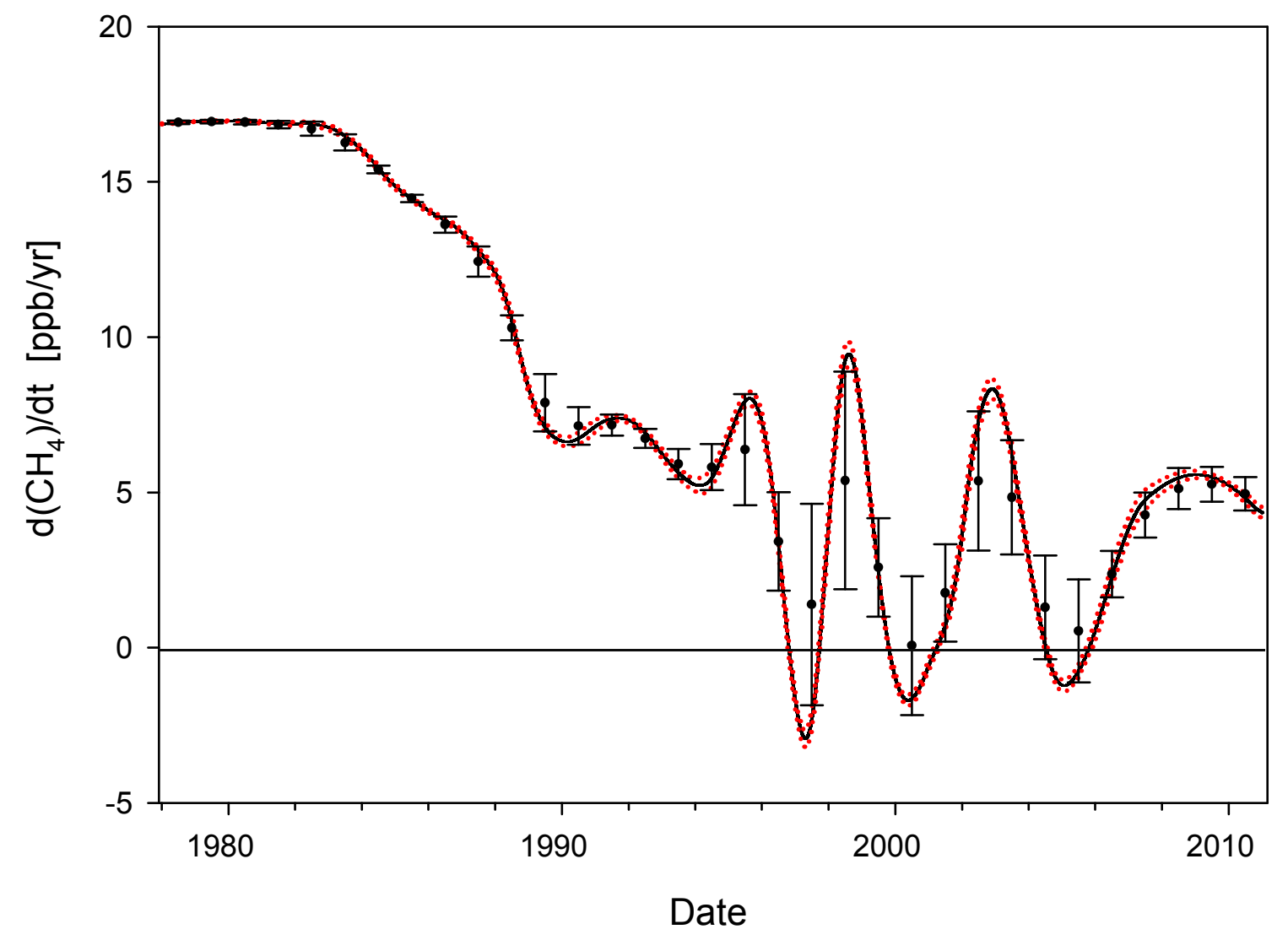

Figure B.11. The instantaneous $\mathrm{CH}_{4}$ growth rate (1978-2010) calculated from the derivative of the black line in figure B.10. with respect to time $\pm 1 \sigma$ (red dots), and average yearly values ( black circles) with $\pm 1 \sigma$. 


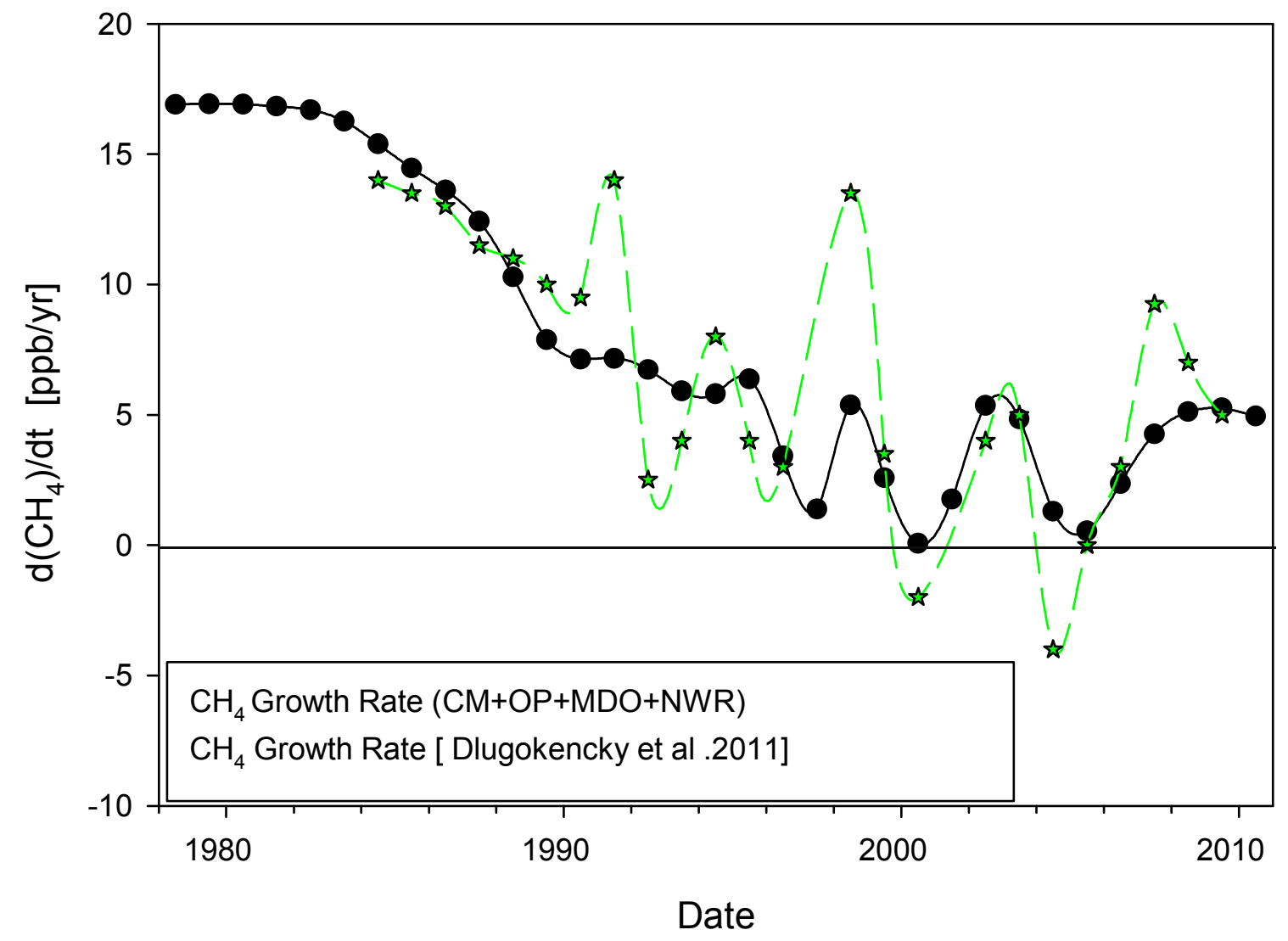

Figure B.12. The annual increases $\mathrm{CH}_{4}$ growth rate for the composite data with black circles during 19782010 measured in ppb/yr represented in figure B.11 as black circles. Green stars are the annual $\mathrm{CH}_{4}$ growth rate calculated from NOAA Global Cooperative Air Sampling Network measurements (values are taken from figure 1(b) [Dlugokencky et al. 2011]) 


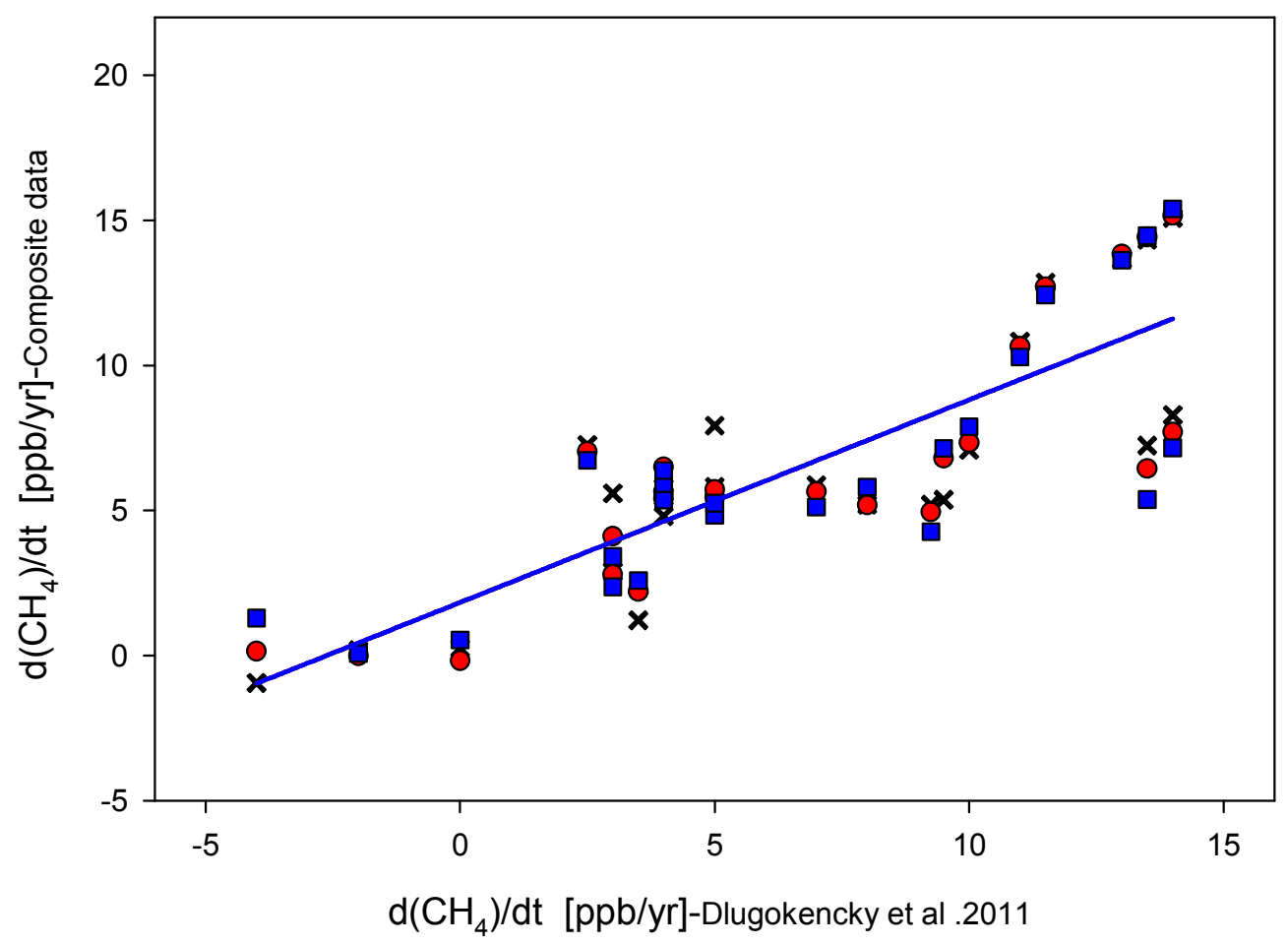

Figure B.13. The correlation between the $\mathrm{CH}_{4}$ - growth rate defined by Dlugokencky et al.[2011] with the $\mathrm{CH}_{4^{-}}$growth rate of the composite dataset results from different smoothing spans (black cross $=0.09$, red circle $=0.12$, and blue square $=0.15$ ) 


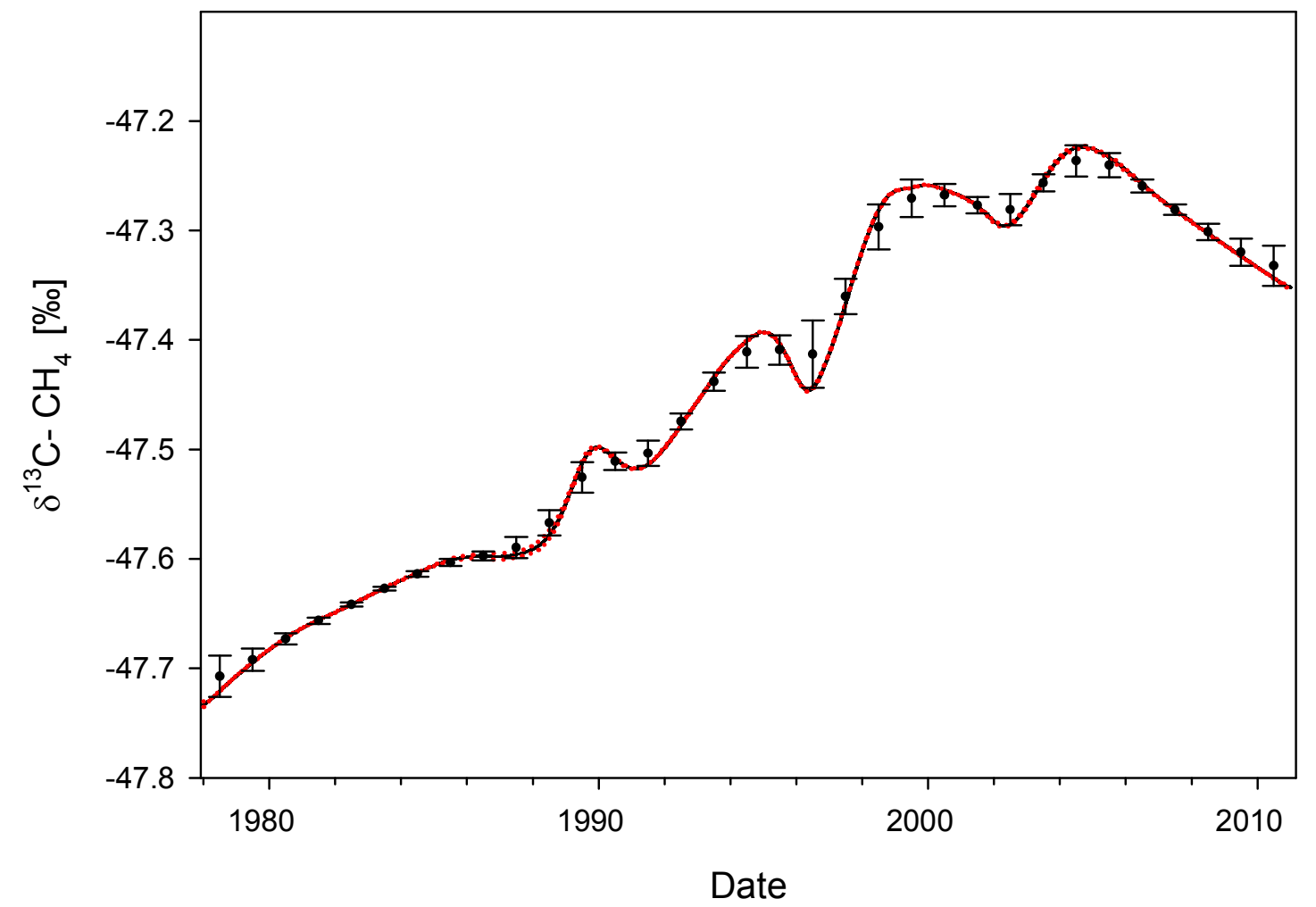

Figure B.14. The instantaneous $\delta^{13} \mathrm{C}$ trend during 1978-2010 with mean values (black line), $\pm 1 \sigma$ (red dots), and average yearly values (black circles) with $\pm 1 \sigma$ calculate from 1 January in one year to 1 January in the next year by smoothing the deseaonalize data with a span $=0.12$. 


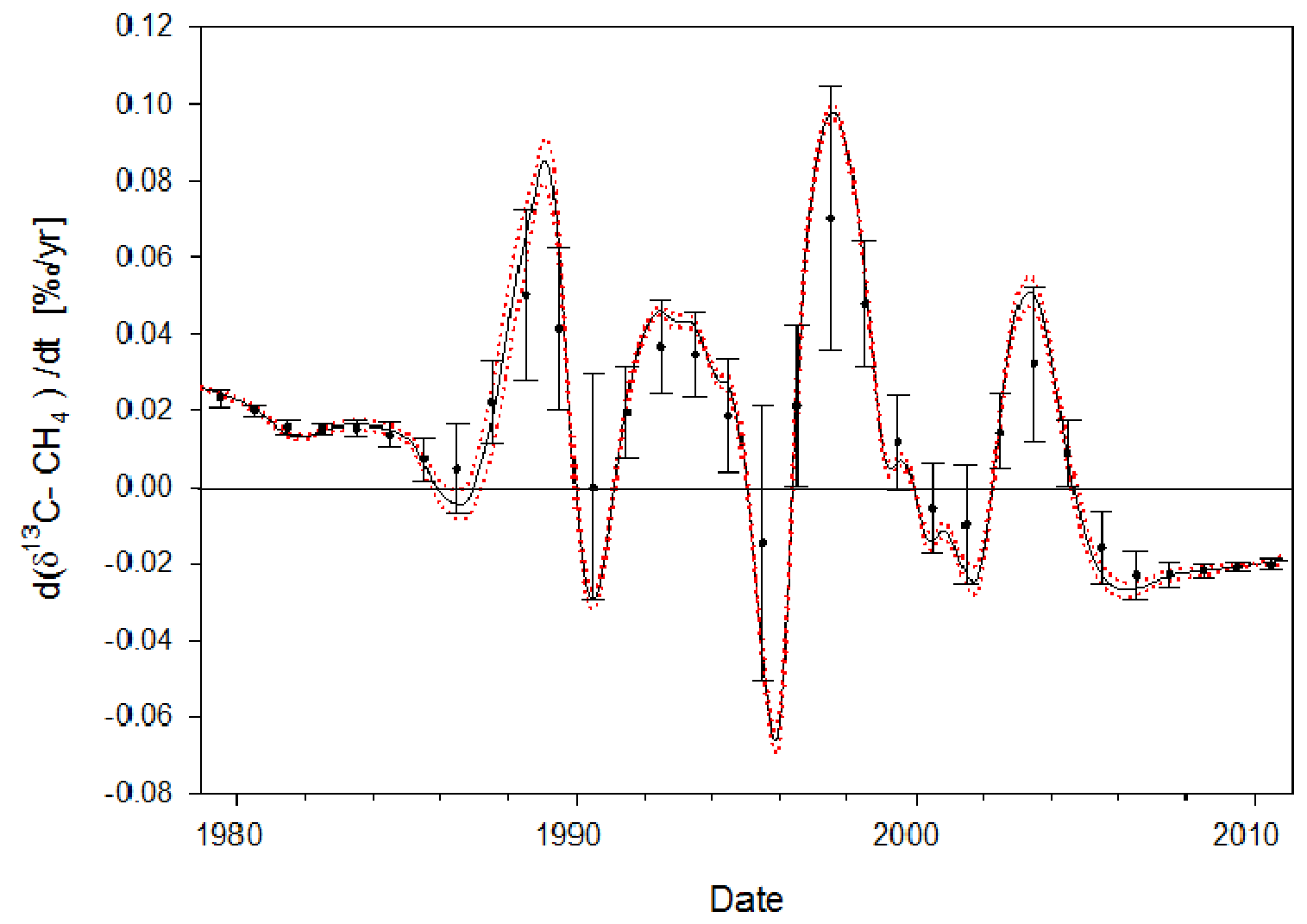

Figure B.14. The instantaneous $\delta^{13} \mathrm{C}$ growth rate of composite data (by differentiating black line with respect to time in figure B.13) during 1978-2010. Red dots are \pm standard deviation and black circles are the average yearly value calculated from 1 January in one year to 1 January in the next year. 


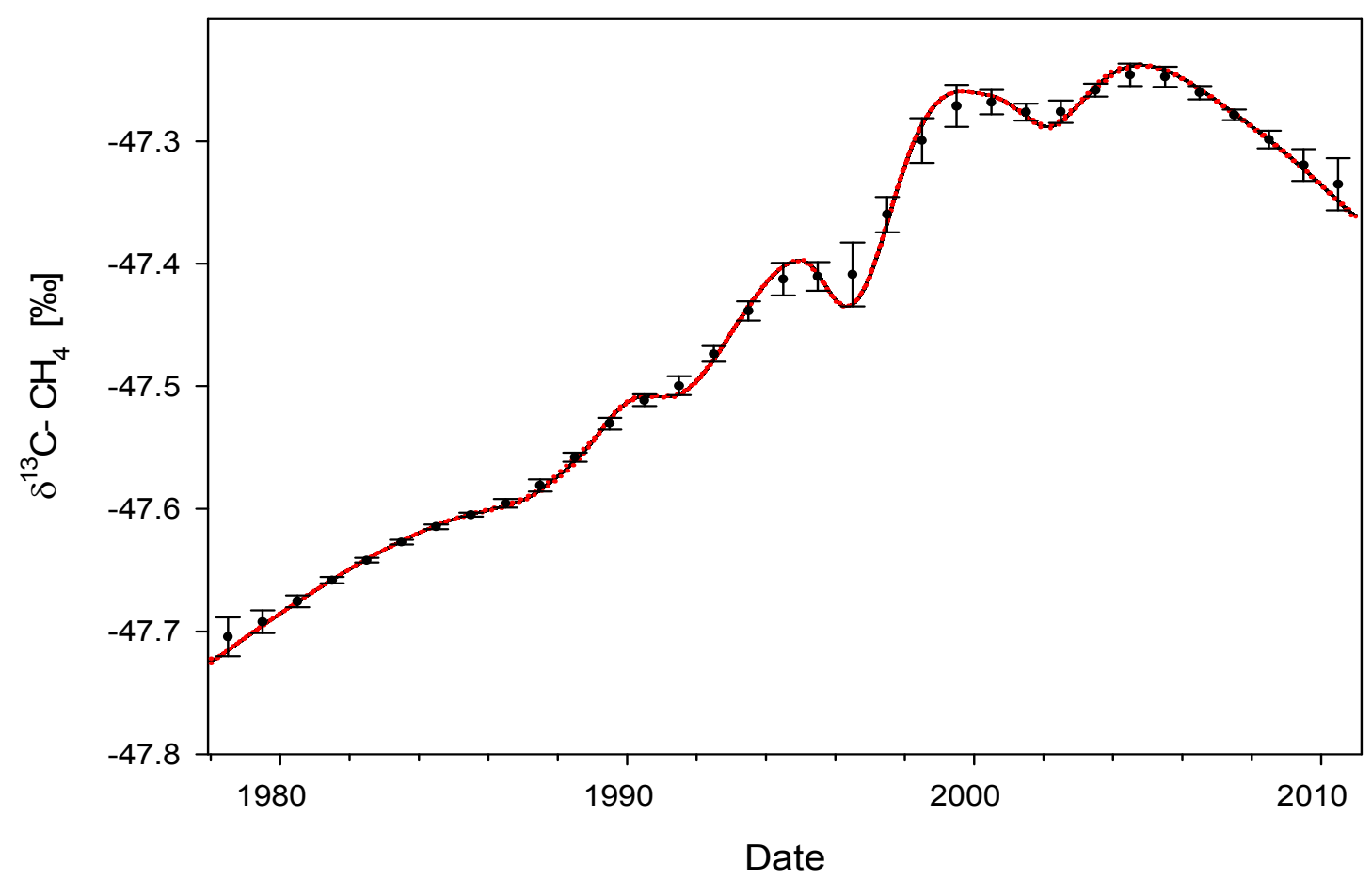

Figure B.15. The instantaneous $\delta^{13} \mathrm{C}$ trend during 1978-2010 with mean values (black line), $\pm 1 \sigma$ (red dots), and average yearly values (black circles) with $\pm 1 \sigma$ calculate from 1 January in one year to 1 January in the next year by smoothing the deseaonalize data with a span $=0.15$. 


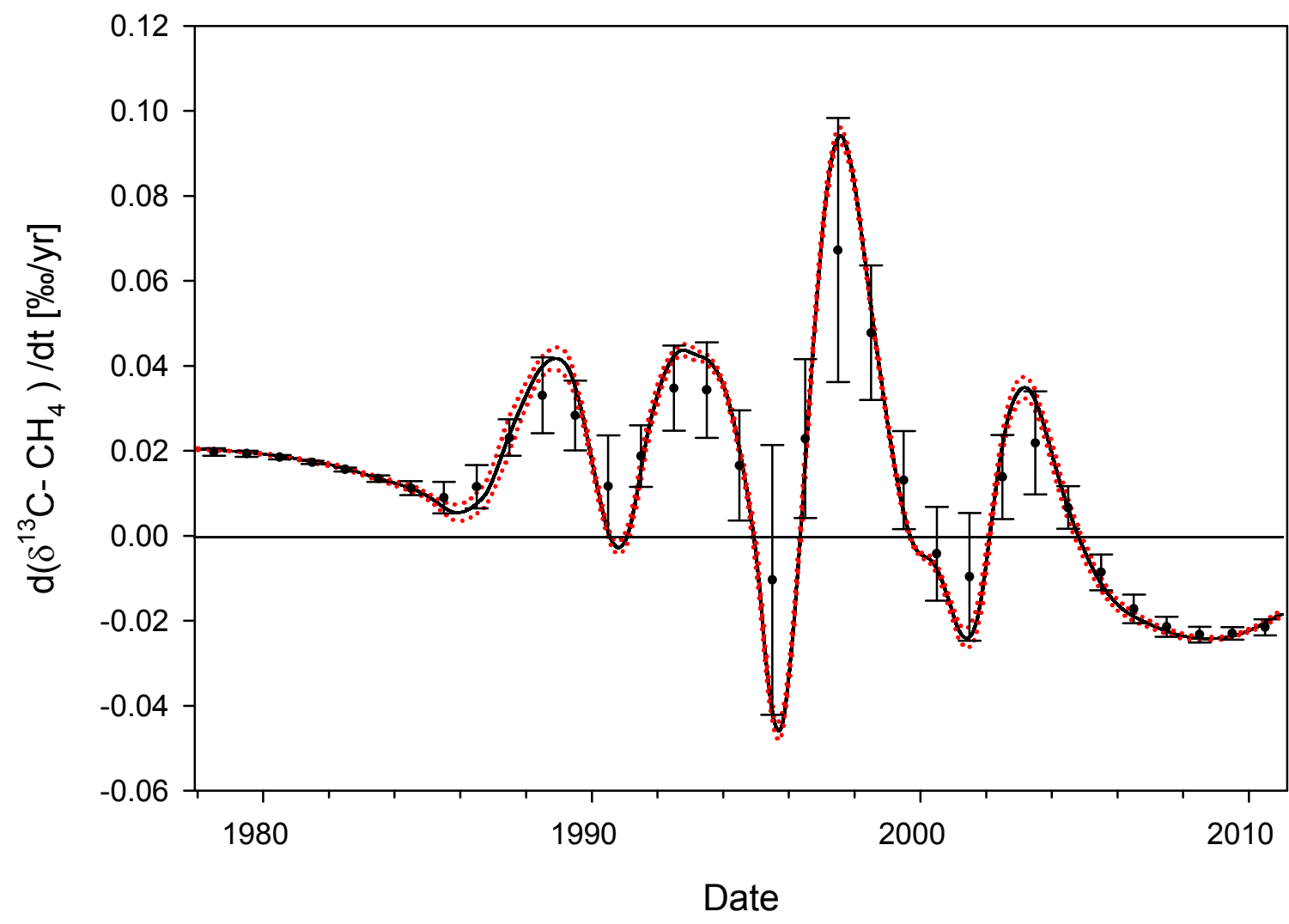

Figure B.16. The instantaneous $\delta^{13} \mathrm{C}$ growth rate of composite data (by differentiating black line with respect to time in figure B.15) during 1978-2010. Red dots are \pm standard deviation and black circles are the average yearly value calculated from 1 January in one year to 1 January in the next year. 


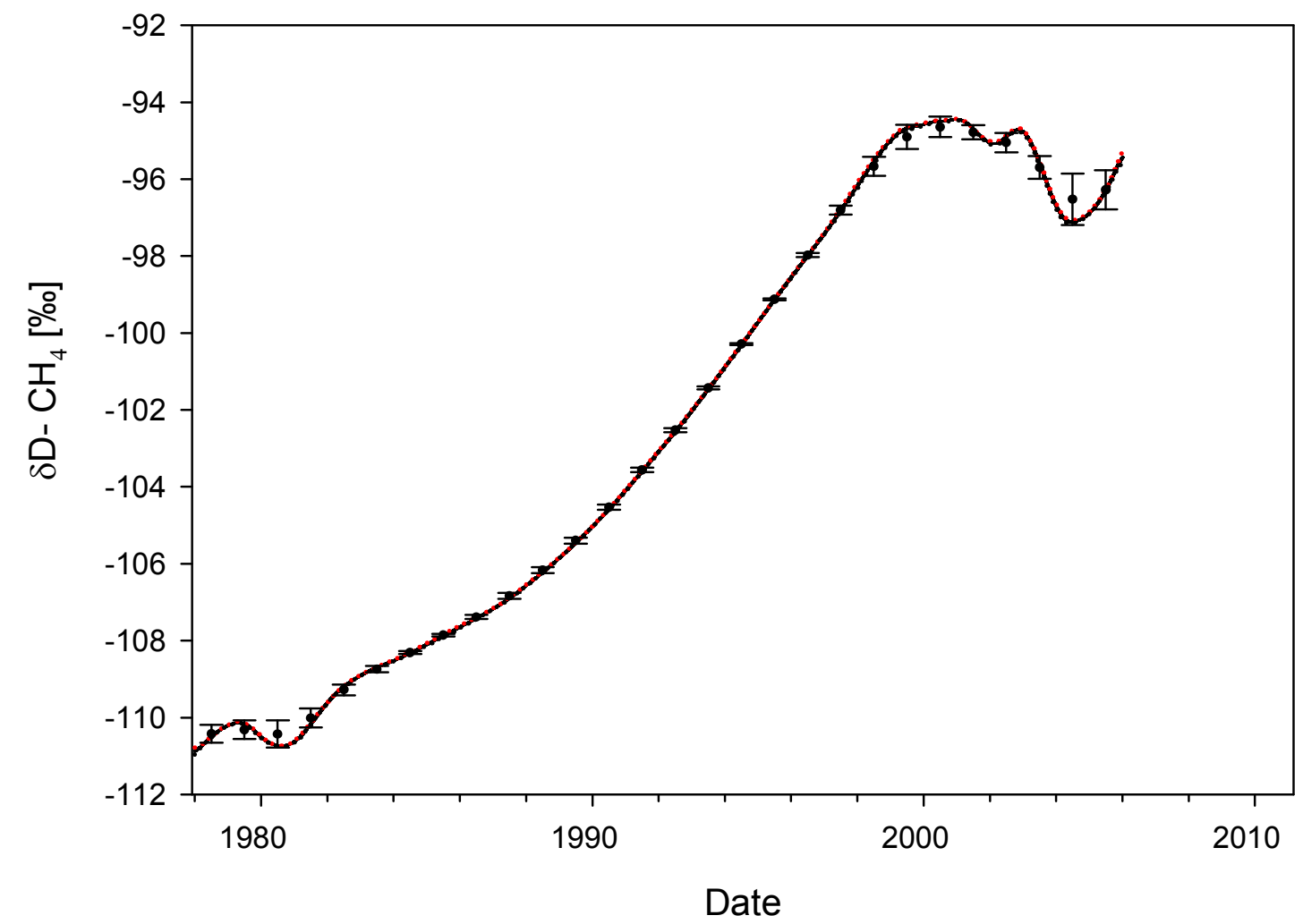

Figure B.17. The instantaneous $\delta$ D trend (1978-2005) with mean values (black line), $\pm 1 \sigma$ (red dots), and average yearly values (black circles) with $\pm 1 \sigma$ calculate from 1 January in one year to 1 January in the next year by smoothing the deseaonalize data with a span of 0.138 . 


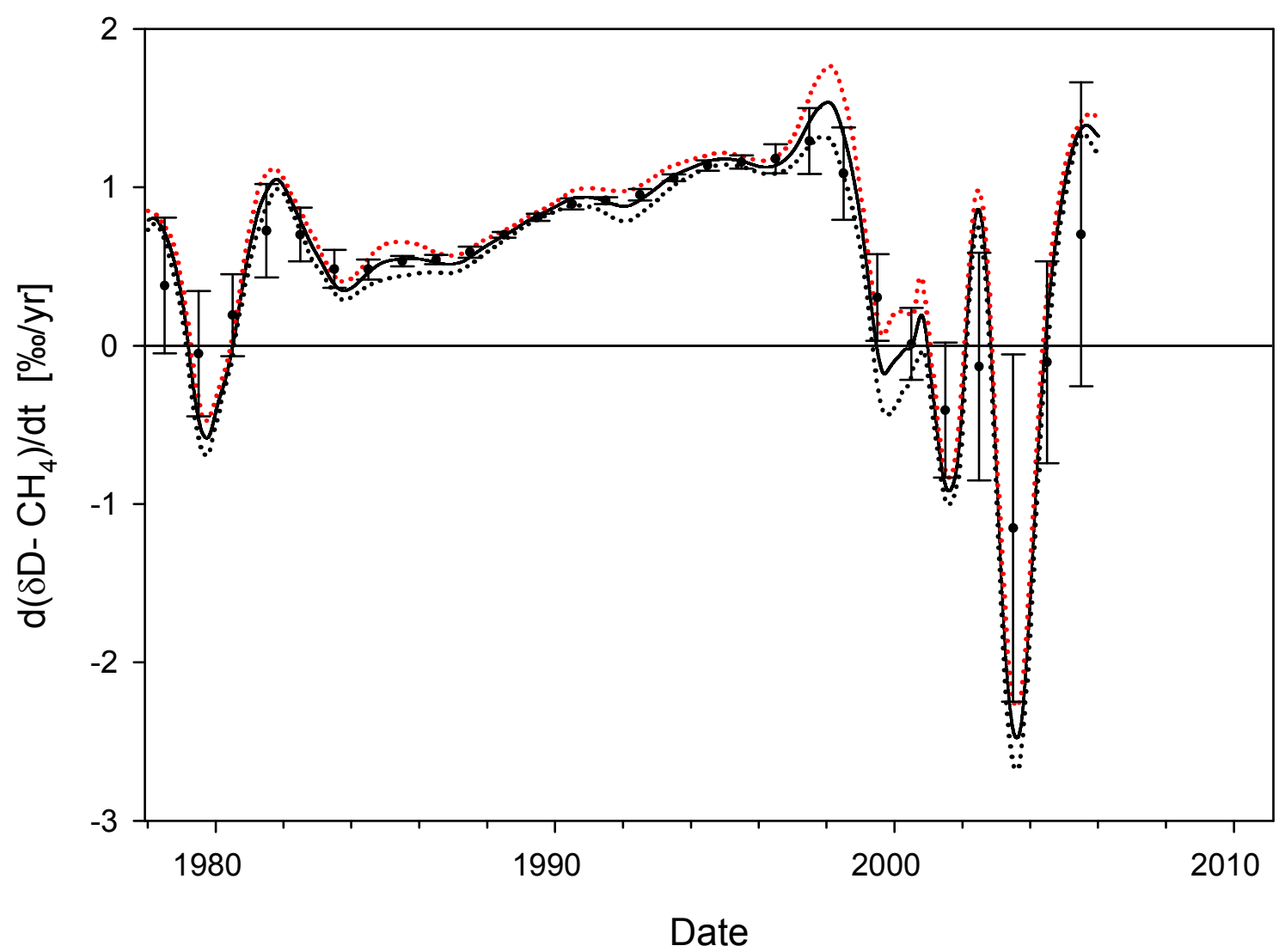

Figure B.18. The instantaneous $\delta$ D time rate of change of composite data (by differentiating black line in figure B.17 with respect to time) during 1978-2005. Red dots are \pm standard deviation and black circles are the average yearly values calculated from 1 January in one year to 1 January in the next year. 


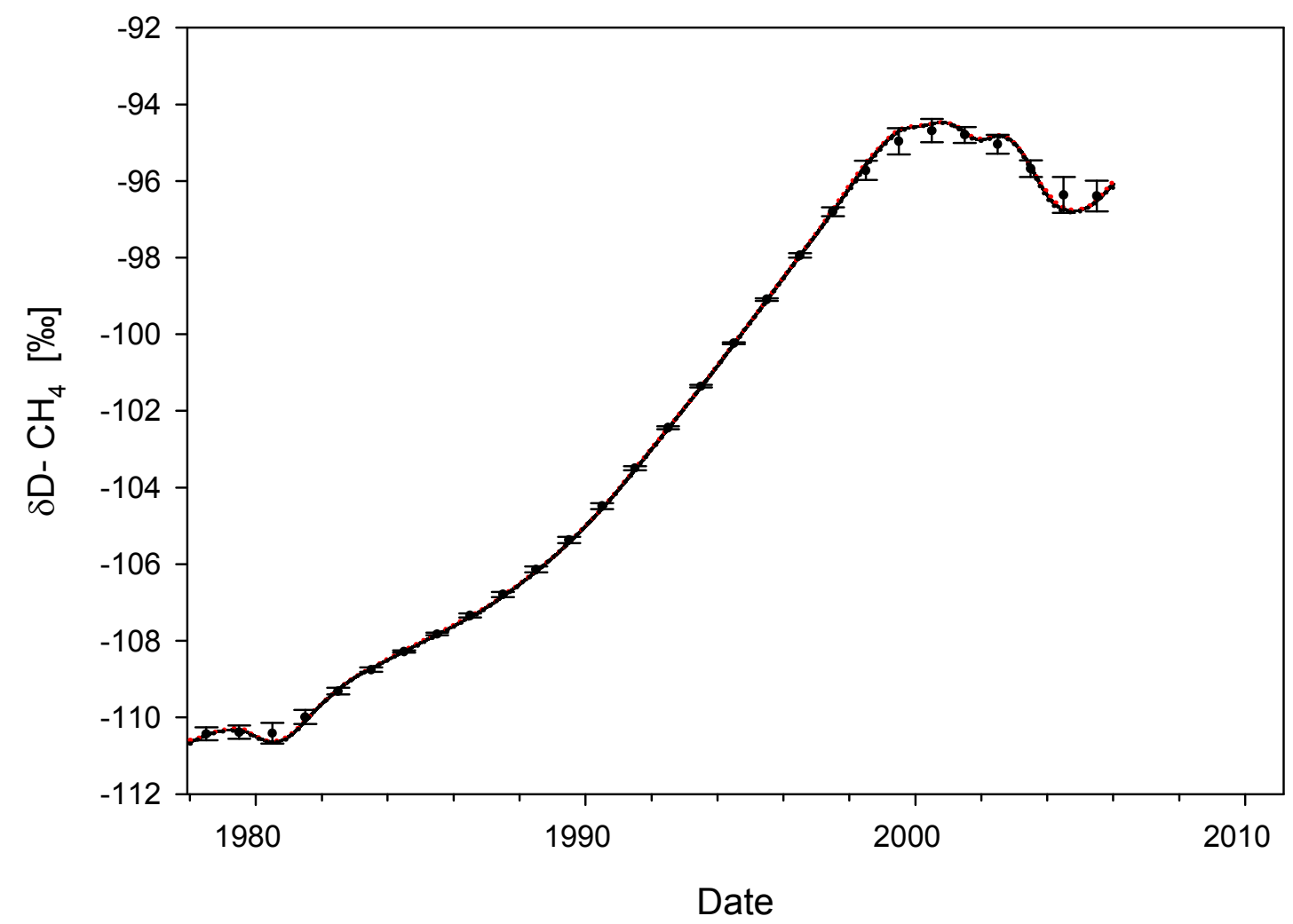

Figure B.19. The instantaneous $\delta \mathrm{D}$ trend (1978-2005) with mean values (black line), $\pm 1 \sigma$ (red dots), and average yearly values (black circles) with $\pm 1 \sigma$ calculate from 1 January in one year to 1 January in the next year by smoothing the deseaonalize data with a span of 0.172 . 


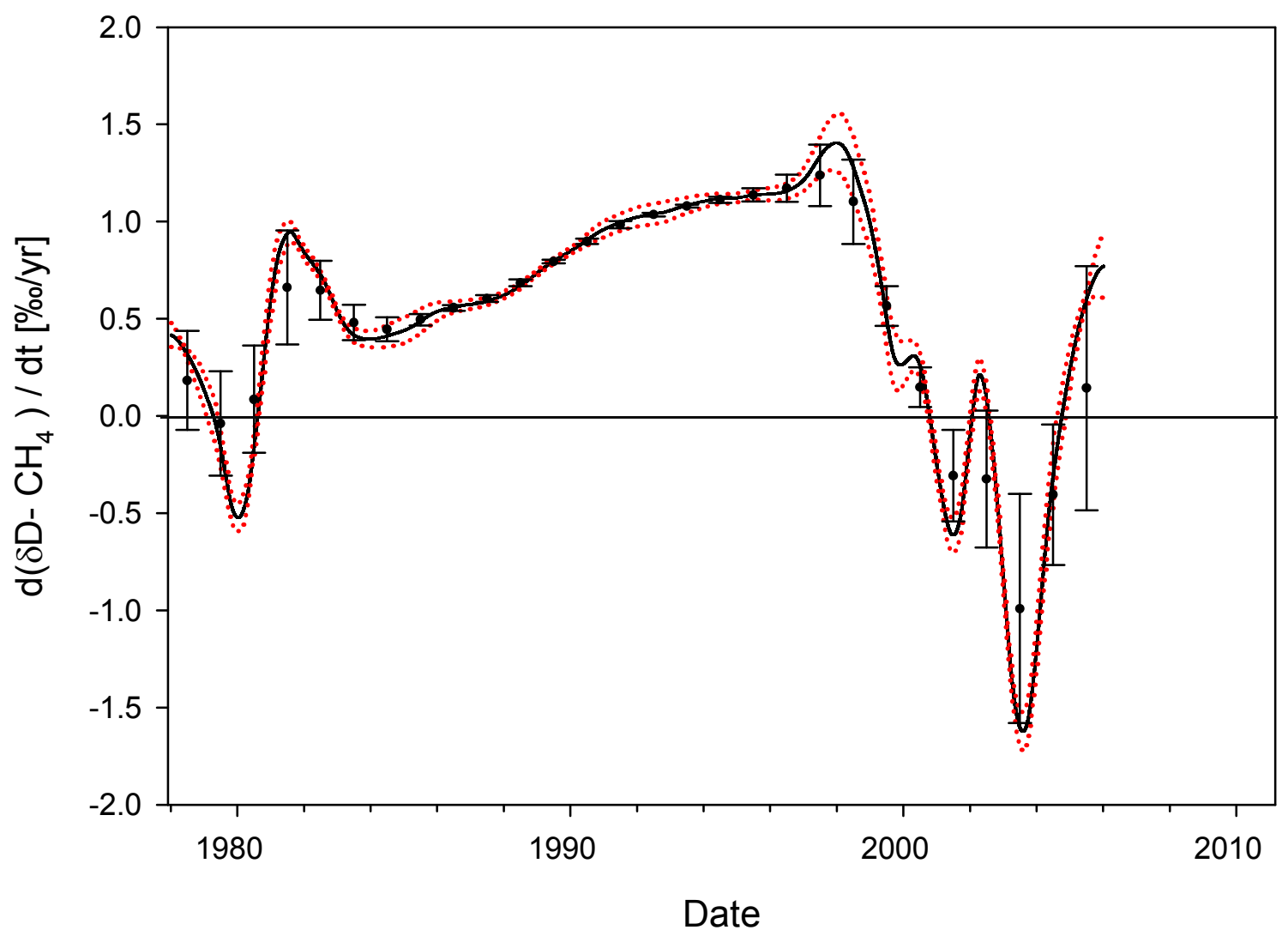

Figure B.20. The instantaneous $\delta \mathrm{D}$ time rate of change of composite data (by differentiating black line in figure B.19 with respect to time) during 1978-2005. Red dots are \pm standard deviation and black circles are the average yearly values calculated from 1 January in one year to 1 January in the next year. 


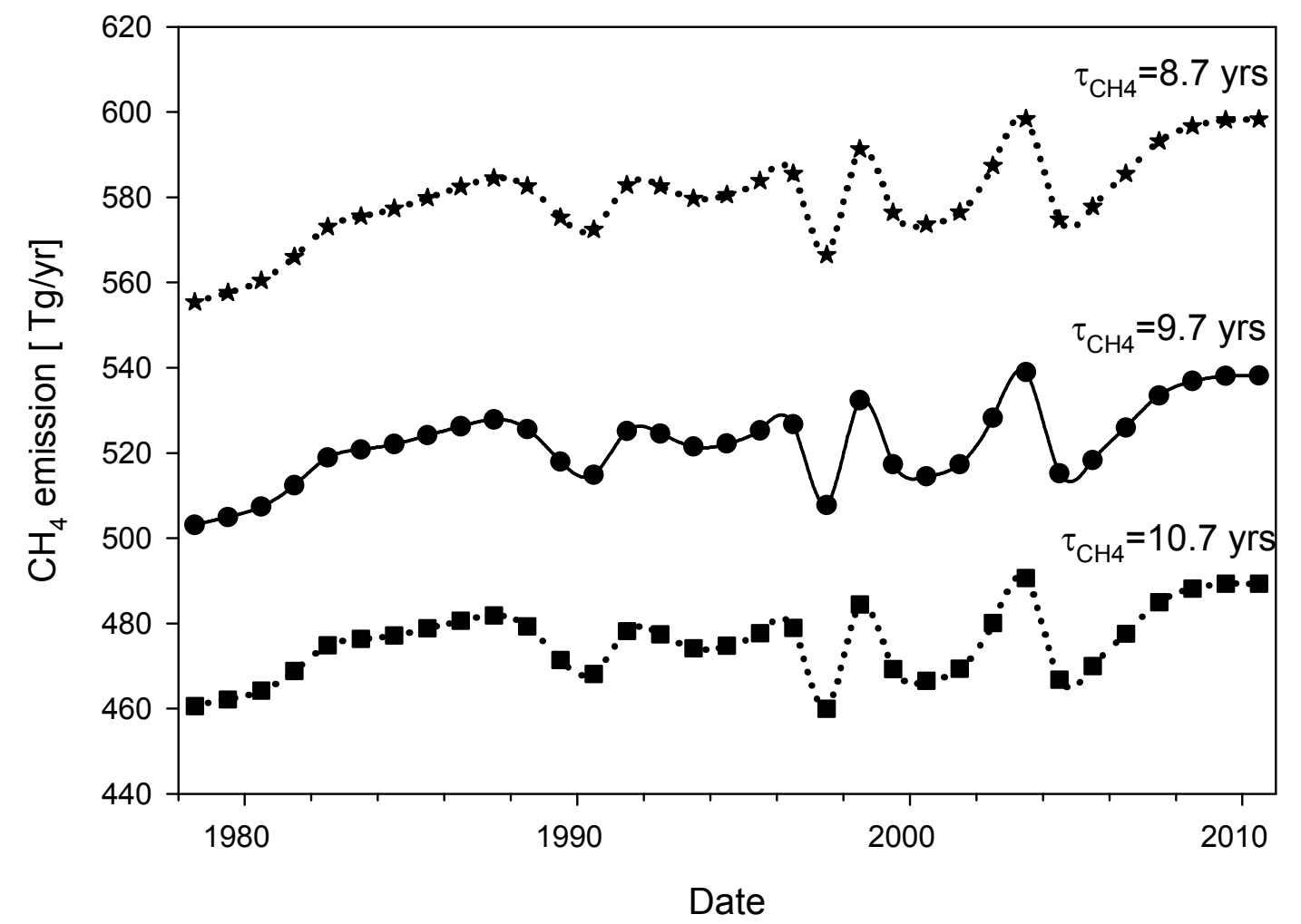

Figure B.21. Annual $\mathrm{CH}_{4}$ emission during 1978-2010 using the mass balance equation and based on $\mathrm{CH}_{4}$ lifetimes of $8.7 \mathrm{yrs}, 9.7 \mathrm{yrs}$, and $10.7 \mathrm{yrs}$, respectively. 


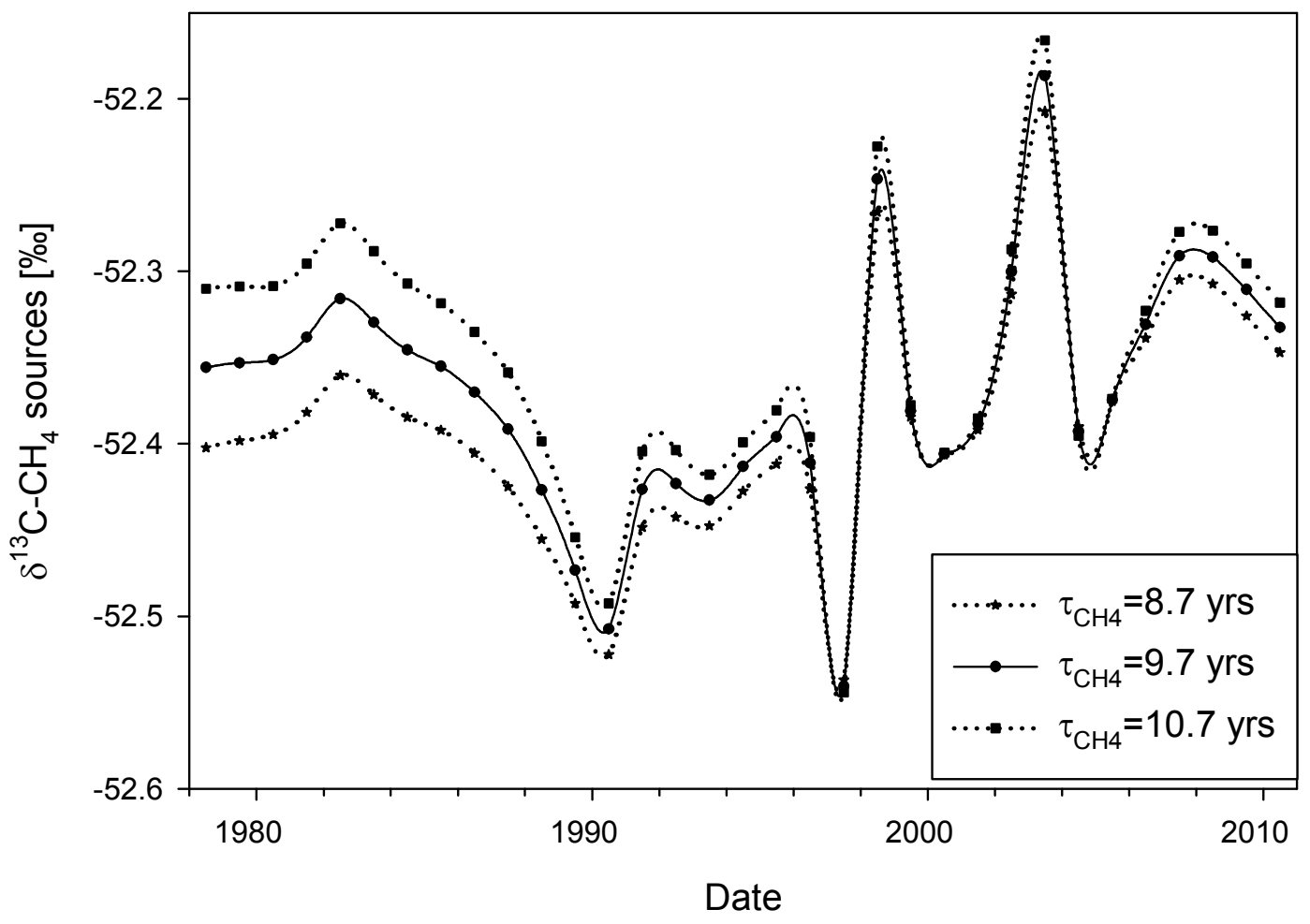

Figure B.22. Annual $\delta^{13} \mathrm{C}-\mathrm{CH}_{4}$ sources during 1978-2010 based on $\mathrm{CH}_{4}$ lifetimes of $8.7 \mathrm{yrs}, 9.7 \mathrm{yrs}$, and $10.7 \mathrm{yrs}$, respectively. 


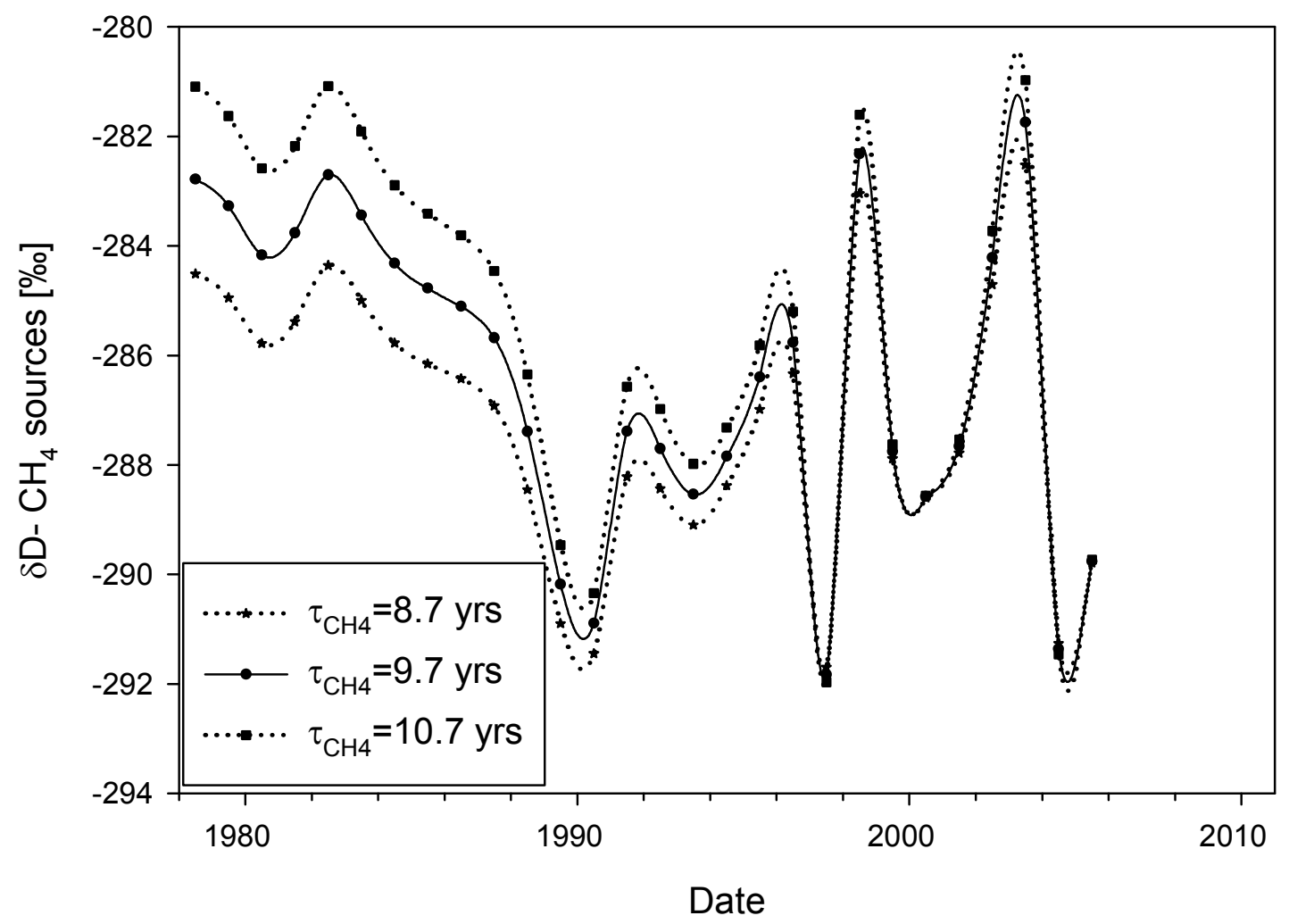

Figure B.23. Annual $\delta^{13} \mathrm{D}-\mathrm{CH}_{4}$ sources during 1978-2005 based on $\mathrm{CH}_{4}$ lifetimes of $8.7 \mathrm{yrs}, 9.7 \mathrm{yrs}$, and 10.7 yrs, respectively 


\section{Appendix C}

Recent Air Sampling at Cape Meares (March 2012- October 2012)

Table I.1. Measurements description

\begin{tabular}{|c|l|}
\hline Term & \multicolumn{1}{|c|}{ Description } \\
\hline WDIR & $\begin{array}{l}\text { Wind direction (the direction the wind is coming from in degrees clockwise } \\
\text { from true N) during the same period used for WSPD. See Wind Averaging } \\
\text { Methods }\end{array}$ \\
\hline WSPD & $\begin{array}{l}\text { Wind speed (m/s) averaged over an eight-minute period for buoys and a two- } \\
\text { minute period for land stations. Reported Hourly. See Wind Averaging } \\
\text { Methods. }\end{array}$ \\
\hline GST & $\begin{array}{l}\text { Peak 5 or 8 second gust speed (m/s) measured during the eight-minute or two- } \\
\text { minute period. The 5 or 8 second period can be determined by payload, See } \\
\text { the Sensor Reporting, Sampling, and Accuracy section. }\end{array}$ \\
\hline PRES & $\begin{array}{l}\text { Sea level pressure (hPa). For C-MAN sites and Great Lakes buoys, the } \\
\text { recorded pressure is reduced to sea level using the method described in NWS } \\
\text { Technical Procedures Bulletin 291 (11/14/80). (labeled BAR in Historical } \\
\text { files) }\end{array}$ \\
\hline ATMP & $\begin{array}{l}\text { Air temperature (Celsius). For sensor heights on buoys, see Hull Descriptions. } \\
\text { For sensor heights at C-MAN stations, see C-MAN Sensor Locations }\end{array}$ \\
\hline
\end{tabular}




\section{NOAA HYSPLIT MODEL \\ Backward trajectory ending at 1800 UTC 28 Mar 12 NAM Meteorological Data}

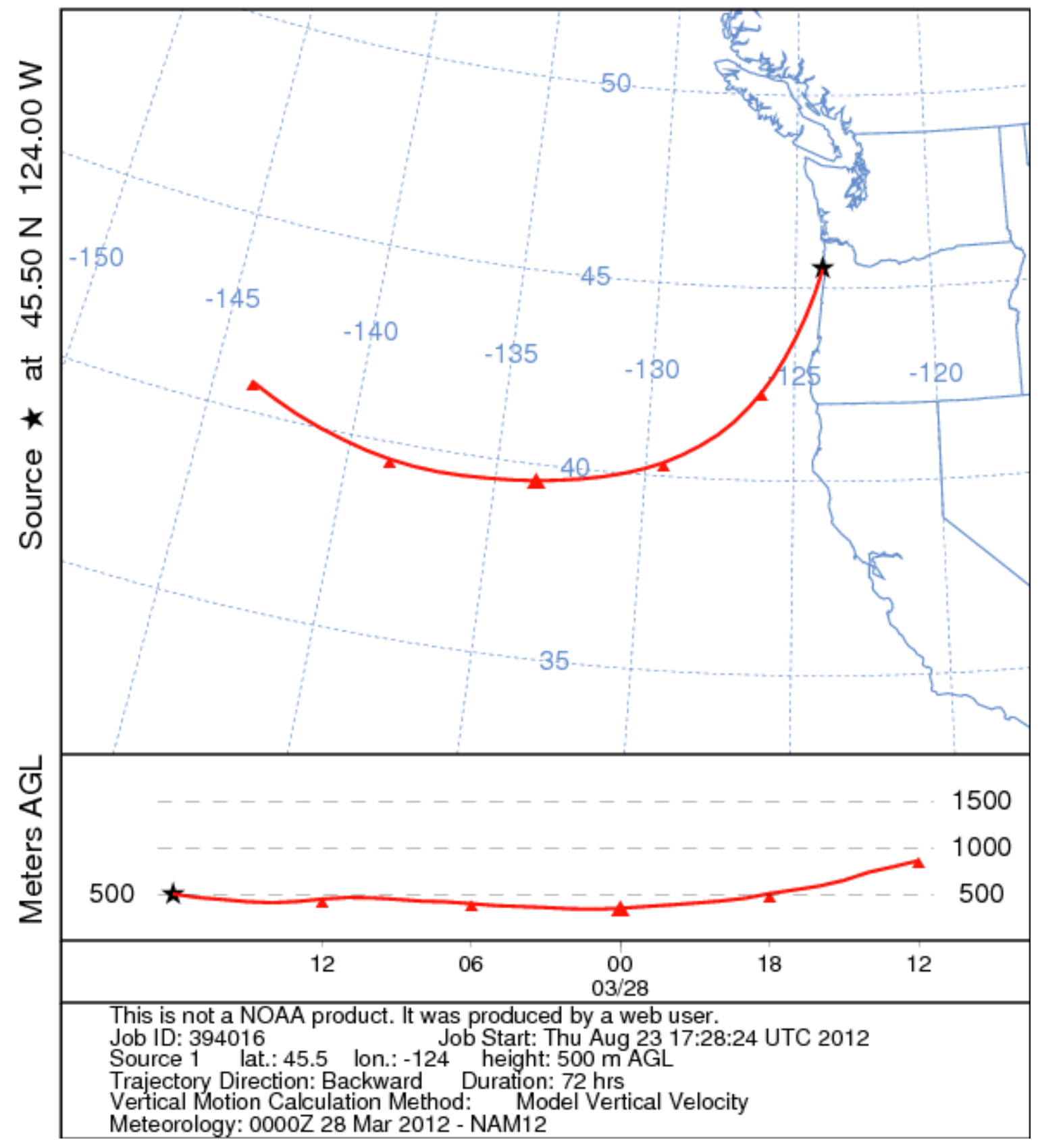




\begin{tabular}{|c|c|c|c|c|c|c|c|c|c|}
\hline \#YY & MM & DD & hh & $\mathbf{m m}$ & WDIR & WSPD & GST & PRES & ATMP \\
\hline \#yr & $\mathbf{m o}$ & $\mathbf{d y}$ & $\mathbf{h r}$ & $\mathbf{m n}$ & $\mathbf{d e g T}$ & $\mathbf{m} / \mathbf{s}$ & $\mathbf{m} / \mathbf{s}$ & $\mathbf{h P a}$ & $\mathbf{d e g C}$ \\
\hline 2012 & 3 & 28 & 11 & 0 & 138 & 10.3 & 12.8 & 1002.8 & 7.9 \\
\hline 2012 & 3 & 28 & 11 & 6 & 149 & 9.1 & 12.5 & 1002.8 & 7.9 \\
\hline 2012 & 3 & 28 & 11 & 12 & 152 & 10.2 & 12.4 & 1003 & 7.9 \\
\hline 2012 & 3 & 28 & 11 & 18 & 148 & 8.3 & 10 & NA & NA \\
\hline 2012 & 3 & 28 & 11 & 24 & 148 & 9.3 & 11.9 & 1003.1 & 7.7 \\
\hline 2012 & 3 & 28 & 11 & 30 & 150 & 9.2 & 11.8 & 1003 & 7.6 \\
\hline 2012 & 3 & 28 & 11 & 36 & 157 & 8.6 & 11.3 & 1002.9 & 7.7 \\
\hline 2012 & 3 & 28 & 11 & 42 & 165 & 8.5 & 10.8 & 1003.1 & 7.7 \\
\hline 2012 & 3 & 28 & 11 & 48 & 145 & 8.5 & 10.6 & NA & NA \\
\hline 2012 & 3 & 28 & 11 & 54 & 148 & 9.1 & 12.2 & 1003.2 & 7.7 \\
\hline 2012 & 3 & 28 & 12 & 0 & 137 & 9.9 & 11.5 & 1003.1 & 7.7 \\
\hline 2012 & 3 & 28 & 12 & 6 & 137 & 9.1 & 12.2 & 1003 & 7.7 \\
\hline 2012 & 3 & 28 & 12 & 12 & 133 & 9.9 & 11.7 & 1003.1 & 7.7 \\
\hline 2012 & 3 & 28 & 12 & 18 & 139 & 9.9 & 12.3 & NA & NA \\
\hline 2012 & 3 & 28 & 12 & 24 & 149 & 9.5 & 12.2 & 1003.1 & 7.8 \\
\hline 2012 & 3 & 28 & 12 & 30 & 152 & 8.9 & 12.9 & 1003.1 & 7.9 \\
\hline 2012 & 3 & 28 & 12 & 36 & 146 & 9 & 10.5 & 1003.1 & 7.9 \\
\hline 2012 & 3 & 28 & 12 & 42 & 146 & 9.6 & 11.9 & 1003.1 & 7.8 \\
\hline 2012 & 3 & 28 & 12 & 48 & 137 & 10.2 & 12.8 & NA & NA \\
\hline 2012 & 3 & 28 & 12 & 54 & 135 & 11.4 & 13.2 & 1003.3 & 7.7 \\
\hline 2012 & 3 & 28 & 13 & 0 & 138 & 10.9 & 12.6 & 1003.3 & 7.7 \\
\hline 2012 & 3 & 28 & 13 & 6 & 149 & 9.5 & 11.6 & 1003.4 & 7.6 \\
\hline 2012 & 3 & 28 & 13 & 12 & 134 & 10.2 & 14.3 & 1003.3 & 7.7 \\
\hline 2012 & 3 & 28 & 13 & 18 & 138 & 11.6 & 14 & 1003.5 & 7.7 \\
\hline 2012 & 3 & 28 & 13 & 24 & 141 & 12.2 & 14.3 & 1003.7 & 7.8 \\
\hline 2012 & 3 & 28 & 13 & 30 & 141 & 11.3 & 14.2 & 1003.7 & 7.8 \\
\hline 2012 & 3 & 28 & 13 & 36 & 149 & 9.1 & 13.5 & 1003.7 & 7.7 \\
\hline 2012 & 3 & 28 & 13 & 42 & 157 & 8.5 & 10.6 & 1003.9 & 7.7 \\
\hline 2012 & 3 & 28 & 13 & 48 & 159 & 11.8 & 16.9 & NA & NA \\
\hline 2012 & 3 & 28 & 13 & 54 & 170 & 11.7 & 17.5 & 1004.1 & 7.7 \\
\hline
\end{tabular}



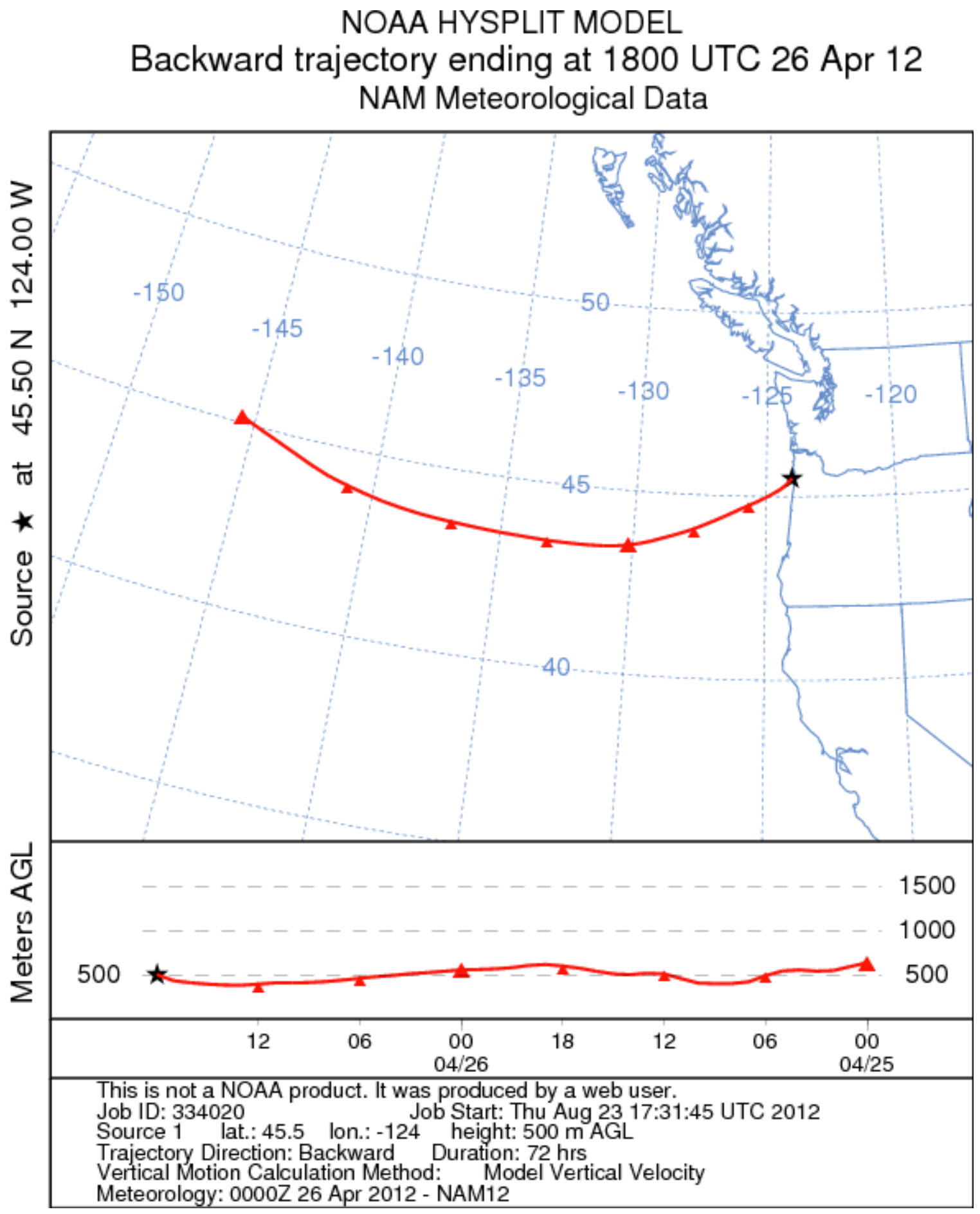


\begin{tabular}{|c|c|c|c|c|c|c|c|c|c|}
\hline \#YY & MM & DD & hh & $\mathbf{m m}$ & WDIR & WSPD & GST & PRES & ATMP \\
\hline \#yr & mo & dy & hr & $\mathbf{m n}$ & $\mathbf{d e g T}$ & $\mathbf{m} / \mathbf{s}$ & $\mathbf{m} / \mathbf{s}$ & $\mathbf{h P a}$ & $\mathbf{d e g C}$ \\
\hline 2012 & 4 & 26 & 11 & 0 & 132 & 2 & 2.4 & 1003.7 & 8.5 \\
\hline 2012 & 4 & 26 & 11 & 6 & 119 & 1.4 & 2 & 1003.8 & 8.4 \\
\hline 2012 & 4 & 26 & 11 & 12 & 96 & 1.5 & 1.8 & 1003.9 & 8.3 \\
\hline 2012 & 4 & 26 & 11 & 18 & 124 & 1.2 & 1.8 & 1004 & 8.3 \\
\hline 2012 & 4 & 26 & 11 & 24 & 151 & 2.4 & 2.9 & 1003.9 & 8.3 \\
\hline 2012 & 4 & 26 & 11 & 30 & 159 & 2 & 2.9 & 1004 & 8.4 \\
\hline 2012 & 4 & 26 & 11 & 36 & 135 & 2.4 & 2.8 & 1003.9 & 8.5 \\
\hline 2012 & 4 & 26 & 11 & 42 & 129 & 2.2 & 3.2 & 1004 & 8.5 \\
\hline 2012 & 4 & 26 & 11 & 48 & 135 & 2.6 & 3 & NA & NA \\
\hline 2012 & 4 & 26 & 11 & 54 & 128 & 2.3 & 2.7 & 1004.1 & 8.5 \\
\hline 2012 & 4 & 26 & 12 & 0 & 127 & 2.5 & 3.2 & 1004.1 & 8.4 \\
\hline 2012 & 4 & 26 & 12 & 6 & 109 & 2.5 & 2.8 & 1004 & 8.4 \\
\hline 2012 & 4 & 26 & 12 & 12 & 119 & 2.5 & 3.1 & 1004 & 8.5 \\
\hline 2012 & 4 & 26 & 12 & 18 & 135 & 2.8 & 3.1 & 1004.1 & 8.4 \\
\hline 2012 & 4 & 26 & 12 & 24 & 137 & 2.2 & 2.9 & 1003.9 & 8.4 \\
\hline 2012 & 4 & 26 & 12 & 30 & 121 & 1.7 & 2 & 1003.9 & 8.4 \\
\hline 2012 & 4 & 26 & 12 & 36 & 133 & 1.4 & 2.3 & 1003.9 & 8.4 \\
\hline 2012 & 4 & 26 & 12 & 42 & 166 & 0.6 & 1.8 & 1003.9 & 8.4 \\
\hline 2012 & 4 & 26 & 12 & 48 & 145 & 1.1 & 1.6 & NA & NA \\
\hline 2012 & 4 & 26 & 12 & 54 & 123 & 2.1 & 3 & 1004.1 & 8.4 \\
\hline 2012 & 4 & 26 & 13 & 0 & 217 & 1.8 & 2.9 & 1004.1 & 8.3 \\
\hline 2012 & 4 & 26 & 13 & 6 & 256 & 2.1 & 3.2 & 1004.1 & 8.3 \\
\hline 2012 & 4 & 26 & 13 & 12 & 264 & 3.2 & 4.2 & 1004.2 & 8.3 \\
\hline 2012 & 4 & 26 & 13 & 18 & 257 & 3.6 & 4.1 & 1004.2 & 8.3 \\
\hline 2012 & 4 & 26 & 13 & 24 & 266 & 3.5 & 4.1 & NA & NA \\
\hline 2012 & 4 & 26 & 13 & 30 & 258 & 3.7 & 4.2 & 1004.3 & 8.3 \\
\hline 2012 & 4 & 26 & 13 & 36 & 266 & 3.2 & 4.2 & 1004.3 & 8.2 \\
\hline 2012 & 4 & 26 & 13 & 42 & 247 & 3.7 & 4.2 & 1004.5 & 8.2 \\
\hline 2012 & 4 & 26 & 13 & 48 & 247 & 3.7 & 4.1 & NA & NA \\
\hline 2012 & 4 & 26 & 13 & 54 & 250 & 3.6 & 4.4 & 1004.6 & 8.2 \\
\hline
\end{tabular}




\section{NOAA HYSPLIT MODEL \\ Backward trajectory ending at 1800 UTC 30 May 12 GDAS Meteorological Data}

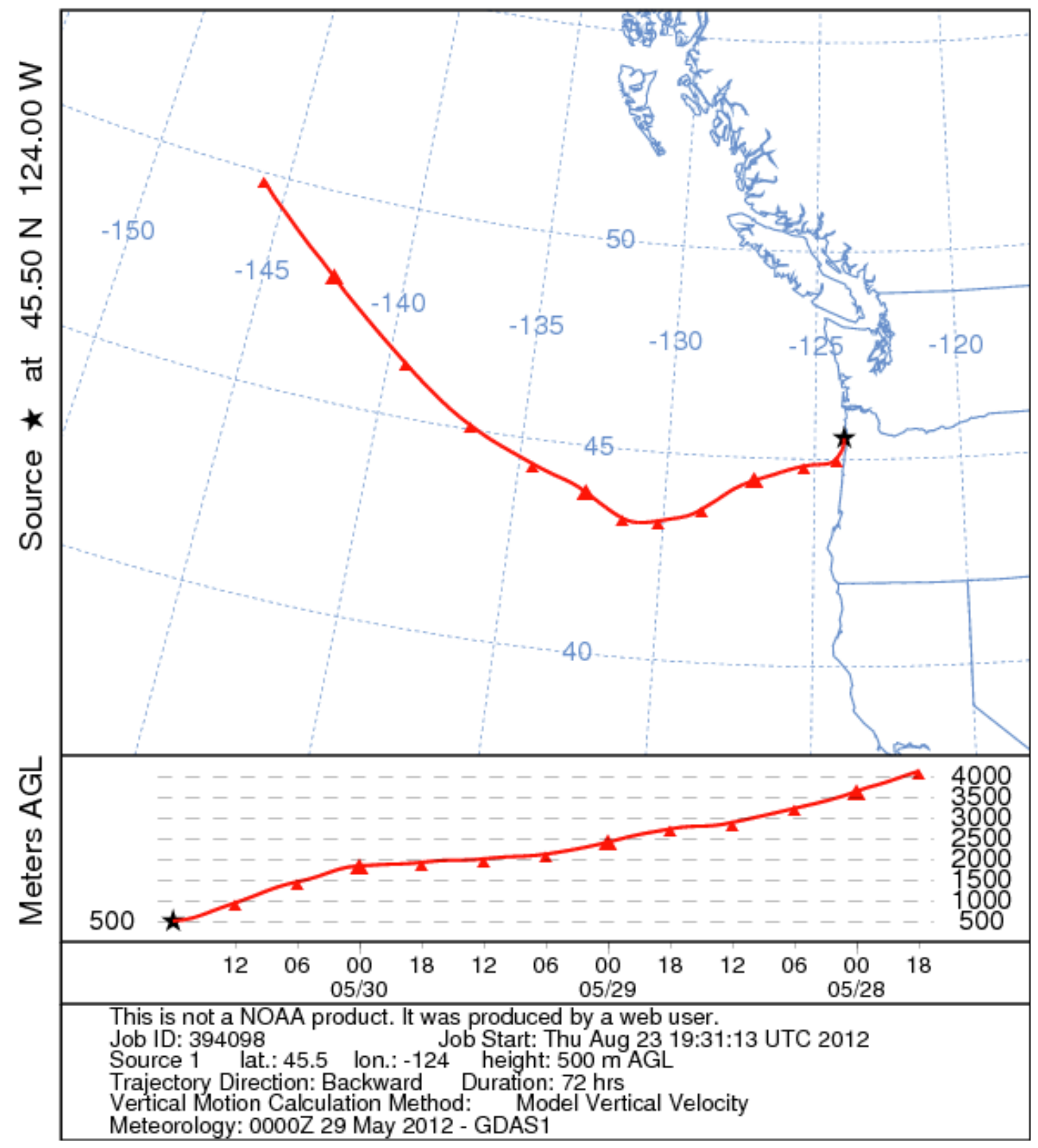




\begin{tabular}{|c|c|c|c|c|c|c|c|c|c|}
\hline \#YY & MM & DD & hh & $\mathbf{m m}$ & WDIR & WSPD & GST & PRES & ATMP \\
\hline \#yr & mo & dy & hr & $\mathbf{m n}$ & $\mathbf{d e g T}$ & $\mathbf{m} / \mathbf{s}$ & $\mathbf{m} / \mathbf{s}$ & $\mathbf{h P a}$ & $\mathbf{d e g C}$ \\
\hline 2012 & 5 & 30 & 11 & 0 & 141 & 2.7 & 3 & 1022.1 & 9.4 \\
\hline 2012 & 5 & 30 & 11 & 6 & 138 & 3 & 3.2 & 1022.1 & 9.4 \\
\hline 2012 & 5 & 30 & 11 & 12 & 138 & 2.7 & 3.2 & 1022.1 & 9.4 \\
\hline 2012 & 5 & 30 & 11 & 18 & 139 & 2.2 & 2.7 & NA & NA \\
\hline 2012 & 5 & 30 & 11 & 24 & 139 & 2.3 & 2.8 & 1022.3 & 9.3 \\
\hline 2012 & 5 & 30 & 11 & 30 & NA & NA & NA & 1022.3 & 9.3 \\
\hline 2012 & 5 & 30 & 11 & 36 & NA & NA & NA & 1022.2 & 9.3 \\
\hline 2012 & 5 & 30 & 11 & 42 & NA & NA & NA & 1022.2 & 9.1 \\
\hline 2012 & 5 & 30 & 11 & 48 & 131 & 3 & 3.9 & 1022.2 & 9.1 \\
\hline 2012 & 5 & 30 & 11 & 54 & 139 & 1.8 & 2.7 & 1022.3 & 9.1 \\
\hline 2012 & 5 & 30 & 12 & 0 & 132 & 2.5 & 2.9 & 1022.3 & 9.2 \\
\hline 2012 & 5 & 30 & 12 & 6 & 123 & 3.3 & 3.7 & 1022.3 & 9.1 \\
\hline 2012 & 5 & 30 & 12 & 12 & 127 & 2.5 & 3.6 & 1022.1 & 9 \\
\hline 2012 & 5 & 30 & 12 & 18 & 125 & 2.9 & 3.2 & NA & NA \\
\hline 2012 & 5 & 30 & 12 & 24 & 121 & 2.6 & 3.2 & 1022.2 & 8.9 \\
\hline 2012 & 5 & 30 & 12 & 30 & 127 & 2 & 2.8 & 1022.4 & 8.9 \\
\hline 2012 & 5 & 30 & 12 & 36 & NA & NA & NA & 1022.4 & 9 \\
\hline 2012 & 5 & 30 & 12 & 42 & 131 & 2.3 & 2.7 & NA & NA \\
\hline 2012 & 5 & 30 & 12 & 48 & 123 & 2.7 & 3.4 & NA & NA \\
\hline 2012 & 5 & 30 & 12 & 54 & NA & NA & NA & 1022.3 & 9.1 \\
\hline 2012 & 5 & 30 & 13 & 0 & 144 & 2.9 & 3.2 & NA & NA \\
\hline 2012 & 5 & 30 & 13 & 6 & 145 & 3.7 & 4.4 & 1022.5 & 9 \\
\hline 2012 & 5 & 30 & 13 & 12 & 131 & 6.3 & 7 & 1022.3 & 9 \\
\hline 2012 & 5 & 30 & 13 & 18 & 136 & 5.5 & 6.6 & NA & NA \\
\hline 2012 & 5 & 30 & 13 & 24 & 142 & 5.6 & 6.4 & 1022.3 & 9.4 \\
\hline 2012 & 5 & 30 & 13 & 30 & 142 & 5.1 & 5.8 & 1022.3 & 9.3 \\
\hline 2012 & 5 & 30 & 13 & 36 & 140 & 4.8 & 5.5 & 1022.3 & 9.3 \\
\hline 2012 & 5 & 30 & 13 & 42 & 144 & 4.6 & 5.4 & 1022.3 & 9.2 \\
\hline 2012 & 5 & 30 & 13 & 48 & NA & NA & NA & 1022.4 & 9.3 \\
\hline 2012 & 5 & 30 & 13 & 54 & 135 & 3.5 & 4.4 & NA & NA \\
\hline
\end{tabular}



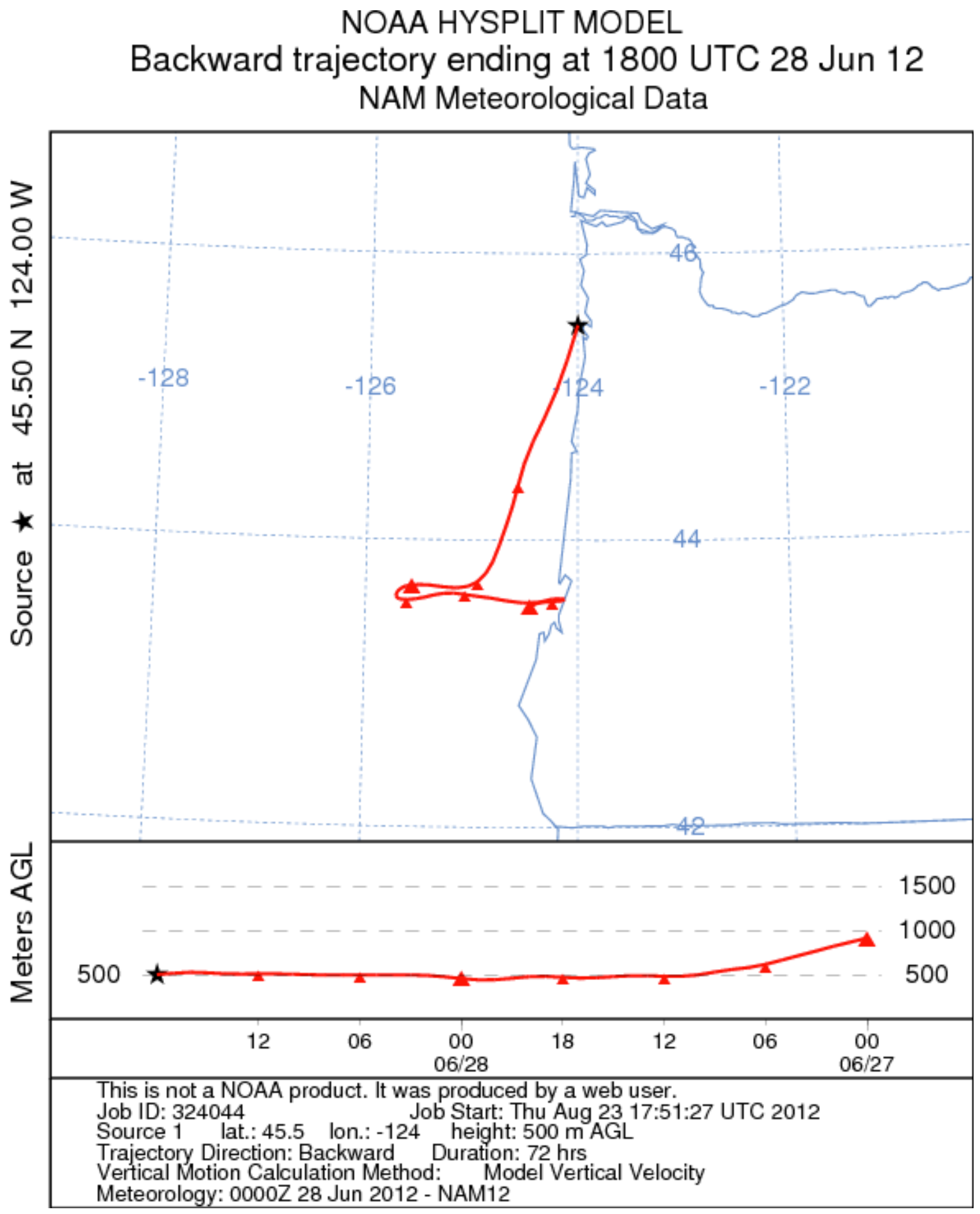


\begin{tabular}{|c|c|c|c|c|c|c|c|c|c|}
\hline \#YY & MM & DD & hh & $\mathbf{m m}$ & WDIR & WSPD & GST & PRES & ATMP \\
\hline \#yr & mo & dy & hr & $\mathbf{m n}$ & $\mathbf{d e g T}$ & $\mathbf{m} / \mathbf{s}$ & $\mathbf{m} / \mathbf{s}$ & $\mathbf{h P a}$ & $\mathbf{d e g C}$ \\
\hline 2012 & 6 & 28 & 11 & 0 & 139 & 4.9 & 5.2 & 1012.9 & 10 \\
\hline 2012 & 6 & 28 & 11 & 6 & 136 & 5.1 & 5.5 & 1013 & 10.1 \\
\hline 2012 & 6 & 28 & 11 & 12 & 133 & 5.5 & 6.1 & 1013.1 & 10.1 \\
\hline 2012 & 6 & 28 & 11 & 18 & 135 & 5.7 & 6.3 & NA & NA \\
\hline 2012 & 6 & 28 & 11 & 24 & 138 & 6 & 6.3 & 1013.1 & 10.2 \\
\hline 2012 & 6 & 28 & 11 & 30 & 139 & 5.9 & 6.3 & 1013.2 & 10.1 \\
\hline 2012 & 6 & 28 & 11 & 36 & 137 & 5.9 & 6.4 & 1013.2 & 10 \\
\hline 2012 & 6 & 28 & 11 & 42 & 134 & 5.8 & 6.2 & 1013.2 & 10 \\
\hline 2012 & 6 & 28 & 11 & 48 & 139 & 5.8 & 6.2 & NA & NA \\
\hline 2012 & 6 & 28 & 11 & 54 & 136 & 6 & 6.6 & 1013.2 & 9.9 \\
\hline 2012 & 6 & 28 & 12 & 0 & 139 & 5.9 & 6.5 & 1013.2 & 9.9 \\
\hline 2012 & 6 & 28 & 12 & 6 & 138 & 5.9 & 6.6 & 1013.2 & 9.9 \\
\hline 2012 & 6 & 28 & 12 & 12 & 133 & 6.2 & 6.6 & 1013.2 & 10 \\
\hline 2012 & 6 & 28 & 12 & 18 & 138 & 5.9 & 6.7 & NA & NA \\
\hline 2012 & 6 & 28 & 12 & 24 & 140 & 5.8 & 6.6 & 1013.2 & 10 \\
\hline 2012 & 6 & 28 & 12 & 30 & 150 & 5.7 & 6.5 & 1013.2 & 9.9 \\
\hline 2012 & 6 & 28 & 12 & 36 & 141 & 5.9 & 6.5 & 1013.2 & 9.9 \\
\hline 2012 & 6 & 28 & 12 & 42 & 144 & 6.7 & 7.4 & 1013.2 & 9.9 \\
\hline 2012 & 6 & 28 & 12 & 48 & 143 & 6.7 & 7.3 & 1013.2 & 10 \\
\hline 2012 & 6 & 28 & 12 & 54 & NA & NA & NA & 1013.2 & 10.2 \\
\hline 2012 & 6 & 28 & 13 & 0 & 146 & 6.3 & 7.2 & NA & NA \\
\hline 2012 & 6 & 28 & 13 & 6 & 147 & 6.7 & 7.3 & 1013.3 & 10.3 \\
\hline 2012 & 6 & 28 & 13 & 12 & 144 & 6.4 & 7 & NA & NA \\
\hline 2012 & 6 & 28 & 13 & 18 & 145 & 6.8 & 7.3 & NA & NA \\
\hline 2012 & 6 & 28 & 13 & 24 & 147 & 6.3 & 7.1 & NA & NA \\
\hline 2012 & 6 & 28 & 13 & 30 & 141 & 6.6 & 7.2 & NA & NA \\
\hline 2012 & 6 & 28 & 13 & 36 & 143 & 6.9 & 7.5 & 1013.4 & 10.6 \\
\hline 2012 & 6 & 28 & 13 & 42 & 143 & 6.4 & 7 & NA & NA \\
\hline 2012 & 6 & 28 & 13 & 48 & 147 & 5.9 & 7.2 & 1013.3 & 10.5 \\
\hline 2012 & 6 & 28 & 13 & 54 & 150 & 6 & 7 & NA & NA \\
\hline
\end{tabular}




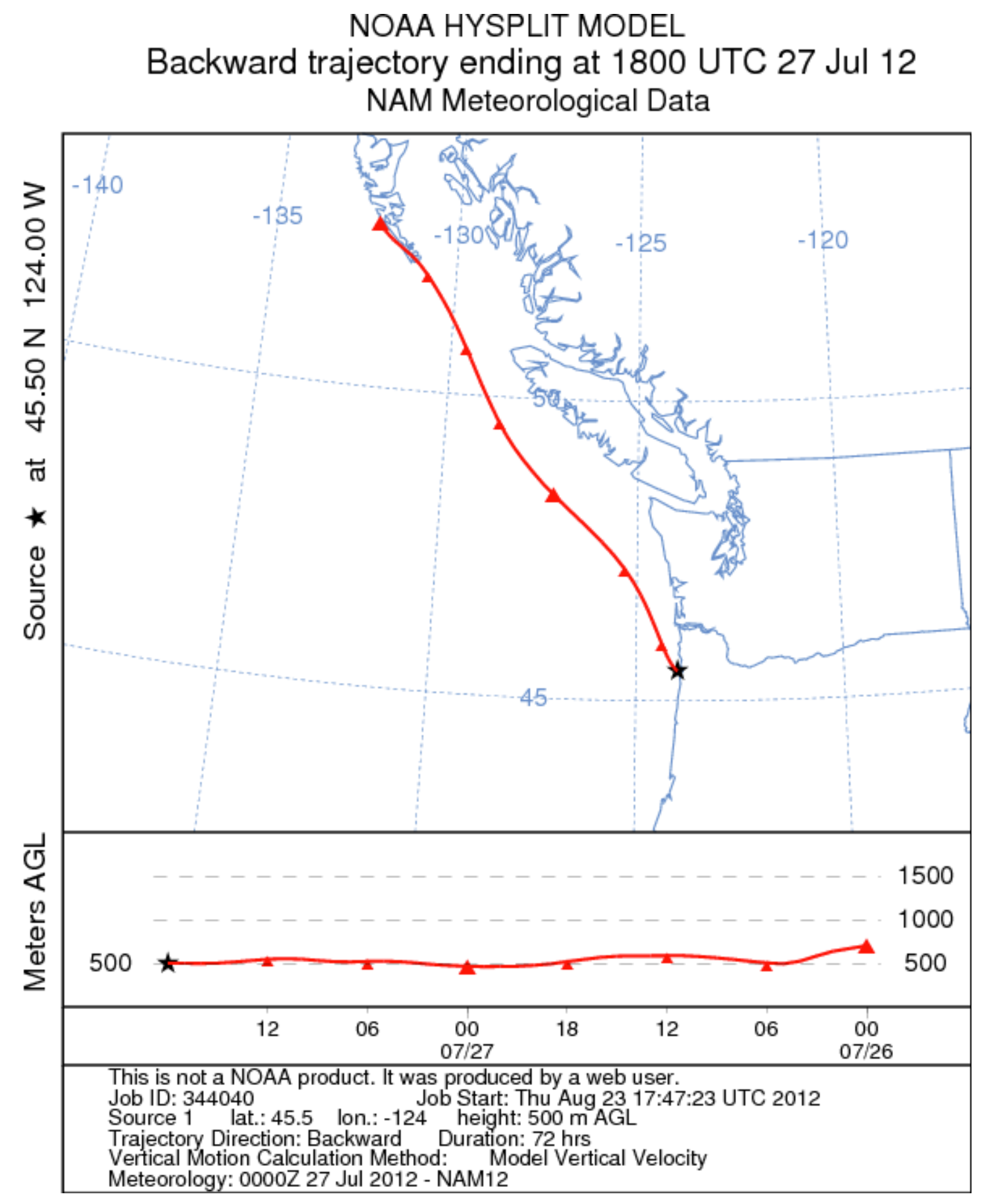




\begin{tabular}{|c|c|c|c|c|c|c|c|c|c|}
\hline \#YY & MM & DD & hh & $\mathbf{m m}$ & WDIR & WSPD & GST & PRES & ATMP \\
\hline \#yr & mo & dy & hr & $\mathbf{m n}$ & $\mathbf{d e g}$ & $\mathbf{m} / \mathbf{s}$ & $\mathbf{m} / \mathbf{s}$ & $\mathbf{h P a}$ & $\mathbf{d e g C}$ \\
\hline 2012 & 7 & 27 & 11 & 0 & 11 & 1.2 & 1.8 & 1016.2 & 13.8 \\
\hline 2012 & 7 & 27 & 11 & 6 & 191 & 1 & 2.1 & 1016.3 & 13.8 \\
\hline 2012 & 7 & 27 & 11 & 12 & 182 & 1 & 2.2 & 1016.3 & 13.8 \\
\hline 2012 & 7 & 27 & 11 & 18 & 168 & 1.3 & 1.6 & NA & NA \\
\hline 2012 & 7 & 27 & 11 & 24 & 133 & 1 & 1.4 & 1016.3 & 13.7 \\
\hline 2012 & 7 & 27 & 11 & 30 & 100 & 1.2 & 1.8 & 1016.3 & 13.7 \\
\hline 2012 & 7 & 27 & 11 & 36 & 95 & 1.8 & 2 & 1016.3 & 13.7 \\
\hline 2012 & 7 & 27 & 11 & 42 & 66 & 2 & 2.7 & 1016.4 & 13.7 \\
\hline 2012 & 7 & 27 & 11 & 48 & 40 & 0.8 & 1.8 & NA & NA \\
\hline 2012 & 7 & 27 & 11 & 54 & 235 & 1.1 & 1.6 & 1016.4 & 13.7 \\
\hline 2012 & 7 & 27 & 12 & 0 & 221 & 0.8 & 1.4 & 1016.4 & 13.8 \\
\hline 2012 & 7 & 27 & 12 & 6 & 261 & 1.3 & 1.6 & 1016.5 & 13.7 \\
\hline 2012 & 7 & 27 & 12 & 12 & 236 & 0.7 & 1.1 & 1016.5 & 13.7 \\
\hline 2012 & 7 & 27 & 12 & 18 & 229 & 0.2 & 0.5 & 1016.6 & 13.7 \\
\hline 2012 & 7 & 27 & 12 & 24 & 229 & 0 & 0.2 & 1016.7 & 13.7 \\
\hline 2012 & 7 & 27 & 12 & 30 & 229 & 0 & NA & 1016.8 & 13.7 \\
\hline 2012 & 7 & 27 & 12 & 36 & 220 & 0.4 & 0.7 & 1016.8 & 13.7 \\
\hline 2012 & 7 & 27 & 12 & 42 & 205 & 0.7 & 0.8 & 1016.9 & 13.7 \\
\hline 2012 & 7 & 27 & 12 & 48 & 250 & 0.6 & 1.1 & NA & NA \\
\hline 2012 & 7 & 27 & 12 & 54 & NA & NA & NA & 1017 & 13.6 \\
\hline 2012 & 7 & 27 & 13 & 0 & 231 & 0.7 & 0.9 & NA & NA \\
\hline 2012 & 7 & 27 & 13 & 6 & 190 & 0 & 0.6 & 1017 & 13.5 \\
\hline 2012 & 7 & 27 & 13 & 12 & 185 & 0.7 & 0.8 & 1017 & 13.6 \\
\hline 2012 & 7 & 27 & 13 & 18 & 202 & 0.7 & 0.8 & NA & NA \\
\hline 2012 & 7 & 27 & 13 & 24 & 182 & 0.6 & 0.7 & 1017.1 & 13.6 \\
\hline 2012 & 7 & 27 & 13 & 30 & 179 & 0.7 & 0.8 & 1017.2 & 13.6 \\
\hline 2012 & 7 & 27 & 13 & 36 & 167 & 0.9 & 1.1 & 1017.2 & 13.6 \\
\hline 2012 & 7 & 27 & 13 & 42 & 179 & 1.2 & 1.3 & 1017.2 & 13.6 \\
\hline 2012 & 7 & 27 & 13 & 48 & 166 & 1.3 & 1.4 & NA & NA \\
\hline 2012 & 7 & 27 & 13 & 54 & 168 & 1.6 & 1.7 & 1017.2 & 13.6 \\
\hline
\end{tabular}




\section{NOAA HYSPLIT MODEL \\ Backward trajectory ending at 1800 UTC 26 Aug 12 18 UTC 24 Aug NAM Forecast Initialization}

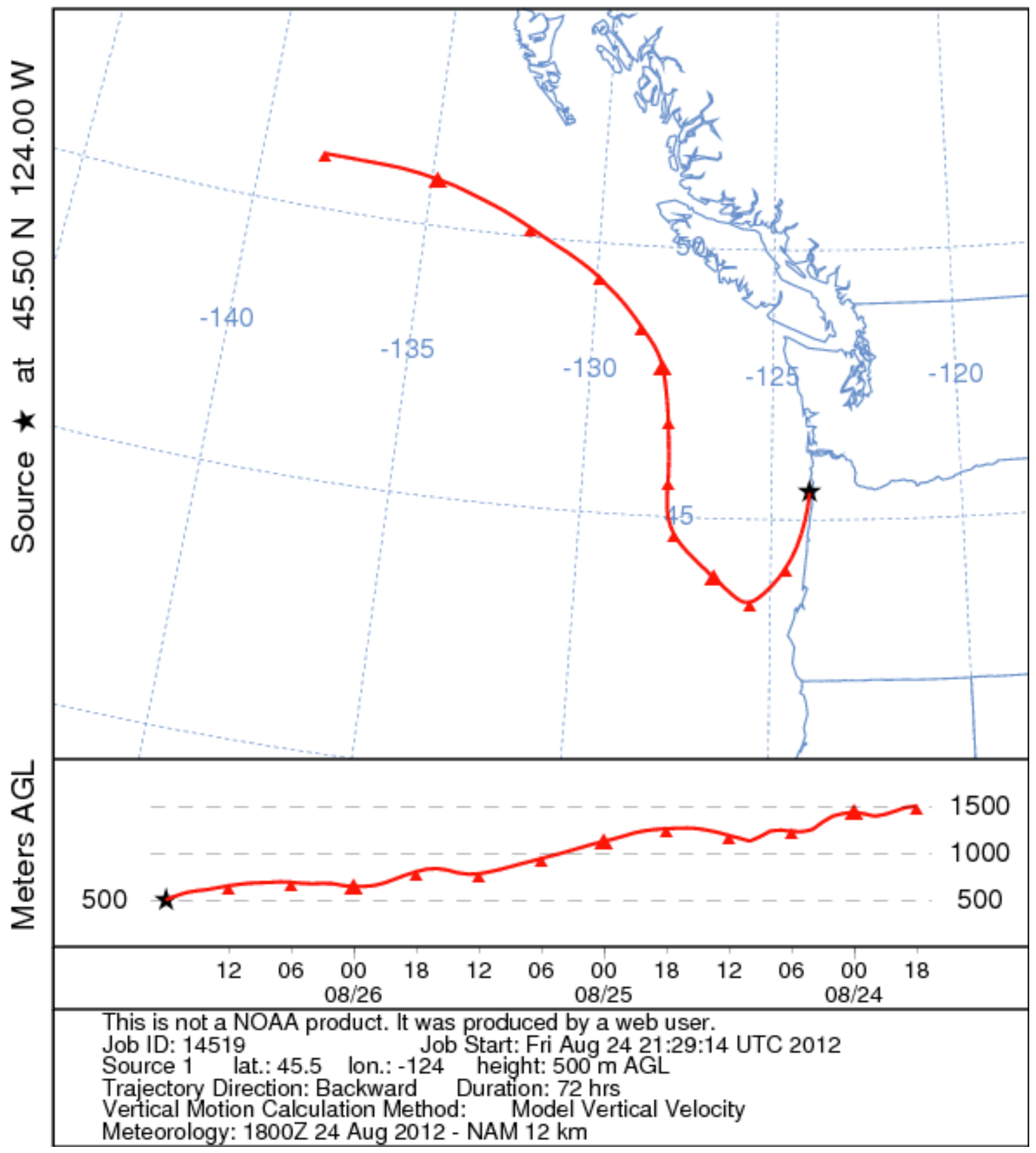




\begin{tabular}{|c|c|c|c|c|c|c|c|c|c|}
\hline \#YY & MM & DD & hh & $\mathbf{m m}$ & WDIR & WSPD & GST & PRES & ATMP \\
\hline \#yr & mo & dy & hr & $\mathbf{m n}$ & $\mathbf{d e g}$ & $\mathbf{m} / \mathbf{s}$ & $\mathbf{m} / \mathbf{s}$ & $\mathbf{h P a}$ & $\mathbf{d e g C}$ \\
\hline 2012 & 8 & 26 & 11 & 0 & 139 & 4 & 4.4 & 1008.4 & 12.7 \\
\hline 2012 & 8 & 26 & 11 & 6 & 137 & 4 & 4.4 & 1008.4 & 12.7 \\
\hline 2012 & 8 & 26 & 11 & 12 & 138 & 3.7 & 4.4 & 1008.4 & 12.7 \\
\hline 2012 & 8 & 26 & 11 & 18 & 144 & 4.1 & 4.5 & NA & NA \\
\hline 2012 & 8 & 26 & 11 & 24 & 146 & 3.9 & 4.6 & 1008.3 & 12.7 \\
\hline 2012 & 8 & 26 & 11 & 30 & 154 & 3.6 & 4.3 & 1008.3 & 12.7 \\
\hline 2012 & 8 & 26 & 11 & 36 & 148 & 3.8 & 4.2 & 1008.4 & 12.7 \\
\hline 2012 & 8 & 26 & 11 & 42 & 145 & 4 & 4.5 & 1008.3 & 12.7 \\
\hline 2012 & 8 & 26 & 11 & 48 & 137 & 3.8 & 4.4 & NA & NA \\
\hline 2012 & 8 & 26 & 11 & 54 & 137 & 4 & 4.4 & 1008.3 & 12.8 \\
\hline 2012 & 8 & 26 & 12 & 0 & 134 & 4.7 & 5 & 1008.3 & 12.8 \\
\hline 2012 & 8 & 26 & 12 & 6 & 133 & 4.8 & 5.3 & 1008.2 & 12.8 \\
\hline 2012 & 8 & 26 & 12 & 12 & 141 & 4.7 & 5.1 & 1008.1 & 12.8 \\
\hline 2012 & 8 & 26 & 12 & 18 & 145 & 4.4 & 4.7 & NA & NA \\
\hline 2012 & 8 & 26 & 12 & 24 & 139 & 4.2 & 4.4 & 1008.2 & 12.8 \\
\hline 2012 & 8 & 26 & 12 & 30 & 137 & 4 & 4.3 & 1008.2 & 12.8 \\
\hline 2012 & 8 & 26 & 12 & 36 & 136 & 4.2 & 4.5 & 1008.2 & 12.8 \\
\hline 2012 & 8 & 26 & 12 & 42 & 147 & 4.6 & 4.8 & 1008.2 & 12.9 \\
\hline 2012 & 8 & 26 & 12 & 48 & 137 & 4.6 & 4.9 & NA & NA \\
\hline 2012 & 8 & 26 & 12 & 54 & 141 & 4.6 & 5 & 1008.2 & 12.9 \\
\hline 2012 & 8 & 26 & 13 & 0 & 139 & 3.9 & 4.7 & 1008.1 & 12.9 \\
\hline 2012 & 8 & 26 & 13 & 6 & 144 & 4.5 & 4.7 & 1008.1 & 12.9 \\
\hline 2012 & 8 & 26 & 13 & 12 & 145 & 4.6 & 5 & 1008.1 & 12.9 \\
\hline 2012 & 8 & 26 & 13 & 18 & 153 & 4.5 & 4.9 & 1008.1 & 12.9 \\
\hline 2012 & 8 & 26 & 13 & 24 & 160 & 4.7 & 5.1 & 1008.2 & 12.9 \\
\hline 2012 & 8 & 26 & 13 & 30 & 143 & 4 & 4.6 & 1008.2 & 12.9 \\
\hline 2012 & 8 & 26 & 13 & 36 & 150 & 5.1 & 5.4 & 1008.2 & 12.9 \\
\hline 2012 & 8 & 26 & 13 & 42 & 146 & 5.1 & 5.5 & 1008.3 & 13 \\
\hline 2012 & 8 & 26 & 13 & 48 & 146 & 5.2 & 5.8 & NA & NA \\
\hline 2012 & 8 & 26 & 13 & 54 & 150 & 5.5 & 5.9 & 1008.3 & 13 \\
\hline
\end{tabular}




\section{NOAA HYSPLIT MODEL \\ Backward trajectory ending at 1800 UTC 25 Sep 12 18 UTC 24 Sep NAM Forecast Initialization}

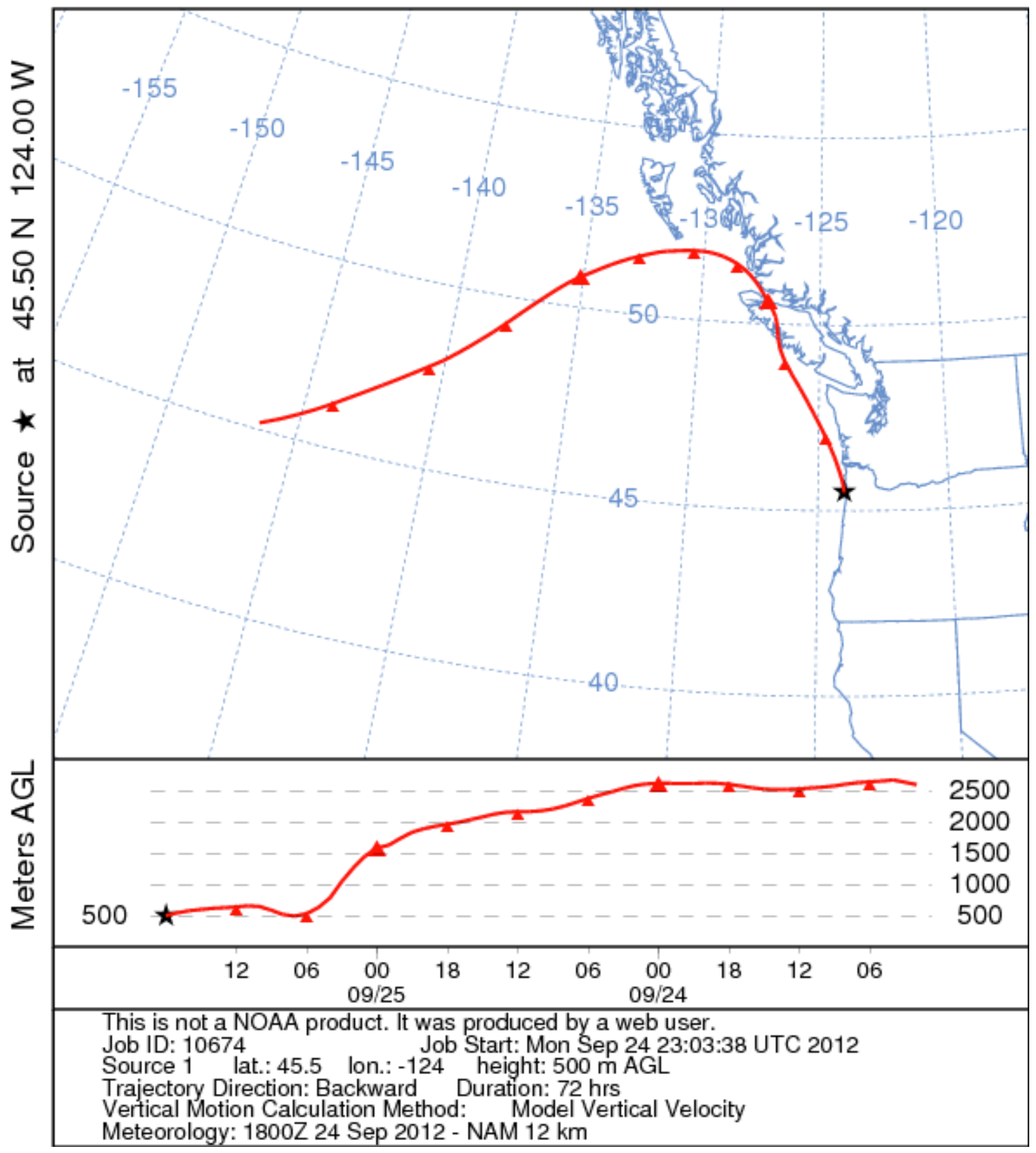




\begin{tabular}{|c|c|c|c|c|c|c|c|c|c|}
\hline \#YY & MM & DD & hh & $\mathbf{m m}$ & WDIR & WSPD & GST & PRES & ATMP \\
\hline \#yr & mo & dy & hr & $\mathbf{m n}$ & $\mathbf{d e g T}$ & $\mathbf{m} / \mathbf{s}$ & $\mathbf{m} / \mathbf{s}$ & $\mathbf{h P a}$ & $\mathbf{d e g C}$ \\
\hline 2012 & 9 & 25 & 11 & 0 & 358 & 3.2 & 3.9 & 1019.7 & 10.5 \\
\hline 2012 & 9 & 25 & 11 & 6 & 357 & 3.4 & 3.9 & 1019.7 & 10.3 \\
\hline 2012 & 9 & 25 & 11 & 12 & 360 & 3.4 & 3.8 & 1019.7 & 10.3 \\
\hline 2012 & 9 & 25 & 11 & 18 & 359 & 4 & 4.3 & NA & NA \\
\hline 2012 & 9 & 25 & 11 & 24 & 359 & 3.5 & 4.2 & 1019.8 & 10.2 \\
\hline 2012 & 9 & 25 & 11 & 30 & 5 & 3.6 & 4.2 & 1019.8 & 10.1 \\
\hline 2012 & 9 & 25 & 11 & 36 & 359 & 3.6 & 4.2 & 1019.8 & 10 \\
\hline 2012 & 9 & 25 & 11 & 42 & 2 & 3.9 & 4.1 & NA & NA \\
\hline 2012 & 9 & 25 & 11 & 48 & NA & NA & NA & 1019.8 & 9.8 \\
\hline 2012 & 9 & 25 & 11 & 54 & 3 & 4.1 & 4.4 & 1019.8 & 9.7 \\
\hline 2012 & 9 & 25 & 12 & 0 & 359 & 3.8 & 4.3 & 1019.8 & 9.7 \\
\hline 2012 & 9 & 25 & 12 & 6 & 359 & 3.7 & 4.3 & 1019.8 & 9.6 \\
\hline 2012 & 9 & 25 & 12 & 12 & NA & NA & NA & 1019.9 & 9.5 \\
\hline 2012 & 9 & 25 & 12 & 18 & 5 & 3.6 & 4.3 & 1019.9 & 9.5 \\
\hline 2012 & 9 & 25 & 12 & 24 & 11 & 3.5 & 4.7 & 1020 & 9.5 \\
\hline 2012 & 9 & 25 & 12 & 30 & 4 & 3.5 & 4.4 & 1020 & 9.4 \\
\hline 2012 & 9 & 25 & 12 & 36 & 9 & 3.9 & 5.5 & 1020 & 9.4 \\
\hline 2012 & 9 & 25 & 12 & 42 & 5 & 4.2 & 5.7 & 1020 & 9.3 \\
\hline 2012 & 9 & 25 & 12 & 48 & 1 & 3.4 & 5.2 & NA & NA \\
\hline 2012 & 9 & 25 & 12 & 54 & 8 & 4 & 5.8 & 1020.2 & 9.4 \\
\hline 2012 & 9 & 25 & 13 & 0 & 13 & 4.1 & 5.9 & 1020.1 & 9.3 \\
\hline 2012 & 9 & 25 & 13 & 6 & 21 & 4.8 & 6.2 & 1020.2 & 9.4 \\
\hline 2012 & 9 & 25 & 13 & 12 & 17 & 4.7 & 6.4 & 1020.1 & 9.3 \\
\hline 2012 & 9 & 25 & 13 & 18 & 16 & 5 & 6.6 & NA & NA \\
\hline 2012 & 9 & 25 & 13 & 24 & 26 & 4.9 & 6.3 & 1020 & 9.4 \\
\hline 2012 & 9 & 25 & 13 & 30 & 38 & 3.7 & 6.4 & 1020 & 9.3 \\
\hline 2012 & 9 & 25 & 13 & 36 & 32 & 3 & 4.9 & 1020 & 9.3 \\
\hline 2012 & 9 & 25 & 13 & 42 & 33 & 3.3 & 4.9 & 1020.1 & 9.2 \\
\hline 2012 & 9 & 25 & 13 & 48 & 40 & 3.3 & 5.5 & NA & NA \\
\hline 2012 & 9 & 25 & 13 & 54 & 47 & 1.4 & 4.3 & 1020.1 & 9.1 \\
\hline
\end{tabular}




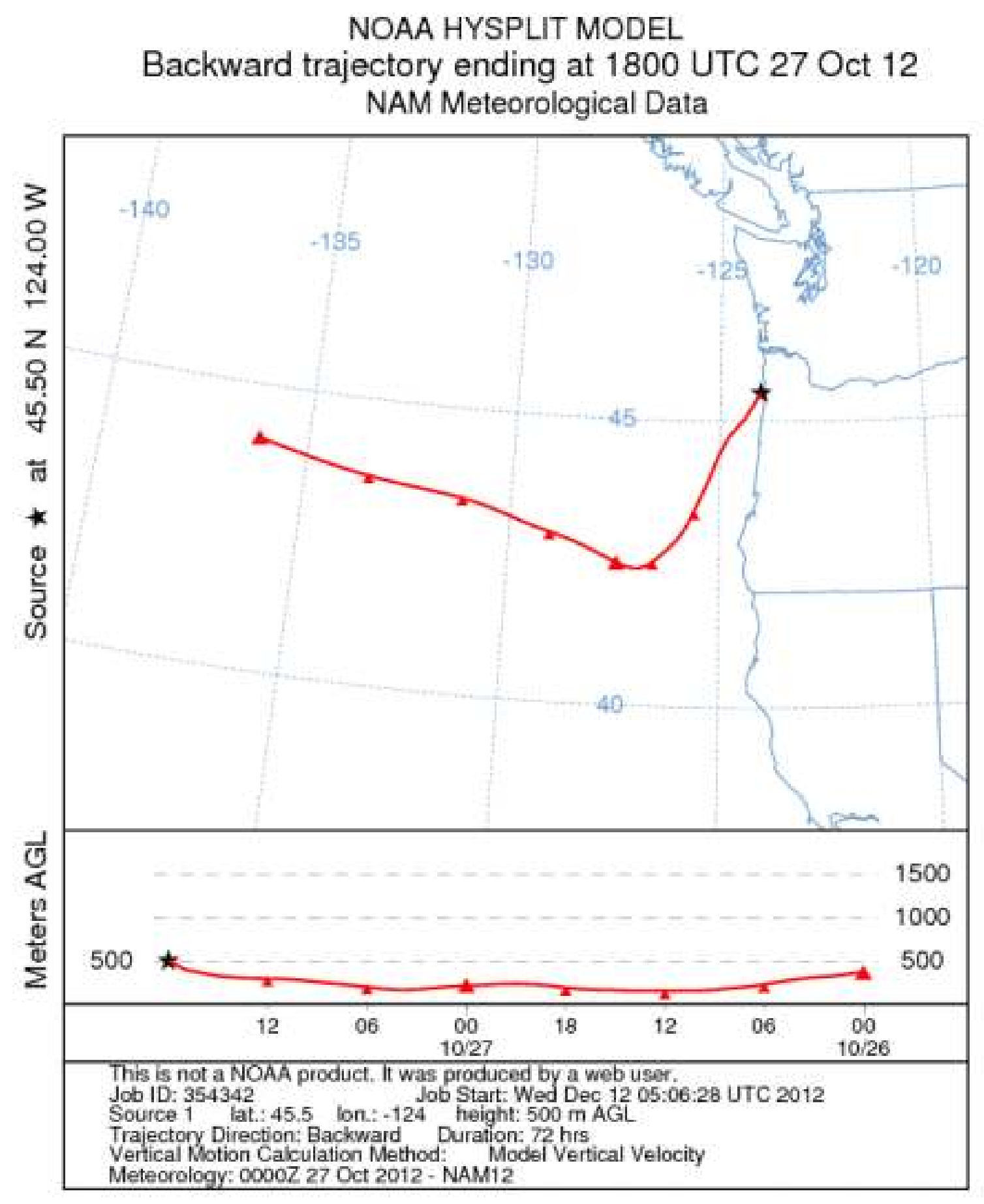




\begin{tabular}{|c|c|c|c|c|c|c|c|c|c|}
\hline \#YY & MM & DD & hh & $\mathbf{m m}$ & WDI & R WSP & D GST & PRES & ATMP \\
\hline \#yr & mo & dy & hr & $\mathbf{m n}$ & $\mathbf{d e g}$ & $\mathbf{T ~ m} / \mathbf{s}$ & $\mathbf{m} / \mathbf{s}$ & $\mathbf{h P a}$ & $\mathbf{d e g C}$ \\
\hline 2012 & 10 & 27 & 13 & 0 & 136 & 5.2 & 6.9 & 1018 & 12.1 \\
\hline 2012 & 10 & 27 & 13 & 6 & 134 & 5.6 & 6 & 1017.6 & 12.1 \\
\hline 2012 & 10 & 27 & 13 & 12 & 143 & 6.1 & 6.8 & 1017.5 & 12 \\
\hline 2012 & 10 & 27 & 13 & 18 & 151 & 5.2 & 6 & NA & NA \\
\hline 2012 & 10 & 27 & 13 & 24 & 136 & 6 & 6.5 & 1017.3 & 12 \\
\hline 2012 & 10 & 27 & 13 & 30 & 133 & 5.9 & 6.8 & 1017.2 & 12 \\
\hline 2012 & 10 & 27 & 13 & 36 & 135 & 6.5 & 7.1 & 1017.3 & 12.1 \\
\hline 2012 & 10 & 27 & 13 & 42 & 138 & 6.4 & 7.1 & 1017.2 & 12.1 \\
\hline 2012 & 10 & 27 & 13 & 48 & 151 & 5.8 & 6.9 & 1017.1 & 12.2 \\
\hline 2012 & 10 & 27 & 13 & 54 & 151 & 6 & 6.7 & 1017.2 & 12.1 \\
\hline 2012 & 10 & 27 & 14 & 0 & 149 & 5.5 & 6.4 & 1017.3 & 11.9 \\
\hline 2012 & 10 & 27 & 14 & 6 & 147 & 6.6 & 7.5 & 1017.4 & 11.9 \\
\hline 2012 & 10 & 27 & 14 & 12 & 144 & 8.2 & 8.9 & 1016.8 & 11.7 \\
\hline 2012 & 10 & 27 & 14 & 18 & 142 & 9.2 & 10.4 & NA & NA \\
\hline 2012 & 10 & 27 & 14 & 24 & 146 & 8.2 & 10 & 1016.3 & 11.6 \\
\hline 2012 & 10 & 27 & 14 & 30 & 147 & 8.1 & 9.1 & 1016.2 & 11.8 \\
\hline 2012 & 10 & 27 & 14 & 36 & 151 & 7.9 & 9.6 & 1016.3 & 11.9 \\
\hline 2012 & 10 & 27 & 14 & 42 & 152 & 8.8 & 10.1 & 1016.4 & 11.9 \\
\hline 2012 & 10 & 27 & 14 & 48 & NA & NA & NA & 1016.2 & 11.8 \\
\hline 2012 & 10 & 27 & 14 & 54 & 141 & 8 & 9.4 & 1016.1 & 11.7 \\
\hline 2012 & 10 & 27 & 15 & 0 & 142 & 7.9 & 9.2 & 1015.9 & 11.6 \\
\hline 2012 & 10 & 27 & 15 & 6 & 146 & 8.4 & 9.5 & 1015.8 & 11.7 \\
\hline 2012 & 10 & 27 & 15 & 12 & 153 & 8.1 & 9.5 & 1015.8 & 11.7 \\
\hline 2012 & 10 & 27 & 15 & 18 & 150 & 8.5 & 10 & 1016.1 & 11.7 \\
\hline 2012 & 10 & 27 & 15 & 24 & 144 & 9.1 & 10.6 & 1015.8 & 11.7 \\
\hline 2012 & 10 & 27 & 15 & 30 & 145 & 9.8 & 12.2 & 1015.6 & 11.7 \\
\hline 2012 & 10 & 27 & 15 & 36 & 146 & 10.7 & 12.9 & 1015.5 & 11.7 \\
\hline 2012 & 10 & 27 & 15 & 42 & 151 & 9.1 & 11.1 & 1015.7 & 11.8 \\
\hline 2012 & 10 & 27 & 15 & 48 & 151 & 8.1 & 9.7 & 1015.8 & 11.8 \\
\hline 2012 & 10 & 27 & 15 & 54 & 147 & 8.3 & 10.2 & 1015.7 & 11.8 \\
\hline
\end{tabular}

